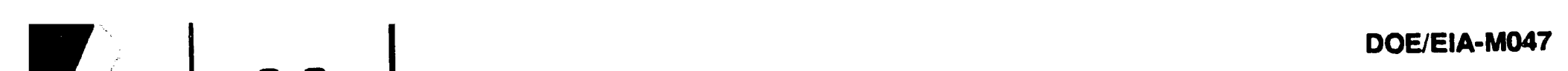

\title{
The International Coal
} $\mathbf{N}$ Statistics Data Base

\author{
June 1991
}




\section{THE INTERNATIONAL COAL STATISTICS DATA BASE}

\section{PROGRAM MAINTENANCE GUIDE}

June 1991

\section{Energy Information Administration \\ Washington, D.C.}

\section{MASTER}

DISTRIBUTION OF THIS DOCUMENT IS UNLIMITED

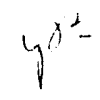

This report was prepared by the Energy Information Administration, the independent statistical and analytical agency within the Department of Energy. The information contained herein should not be construed as edvocating or reflecting any policy position of the Department of Energy or any other organization. 


\section{Preface}

The International Coal Statistics Data Base (ICSD) is a microcomputer-based system which contains information related to international cosl trade. This includes cosl production, consumption, imports and exports information. The ICSD is a secondary data base, meaning that information contained therein is derived entirely from other primary sources. It uses ABase III+ and Lotus 1-2-3 to locate, report and display data. The system is used for analysis in preparing the Annual Prospects for World Coal Trade (DOE/EIA-0363) publication. The ICSD system is menu driven and also permits the user who is familine with dBase and Lotus operations to leave the menu structure to perform independent queries.

Documentation for the ICSD consists of three manuals - the User's Guide, the Operations Manual, and the Program Maintenance Manual. This Program Maintenance Manual provides the information necessary to maintain and update the ICSD system. Two major types of program maintenance documentation are presented in this manual. The first is the source code for the dBase III+ routines and related non-dBase programs used in operating the ICSD. The second is listings of the major component database field structures. A third important consideration for dBase programming, the structure of index files, is presented in the listing of source code for the index maintenance program. 


\title{
International Coal Statistics Data Base
}

\author{
Program Maintenance Manual
}

Contents

Preface

1. General Information $\ldots \ldots \ldots \ldots \ldots \ldots \ldots \ldots \ldots \ldots \ldots \ldots \ldots \ldots$

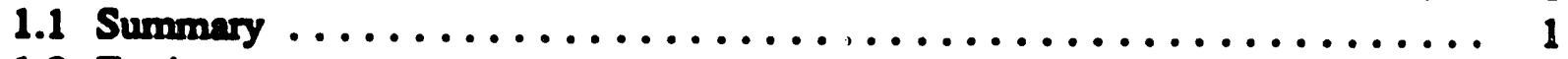

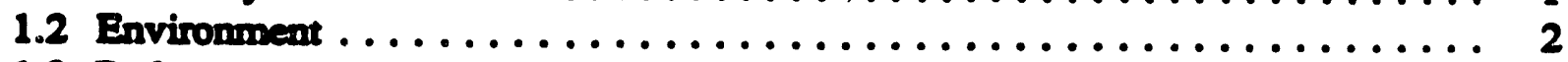

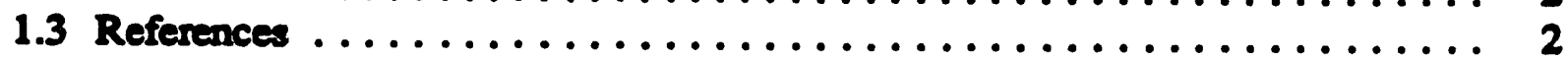

1.3.a Project Requests (Authorizations) ................. 2

1.3.b Previously Published Documents ................. 2

- 1.3.c Related Documentation ........................... 3

1.3.d Other Reference Documentation .................. 3

2. Program Descriptions $\ldots \ldots \ldots \ldots \ldots \ldots \ldots \ldots \ldots \ldots \ldots \ldots \ldots \ldots$

2.1 Overview of Automated Operations ..................... 3

2.1.a Inventory of Software Libraries and Data Files ........... 3

2.1.b Integrated Flow to Link all Software Modules and Files ......... 7

2.1.c Description of Sequence of Software Operation ............ 7

2.1.d Description of Data File Contents ................ 8

2.1.e General Approsch to File Security Measures ............. 15

2.1.f General Approach to Verification Procedures Using Test Data .... 15

2.2 Progrum Description For Each Discrete Software Module ........... 15

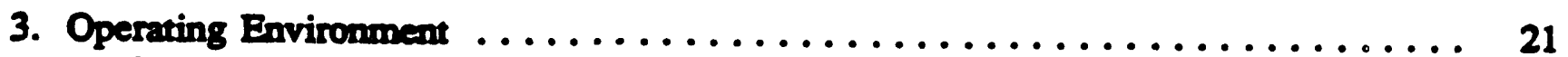

3.1 Handware $\ldots \ldots \ldots \ldots \ldots \ldots \ldots \ldots \ldots \ldots \ldots \ldots \ldots \ldots \ldots, 21$

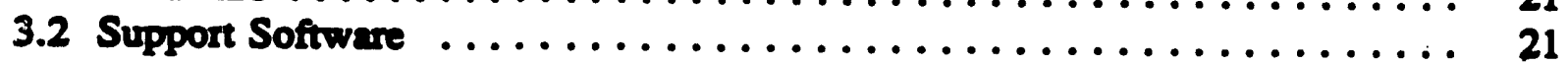

4. Maintenance Procedures ........................... 21

4.1 Programming Conventions $\ldots \ldots \ldots \ldots \ldots \ldots \ldots \ldots \ldots \ldots \ldots \ldots \ldots, 21$

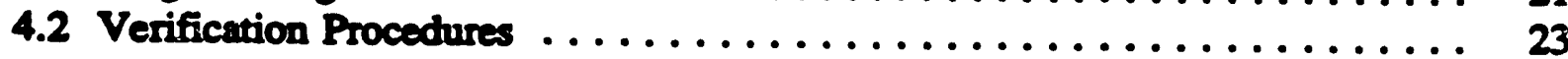

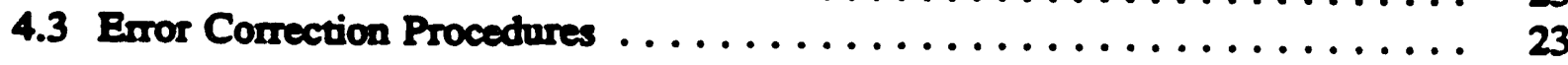


4.4 Special Maintenance Procedures . . . . . . . . . . . . . . . . . . 23

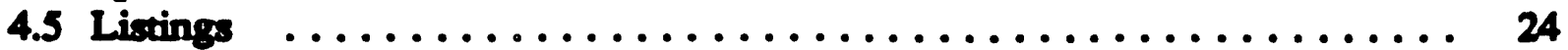

Organization of Source Code Lixing ................... 24

Source Code for Main ICSD Programs .................. 24

AUTOMATEPRG ....................... 24

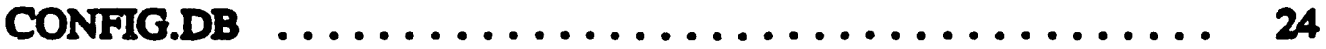

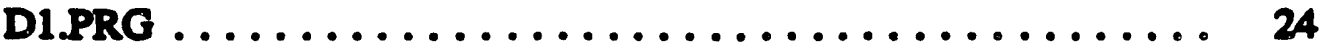

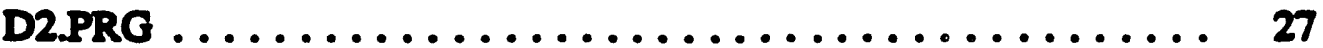

D3.PRG ....................................... 28

D4PRG .............................. 28

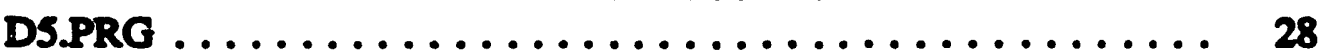

DEMANDPRG ........................ 29

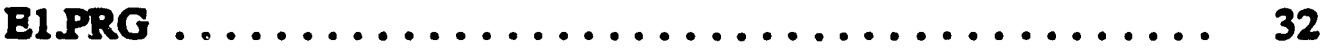

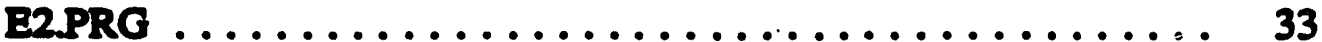

E3PRG .............................. 50

E4PRG .......................... 67

ESPRG ......................... 68

ERRMESS.PRG ....................... 69

EXPORTS.PRG ........................ 70

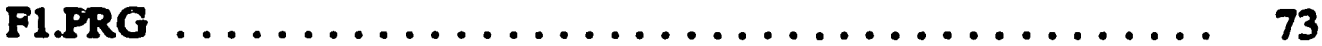

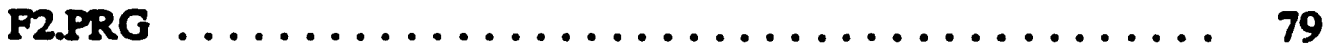

F3.PRG $\ldots \ldots \ldots \ldots \ldots \ldots \ldots \ldots \ldots$

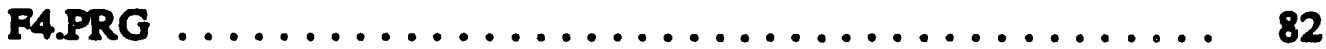

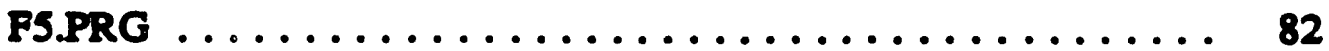

FLOWSPRG .......................... 82

HELP.PRG . . . . . . . . . . . . . . . . . . . 86

MASTER.PRG ....................... 87

O1.PRG ................................ 90

O2.PRG . . . . . . . . . . . . . . . . . . . . . 92

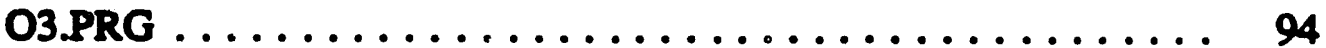

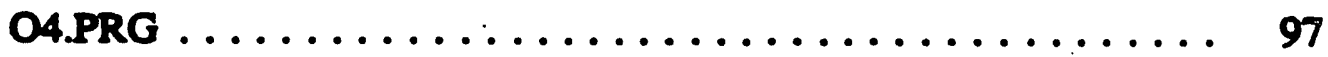

OS6A.PRG ............................... 100

OSGB.PRG ............................... 108

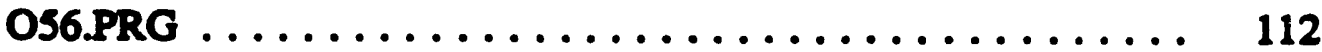

OS7.PRG ................................ 113

OSPRG ................................. 114

OPTIONS.PRG ........................ 116

P1.PRG .................................. 119

P2.PRG .................................. 120

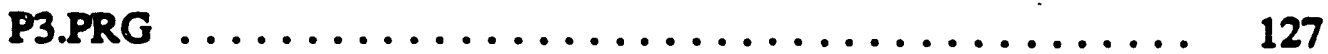

P4.PRG .................................. 133

PS.PRG . . . . . . . . . . . . . . . . . . . . . 134

PRICES.PRG ............................. 135

U1.PRG . . . . . . . . . . . . . . . . . . . . . 139 
U2 PRG

U3.PRG

U4.PRG

U6.PRG

U7.PRG

U8.PRG

UCOUNTRYPRG ..................... 149

UDEMANDPRG $\ldots \ldots \ldots \ldots \ldots \ldots \ldots \ldots \ldots \ldots \ldots, 150$

UDIR.PRG $\ldots \ldots \ldots \ldots \ldots \ldots \ldots \ldots \ldots \ldots \ldots \ldots, 151$

UDMD1.PRG $\ldots \ldots \ldots \ldots \ldots \ldots \ldots \ldots \ldots \ldots \ldots \ldots$

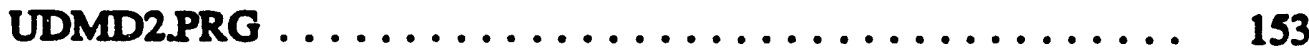

UDMD3.PRG $\ldots \ldots \ldots \ldots \ldots \ldots \ldots \ldots \ldots \ldots \ldots \ldots, 156$

UDMD4.PRG $\ldots \ldots \ldots \ldots \ldots \ldots \ldots \ldots \ldots \ldots \ldots, 162$

UDMDS.PRG $\ldots \ldots \ldots \ldots \ldots \ldots \ldots \ldots \ldots \ldots \ldots \ldots \ldots$

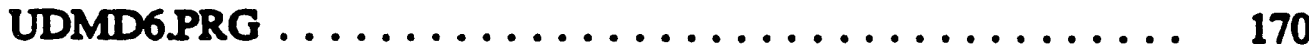

UDMD7.PRG $\ldots \ldots \ldots \ldots \ldots \ldots \ldots \ldots \ldots \ldots \ldots \ldots, 172$

UDMD8.PRG $\ldots \ldots \ldots \ldots \ldots \ldots \ldots \ldots \ldots \ldots \ldots \ldots, 186$

UDMD9.PRG ......................... 194

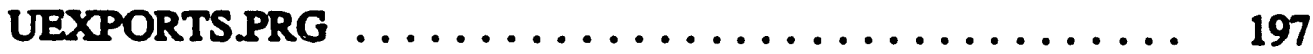

UIMPORTS.PRG $\ldots \ldots \ldots \ldots \ldots \ldots \ldots \ldots \ldots \ldots \ldots \ldots$

UPDATEPRG $\ldots \ldots \ldots \ldots \ldots \ldots \ldots \ldots \ldots \ldots \ldots \ldots$

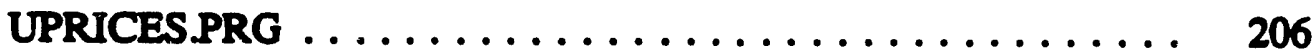

UV1.PRG $\ldots \ldots \ldots \ldots \ldots \ldots \ldots \ldots \ldots \ldots \ldots \ldots \ldots \ldots$

UVOLUME.PRG $\ldots \ldots \ldots \ldots \ldots \ldots \ldots \ldots \ldots \ldots \ldots, 211$

ICSD.BAT $\ldots \ldots \ldots \ldots \ldots \ldots \ldots \ldots \ldots \ldots \ldots, 212$

Source Code for ICSD Installation Programs $\ldots \ldots \ldots \ldots \ldots \ldots \ldots, 214$

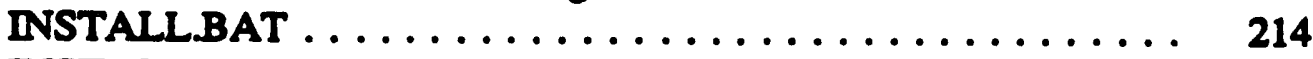

INSTALL1.PRG $\ldots \ldots \ldots \ldots \ldots \ldots \ldots \ldots \ldots \ldots, 215$

INSTALL2PRG $\ldots \ldots \ldots \ldots \ldots \ldots \ldots \ldots \ldots \ldots \ldots, 222$

4.6 Security 


\section{International Coal Statistics Data Base}

\section{Program Maintenance Manual}

\section{General Information}

\subsection{Summary}

Principal features include:

- Menu-driven, interactive database using dBase III Plus and Lotus 1-2-3.

- Inputs of official and commercial statistics on international coal trade volumes, prices and shipping rates for stean and metallurgical coal.

- Outputs of dozens of reports and culor graphic displays. Output report types include Lotns worksheets, dBase data bases, ASCII text files, screen displays and printed reports.

- Flexible design permits the user to follow structured query system or design own queries using either Lotus or dBase procedures. Assumes some familiarity with these microcomputer programs.

- Maintenance programs to configure the system, correct indexing errors, backup work, restore corrupted files, annotate user-created files, and update system, use DOS shells, and many more.

Two major types of program maintenance documentation are presented in this manual. The first is the source code for the dBase III routines and related non-dBase programs used in operating the ICSD. The second is listings of the field structure of the major component databases. A third important consideration for dBase programming, the structure of index files, is presented in the listing of source code for the index maintenance program.

It is common practice among dBase programmers to indent sections of code to clarify the relationship between a given section and earlier commands, such as indenting the commands applicable to a particular nested loop or similar decision structure. These conventions have been followed to make it easier to follow program logic. In addition, various commenting procedures and visual devices have been used to help clarify where major sections of a program begin or end. It should also be noted that screen colors have been established to give the user a sense of location within the structure of menus and submenus. The general color scheme is for the master menu to be light gray against a cyan background, 
while each of the five submenus called from the master menu is light gray against a red background. Further subprograms beyond the submenu level, other than the data update programs, take place with white foreground characters against a blue background. The sole exception to the scheme is the submenu for data update which is black foreground characters and white background characters. Of course, this scheme is only visible on color monitors.

Not all programs used by the ICSD are documented in this manual. There are several minor routines that are in either binary or executable format that are not listed. Two examples are the Cursoff.bin program, which is alightly different than the program of the same name provided with dBase III in onder to work with a wider array of monitors, and Pstatus.com, which sets the system error level depending on whether the user's printer is on or off. The modified curson.bin and cursoff.bin routines were necessary because the Compac 386 computers in use by EIA contain graphic boards that would not respond properly to the dBase III versions of those programs. The Pstatus.com and related batch file, Isiton.bat, are provided as conveniences to the user. Any of these bin or .com programs may be disassembled if necessary, but there is little purpose in documenting their code as each is about 20 bytes long.

\subsection{Environment}

The ICSD was developed under contract No. DE-AC01-87E119801 for the Office of Coal, Nuclear, Electric and Altemate Fuels by the Decision Analysis Corporation of Virginia.

\subsection{References}

\section{3.a Project Requests (Authorizations)}

Section 205(a)(2) of the Department of Energy Organization Act (Public Law 95-91) requires the Administrator of the Energy Information Administration (EIA) to carry out a central, comprehensive, and unified energy data information program that will collect, evaluate, assemble, analyze, and disseminate data and information relevant to technology, and related economic and statistical information. To meet these responsibilities in the area of intemational coal analysis, the EIA prepared this report.

\section{3.b Previously Published Documents}

U.S. Department of Energy, Energy Information Administration, Office of Coal, Nuclear, Electric and Altemate Fuels, 1989 Update International Coal Statistics Data Base, September 1989. 


\section{3.c Related Documentation}

U.S. Department of Energy, Energy Information Administration, Office of Coal, Nuclear, Electric and Altemate Fuels, 1990 Update International Coal Statistics Data Base Operations Guide, September 1989.

\section{3.d Other Reference Documentation}

See Lotus 123 and dBase Reference Manuals.

\section{Program Descriptions}

\subsection{Overview of Automated Operations}

\section{1.a Inventory of Software Libraries and Data Files}

The following programs make up the ICSD. They must be stored in a directory named VCSD on any hard drive.

VCSD
auto123.d1
auto123.e2
auto123.e3
auto123.f1
auto123. 2
auto123.13
auto123.05
auto123.p2
auto123.p3
auto123.wk1
automate.prg
backup.mem
cnumber.ndx
coldboot.com
config.db
config.mem
country.dbf
country.ndx
cursoff.bin
curson.bin
dl.prg
d1.wk1
dl.wks

2,865 bytes

2,865 bytes

2,865 bytes

2,865 bytes

2,865 bytes

2,865 bytes

2,865 bytes

2,865 bytes

2,865 bytes

2,865 bytes

614 bytes

38 bytes

3,584 bytes

17 bytes

272 bytes

123 bytes

7,746 bytes

5,120 bytes

12 bytes

21 bytes

4,836 bytes

160,794 bytes

49,813 bytes

$\begin{array}{lc}\text { d2.prg } & 916 \text { bytes } \\ \text { d3.prg } & 913 \text { bytes } \\ \text { d4.prg } & 411 \text { bytes } \\ \text { d5.prg } & 894 \text { bytes } \\ \text { demand.dbf } & 1,124,698 \text { bytes } \\ \text { demand.ndx } & 184,320 \text { bytes } \\ \text { demand.prg } & 6,168 \text { bytes } \\ \text { demand1.dbf } & 333,824 \text { bytes } \\ \text { demand1.ndx } & 16,384 \text { bytes } \\ \text { dreport.dbf } & 28,058 \text { bytes } \\ \text { e1.prg } & 1,760 \text { bytes } \\ \text { e2.dbf } & 4,534 \text { bytes } \\ \text { e2.prg } & 36,050 \text { bytes } \\ \text { e2.qry } & 29 \text { bytes } \\ \text { e2.txt } & 2,141 \text { bytes } \\ \text { e2.wk1 } & 43,485 \text { bytes } \\ \text { e2.wks } & 24,702 \text { bytes } \\ \text { e2a.frm } & 1,990 \text { bytes } \\ \text { e2a.ndx } & 241,152 \text { bytes } \\ \text { e2b.frm } & 1,990 \text { bytes } \\ \text { e2b.ndx } & 329,216 \text { bytes } \\ \text { e3.dbf } & 634 \text { bytes } \\ \text { e3.prg } & 33,837 \text { bytes } \\ \text { e3.qry } & 49 \text { bytes } \\ \text { e3.trt } & 7,236 \text { bytes } \\ \text { e3.wk1 } & 44,610 \text { bytes } \\ & \end{array}$




\begin{tabular}{|c|c|c|c|}
\hline 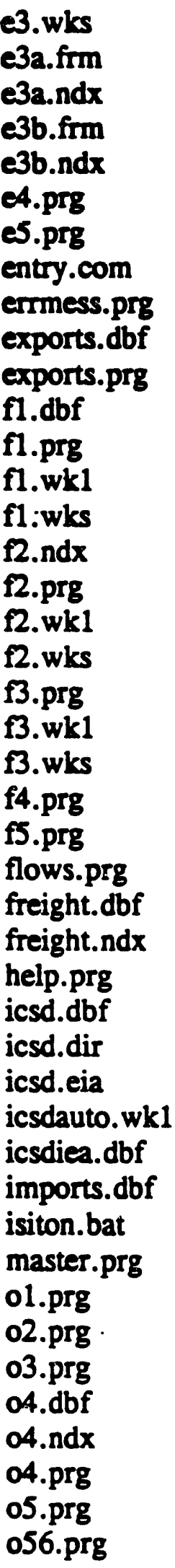 & $\begin{array}{c}3,894 \text { bytes } \\
1,990 \text { bytes } \\
74,240 \text { bytes } \\
1,990 \text { bytes } \\
100,352 \text { bytes } \\
1,847 \text { bytes } \\
1,953 \text { bytes } \\
536 \text { bytes } \\
1,60 \text { bytes } \\
2,077,184 \text { bytes } \\
6,043 \text { bytes } \\
1,216 \text { bytes } \\
10,518 \text { bytes } \\
19,992 \text { bytes } \\
1,509 \text { bytes } \\
47,616 \text { bytes } \\
2,947 \text { bytes } \\
118,020 \text { bytes } \\
11,609 \text { bytes } \\
1,853 \text { bytes } \\
114,116 \text { bytes } \\
101,465 \text { bytes } \\
1,027 \text { bytes } \\
328 \text { bytes } \\
6,181 \text { bytes } \\
201,905 \text { bytes } \\
12,800 \text { bytes } \\
1,950 \text { bytes } \\
79 \text { bytes } \\
9 \text { bytes } \\
48 \text { bytes } \\
2,147 \text { bytes } \\
40,169 \text { bytes } \\
337,224 \text { bytes } \\
1,285 \text { bytes } \\
7,375 \text { bytes } \\
1,992 \text { bytes } \\
5,972 \text { bytes } \\
5,258 \text { bytes } \\
21,504 \text { bytes } \\
5,120 \text { bytes } \\
4,602 \text { bytes } \\
1,923 \text { bytes }\end{array}$ & 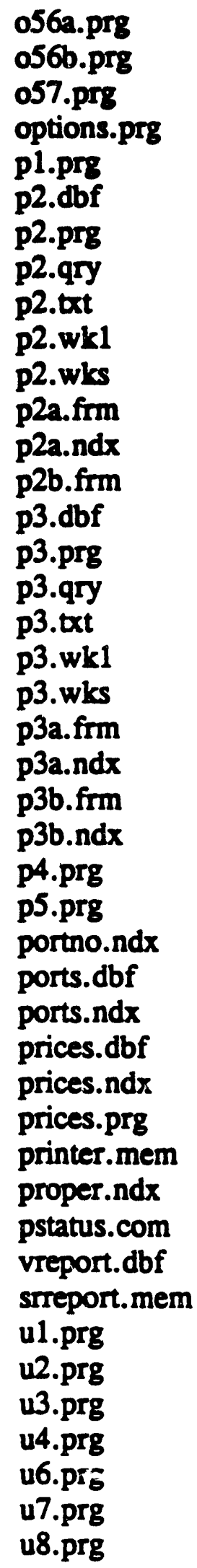 & $\begin{array}{c}20,266 \text { bytes } \\
8,083 \text { bytes } \\
2,773 \text { bytes } \\
6,081 \text { bytes } \\
1,611 \text { bytes } \\
744 \text { bytes } \\
13,884 \text { bytes } \\
62 \text { bytes } \\
898 \text { bytes } \\
45,240 \text { bytes } \\
21,586 \text { bytes } \\
1,990 \text { bytes } \\
1,024 \text { bytes } \\
1,990 \text { bytes } \\
39,095 \text { bytes } \\
11,271 \text { bytes } \\
34 \text { bytes } \\
3,381 \text { bytes } \\
88,899 \text { bytes } \\
20,453 \text { bytes } \\
1,990 \text { bytes } \\
1,024 \text { bytes } \\
1,990 \text { bytes } \\
1,024 \text { bytes } \\
1,759 \text { bytes } \\
2,048 \text { bytes } \\
1,090 \text { bytes } \\
2,560 \text { bytes } \\
400,978 \text { bytes } \\
27,648 \text { bytes } \\
6,529 \text { bytes } \\
203 \text { bytes } \\
5,191 \text { bytes } \\
2,294 \text { bytes } \\
20 \text { bytes } \\
4,126 \text { bytes } \\
2,332 \text { bytes } \\
2,147 \text { bytes } \\
5,340 \text { bytes } \\
1,064 \text { bytes }\end{array}$ \\
\hline
\end{tabular}




$$
\begin{array}{lc}
\text { ucountry.prg } & 1,742 \text { bytes } \\
\text { udemand.dbf } & 28,820 \text { bytes } \\
\text { udemand.prg } & 1,739 \text { bytes } \\
\text { udir.dbf } & 322 \text { bytes } \\
\text { udir.ndx } & 1,025 \text { bytes } \\
\text { udir.prg } & 645 \text { bytes } \\
\text { udmd.mem } & 324 \text { bytes } \\
\text { udmd1.dbf } & 512 \text { bytes } \\
\text { udmd1.prg } & 2,369 \text { bytes } \\
\text { udmd1tem.dbf } & 512 \text { bytes } \\
\text { udmd2.dbf } & 1,536 \text { bytes } \\
\text { udmd2.prg } & 3,000 \text { bytes } \\
\text { udmd2tem.dbf } & 1,536 \text { bytes } \\
\text { udmd3.prg } & 7,591 \text { bytes } \\
\text { udmd4.dbf } & 512 \text { bytes } \\
\text { udmd4.prg } & 2,111 \text { bytes } \\
\text { udmd5.prg } & 7,783 \text { bytes } \\
\text { udmd6.dbf } & 226 \text { bytes } \\
\text { udmd6.prg } & 3,333 \text { bytes } \\
\text { udmd6tem.dbf } & 770 \text { bytes } \\
\text { udmd7.prg } & 18,258 \text { bytes } \\
\text { udmd8.prg } & 21,039 \text { bytes } \\
\text { udmd9.prg } & 3,379 \text { bytes } \\
\text { uexports.dbf } & 1,024 \text { bytes } \\
\text { uexports.prg } & 3,149 \text { bytes } \\
\text { ufreight.dbf } & 7,216 \text { bytes } \\
\text { uimports.dbf } & 76,800 \text { bytes } \\
\text { uimports.prg } & 10,293 \text { bytes } \\
\text { update.prg } & 5,439 \text { bytes } \\
\text { uprices.dbf } & 11,264 \text { bytes } \\
\text { uprices.prg } & 863 \text { bytes } \\
\text { uv1.prg } & 8,383 \text { bytes } \\
\text { uvolume.dbf } & 19,454 \text { bytes } \\
\text { uvolume.prg } & 1,129 \text { bytes } \\
\text { vcountry.dbf } & 710 \text { bytes } \\
\text { vcountry.ndx } & 1,024 \text { bytes } \\
\text { volumes.ndx } & 115,200 \text { bytes } \\
\text { volumes1.dbf } & 162,082 \text { bytes } \\
\text { volumes1.ndx } & 47,616 \text { bytes } \\
\text { icsd.bat } & 4,888 \text { bytes } \\
\text { volumes.dbf } & 239,666 \text { bytes } \\
& \\
\hline & \\
\hline
\end{array}
$$

$7,689,031$ total bytes in 178 files$$
239,666 \text { bytes }
$$

The following files are supplied on the ICSD installation diskette and do not become part of the overall system.

\author{
UCSDIDNSTALL \\ install.bat 515 bytes \\ install1.prg 13,090 bytes \\ install2.prz 3,030 bytes
}

16,635 total bytes in 3 files

Total of all files

$7,705,666$ total bytes 


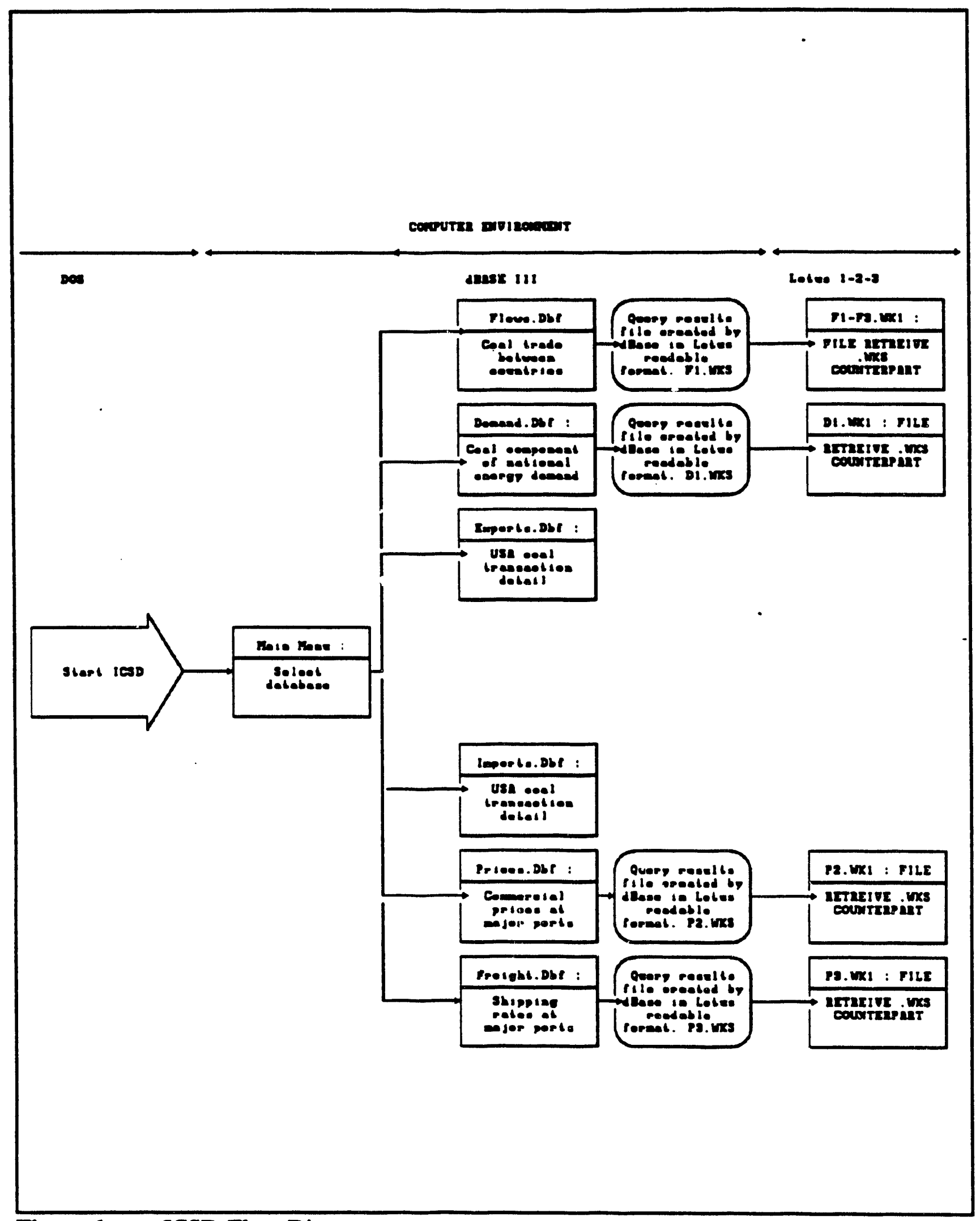

Figure 1. ICSD Flow Diagram 


\section{1.b Integrated Flow to Link all Software Modules and Files}

\section{1.c Description of Sequeice of Software Operation}

The program is started from any directory by entering the name of the batch program created during the installation process, ICSD.BAT. This batch program turns over ontrol to a second batch program located in the ICSID file directory, ICSD.BAT. The latter is called with two parameters that correspond to the locations of the user's dBase and Lotus file directories. DBase is then loaded, which in turn loads the master program that controls the initial menu, MASTER.PRG. This program controls access to all others including programs that subsequently load Lotus 1-2-3 from a shell, as well as exit from the system. Once the ICSD is exited, control is returned to the ICSD.BAT program, which handles several file mainienance routines and finally relinquishes control back to DOS. Automated access to Lotus is conirolled by having the relevant dBase program copy a predefined program shell, each with the prefix AUTO123 and an extension corresponding to the dBase program that made the call, into the name AUTO123.WK1, the generic name used by Lotus to control automatic loading of worksheets.

\section{1.c.1 Program Functions - Using dBase and Lotus}

The International Coal Statistics Data Base was designed to make coal statistics from disparate sources available in a common microcomputer format. The major databases came from different sources: the data making up Volumes.Dbf came from Lotus worksheets prepared by the Energy Information Administration. The Demand.Dbf also started as a very large worksheet but was taken from a report prepared by contractors to EIA. The imports and exports databases started as mainframe partitioned data sets originally prepared by the Bureau of the Census of the U.S. Department of Commerce. The prices and freight rate databases were originally downloaded ASCII files from the N'exis information service, which were originally published material in Coal Week International. The main design consideration was how to relate the data in a common format for use on microcomputers using software from the list of EIA supported software. The components of system design and the justification for design decisions are set forth in the document Design Plan for the International Coal Statistics Data Base, Decision Analysis Corporation of Virginia, September 30, 1987.

All data are stored in dBase III file firmat data tables. However, data are frequently transformed in one of two ways. The most common is to be copied to a special file from within dBase that can be read by Lotus. After this file is created and given the extension .WKS, operating control is switched to Lotus. ${ }^{1}$ However, before the switch is made, the

\footnotetext{
'The new file is actually in Lotus 1.A format, as opposed to the Lotus $2 . x$ required to run the ICSD, but the later version of Lotus has the capability of reading files in its earlier format.
} 
corresponding to the program that called them, have a single function under their new name to direct Lotus to the ICSD subdirectory by resetting the directory value and then loading the worksheet required to control the use of the data. For instance, a search of the Prices.dbf might result in queried records being copied to the file P3. Wks. In order to read this data, Auto123.P3 would be copied into Auto123.Wk1, Lotus called, the P3.Wk1 worksheet loaded automatically, which would in turn load the data stored in P3. Wks for analysis, reporting and graphing.

\section{1.d Description of Data File Contents}

This section lists the structures of the ICSD component data bases. Following each numbered field name is the type of data it contains and its size in bytes.

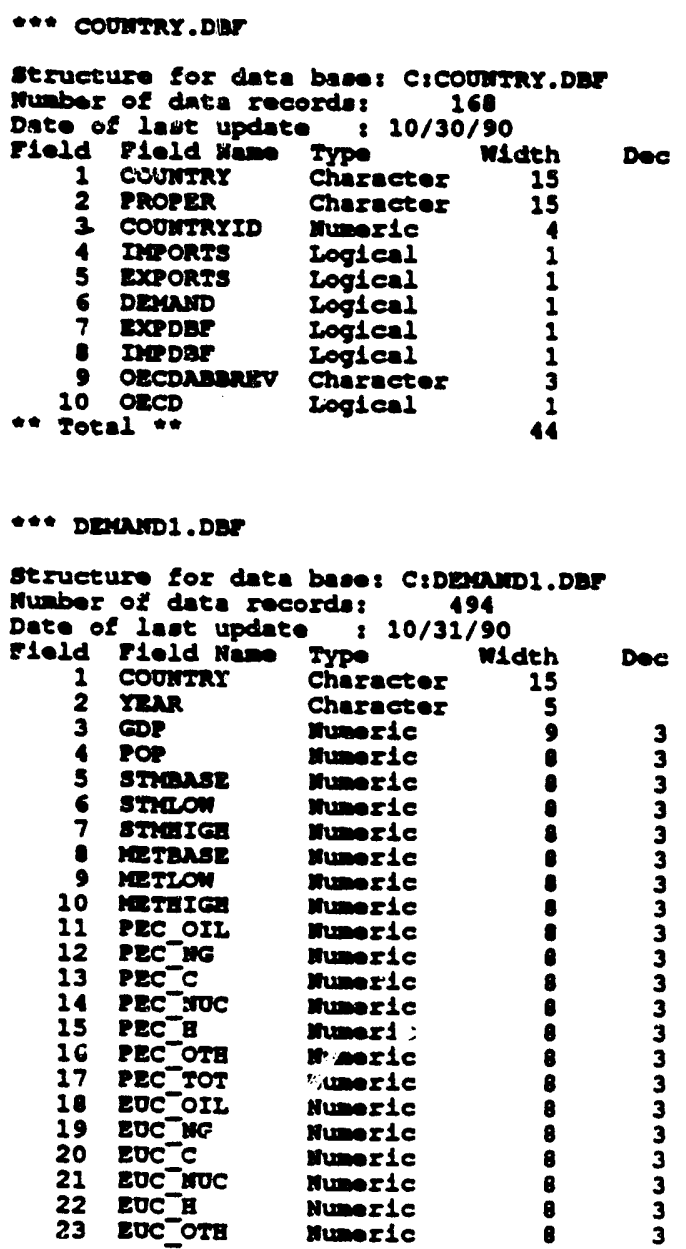

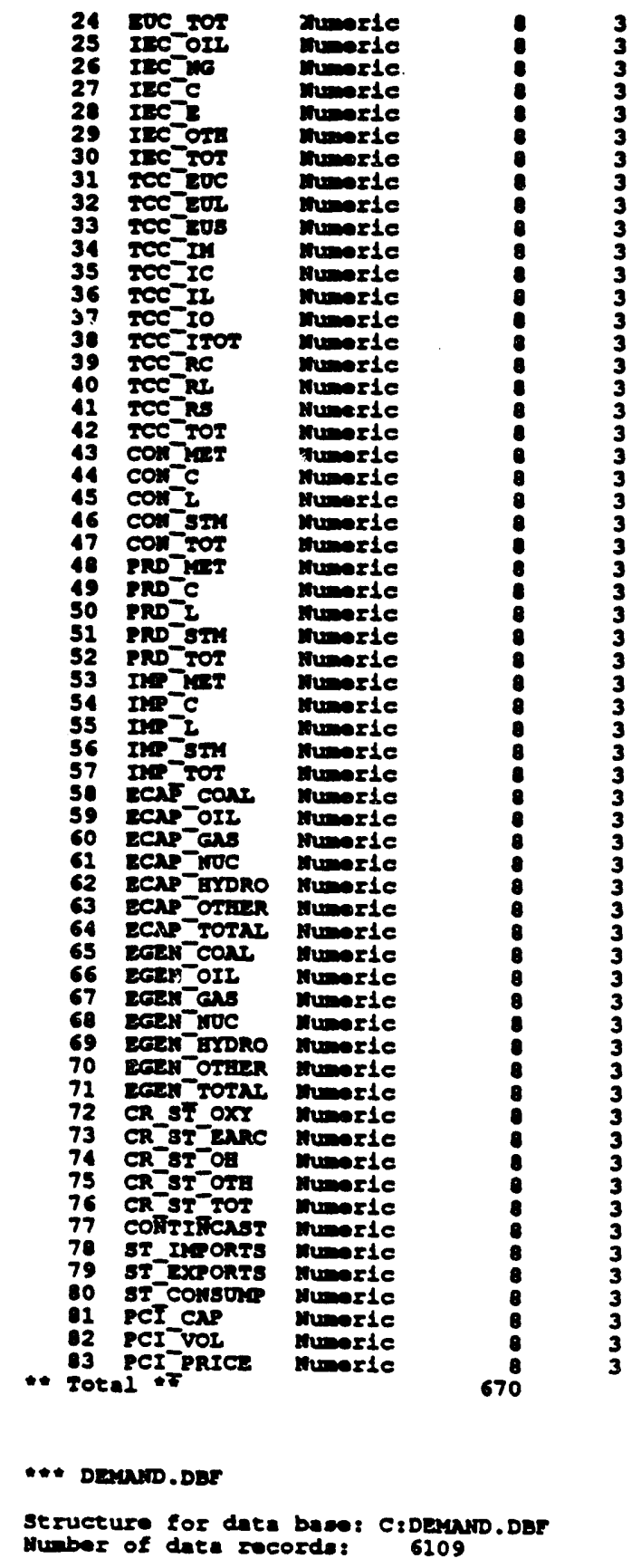




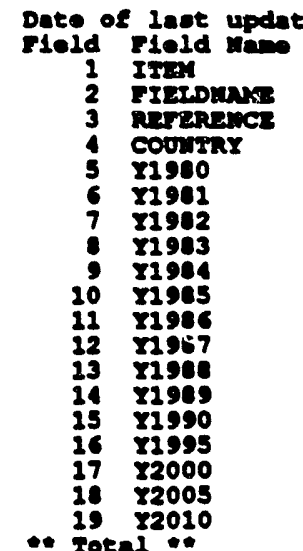

2 $10 / 31 / 90$

Type w1deh

Dec

chasecter

Characte

Munorle

Character

murerte

himerie

mueste

throerte

muserie

minerie

thorie

wrorte

munerie

themeste

nomerte

therde

inserte

arisic

- Total *

tromerte

te Drtpong.Dr

seructuro for data beses CiDRrpont.Der

Muber of date recordos, 249

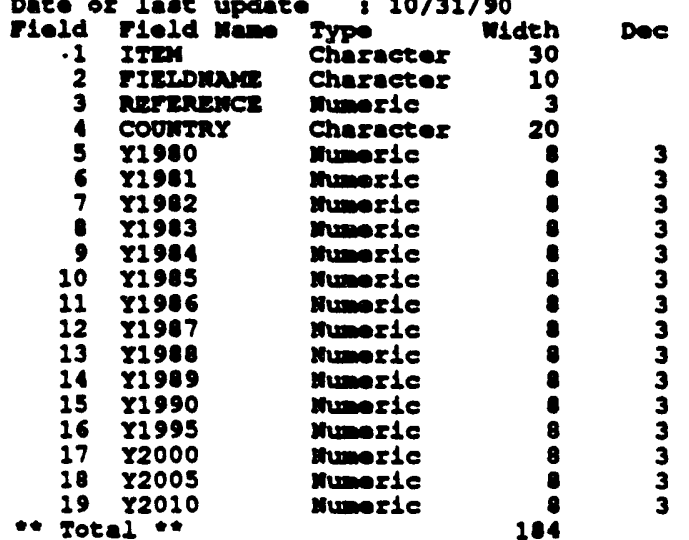

22 . Dar

structure for date beces Ciz2.DAP

Number of date recorda:

Date of lant update; 0s/05/8e

rledd Field uas Typo Mideh D

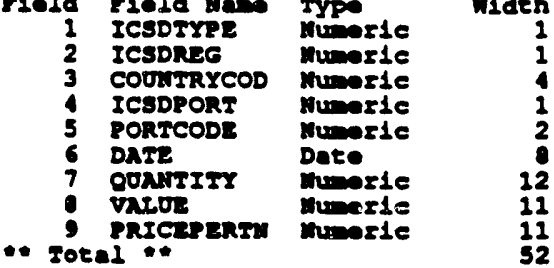

\section{Der}

structure for dite beees C:E3.DB

Murber of date records?

6

Fleld rield han rypo

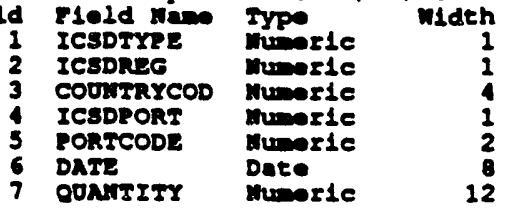

Dee

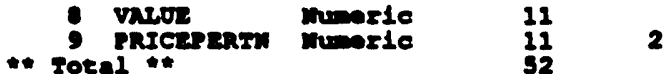

H. Honse.020

stzucture for date beees Ciexokrs.Der

Muber of date recordes 19224

Date of lagt update : 03/13/91

2 2xt

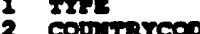

pontcoor

ronscost 2

3 mowrst

y rar

7 coxirstes

- prictaratin

10 Dats.

centren

ICsorner

respriso

ICsDPOnt

conisIT12

sarpwiar

17 sarpvirou

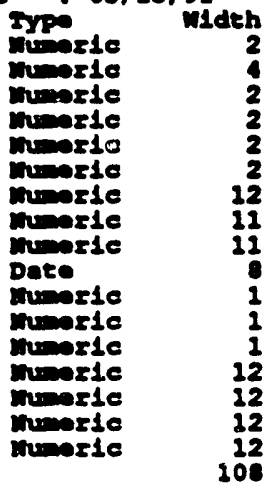

Doe

- Total..

** P2.DAR

seructure for dete baces Cifl.on

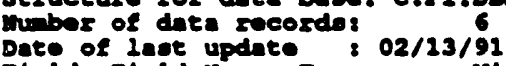

1eld rield uave type

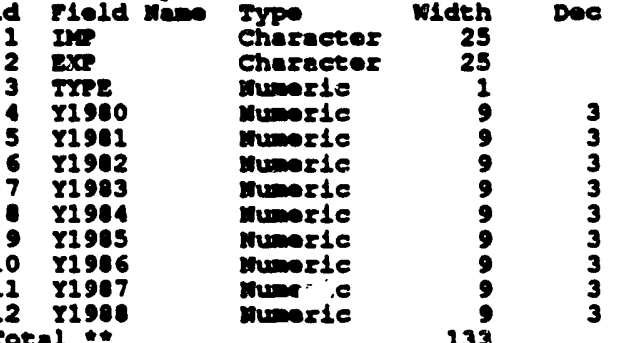

- Total *

133

** mezare.dar

structure for date bees CimeIGar.dar

Muber of data zecorde: 09/20/90

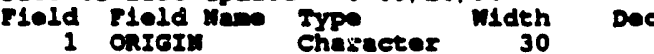

Chasacter 30

2 PokT Character

3 pestrunto Chnereter

Descramio

Murexte

Character

therezte

7 Iran

7 41

- 01

10 Is8Uatr: Date

11 surpsize Wueric

12 necoporic chrracter

Characte

Chareeter

* Total.

* ICSD.DBF

Etructure for date base: CIICSD.DA

Dater of lapt update \& 03/26/91

Fleld Fleld uaw Type 03/26/91 WIdth Dee

* I ICsD Character 12 


\section{*. ICODIRA.DAF}

structure for data beep: CircspInd.Dar minber of date rocordes 149

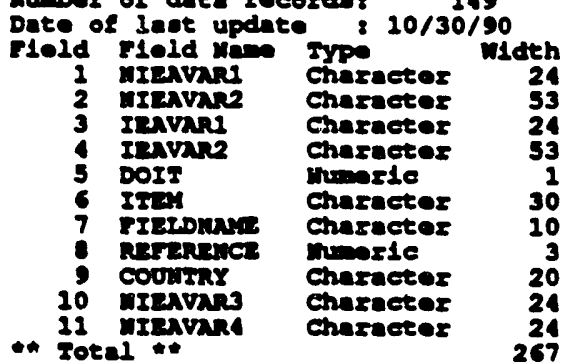

\section{riponzs. Dar}

structure for data beces Ci rpokss. Der Munber of date recorda: 5807 Date of laot update : $03 / 23 / 91$

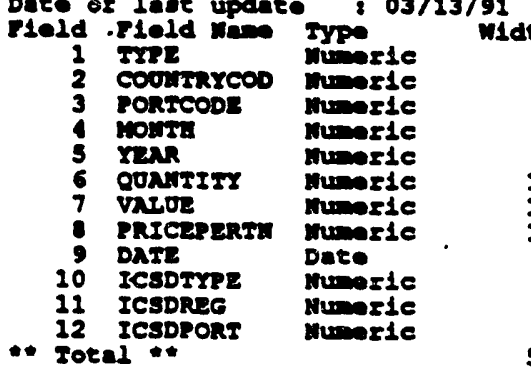

Dec

O4.Dar

structure for data beep: CsO4.DBF Huber of date racordo: 104

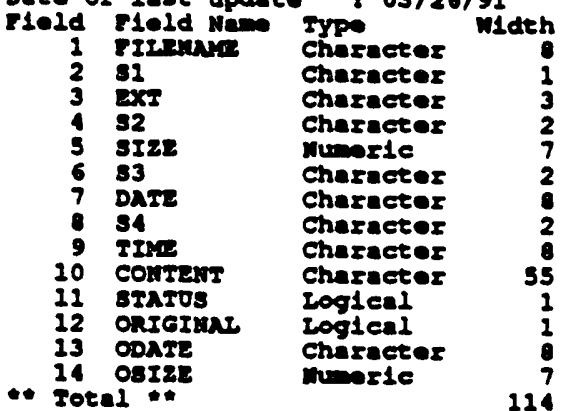

OAD.DER

etrueture for data beees cijunk.dbt lumber of date recorda: $3 / 36$

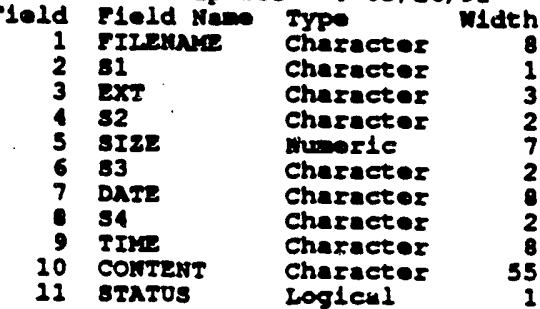

Dee

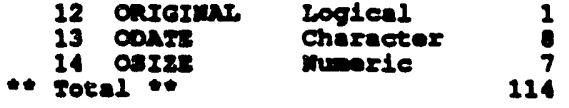

$\leftrightarrow$ P2.DRe

structure for date baces CsP2.DN Duter of date recorda: $05 / 20 / 2$

Fleld Fleld man Typo
1 CoOnIRY

Character

Character

Cheracter

voragre:

4 surior

5 net

6 มxp: Cheracter therese

7 O D morte

- ruaron minerte

9 2Virica

10 groison

11 arozisa

minerie

throric

mimerie

Date

13 mors:

Charecter

17
30

Dec

- Toeal *.

-.* P3.0ur

seructure far date baces CsP3.DPr

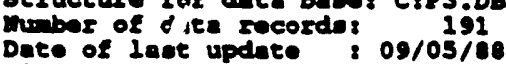
Date of lact update \& 0s/0s/86

i rela

Charaeter Cheracter

2 PORT

3 Destrunto

4 gargerze

Muneste

6 areorom Hurerte

7 Iscovart Date

- Itaris Character

- wosts

- Total *.

Wdeh
30
30
30
10
10
10
30
30
14
203

Dae

* POATE.DN

Jerueture for dete baces Ciponts.Dar Thuber of date rocordo: 32

Field pleld updat $07 / 21 / 89$

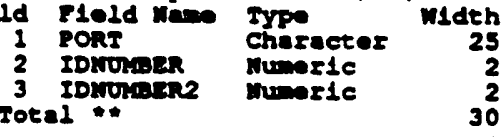

- Totel

\section{\# pRICES.DAr}

structure for date bans CipRICes.Dar thuber of data recorda: 2096 Date of lant update : 09/20/90

ypo vidth

character Character

PORs

voraris.

Character

Character

Character

Chrracter

TERTPRIC

ThapkIe

Itwicon

numerte

Humer le

SPOTPRIC

Characte

Numeric

sporsan

Hurerie

aropers

m2Re

$4 \mathrm{MI}$

15 DI

16 Y1

17 IssU2DATE

Numeric

Mumor $1 \mathrm{c}$

Numerle

Numer 1e

Numer 1c

D D Date

Numerac 


\begin{tabular}{|c|c|c|c|}
\hline 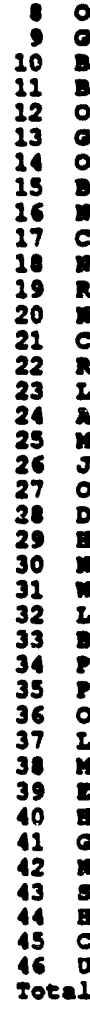 & 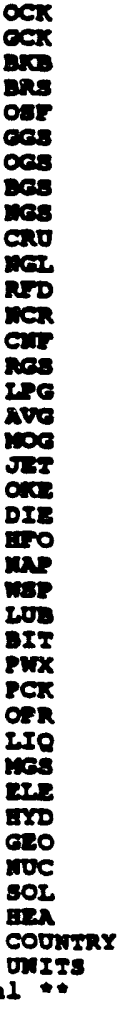 & 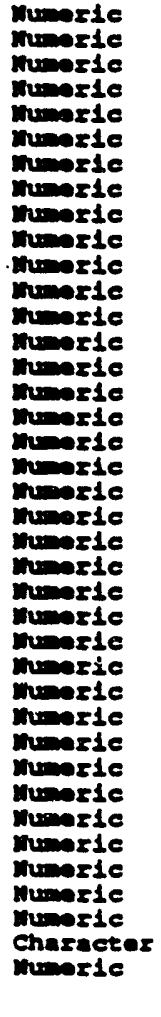 & $\begin{array}{r}\text { ? } \\
? \\
? \\
? \\
? \\
? \\
? \\
? \\
? \\
? \\
? \\
? \\
? \\
9 \\
9 \\
9 \\
? \\
9 \\
9 \\
9 \\
9 \\
13\end{array}$ \\
\hline
\end{tabular}

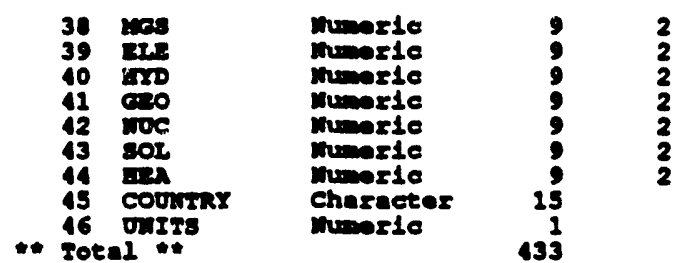

\#" udvad.dar

Btructure for date beees Cs ODiph.DPr

muber of date reeordo: os/24/90

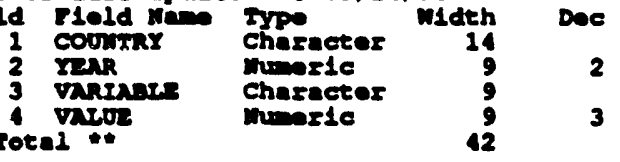

u. udatog.dar

otrueture for data base: Ca Udips.Der

Whiber of date recordes $10 / 31 / 90$

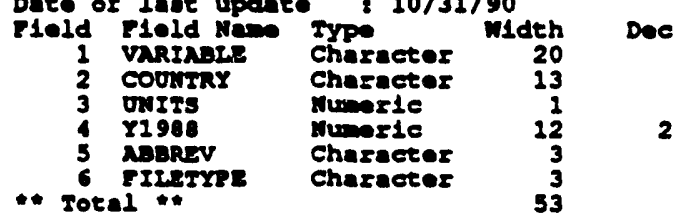

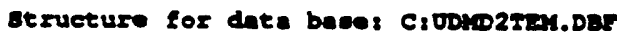
Wuber of date recorda: 09/24;90 uldeh Dec

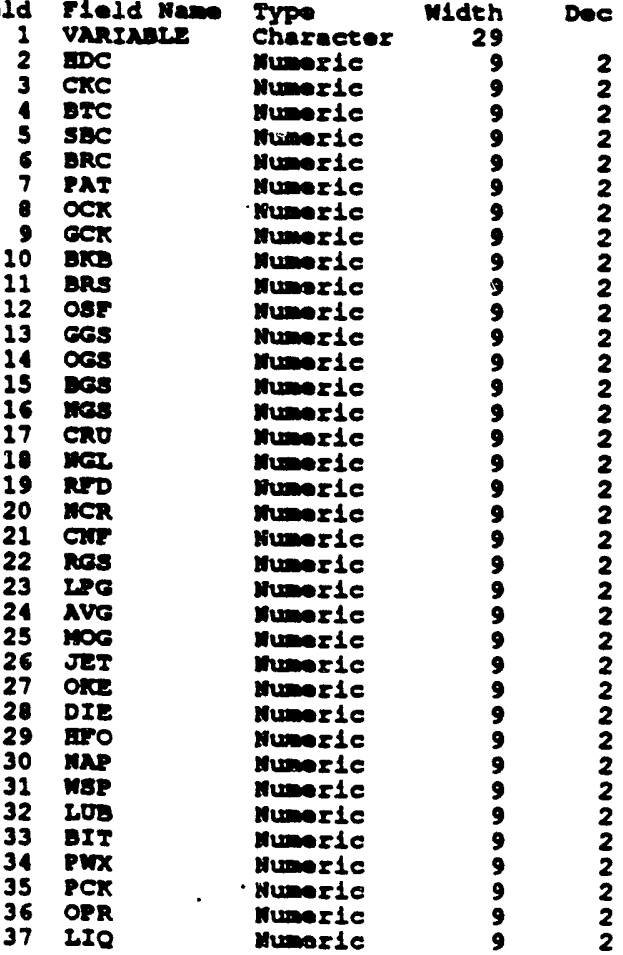

- ODidegray.Dor

structure for date baees Ci ODHDGran.Der Wuiber of date recorde: $10 / 31 / 90$

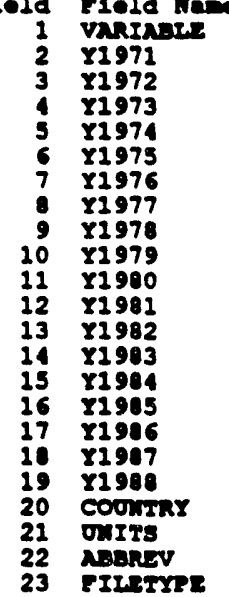

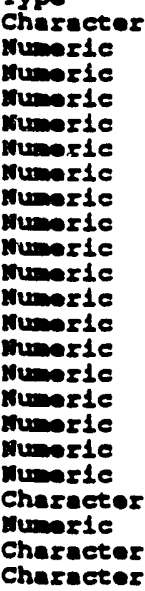

T1dth Dec

* "* Juxporzs.der

structure for date bace: C:0HXPorrs.Dar

Muaber of date recorde: $07 / 03 / 90$

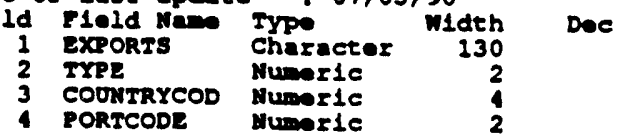




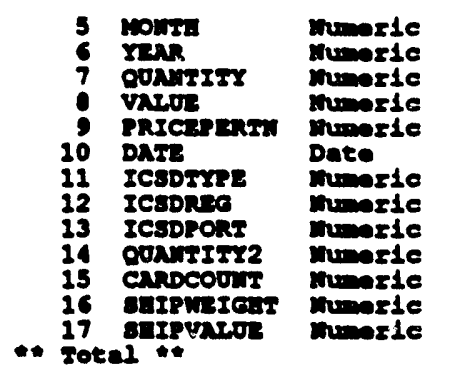

2
2
12
11
13
1
1
1
1
12
12
12
12
236

\section{"* orneighr.dar}

structure for data beeps ciomerear.dar mumber of date recorda? os/20/90

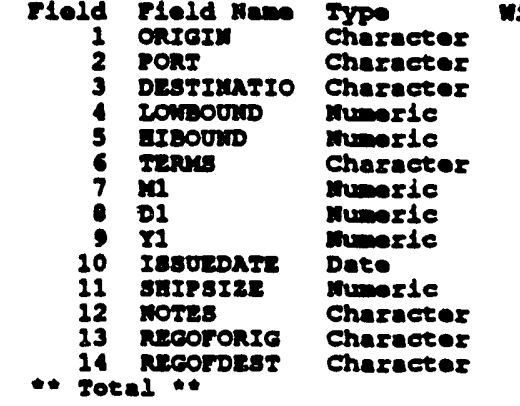
30 Dec 30
30
30 $\begin{array}{ll}10 & 2 \\ 10 & 2\end{array}$

\section{* ormonss.dar}

structure for date baces C: orsponss.Dar Mumber of date recorda: os 316

\begin{tabular}{|c|c|c|c|}
\hline $\begin{array}{r}101 d \\
1 \\
2 \\
3 \\
4 \\
5 \\
6 \\
7 \\
6 \\
9 \\
10 \\
11 \\
12 \\
13 \\
14 \\
15 \\
\text { Tota }\end{array}$ & 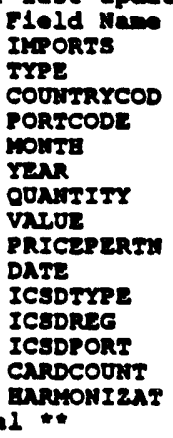 & 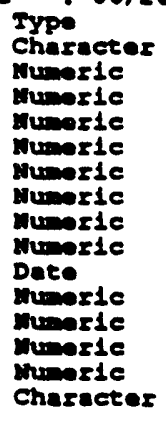 & $\begin{array}{r}\text { W1dth } \\
135 \\
2 \\
1 \\
2 \\
2 \\
2 \\
22 \\
11 \\
11 \\
8 \\
1 \\
1 \\
1 \\
8 \\
20 \\
241\end{array}$ \\
\hline
\end{tabular}

\section{* ut traces.dar}

structure for date baces C: ORRICEs.DAF

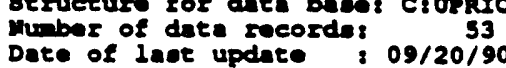
Flold Field mame 1 coomintry 2 PORT 3 voratire 4 somror

18m TzRupraric TzRugon TERHeitis 9 BPOSPRIC gFoTIIOA 2 GTUPERTA 3 TYPE

$14 \mathrm{MI}$

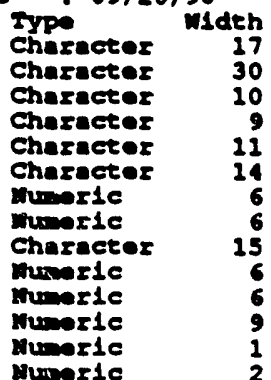

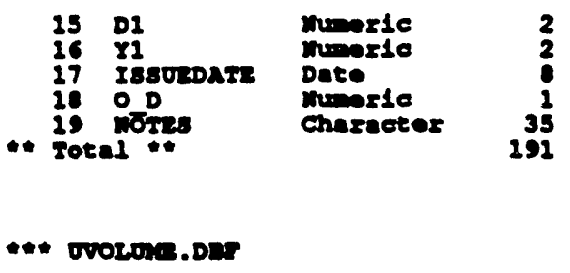

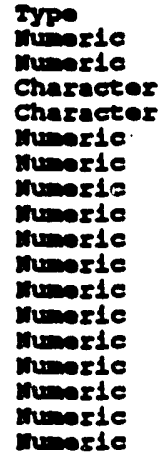

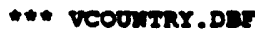

strueture for data baces Civcooniray.Dar muter of deta recordas 12

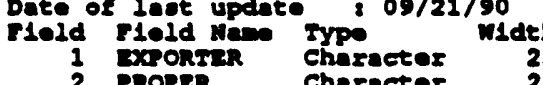
$\begin{array}{lll}2 & \text { proper } & 25 \\ \text { * Toral Character } & 25 \\ & & 51\end{array}$

-." vorovess .D2r

structure for data base: Csvoronesl.Der

Nubber of date recordu: 09/2188

Field Field was Typo Width Dec

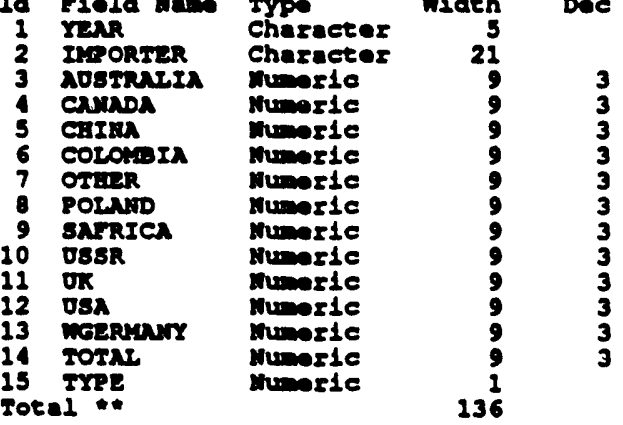

* Total * 136

* vorutas der

structure for data bace: Cavorongs.Der Mutber of date recorda: 1584

Dite of latet update : 03/26/91 width Doc $\begin{array}{lr}\text { Character } & 25 \\ \text { Character } & 25 \\ \text { Muminerte } & \end{array}$ Numer 10 Munerte Numeric Numer 10 


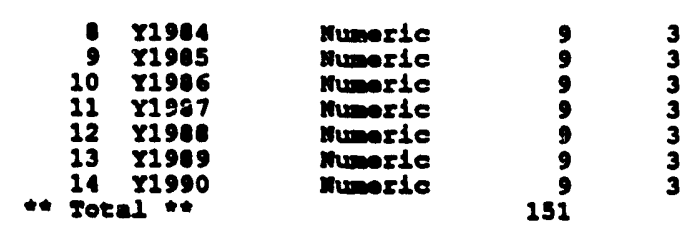

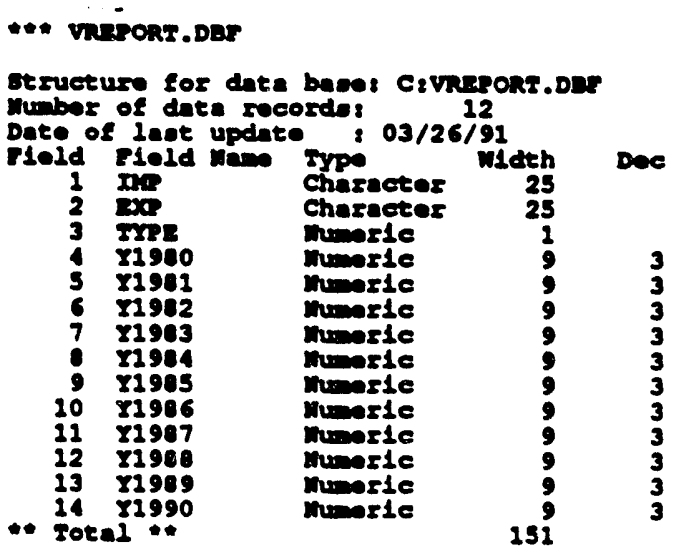

CONIIO.ICS

FIนEge 45

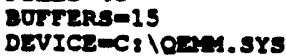

Aorowne. ICs

BCso ort

PROARI SP SC

ICSD

\section{1.e General Approach to File Security Measures}

Present file security and access is determined by the owner of the ICSD data base.

Authorization for the use of the ICSD must then require initial screening of potential users before distribution.

\section{1.f General Approach to Verification Procedures Using Test Data}

Limited opportunity exists for verification of updates to the data base, because of various filters applied to the data which may result in different configurations of the data; this specifically applies to the import and export data. Comparisons can be made by updating the data base and then referring to the initial data sources. If the original data base becomes destroyed or corrupted, backup files exist for safety purposes. See section 2.5.g in the Operations Guide.

2.2 Program Description For Each Discrete Software Module 
The following alphabetical listing sets forth each of the files used in the ICSD system and gives its purpose:

Filename Description

AUTO123 11 Automatically load Lotus for Demand reports

AUTO123 E2 Automatically loads worksheet for US exports query

AUTO123 ES Automatically losds worksheet for US imports query

AUTO123 F1 Controls auto Lotus start for national time series data

AUTO123 F2 Controls auto Lotus start for national time series data

AUTO123 F3 Controls auto Lotus start for region matrix volume data

AUTO123 OS Automatically loads blank worksheet for analyst's use

AUTO123 P2 Automatically loads worksheet for prices query

AUTO123 P3 Automatically loads worksheet for freight rate query

AUTO123 WK1 First loaded by Lotus, calls user's .wk1 choice

AUTOMAT PRG Program to antomate ICSD system configuration

BACK.UP MEM Stores user-supplied data on location of backup copies

CNUMBER NDX Index file for country.dbf; key = country id number

COLDBOOT COM DOS program that restarts computer. Used with ICSD.BAT

CONFIG DB Used by dBase, contains path instructions to find ICSD

CONFIG MEM Stores user-supplied configuration information

COUNTRY DBF Used to establish relations; included countries

COUNIRY NDX Index file for country.dbf

CURSOFF BIN Binary program used to turn cursor off

CURSON BIN Binary program used to restore cursor

D1

D1

D1

D2

PRG Inititates query of demand.dbf

D3

WK1 Main worksheet for loading and reporting demand data

WKS Transition file from dBase to Lotus for demand data

PRG User access to demand.dbf

D4

PRG User access to demand1.dbf

D5

PRG Print graphs

DEMAND1

PRG

DEMAND1

DBF

Displays or prints keys to field names for demand1.dbf

DEMAND

NDX

Original structure of demand data base

DEMAND

DBF

Index for Demand1.dbf key=alpha on country

DEMAND

NDX

Modified demandl.dbf for individual country reports

DREPORT

E1

PRG

Index file for demand.dbf

DBF

Screen and subroutines for demand-related user choices

E2A

PRG

Working dbf used in converting Demand1 to Demand

E2A

FRM

NDX

First menu choice for Exports - sets output mode

E2B

E2B

FRM Reports results of exports.dbf query to printer or file

NDX Index for exports.dbf; compound key 


\section{ENTRY}

\section{ERRMESS}

EXPORTS EXPORTS

F1

F1

F1

F1

F2

F2

F2

F2

F3

F3

F3

F4

F5

FLOWS

FREIGHT

FREIGHT

HELP

ICSDAUTO

ICSD

ICSD

ICSD

ICSDIEA
DBF

PRG

QRY

TXT

WK1

WRS

FRM

NDX

FRM Reports results of imports.dbf query to printer

NDX Index to imports.dbf; compound key

DBF User query of Freight.dbf stored in data base form

PRG Query the U.S. coal imports data base

QRY User fashioned filter for imports.dbf

TXT ASCII file with results of imports query

WK1 Holds results of U.S. imports query for further analysis

WKS Worksheet holding response to U.S. imports query

PRG Loads either .wks or .dbf file for analysis

PRG Direct access to dBase command interpreter

COM Used to hurry through the opening dBase III screen

PRG Advises user that incorrect key has been struck

DBF Main US coal exports data base

PRG Menu selection for queries of the exports \& imports dbf

DBF Intermediate data base holding results of flows query

PRG User selections for time series volumetric data

WK1 Graphic routines for time-series volumetric data

WKS Volumes data for loading into flows matrix worksheet

NDX Index file for volumes1.dbf; key = type and year

PRG Loads Lotus to view national importer/exporter matrices

WK1 Lotus worksheet w/ national importer/exporter matrices

WKS Process worksheet, holds volumesl.dbf query result

PRG Lotus worksheet for regional importer/exporter matrices

WK1 Regional importer/exporter matrices, controlling wk1

WKS Process worksheet holding results of flows comb. query

PRG Permits direct access to volumes.dbf

PRG Prints graph using Lotus 1-2-3 program

PRG Menu choices for using the importer/exporter matrices

DBF Holds data on world-wide shipping freight rates

NDX Index file for freight.dbf; key=date

PRG Displays help screen for any given major menu branch

WK1 The AUTO123.WK1 for the ICSD system before renaming

DBF Holds location of ICSD files

DIR Used to created ICSD.DBF holding file locations

EIA Special file for government edition of ICSD

DBF Used in updating DEMAND1; holds mapping formulae 


\begin{tabular}{|c|c|c|}
\hline $\begin{array}{l}\text { IMPORTS } \\
\text { ISTON }\end{array}$ & DBF & Main U.S. coal imports data base \\
\hline $\begin{array}{l}\text { ISITON } \\
\text { MASTER }\end{array}$ & $\begin{array}{l}\text { BAT } \\
\text { DPC }\end{array}$ & Batch file to wam user whether printer is on \\
\hline MI & PRG & $\begin{array}{l}\text { Opening main menu screen and first subroutune calls } \\
\text { Configures system with location of key files }\end{array}$ \\
\hline 02 & PRG & File maintenance - rebuild indexes \\
\hline $\mathbf{O 3}$ & PRG & File maintenance - back up procedure \\
\hline $\mathbf{0 4}$ & DBF & File maintenance - annotated file list (this dbf) \\
\hline O4D & DBF & Temporary file; used in this program \\
\hline O4D & DOC & Temporary file; used in this program \\
\hline O4D & NDX & Temporary file; used in this program \\
\hline 04 & NDX & Index file for this program \\
\hline & PRG & This program \\
\hline OS6B & $\begin{array}{l}\text { PRG } \\
\text { PRG }\end{array}$ & $\begin{array}{l}\text { Transiforms data base } 1 \text { to data base } 2 \text { (Volumes) } \\
\text { Transforms data base } 1 \text { to data base } 2 \text { (Demand) }\end{array}$ \\
\hline 056 & PRG & Menu selection for user data base transformation \\
\hline 057 & PRG & Lists/prints keys to import/export dbf variables \\
\hline & - PRG & Menu of miscellaneous choices \\
\hline OPTIONS & PRG & Options screen and subroutine calls \\
\hline P1 & PRG & Gets user's output selection for prices/rates queries \\
\hline P2A & FRM & Reports results of prices.dbf query to screen \\
\hline P2A & NDX & Indexes prices.dbf on unique name of country \\
\hline P2B & FRM & Reports results of prices.dbf query to printer \\
\hline P2 & DBF & Holds results of queries to prices.dbf \\
\hline $\mathbf{P 2}$ & PRG & Control queries prices.dbf \\
\hline $\mathbf{P 2}$ & QRY & Sets filter for queries of the prices.dbf \\
\hline P2 & $\mathbf{T X T}$ & Holds in ASCII file the results of query to prices.dbf \\
\hline $\mathbf{P 2}$ & WR1 & Loads p2.wks (results of prices cuery) \\
\hline $\mathbf{P 2}$ & WKS & Holds results of Prices.dbf query - loaded by p2.Wk1 \\
\hline P3A & FRM & Report on query to freight.dbf to screen \\
\hline P3A & NDX & Displays possible regions for coal origin : freight.dbf \\
\hline P3B & FRM & Report on query to freight.dbf to printer and ASCII fil \\
\hline P3B & NDX & Displays possible destination regions: freight.dbf \\
\hline P3 & DBF & Holds results of query of freight.dbf \\
\hline P3 & PRG & Queries freight rates data base \\
\hline P3 & QRY & Sets filter for queries of the freight.dbf \\
\hline P3 & $\mathbf{T X T}$ & ASCII file holding results of query to freight.dbf \\
\hline P3 & $\mathbf{W K 1}$ & Loads p3.wks (data from query of rates.dbf) \\
\hline P3 & WKS & Holds data reported in response to query of rates.dbf \\
\hline P4 & PRG & Analyzes results of prices query \\
\hline & PRG & Direct access to prices.dbf and freight.dbf \\
\hline POR? & NDX & Index file for Ports.dbf; key = port number \\
\hline PO & DBF & Working data base used in U.S. import/export queries \\
\hline PC & ND. & s.dbf; key \\
\hline PRICES & DBF & net prices from major world coal ports \\
\hline
\end{tabular}




\begin{tabular}{|c|c|c|}
\hline PRICES & NDX & Index file for prices.dbf; compound key \\
\hline $\begin{array}{l}\text { PRICES } \\
\text { PRINTRR }\end{array}$ & PRG & Coal prices and shipping rates: screen and subroutines \\
\hline $\begin{array}{l}\text { PRINIER } \\
\text { PROPER }\end{array}$ & MIEM & Stores printer setup string \\
\hline & NDX & Lists unique proper names for countries (country.dbr) \\
\hline $\begin{array}{l}\text { PSTATUS } \\
\text { SRREPORT }\end{array}$ & $\begin{array}{l}\text { COM } \\
\text { MEM }\end{array}$ & $\begin{array}{l}\text { Determines whether printer is on } \\
\text { Holds users choice of }\end{array}$ \\
\hline $\mathbf{U 1}$ & PRG & Resets file listing osize and odate variables $w /$ now \\
\hline $\mathbf{U} 2$ & PRG & Checks counitry names in demand.dbf against country.dbf \\
\hline U3 & PRG & Checks country nanes in imp/exp.dbf against country.dbf \\
\hline U4 & PRG & Used in creating exports.dbf from EIA mainframe file \\
\hline U6 & PRG & Copies programs to backup directory in alpha order \\
\hline $\mathbf{U 7}$ & PRG & Puts ICSD coal codes in imp/exp data base \\
\hline U8 & PRG & Prints ALL demand records; must set D1.WK 1 range first \\
\hline UCOI & PRG & Used for update of DEMAND1; checks country names \\
\hline UDEMAND & DBF & Update template for demand1.dbf \\
\hline UDEMAND & PRG & Used to control subprograms for update of DEMAND1.DBF \\
\hline UDR & DBF & Similar to O4.DBF; makes directory listing of IEA files \\
\hline UDIR & NDX & Index file for use with UDIR.DBF; used in updating \\
\hline UDIR & PRG & Controls conversion of directory lists to a data base \\
\hline UDMD1 & DBF & Holds IEAYOECD data for non-OECD countries in met. tons \\
\hline UDMD1 & PRG & Controls building of UDMD1.DBF for IEA country data \\
\hline UDMD1TE & DBF & Template data base used in building UDMDl;DEMAND1 update \\
\hline UDMD2 & DBF & Holds IEANOECD data for individual IEA countries \\
\hline UDMD2 & PRG & Control building of UDMD2.DBF for IEA countries \\
\hline UDMD2TE & DBF & Template data base used in building UDMD2.DBF (IEA data) \\
\hline UDMD3 & PRG & Uses UDMD2.DBF to update data in DEMAND1.DBF \\
\hline UDMD4 & DBF & Special updatate dbf to hold EIA coal forecast data \\
\hline UDMD4 & PRG & Controls update of DEMAND1.DBF with new coal forecasts \\
\hline UDMDS & PRG & Updates DEMAND1.DBF with data from UDMD1.DBF \\
\hline UDMD6 & DBF & Holds IEAYOECD "BES" data for update of DEMAND1.DBF \\
\hline UDMD6 & PRG & Controls use of UDMD6.DBF data in update of DEMAND1.DBF \\
\hline UDMD6TE & DBF & Template data base used to build UDMD6.DBF;demand update \\
\hline UDMD7 & PRG & Updates DEMAND1.DBF using data stored in UDMD6.DBF \\
\hline UDMD8 & PRG & Used to create DEMAND.DBF from DEMAND1.DBF \\
\hline UDMD9 & PRG & Builds UDMD6.DBF from IEA "BAL" files, units = MTOE \\
\hline UDMD & MEM & Holds directory storage locations for IEA / OECD files \\
\hline UEXPORTS & DBF & Update template for exports.dbf \\
\hline UEXPORTS & PRG & Controls update of U.S. coal exports data base \\
\hline UFREIGHT & DBF & Update template for freight.dbf \\
\hline UMMPORTS & DBF & Update template for imporis.sbf \\
\hline UMMPORTS & PRG & Controls update of U.S. coal imports data base \\
\hline UPDATE & PRG & Menu choices for data update routines \\
\hline UPRICES & DBF & Update template for prices.dbf \\
\hline UPRICES & PRG & CES.DBF and FRE \\
\hline
\end{tabular}


UV1 PRG Similar to O56.PRG;makes VOLUMES.DBF from VOLUMES1.DBF

UVOLUME DBF Update template for volumes1.dbf

UVOLUME PRG Controls update of flows data bases

VCOUNIRY DBF Listing of exporting countries, used by D2.prg for conv

VCOUNIRY NDX Index to vcountry; key=exporter; Used in v. transform

VOLUMES1 DBF Holds trade volumes data from original worksheets

VOLUMES1 NDX Index file for volumesl ndx; compound key

VOLUMES DBF Main trade flows data base, 2 nd structure

VOLUMES NDX Index file for volumes.dbf; compound key

VREPORT DBF Intermediate data base used in converting Volumes.dbf

ICSD BAT Used to start ICSD. Called by ICSD.BAT.

The listing above is available on-line by selecting Option 5. This will display an annotated file list, and allow the user to annotate any files created during ICSD operations, such as PIC files holding graphics. The same option will also print the listing. 


\section{Operating Environment}

\subsection{Hardware}

The ICSD is intended to be used on IBM-compatible microcomputers capable of running . Lotus 1-2-3 and Dbase III +. Both Lotus and Dbase must be accessible by the ICSD system. Because of the size of the component data bases and the use of DOS command shells to load different programs in memory, relatively unusual demands are placed on the system. designed to run on The ICSD system will run on many microcomputer systems, provided adequate fixed disk storage is available and the cormputer comes equipped with and has available the full 640 kilobytes of random access memory.

The processor must be an Intel 8088, 8086, 80286, 80386 or 80486 or fully compatible substitute. A math co-processor is helpful but not required. A color monitor is also useful but not required.

A hard disk with at least 7.8 megabytes of free space is needed. The program will not run from floppy disks.

\subsection{Support Software}

Required support software includes DOS (version 3.x or greater), dBase III +, and Lotus 1-23 (version $2 x$ ). The DOS backup and restore programs must be compatible with MS-DOS 3.3.

\section{Maintenance Procedures}

\subsection{Programming Conventions}

The programming language for most of the ICSD is dBase III. In order to locate particular dBase subroutines, the structured layout of the ICSD program design must be understood. It is also necessary to understand the file naming conventions in use.

This structure is summarized in the Overview section of the Operations Manual. The primary subroutine calling program is Master.prg, which contains the code for the opening menu and makes five subroutine calls to the major program components. Each of these components is given a name that corresponds with the master menu selection that invoked it. For example, the programming code required to access the Prices data base (itself stored in Prices.dbf) is contained in Prices.prg, the routines for studying national coal demands are in Demand.prg, etc. However, where two names are referred to in an opening menu choice, such as Prices and Freight Rates, the source code for both is stored in the first named; that is, there is no 
separate freight menu and program, but there is a freight.dbf file since the freight rate information is stored in a data base file with a different structure than the Prices.dbf.

In fact, each of the subroutines called from the Master.prg are submenu screens used in turn to call the programs that actually do the work required to access the data and use the system. Without exception, the name of each of these programs consists of a letter and at least one number. The letter refers to the calling menu screen. For instance, all programs invoked from the Prices.prg menu screen begin with the letter P. The first menu choice is P1.prg, the second P2.prg, etc. This same logic is used for related worksheets. An intermediate worksheet, with an extension of .wks, that receives data from a dBase III data base, used in the sacond choice from the Fices memu would be called P2.wks, and the final Lotus worksheet that loaded the intermediate .wks file would be called P2.wk1. These extensions are consistent with Lotus version 2 naming conventions. While it may initially seem confusing to have .wks and .wkl files, it should be remembered that dBase's capacity to create Lotus files is limited to Lotus version 1A fles (to which Lotus gave the extension .wks), but these files can be read by Lotus version 2.0 and 2.2 worksheets. The same applies to intermediate data bases used to store information in response to a query. While this does not apply to all queries, since most queries do not require an intermediate data base, those that create an intermediate data base adhere to the naming convention. So P2.dbf is the intermediate data base that holds the results of a user query made in response to the second menu choice of the Prices menu. In a few instances on the Options menu, program names will have a second digit which refers to the number of the subchoice made from a submenu. That is, choice 5 of the Options menu is Miscellaneous, which in turn invokes a menu of routines that can't be classified elsewhere. So the program code required to respond to Options menu choice 5, Miscellaneous menu choice 7 would be stored in 057.prg.

Therefore, to locate the code for a particular subroutine it is necessary only to know where it falls in the hierarchy of menu commands and use the table of contents listed above.

Alternately, the annotated program list may be consulted to read brief descriptions of what each program does. The major programs are also indexed.

There are some exceptions to the general naming convention. Programs stored in files beginning with the letter $U$ are utility programs not associated with or invoked by any ICSD menu. Some programs are transferred and given other names during the process of initiating the ICSD. For instance, the configuration information stored in Config.db is transferred to the directory holding the dBase execution files, as is the ICSD program Autsmate.Prg. This larter file is renamed Master.Prg by the ICSD.bat batch file that starts the program. A similar procedure is used for the file ICSDauto.wk1. It is renamed during start-up to Auto123.wk1 (the program Lotus attempts to load automatically) and transferred to the directory holding the Lotus files.

Another exception to the general convention of menu screens and subroutines comes in the Miscellaneous choices. The O5.prg holds the Miscellaneous menu choices, and some of the more complicated subroutines are stored in separate files (e.g. O57.prg) but the code for some 
simpler menu choices is simply contained in the calling routines of 05.prg. This applies to the first five miscellaneous menu choices.

Normal conventions common to dBase programming were also followed. Nested routines are indented, public variables are declared at the beginning of each procedure, and files are, when possible, opened toward the beginning of each program and identified by work area.

\subsection{Verification Procedures}

See section 2.1.f. The principal data verification procedure is to check data contained in the ICSD against the published sources. This may be done for each data base by using the dBase BROWSE command, locating the record in question, and comparing data.

\subsection{Error Correction Procedures}

Procedures for handling error conditions are described in Section 1.2.b.v.i of the Operations Manual.

The ICSD has an OPTIONAL facility that restores copies of the original files in case data becomes corrupted through user errors. This requires that another 8 megabytes of disk space be available. Accordingly, use of this capability is only recommended for users with large amounts of free disk space and little knowledge of data base procedures.

The mame of a backup director is requested during installation for users who require backup files. The directory to hold the backups should be created with the DOS MD command using a directory name and path chosen by the user (e.g., MD C:NBACKUP). ICSD files should then be copies to that director (e.g., COPY C:VCSD*.* C:LBACKUP).

\subsection{Special Maintenance Procedures}

Versions of $\mathrm{dBase}$ after $\mathrm{dBase}$ III do not require that index files be constantly maintained. However, as there are several possible way the indexes associated with the ICSD data bases can become comupted, it is necessary from time to time to run the index maintenance program from the Options menu.

A type of special data maintenance is required when using the original coal imports and exports data on the EIA mainframe. The two files, containing Customs transaction records, cover a 13 year period and are very large files with in excess of 20,000 records. The convention used for the early years is to represent columns where a space or blank would be used at the end of the file with a null character. This means that nulls must be replaced with spaces or zeros before the file is downloaded to the microcomputer, as the dBase programs used to load the data into ICSD data bases do not work with nulls. 
While dBase III provides a facility for editing program code (the MODI STRU editor), it should not be used to edit ICSD programs. There are two reasons for selecting another editor: MODI STRU is incapable of loading files greater than 5,000 bytes and it will not let programs write to disk any character with the high bit set (that is, it won't permit the use of the IBM extended character set). Since many ICSD programs are either larger than 5,000 bytes, or use ASCII values beyond 128 for screen effects, or both, it is suggested that another editor be used.

\subsection{Listings}

\section{Organization of Source Code Listing}

The following listing of programs is ordered alphabetically to facilitate locating the code for any program. While the alphabetical presentation is not exactly the same as a structural listing, it is close enough to be useful. In this regard, note that all submenus are called from MASTER.PRG. After the submenu screen program, such as DEMAND.PRG, come the programs that are called from that submenu, such as D1.PRG, D2.PRG, and so forth.

\section{Source Code for Main ICSD Programs}

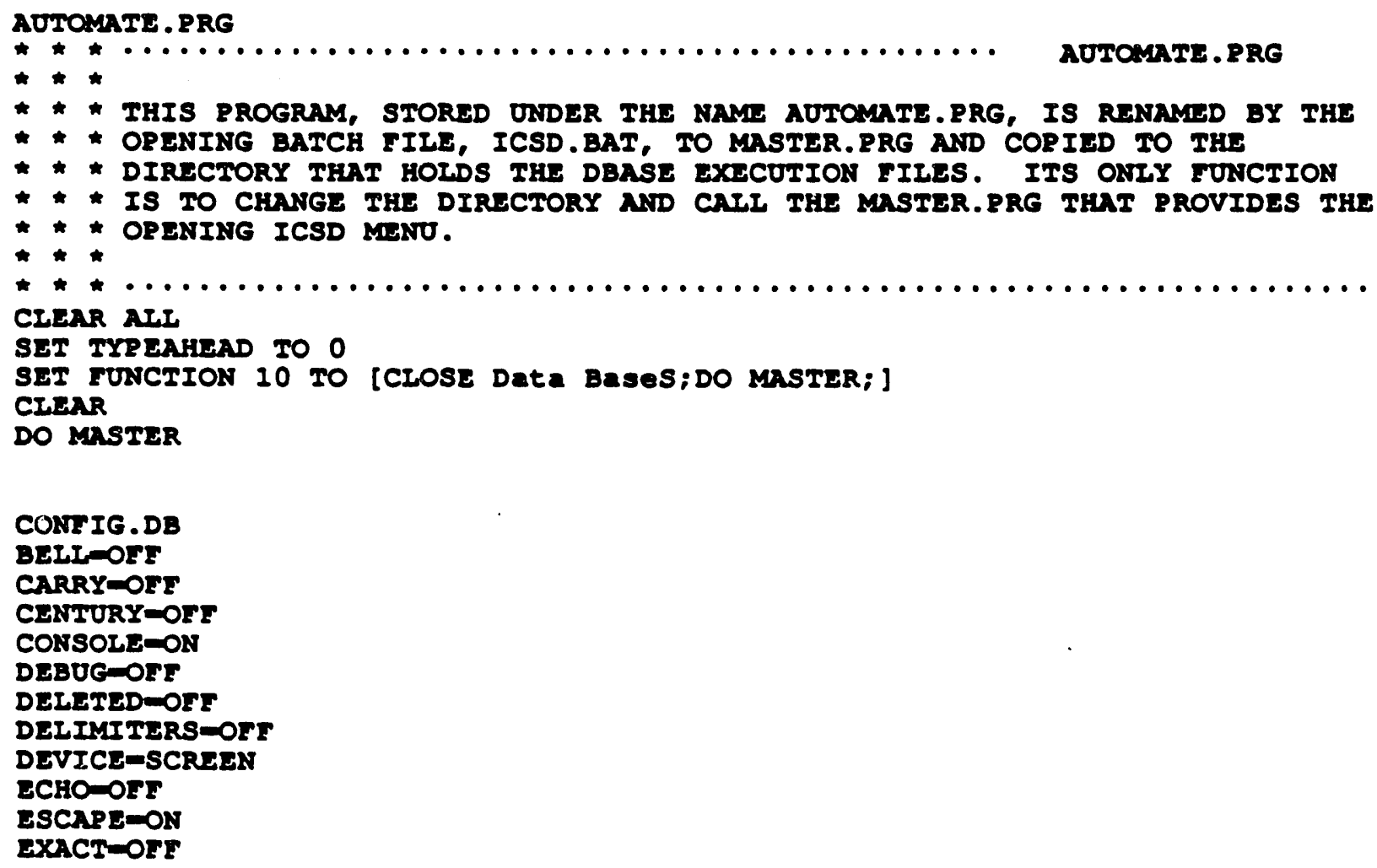



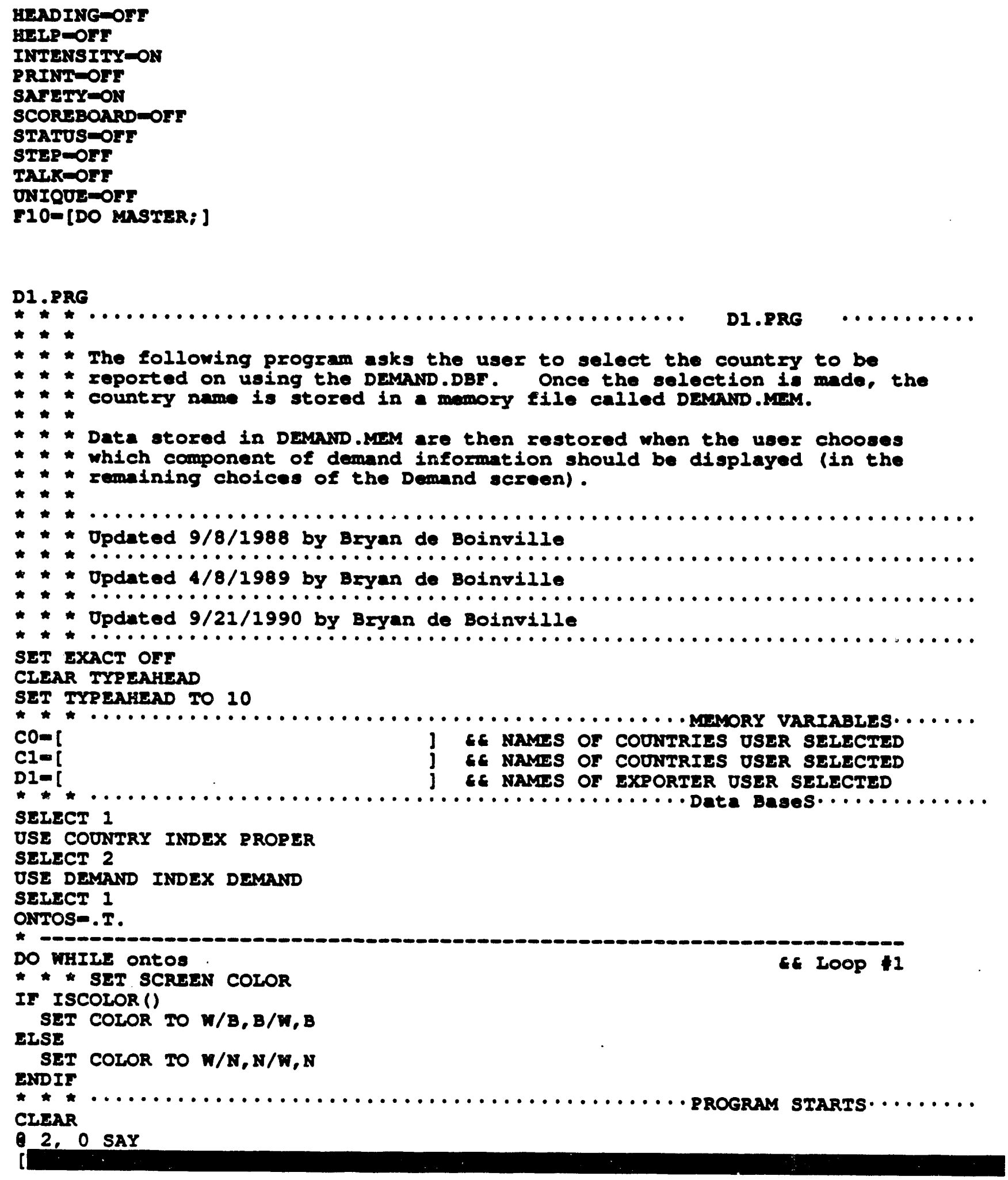


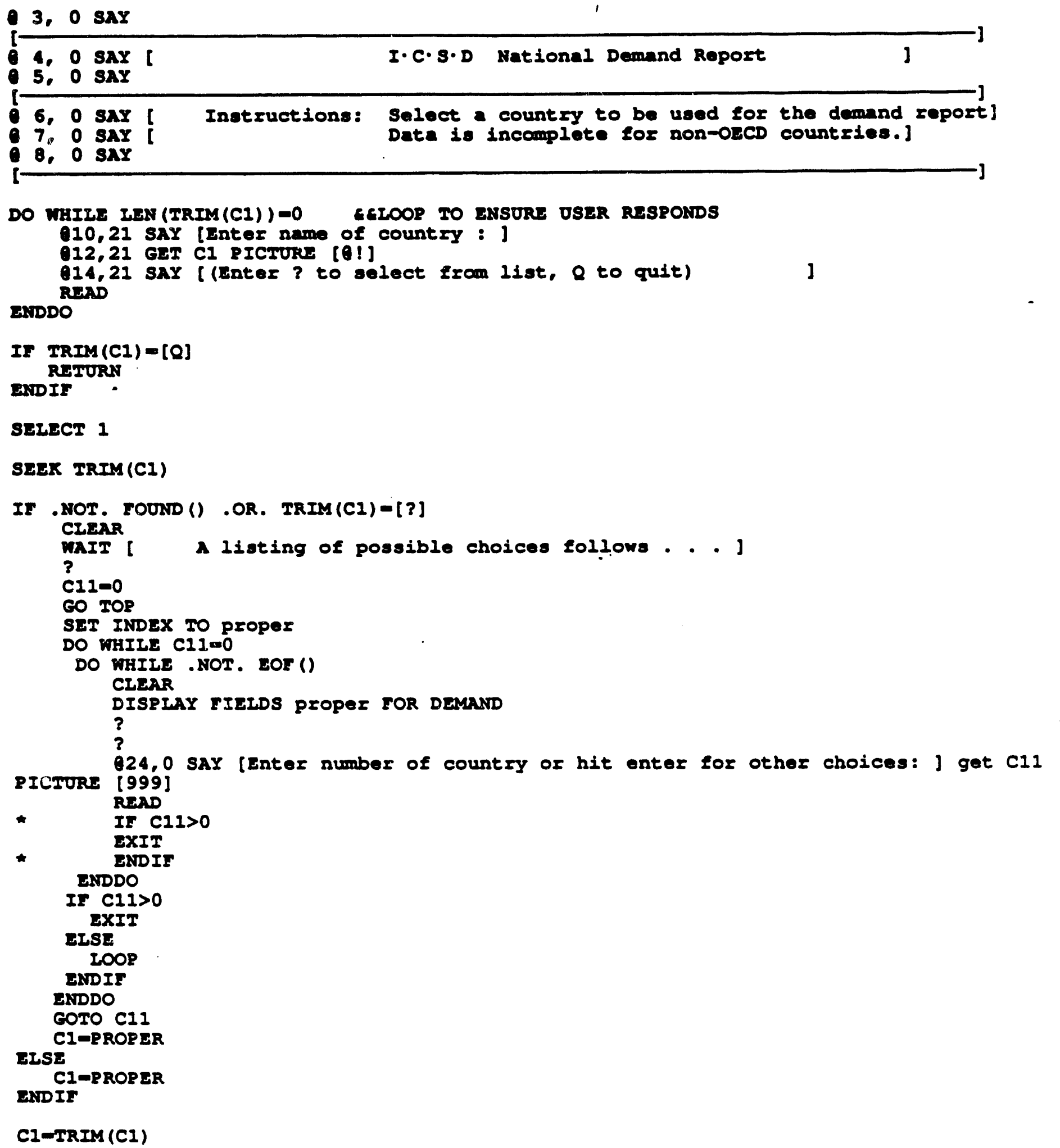




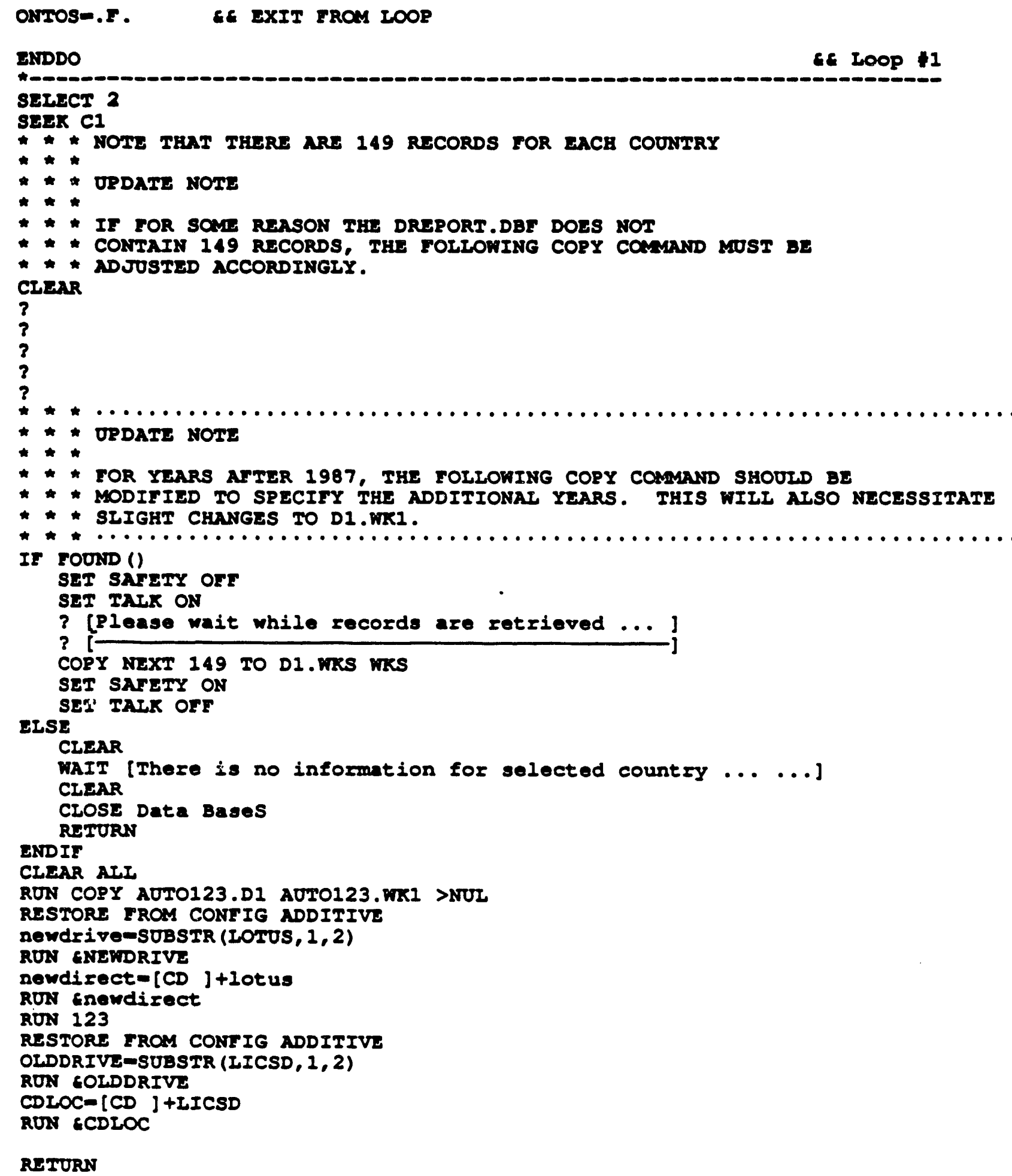

RETURN 
RON PGRAPH

ROS CD IICSD

RGIURS

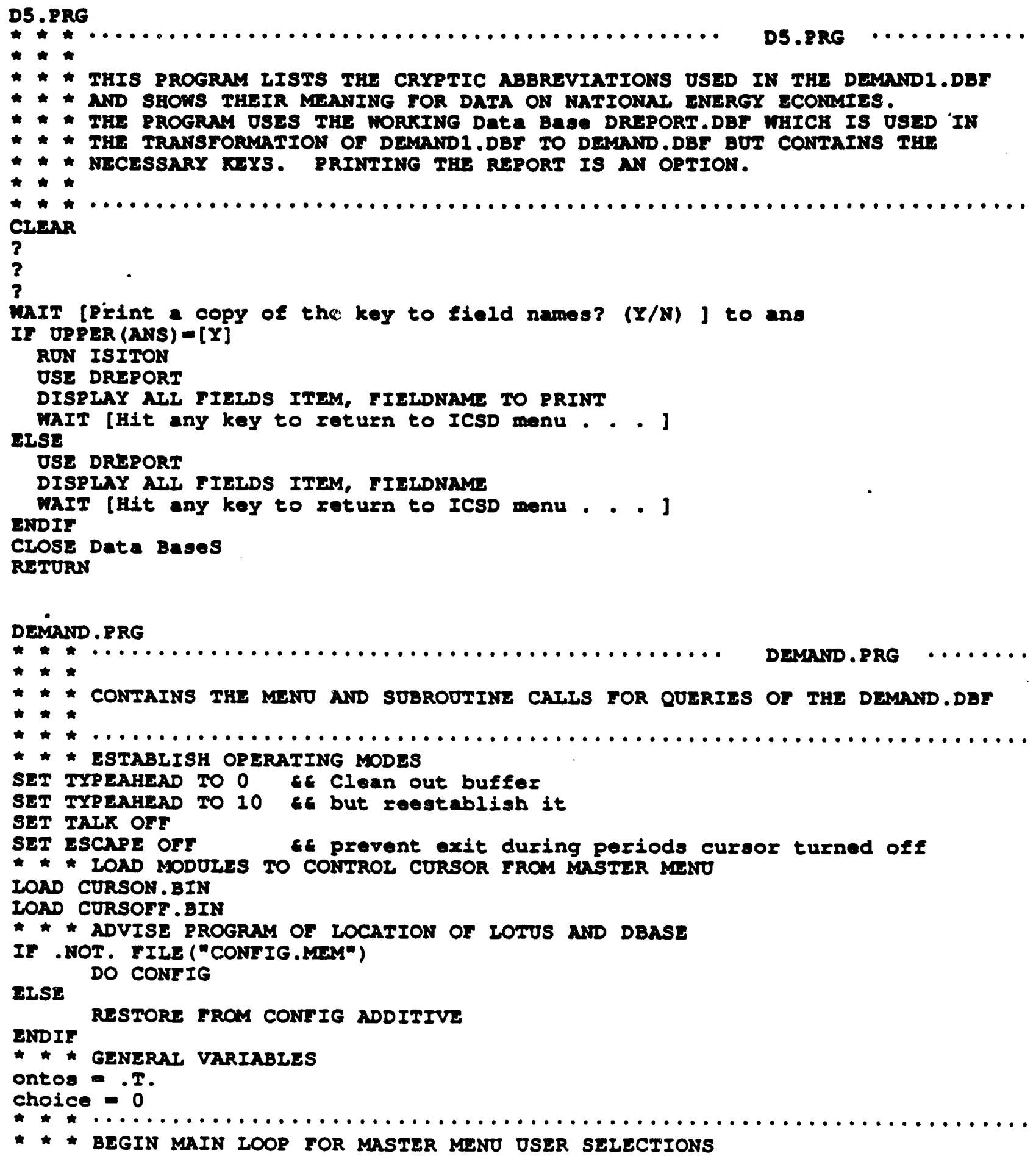




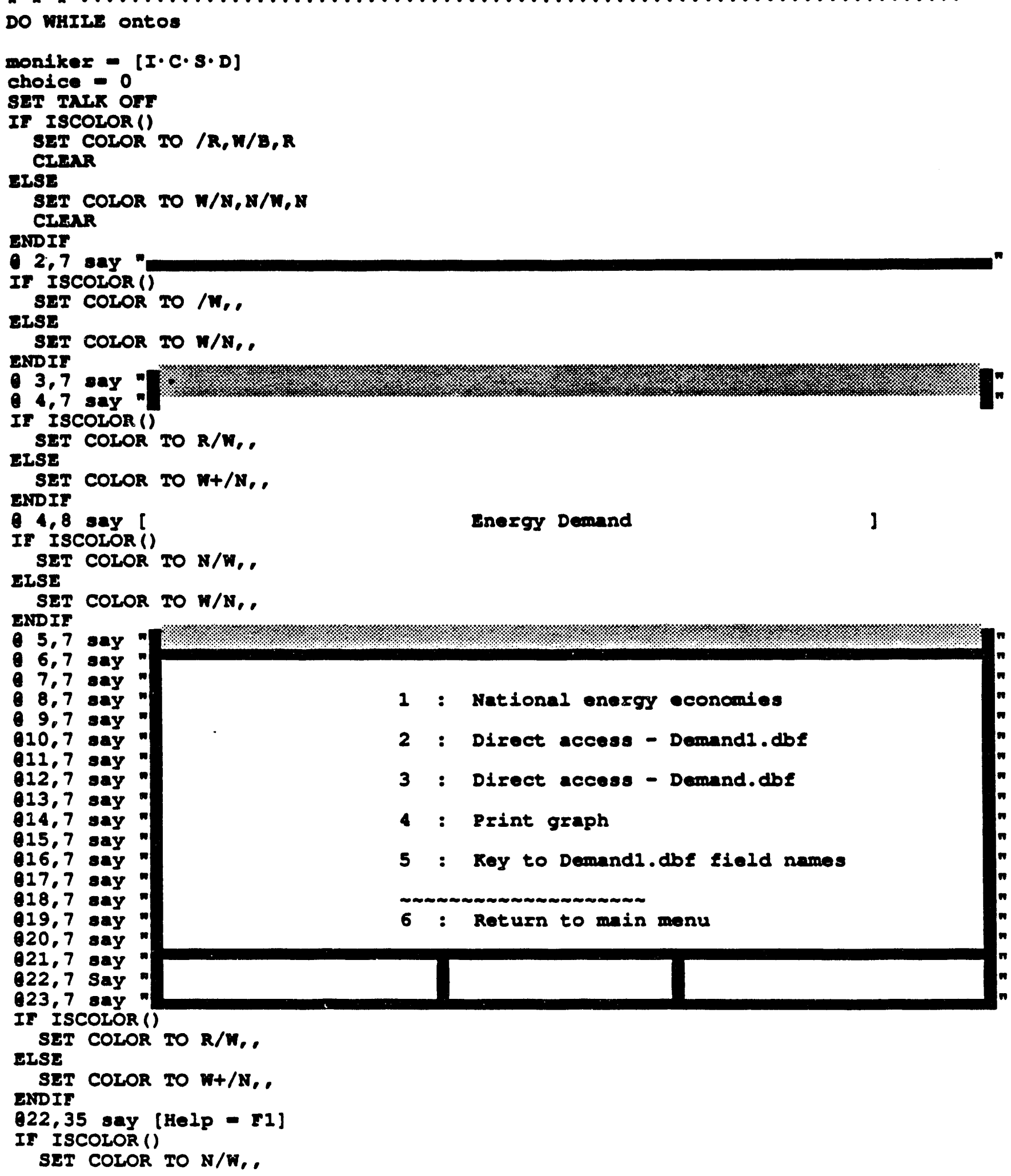

1 : National energy economies

2 : Direct access - Damnndl.dbl

3 : Direct access - Demand.dbs

4 : Print graph

5 : Key to Demandl.dbf field names

6 : Return to main menu 
ILSE

SET COLOR TO $\mathrm{N} / \mathrm{N}$, , ANDIF

CATI CURSOFF ECTURA THE CORSOR OFF WAIIE THE PROGRMY MAITS FOR OSER TO GO

DO WHII cholce-0

choicenINRYY ()

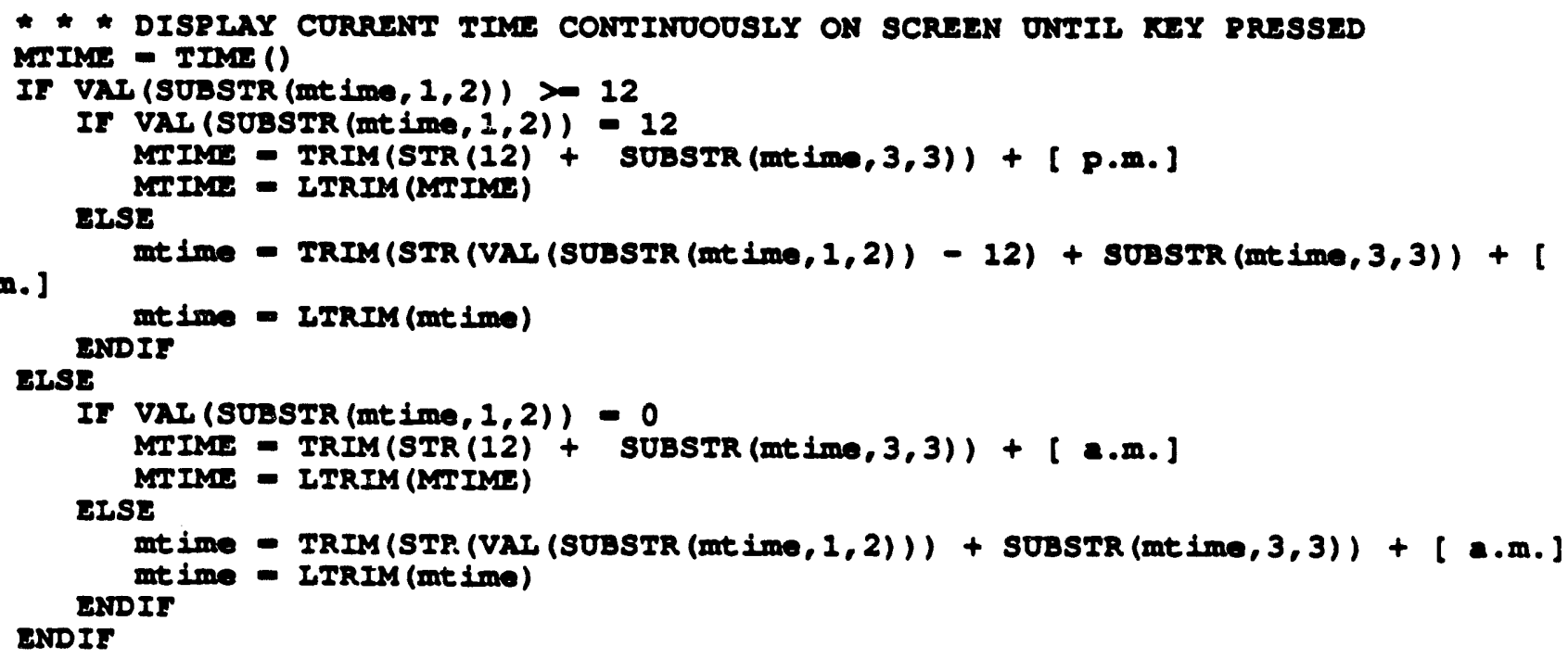

ENDDO GE END OF LOOP TO GET OSER MENO CHOICE

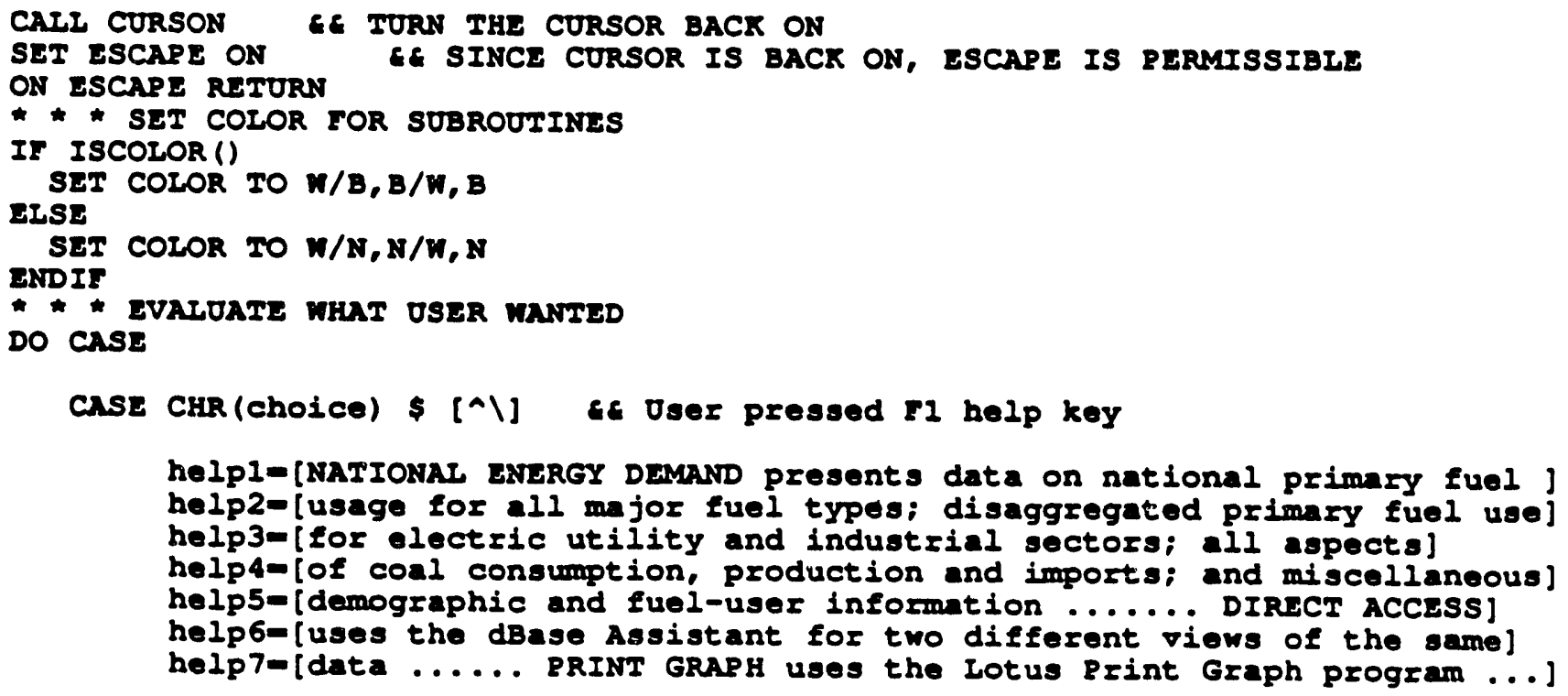


help8-[Reys explains the field names used in Demandl.dbe. ]

DO help VITH monikex, helpl, help2, help3, help4, help5, help6, holp 7, help8

Cass Chis(cholce) \& [1]

DO d1

Se Subroutine call

CAst CHR(cholee) \& [2]

DO D2

se Subroutine cald

Cuse Car (cholco) \& [3]

Do d3

se Subroutine call

Cusz CaR(choice) \& [4]

DO d4

se Subroutine call

Cass Ċar (cholce) \$ [5]

DO d5

68 Subroutine call

CAsE CHR(cheice) \$ [6]

CIEAR

RETURN

OTHERTISE

moniker $=[I \cdot C \cdot S \cdot D]$

message- (Your selection muat be liated in the monu. )

DO ERRMESS VITH moniker, message IOOP

ENDCASE

ENDDO

RSTORN

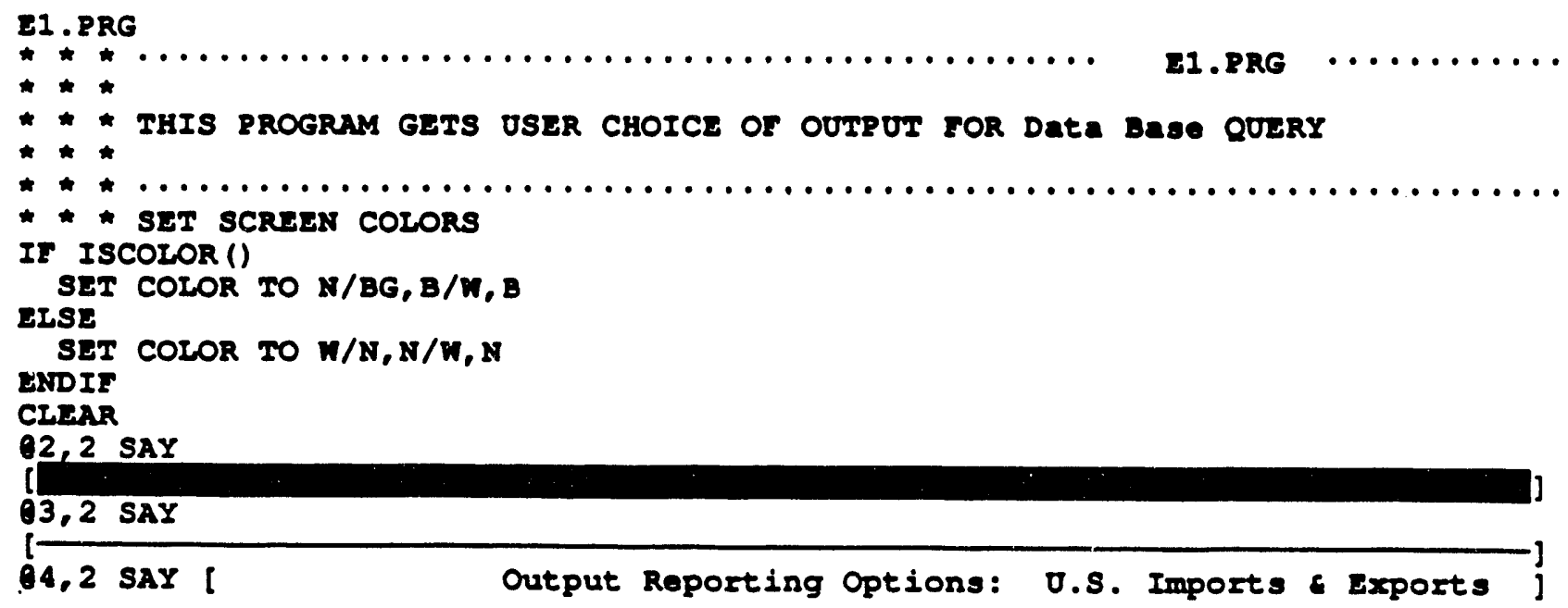


$05,2 \operatorname{sx} x$

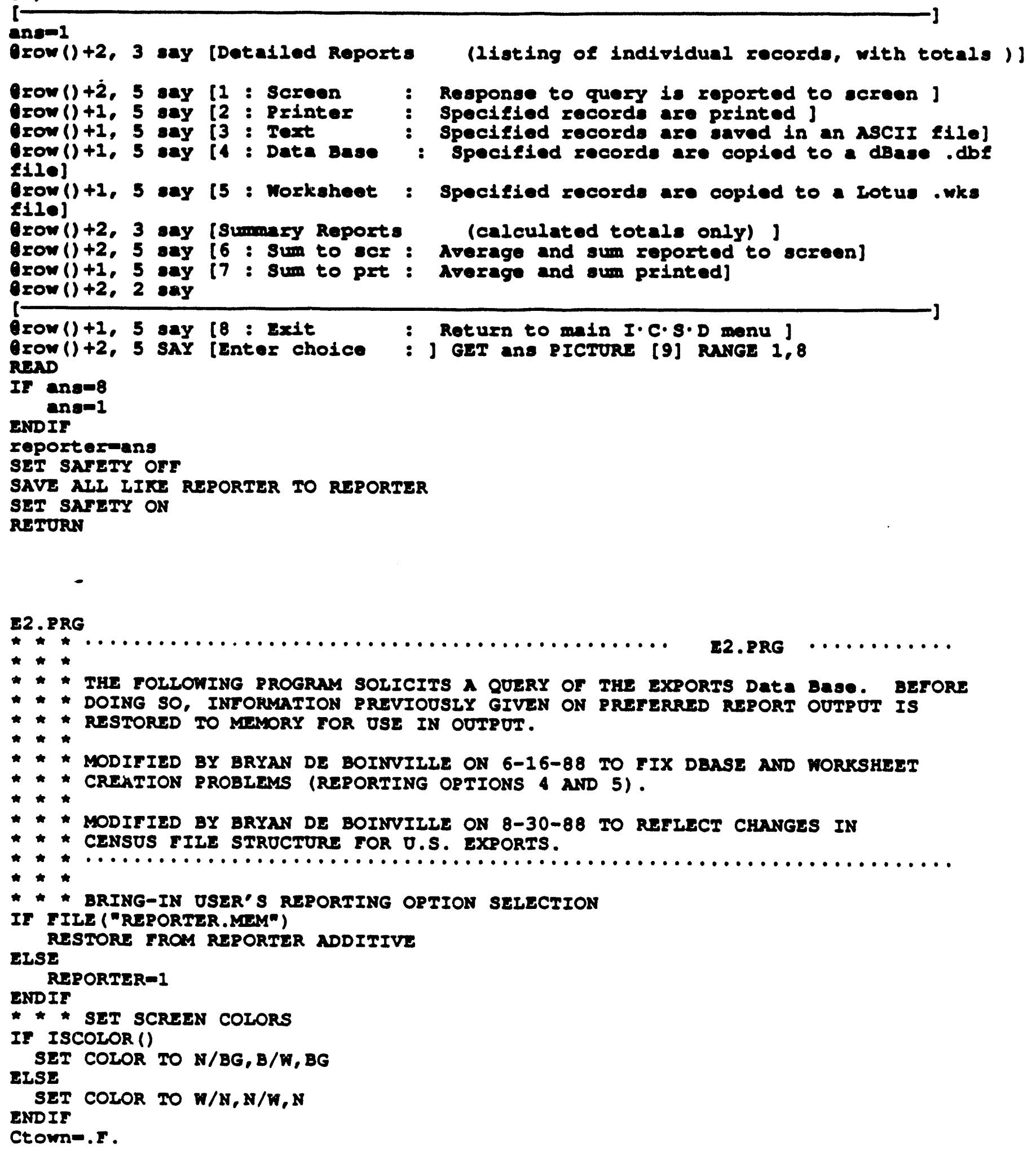




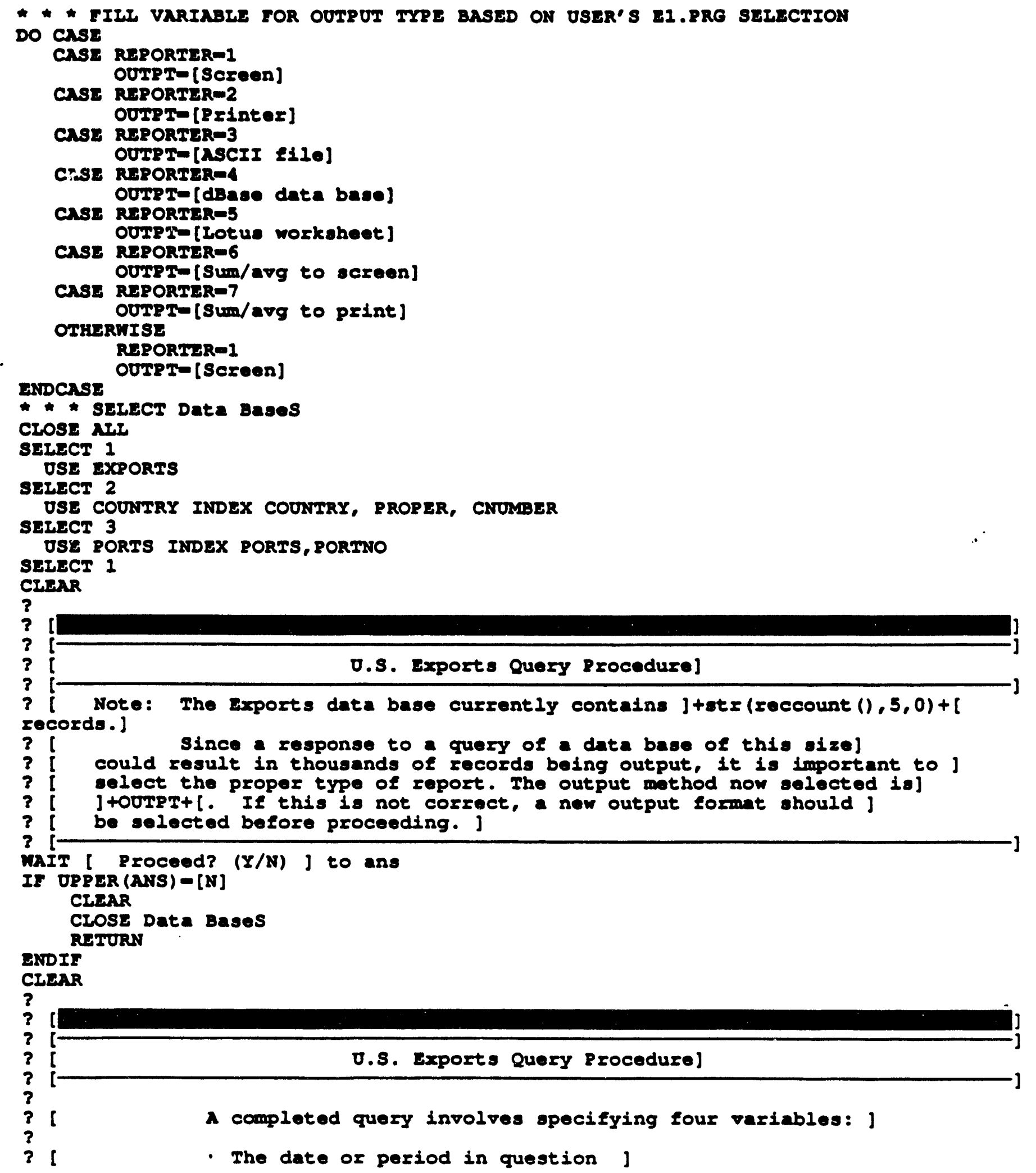




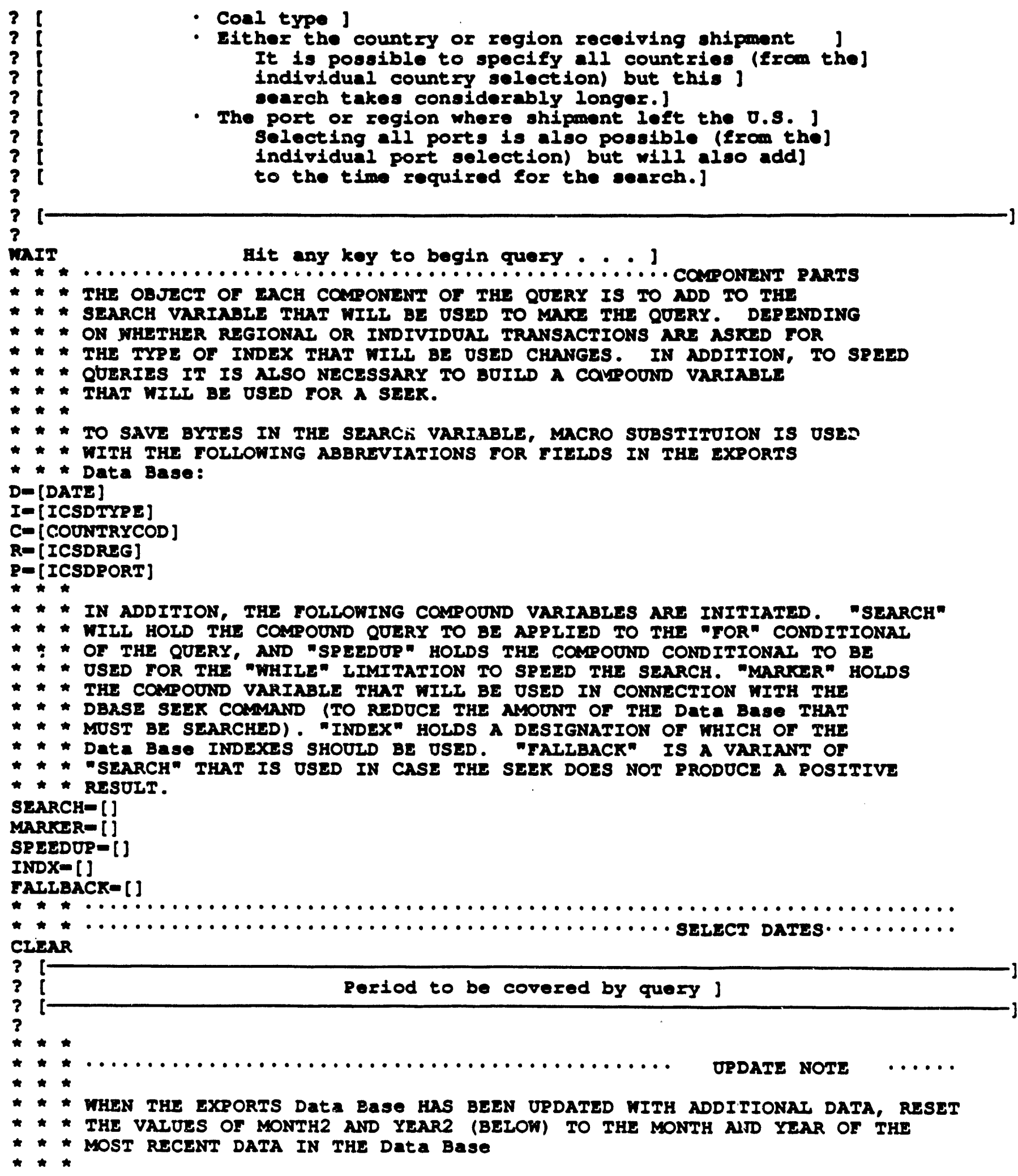




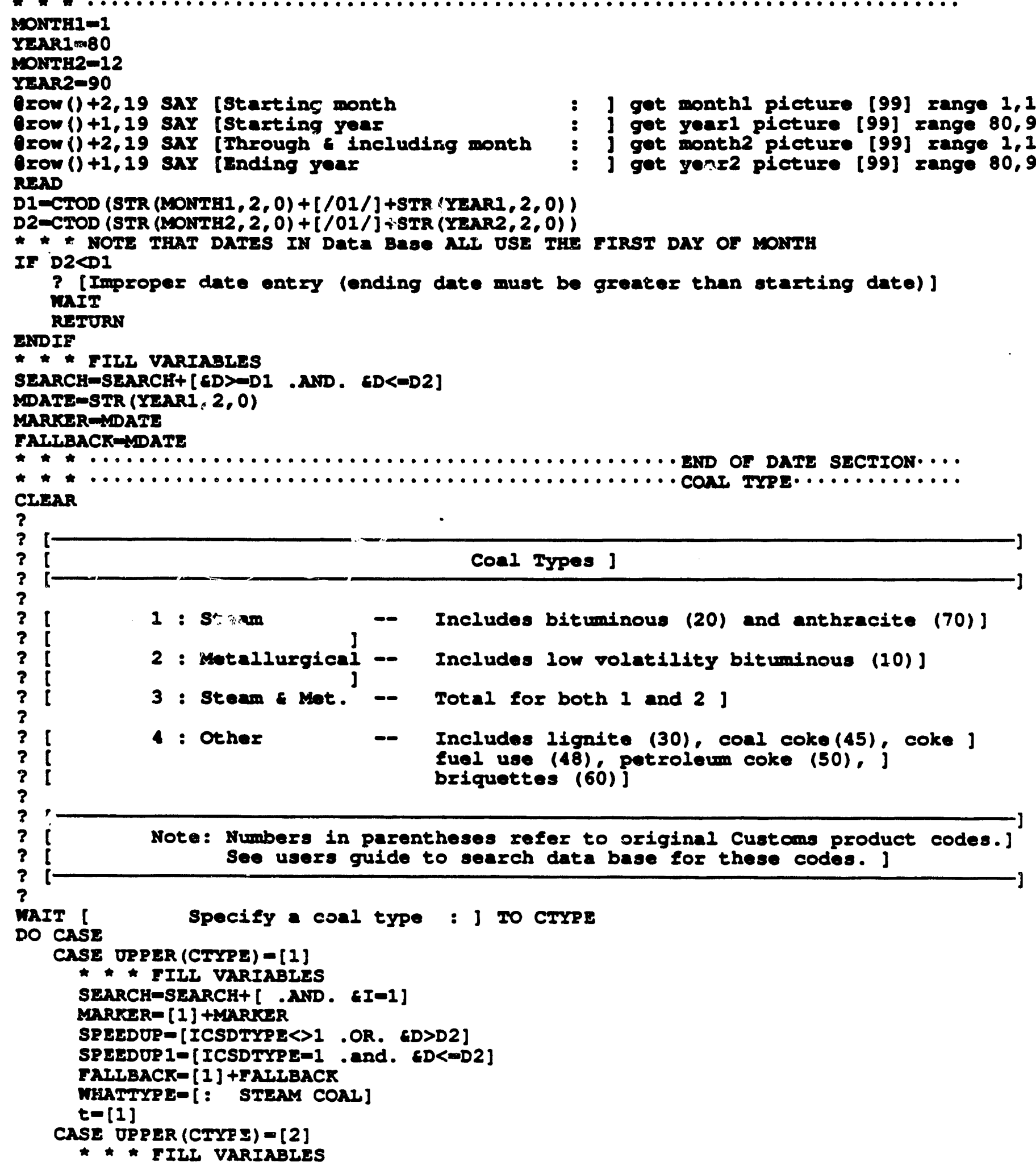




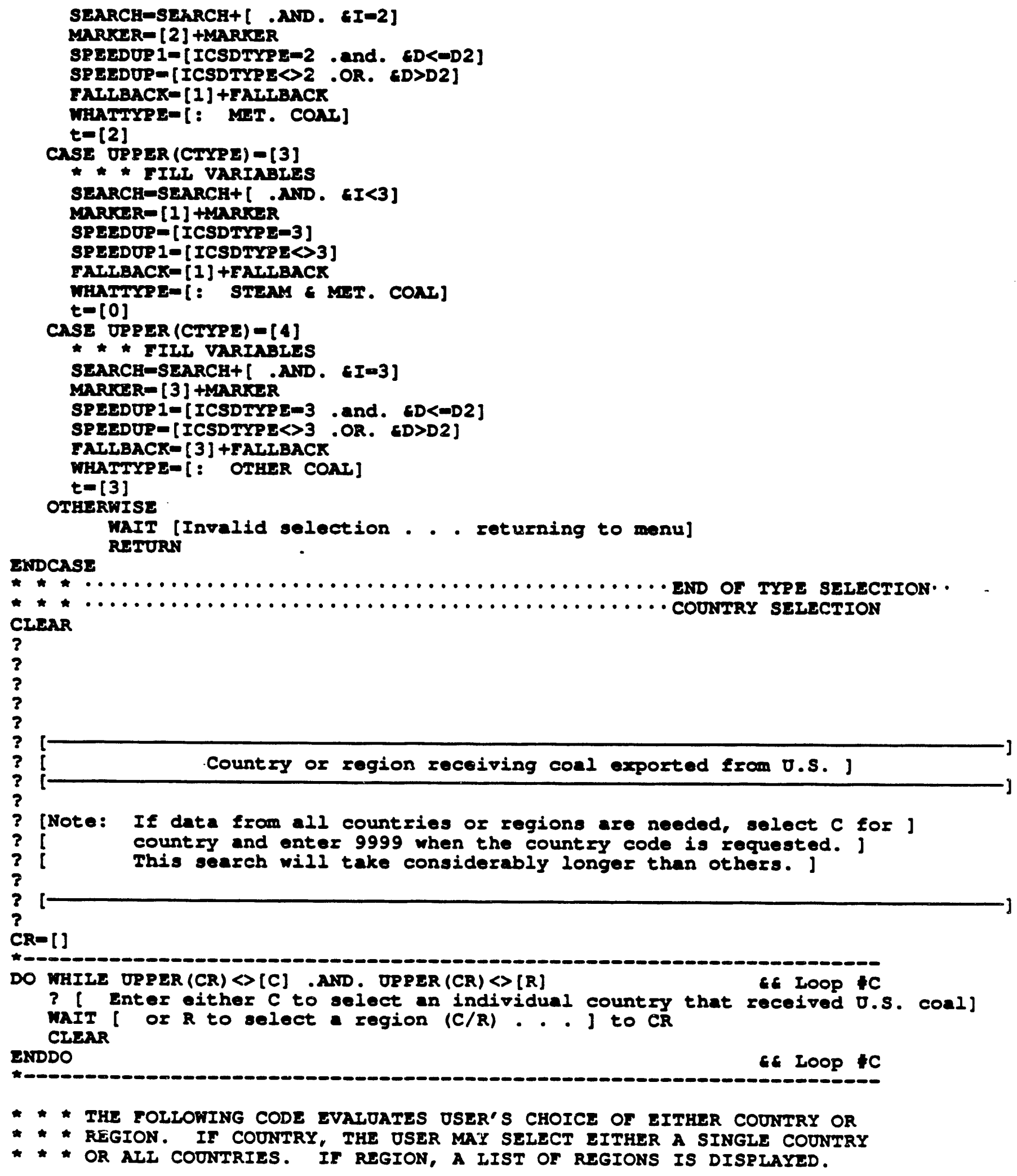


* * tha selection of cotntry or region nLso determines matca

* * INDEX VIIL BL USED.

DO CASE

CRSE UPRER (CR) $=$ [C]

CIFnR

? [Choose the country receifing 0.3 . conl from the following 1ist,]

? [or enter 9999 for all countries . . . ]

? [Note: entering 9999 will slow search considerably]

MAIT []

SELECT 2

SET INDEX TO RROPER

$i d=0$

CO TOP

* * it is necessary for the oser to select a couvtry froy the fotuoniNG

* * IIST

DO WiIIs id<-999

DO WHILE . NOT. BOF()

CIEAR

DISPIAX FIEIDS PROPER, COUNIRYID FOR EXPDEF OEE

$?$

024,0 say [Enter id of receifing country or hit enter for other choices: ]

GST ID PICTURE [9999]

REN

IF id>999

EXIT

ENDIF

GNDDO

IF id>999

SET INDEX TO CNOMBER

SEER ID

IF FOOND ()

ovetrim (proper)

EISE

WAIT [ERROR: The country code apecified was invalid...]

Close Data Bases

CIJAR

RETURN

ENDIF

EXIT

IISE

GO TOR

FNDIF

ENDDO

* * NOA that coUNTRy selection has been made, fill variables

* * ACCORDINGIY

DO CASE

CASE ID $<9999$

SEARCHESEARCH+ [ .AND. ECEID]

IF IE[1] OR. TE[2] OR. T- [3]

SPEEDUP 1- [ICSDTYPEDVAI (T) . and. COUNTRYCOD=ID]

SP EEDUP- [ ICSDTYPESVAL (T) .OR. COUNTRYCOD<>ID]

MARKER-t tatr $(i d, 4,0)$

FAILBACK-T+ [ 122]

ELSE 


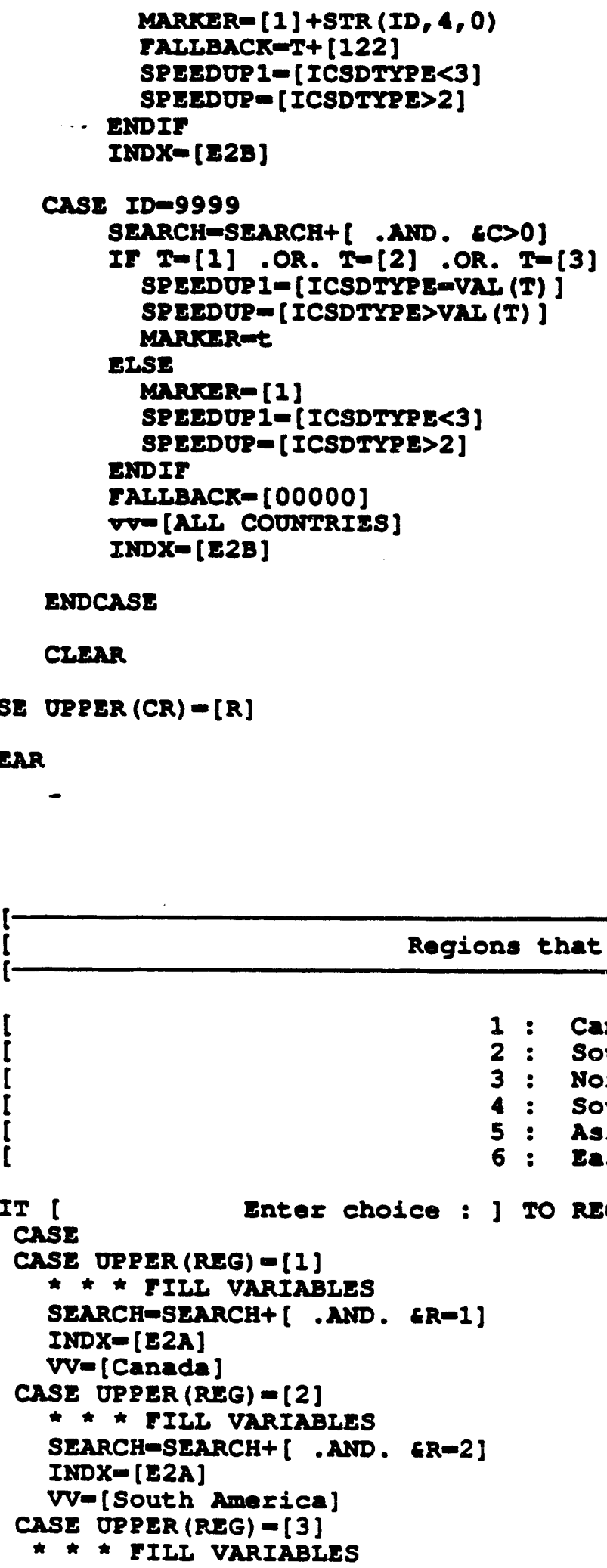

$$
\begin{aligned}
& ? \\
& ? \\
& ? \\
& ? \\
& ? \\
& ? \\
& ? \\
& ? \\
& ? \\
& ? \\
& ? \\
& ? \\
& ?
\end{aligned}
$$


SEARCKESEARCH+ [ .AND. GR-3]

INDX- [.2A]

VV-[North Jurope]

CASE URPER (REG) - [4]

* * fill variabIes

SEARCHESEARCH+ [ .AND. GR=4]

INDX- [-2A]

$V V=[3 o u t h$ surope \& Mediterranean]

CASE UPPTR (REG) - [5]

* * LII VARIABIss

SGARCHESFARCH+ [.NND. GR-5]

INDX- [z2A]

VVo[Aaia]

CASE UPPER (RGG) - [6]

* * fil variables

SEARCHESEARCh+ [ .AND. ER-6]

INDX $[$ [ $2 \mathrm{~A}]$

VV=[Eastern Bloc Nations]

OTHERVISE

MAIT [I

nvalid.... Returning to menu]

CLOSE Data Bases

ENDCASL

RITURN

OTHERWISE

WAIT [Not a valid selection. . . Returning to menu]

CIOSE Data Bases

RETURT

ENDCASE

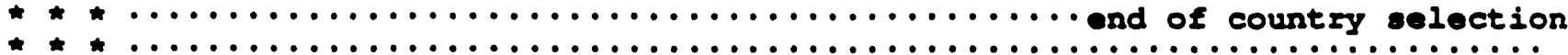

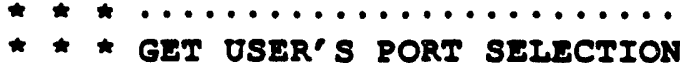

clear

?

[

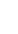

0.s. Port or Region Originating Shipment]

[Note: If data Exme all $0 . S$. ports are needed, select $P$ Lor ]

[ ports and enter 99 when the port code is requeated.]

[ This search will add to the search time.]

$?$

PCR- [ ]

DO MAIIE UPRER (PCR) $>$ [P] . AND. ORPER (PCR) $<>[R]$

? [ Enter either $R$ to select an individunl port that shipped 0.5 . conl

WAIT $[$ or $R$ to select the shipment region (P/R) . . I to PCR CIEAR

ENDDO

SE LOOP $D$

DO CAsE

CASE OPRER (PCR) $=[P]$

WAIT [Select a port number from the following listing . . . ] CIEAR 
$1:$

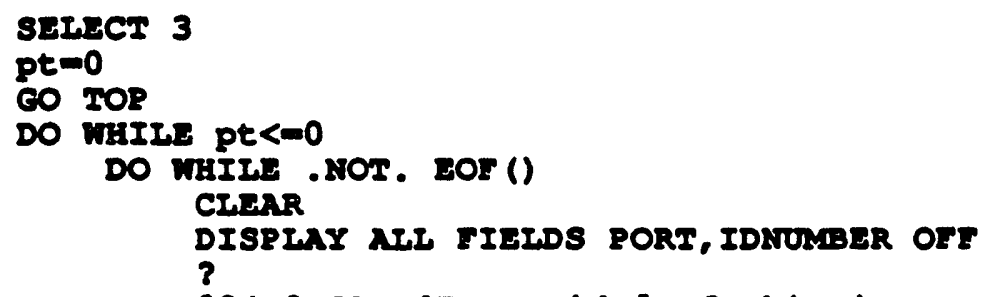

\section{- please note:}

You have selected a port for which apecial treatment is given in Customs Department records. This maans that the sum of the quantity of conl exported from this port will be correct, but the value of ahipments will be mixed with other ports having the same port code in the second columa above.

In other words it is not possible to determine the value of shipments leaving this port. To determine the quantity $f$ value of shipments leaving from the aggregation of ports with the same second port code, rerun this program and select that portcode.

ENDIF

HNDTSXY

HAIT []

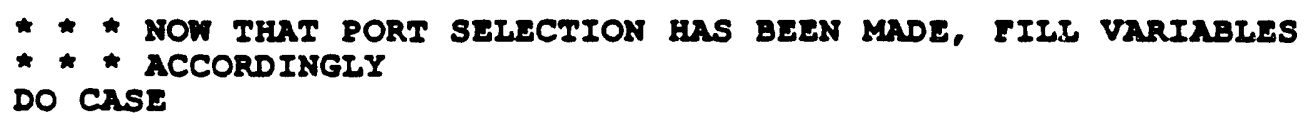


EISE

Ctown- T. PORTCODE<-17) ) ]

ENDIF

Crse PT=99

PNAME= [AII O.S. BORTS]

SEARCHESEARCH+ [ .AND. PORTCODE>0]

ENDCASE

PNAMLOTRIM (PNAMS)

CNSE URPER (PCR) - [R]

CLEAR

$\operatorname{sen} 2$

$?$

$?$

3

$?$

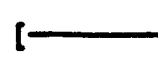

? [

0.3. Export Regions ]

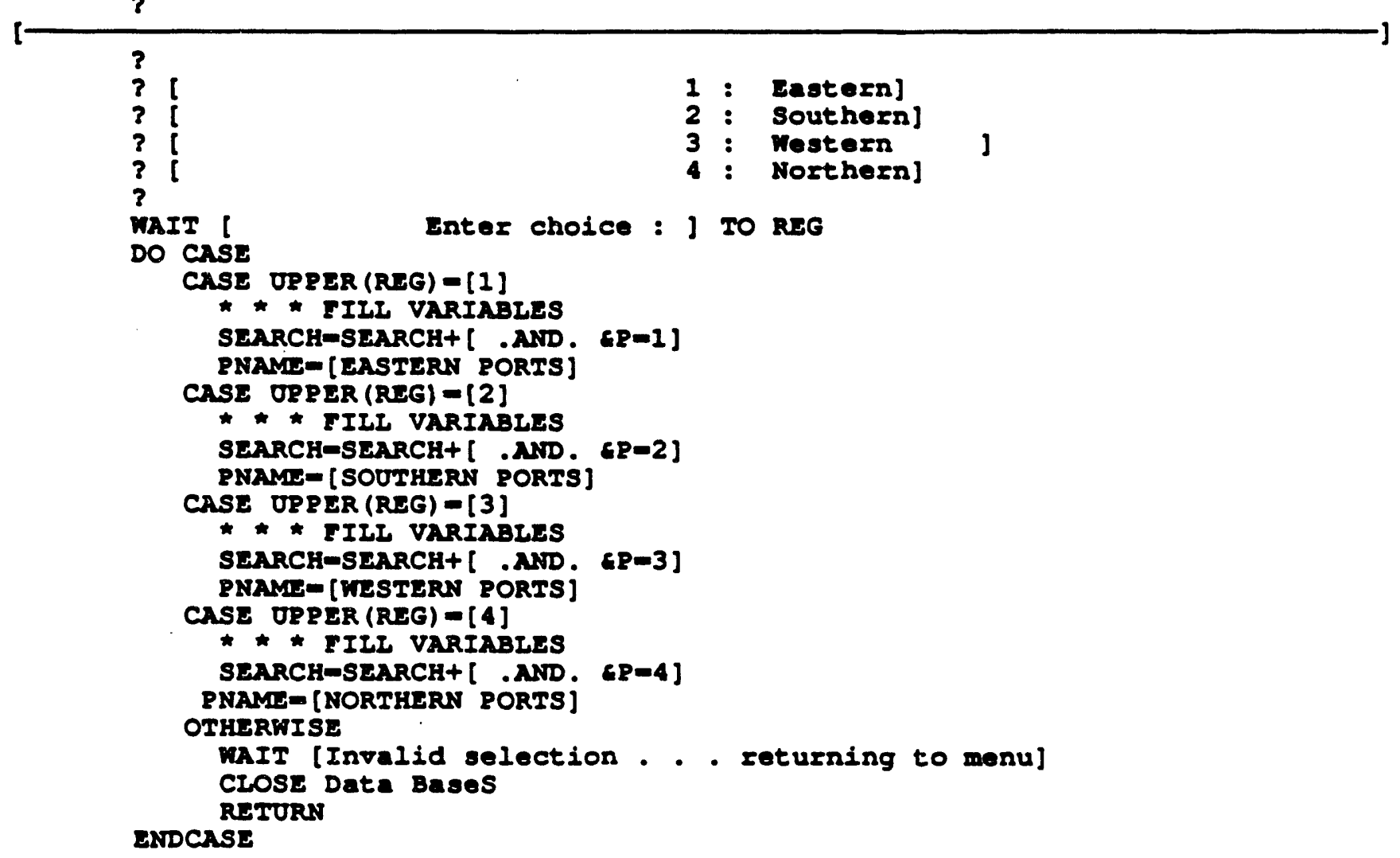

OTHERWISE

WAIT [Invalid selection... returning to menu] 


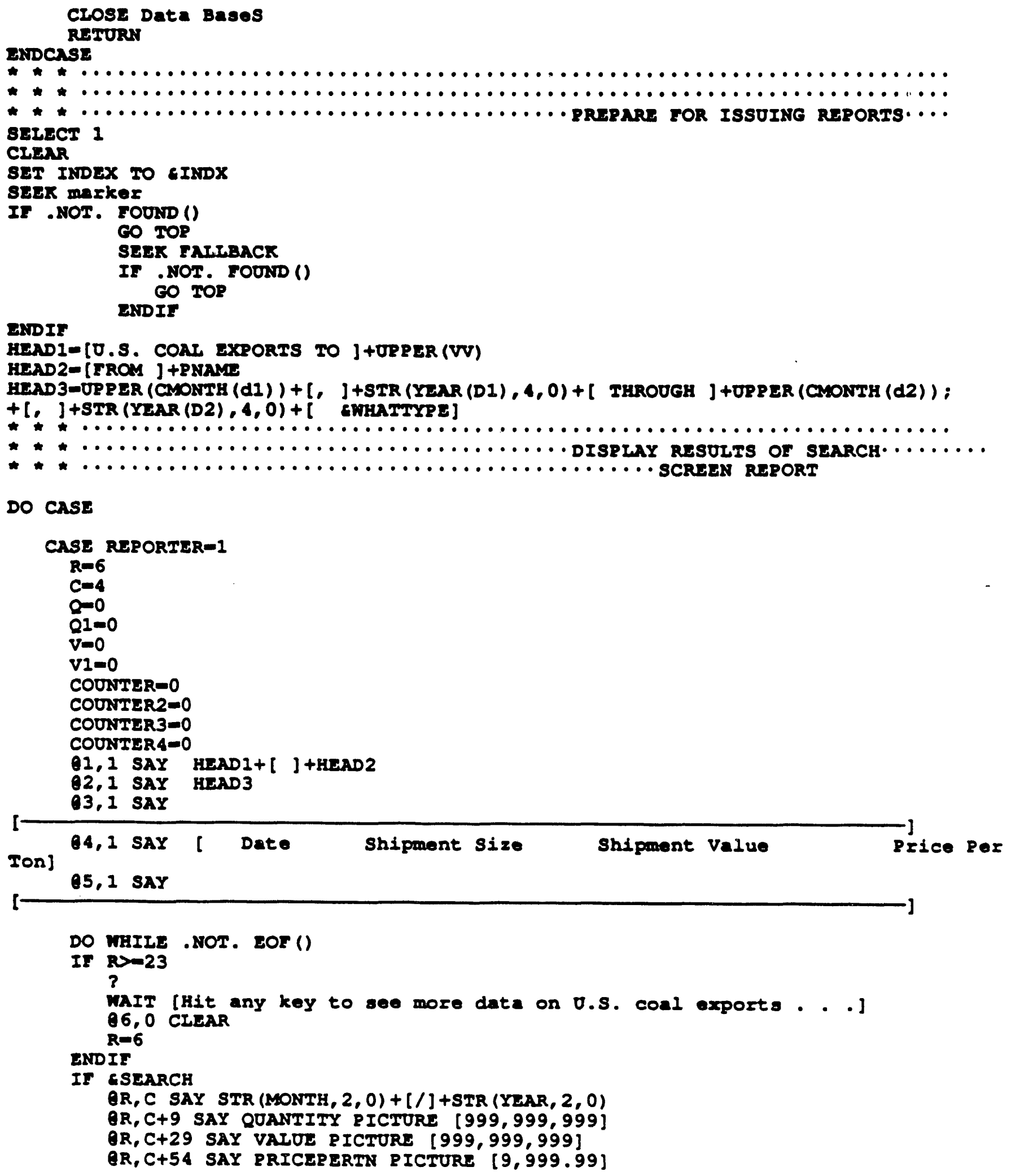




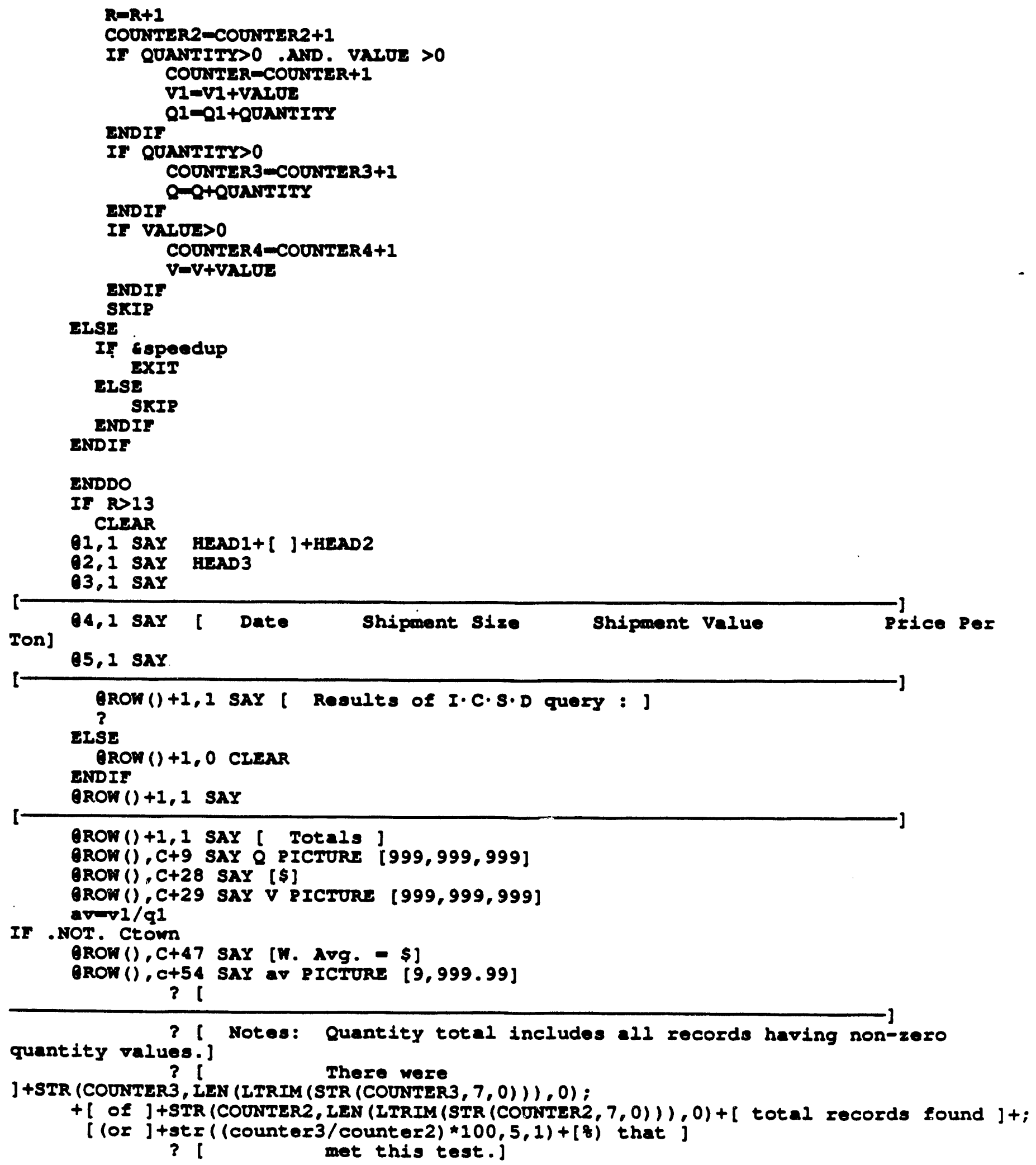




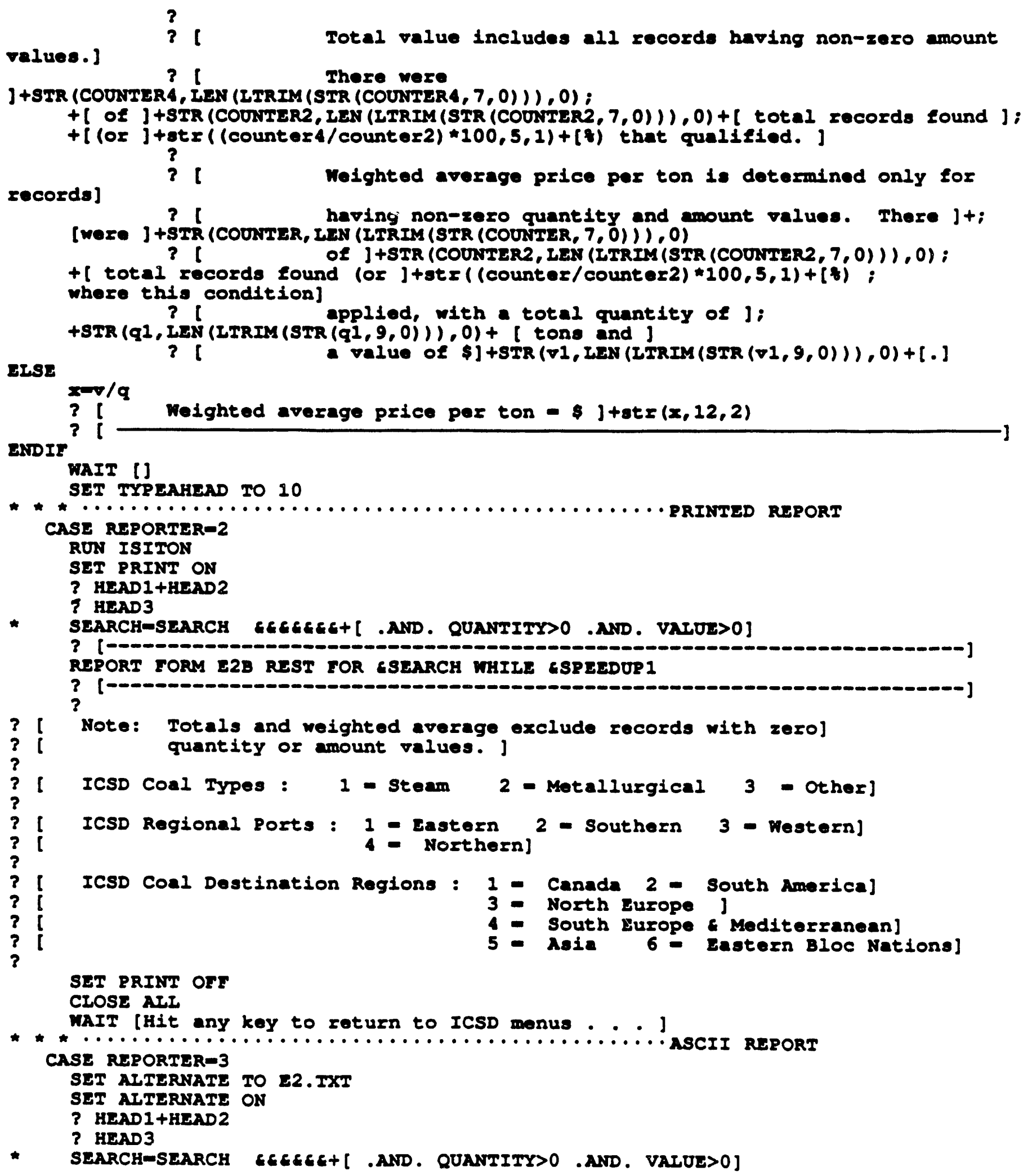




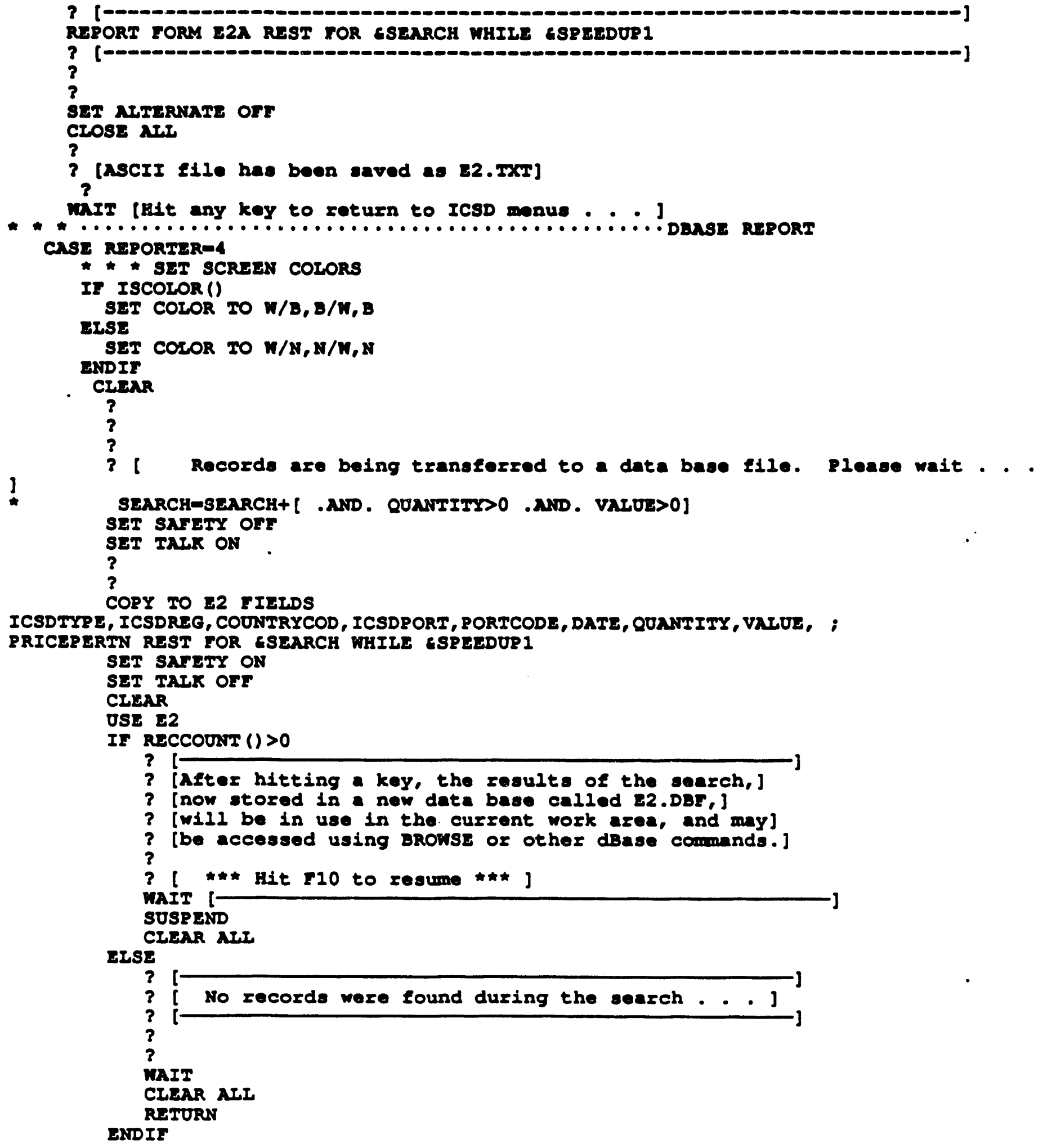




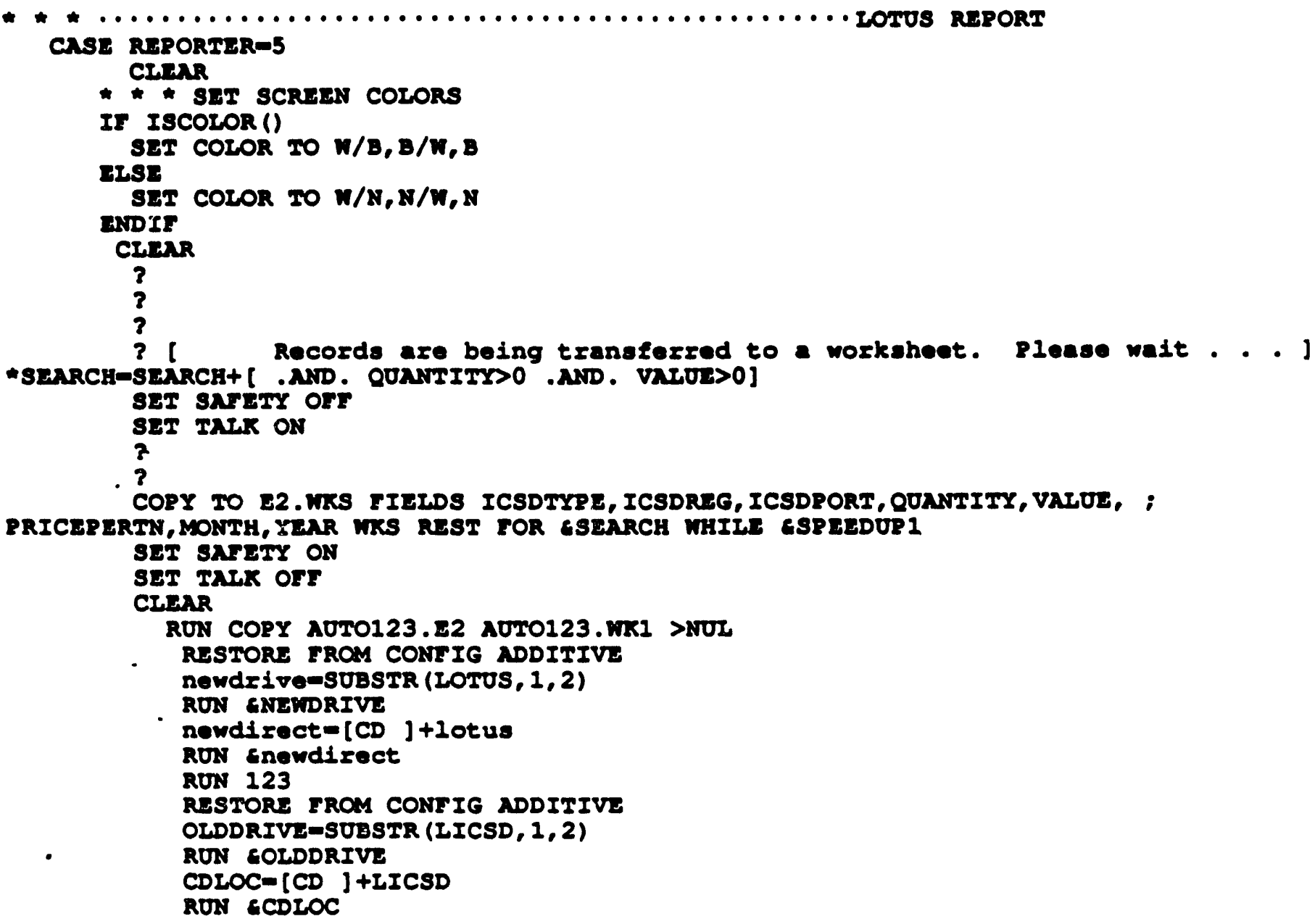




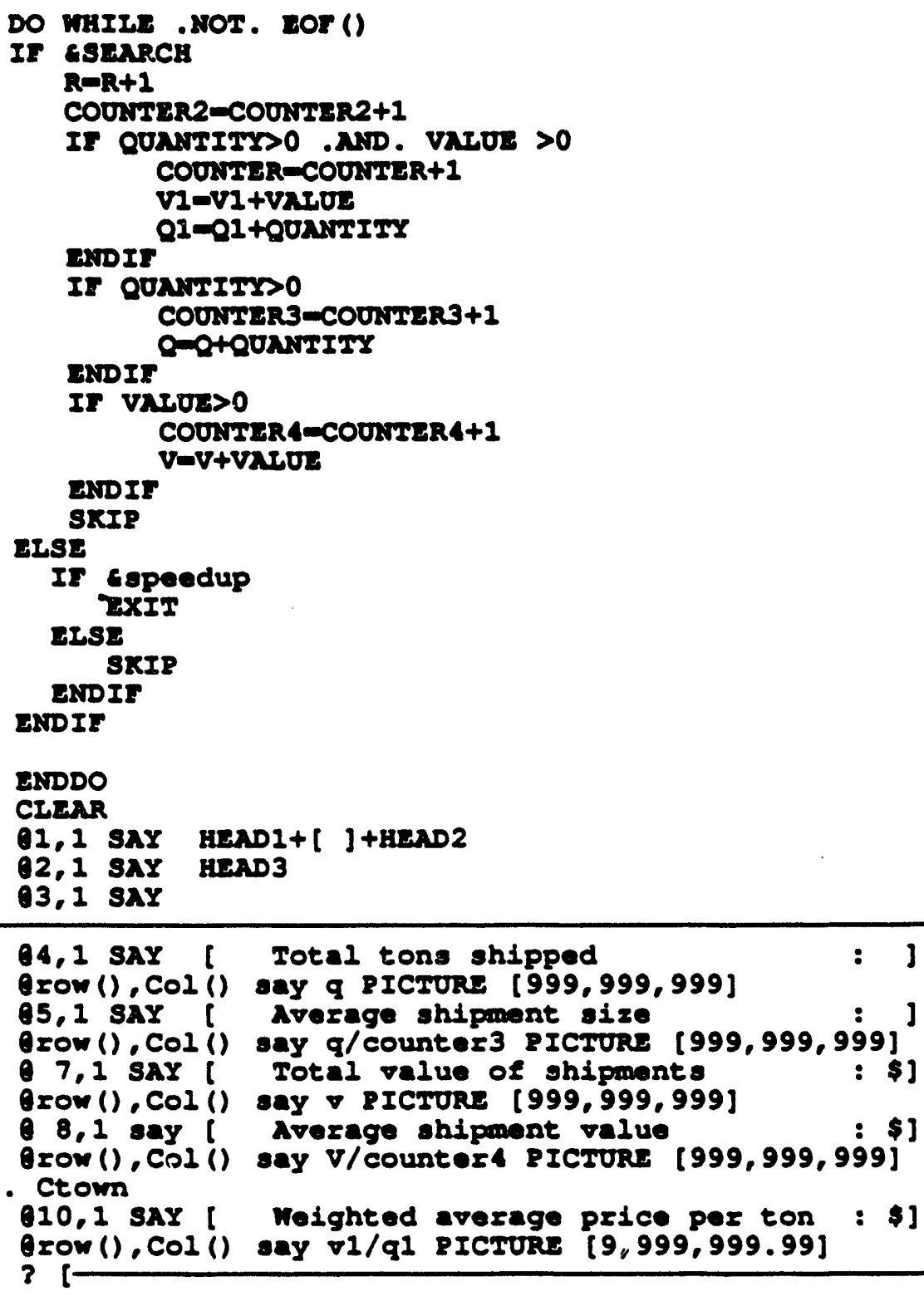

? I Notes: Quantity total includes all records having non-zero quantity values.]

? [ There were 1+STR (COONTER3, LEN (IIRIM (STR (COONTER3, 7, 0))), 0); $+[$ of $]+\operatorname{STR}($ COONTER2, IEN (ITRIM (STR $($ COONTER2, 7,0$))), 0)+[$ total records found $]+;$ 


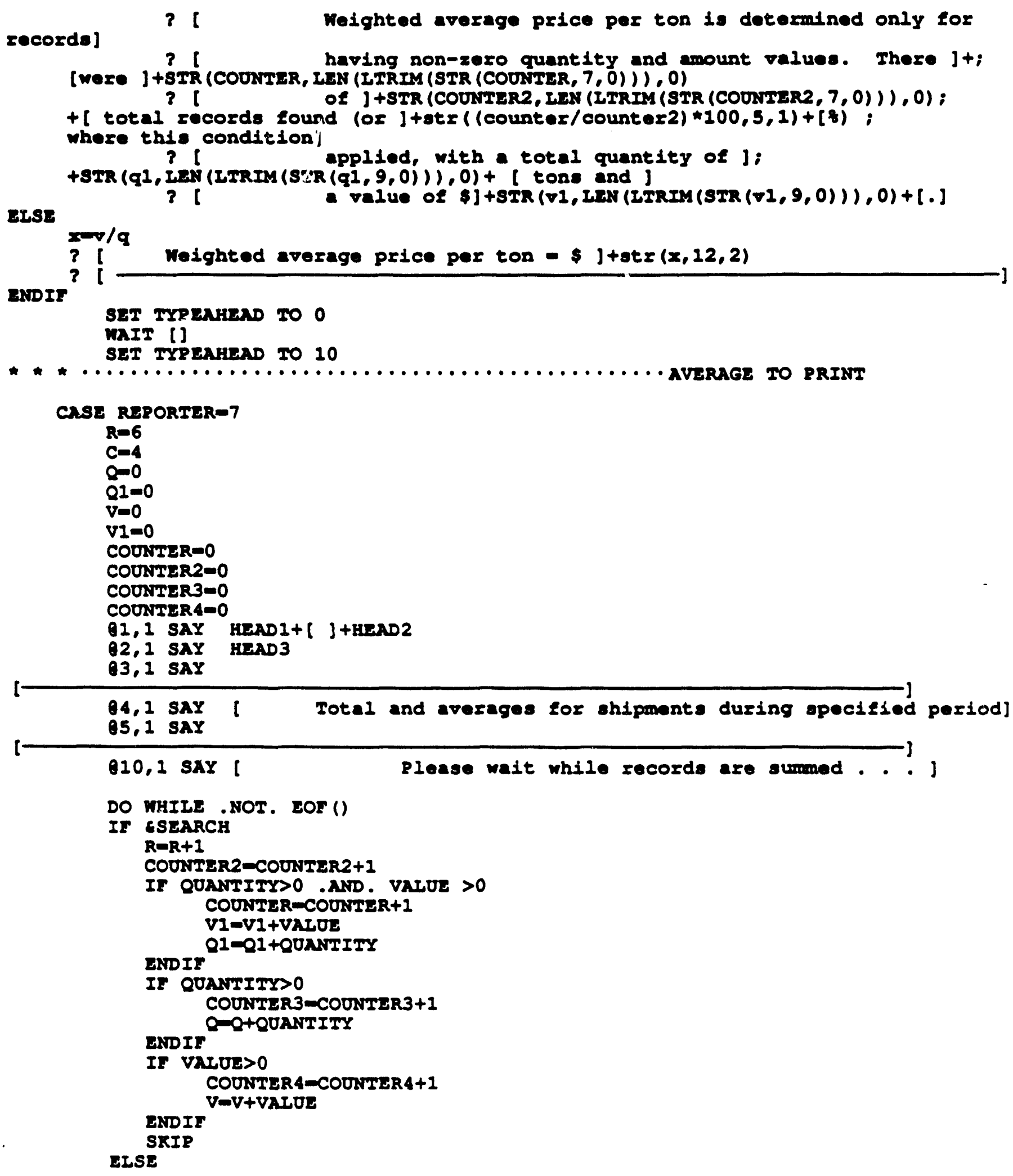




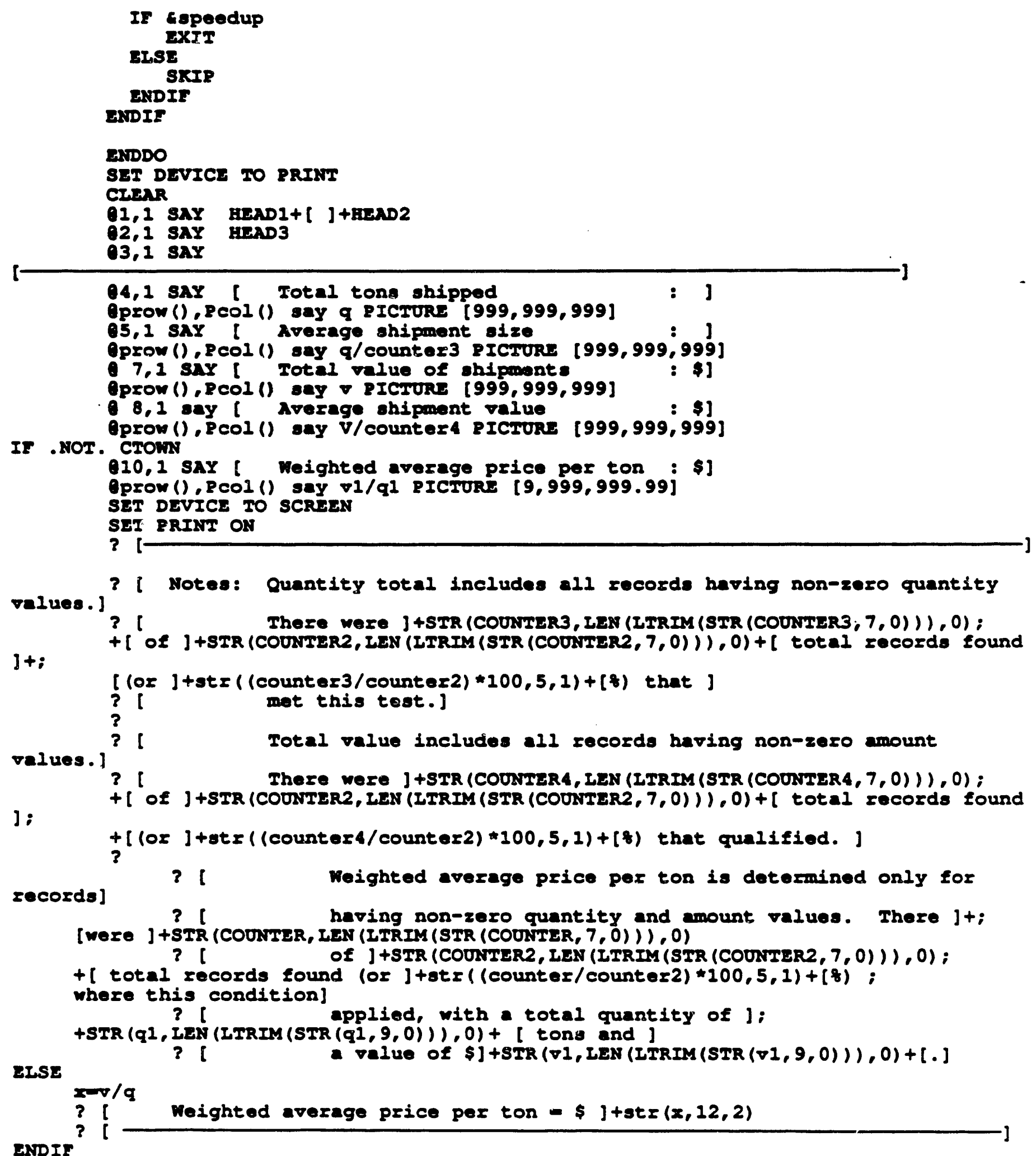




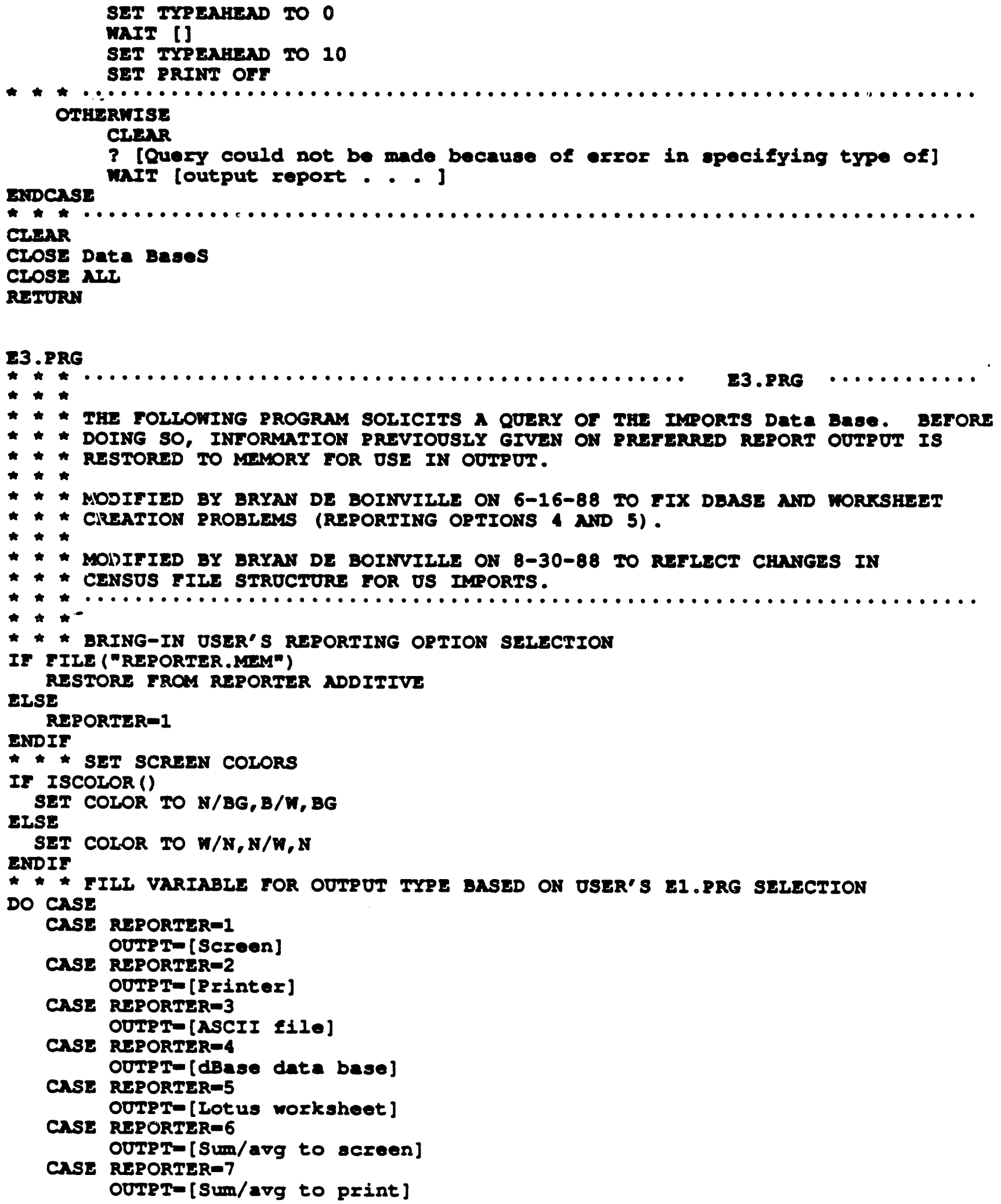

CISE REPORTER-7 OUTPT= [Sum/avg to print] 


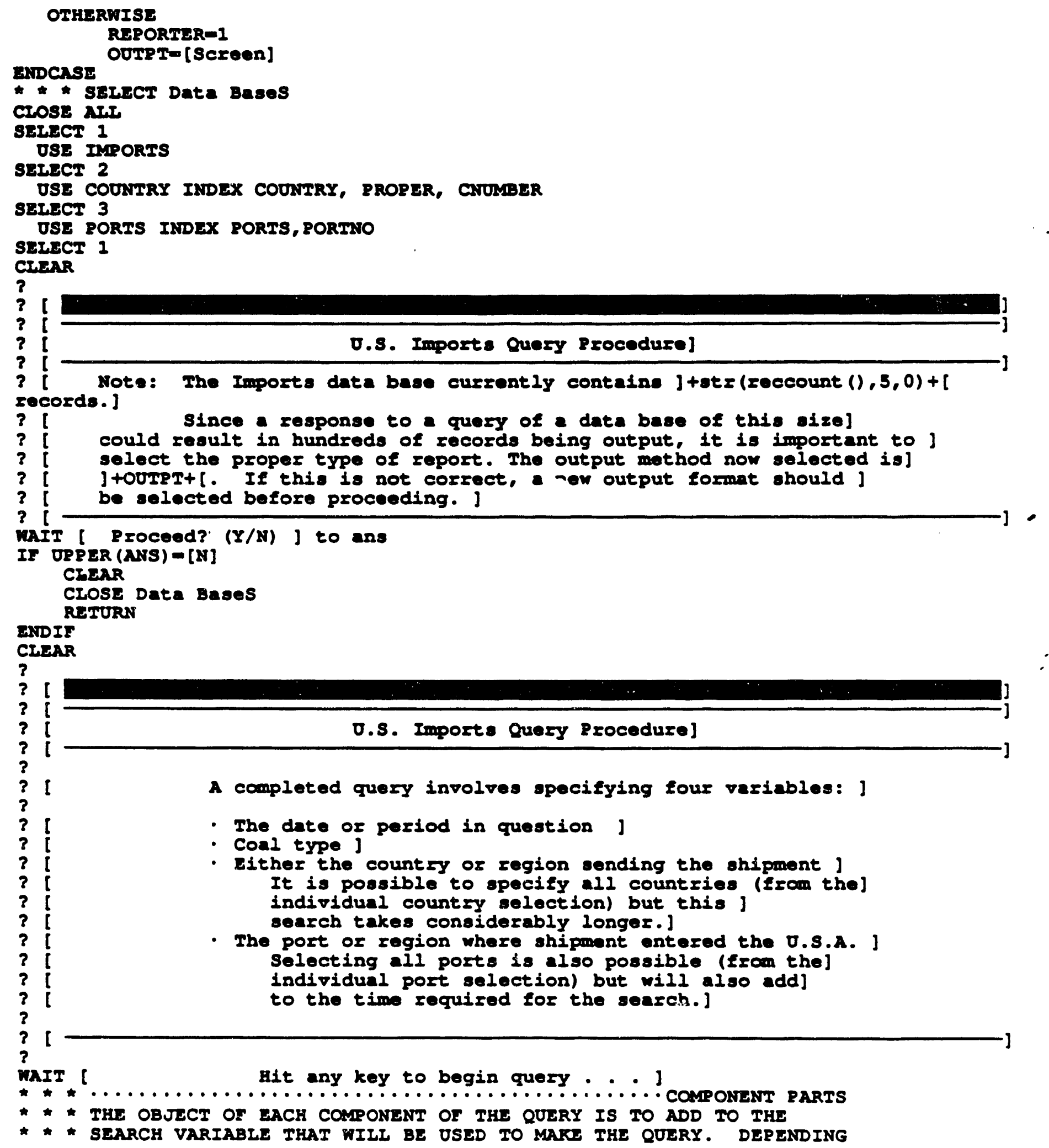



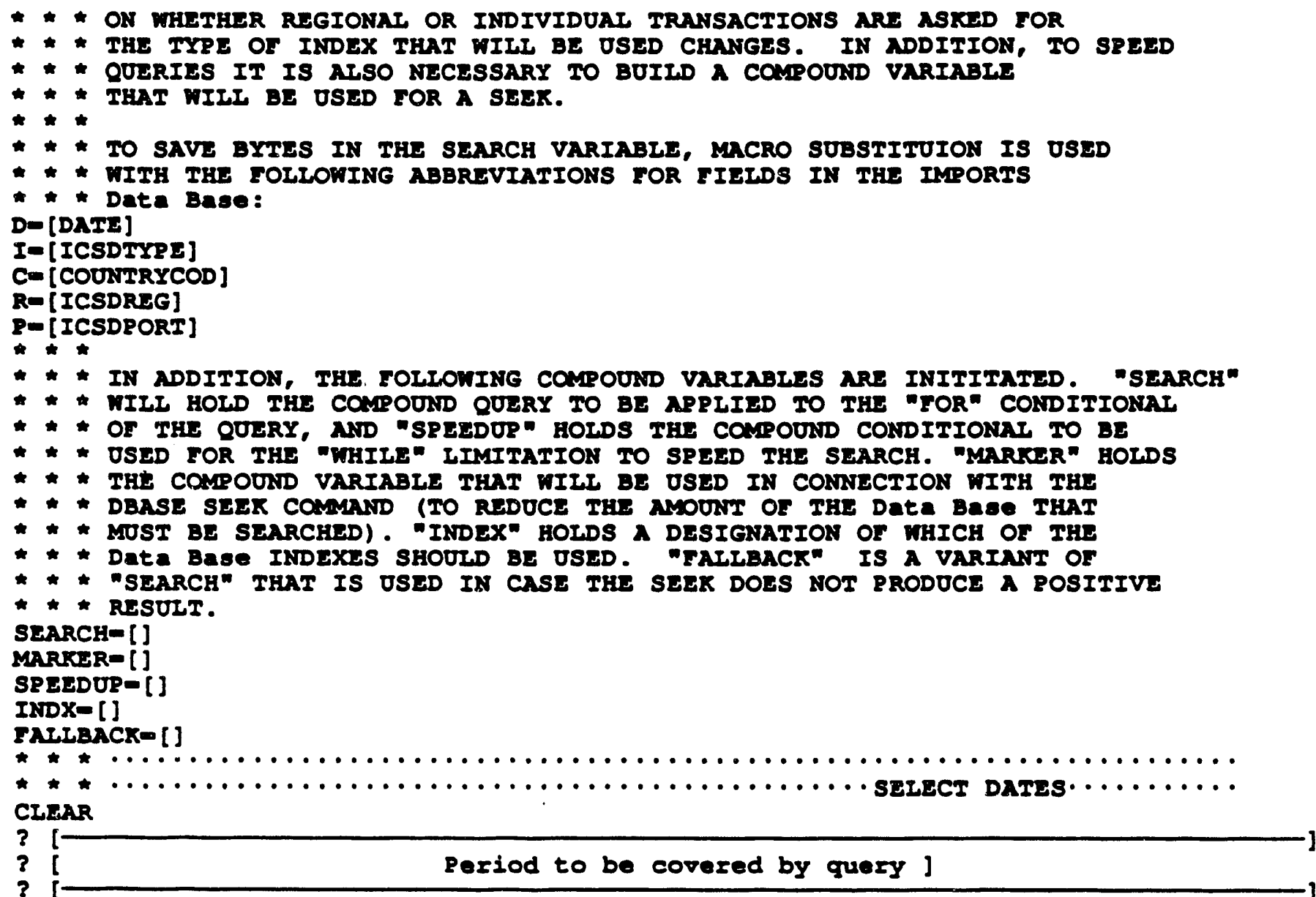

3

$\downarrow \downarrow$

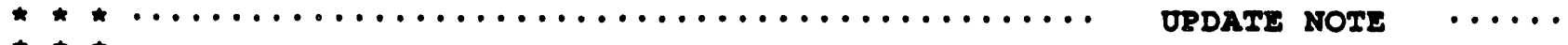

$\star \star \star \star * t$

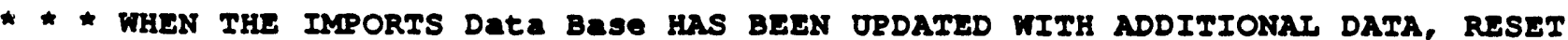

* * the valuzs of month2 and yearz (BELOW) to the Month and year of the

* * most recent data in the data Base

$\star \star \star$

$\star \star *$

MONTHI-1

YTARI -80

МОNTH2-12

YEAR2 -90

Grow ()+2,19 SAY (Starting month

erow () $+1,19$ SAY (starting yoar

Orow () $+2,19$ SAY lThrough including month

erow () $+1,19$ SAY [Ending year

RSAR

DI CTOD (STR (MONTH $1,2,0)+[/ 01 /]+$ STR (YSARI, 2,0))

D2-CTOD (STR (MONTH2, 2,0) $+[/ 01 /]+$ STR (YEAR2, 2, 0))

* * NOTE THAT DATES IN Data Bage ALI OSE THE FIRST DAY OF MONTH

IF $D 2<D 1$

? [Improper date entry (ending date must be greater than starting date)] WAIT 


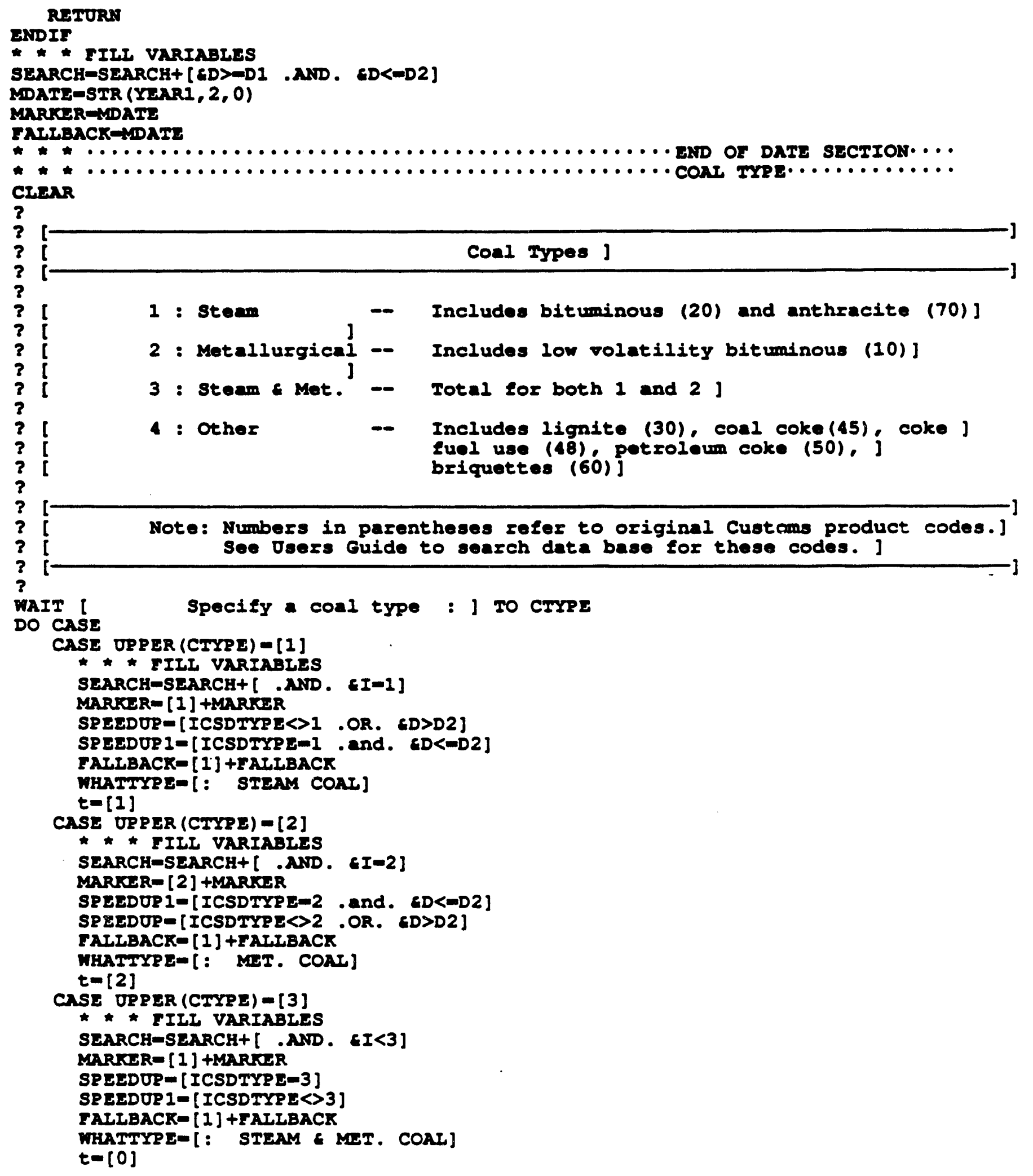




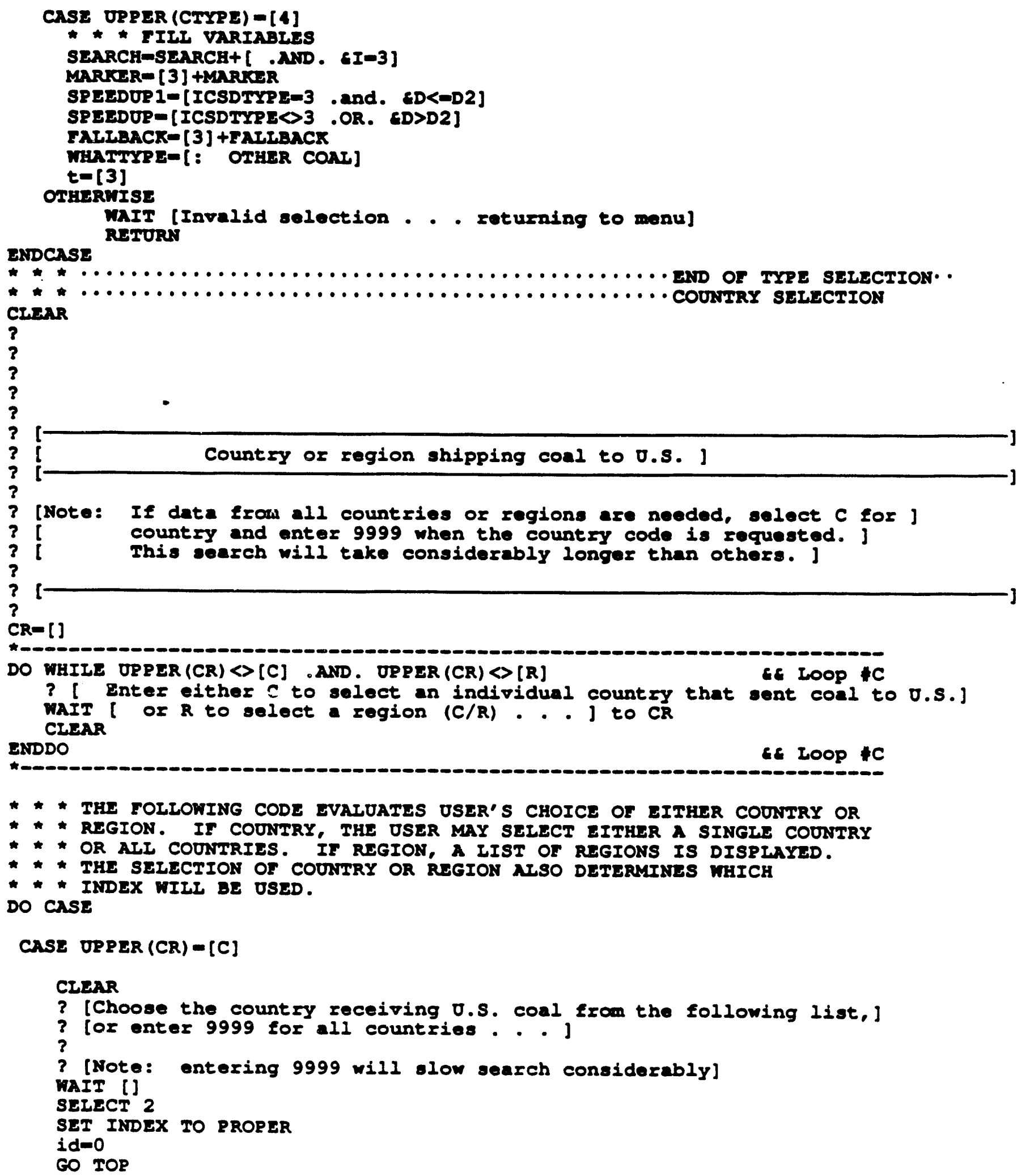




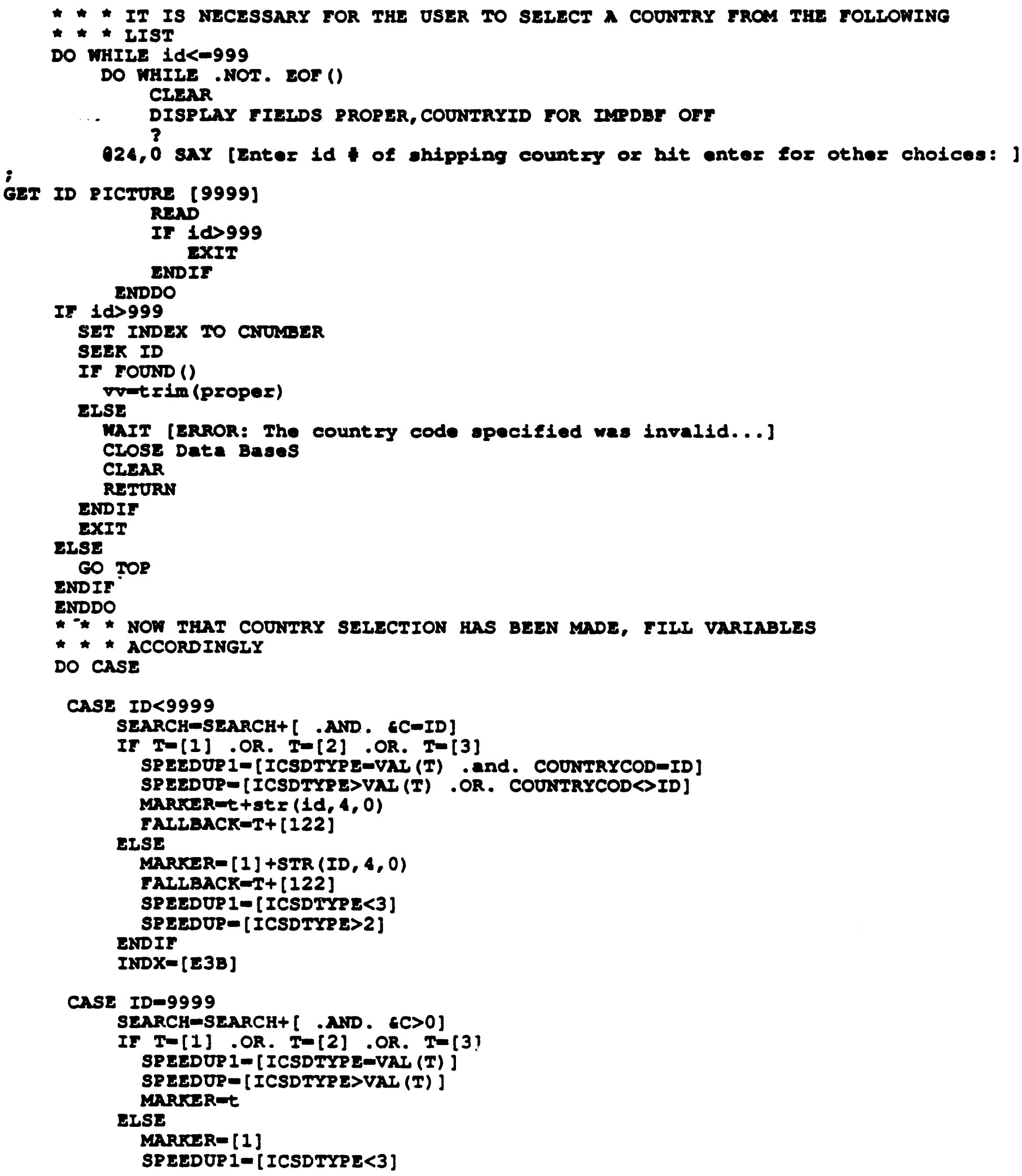


SPESDUP - [ ICSDTYPE>2]

ENDIF

EAILBACK- $[00000]$

VUD [ALL COUNTRIES]

INDX $=$ [E3B]

ENDCNSE

CIEAR

CNSE URPER (CR) - [R]

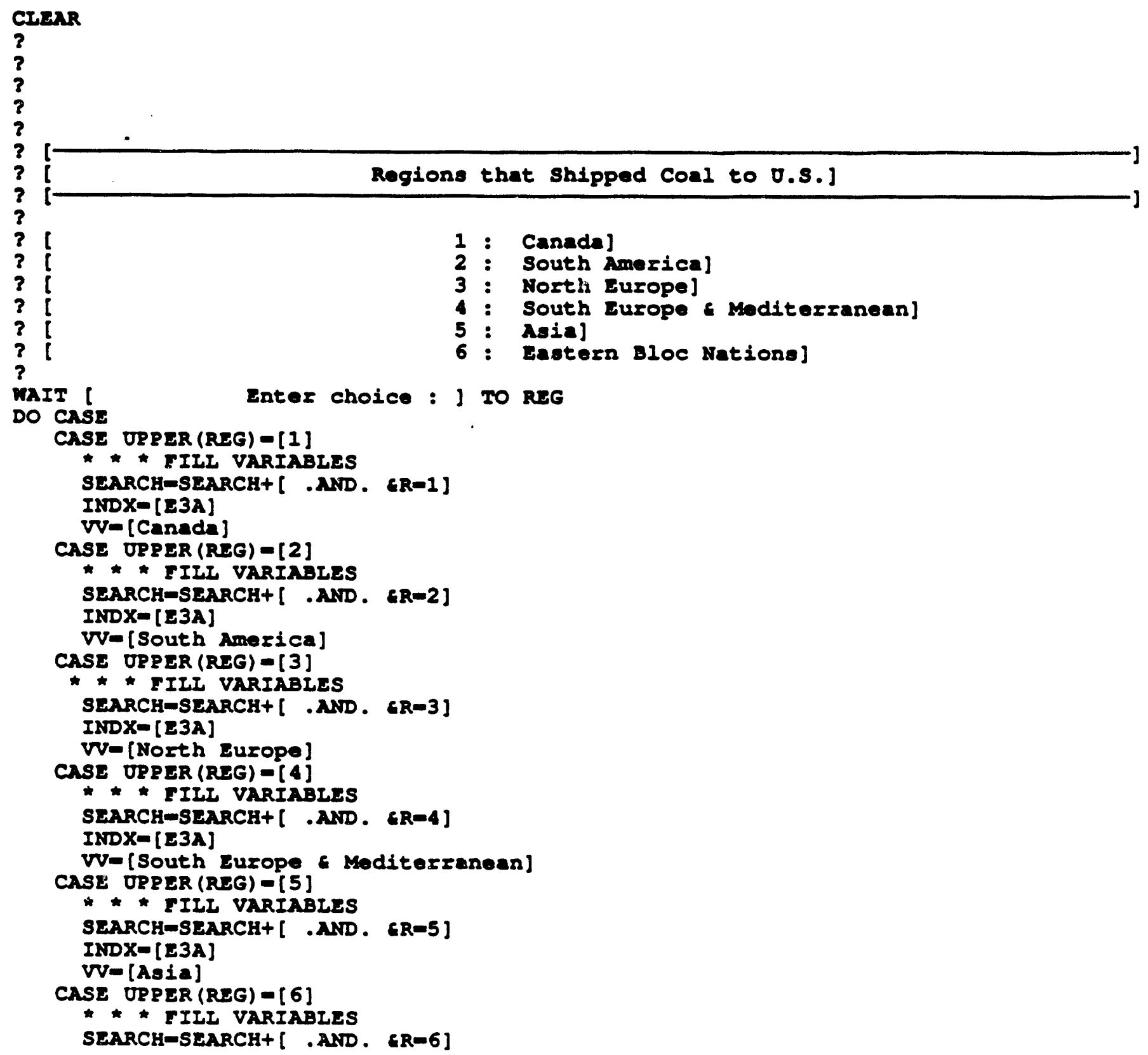




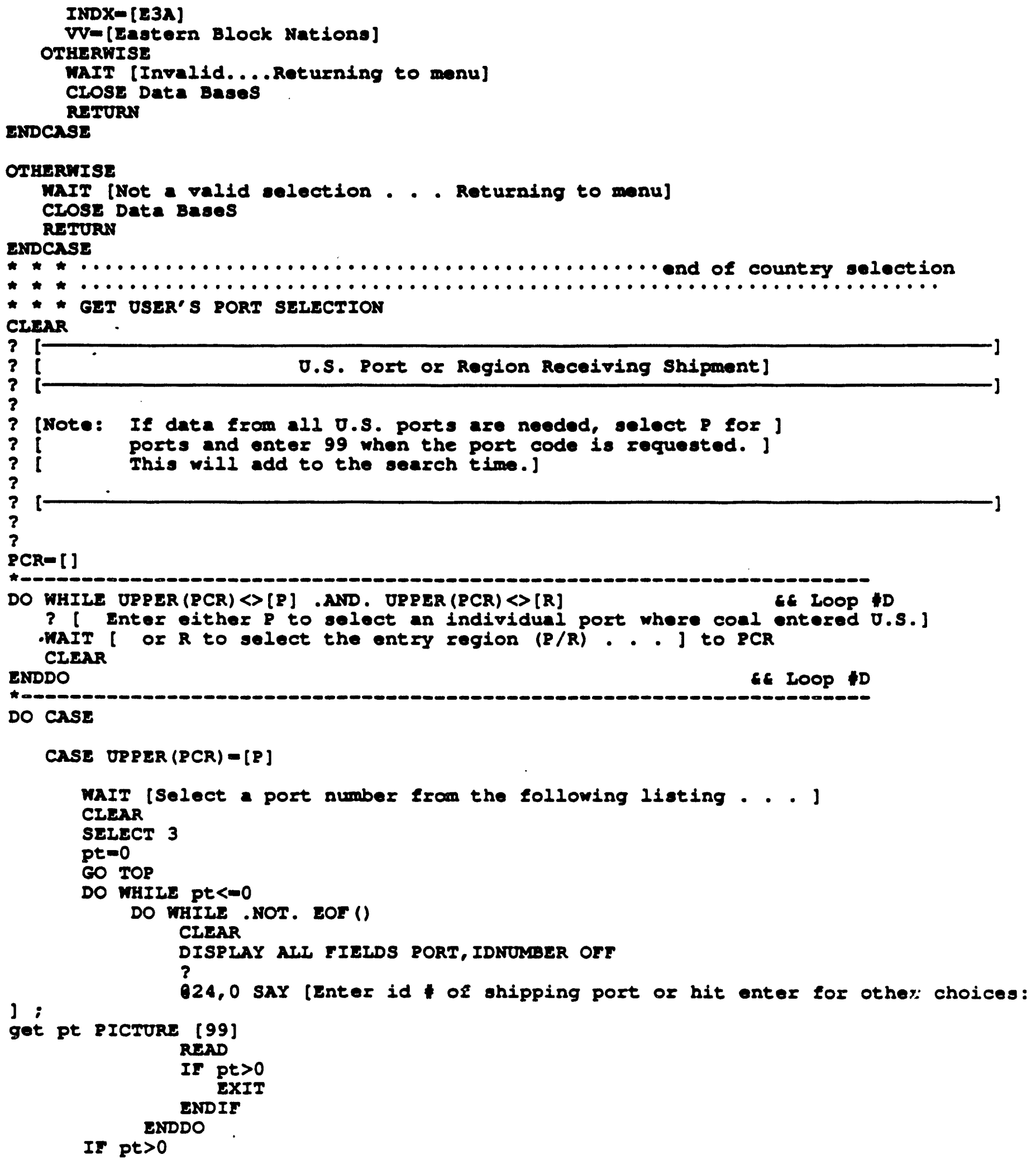




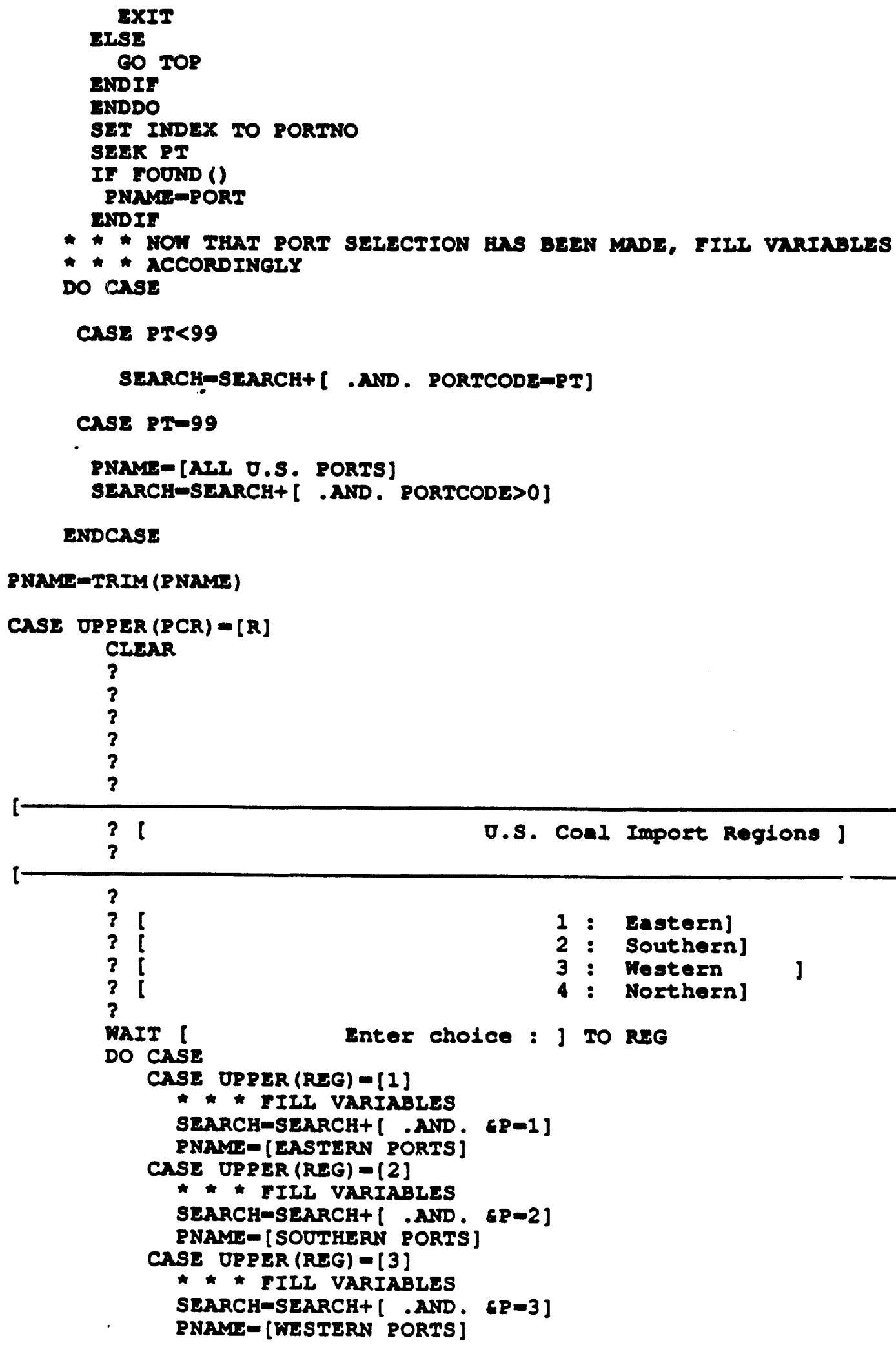




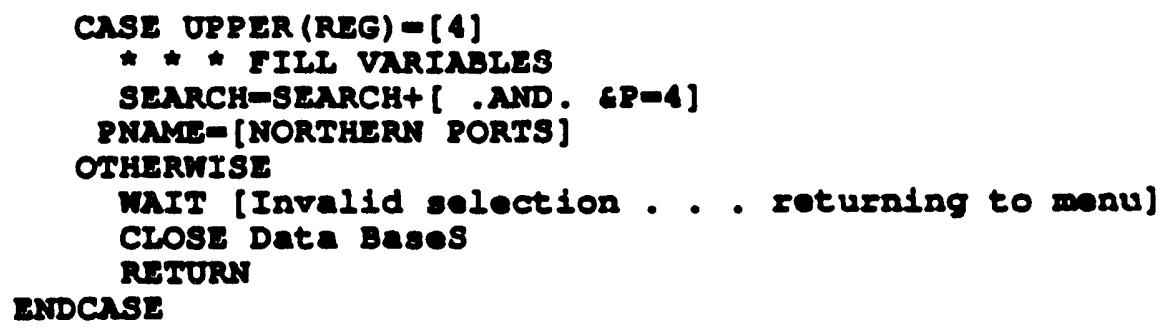

ENDIF

HEADI-[0.s. CONT IMPORTS PROM ]+URPER (VV)

HEND2-[TO ] + PNAML

HEAD 3-UPP ER (CMONTH (d1) ) + [, ] +STR (YEAR (D1), 4, 0) +[ THROUGH ] +OPPER (CYONTH (d2)) ;

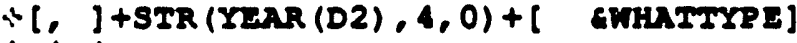

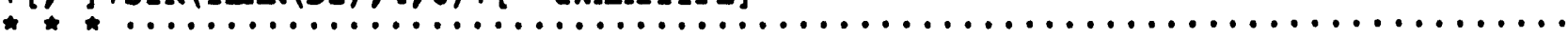

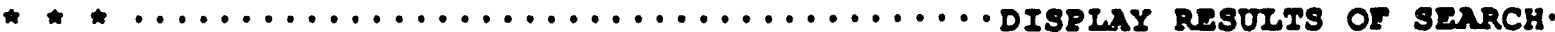

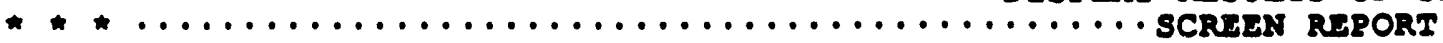

DO Case

$R=6$

CASE REPORTER=1

Cas

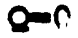

Q1:0

$V=0$

VI=0

COUNTER=0

COUNTER2=0

COUNILR3 0

COONTER 4-0

Q1, 1 SAY

02,1 SAY

03, 1 SAY

04, 1 S.1

05, 1 SAY

HEAD 1 + [ ] +ESAD2

GEAD 3

$\left[\begin{array}{lll}\hline \text { Date Shipment size } & \text { Shipant Value } & \text { Price Per Ton] }\end{array}\right.$

DO MHIL . NOT. BOF()

IF $R>=23$ 
$?$

inIT [HIt any key to 000 more data on 0.3 . coal lmporte. . .]

06,0 char

ENDIF $R=6$

II GSEARCH

OR, C SAY STR (MONTH, 2, 0) + [/] +STR $($ YRNR, 2, 0)

OR, C+9 SAY OUANTITYY PICTURE [999, 999,999]

OR, C+29 SAY VALUS PICTUR. [999, 999, 999]

OR,C+54 SAY PRICAPERIY PICIURE [9,999.99]

$\mathbf{R}-\mathbf{R}+1$

COUNTER2-COUNTER2+1

IF QUANIITY>0 . AND. VAIUL $>0$ COUNTHR-COUNTHR+1

V1-VI+VALUE

ENDIF

$0101+00 x N I I T Y$

IF OONNTITYS>0

COONISR3-COUNIER3 +1

ENDIF Q-O+QOANTITY

IF VRIUE>0

COONTER4 $=$ COONIER $4+1$

ENDIF VOV+VATU

ELSE

IF espeedup

ELSE

EXIT

SKIP

ENDIE

STIP

ENDIF

INDDO

IF $R>13$

CIEAR

Q1.1 SAY HEADI+[ ] HHAD2

Q2,1 SAY HEAD3

03,1 SAY

04, I SAY

05,1 SAY

$\left[\begin{array}{lll}\hline \text { Date Shipment size Shipment Value } & \text { Price Per Ton] } \\ \hline\end{array}\right.$

ERON()+1,1 SAY [ Results of I.C.S.D query : ]

?

ELSE

ORON (1) +1,0 CLEAR

ENDIF

OROW () +1, 1 SAY

enon ()+1,1 SAY [ Totals]

OROW (i, $C+9$ SAY Q RICTURL [999, 999, 999]

ORON (), $C+28$ SAY [\$]

QRON (), $C+29$ SAY $V$ PICrURS $[999,999,999]$

aviv1/q1

QROH (), C+47 SAY [H. Arg. - \$]

ORON (1), c+54 SAY av RICIURS $[9,999.99]$

? 1 
values.

3 I Notes: Quantity total includes all records having non-zero guantity

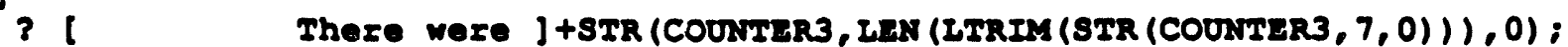

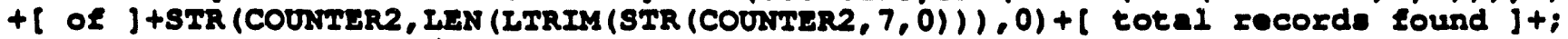

$[$ (or $]$ tot $[($ (counter $3 /$ counter 2$) * 100,3,1)+[()$ that $]$

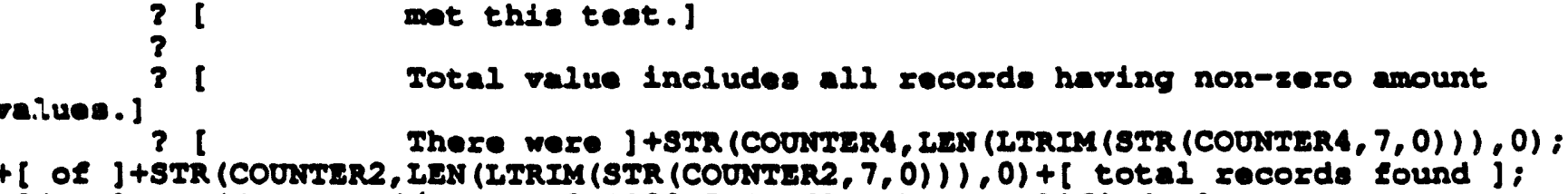

$+[$ (or $]+\operatorname{str}($ (counter $4 /$ counter 2$) \star 100,5,1)+[8$ ) that qualified. $]$

?

? ( Weighted average price per ton is determined only for records]

? i having non-zero quantity and amount values. There ]+;

[were ]+STR (COONTER, LEN (ITRIM (STR (COUTITER, 7, 0))), 0)

$3($ OE ]+STR (COUNTER2, LEN (ITRIM (STR (COONIIER2, 7,0))), 0),

$+[$ total records found (ox $]+\operatorname{st} x(($ counter/counter 2$) * 100,5,1)+[($ ) ;

where this condition]

? [ appliod, with a total guantity of ];

$+\operatorname{STR}(q 1, \operatorname{LEN}(\operatorname{LTRTM}(\operatorname{STR}(q 1,9,0))), 0)+\{$ tors and $]$

WAIT []

$3($ value of $\$]+\sin (\nabla 1, \operatorname{LEN}(\operatorname{ITRIM}(\operatorname{STR}(\nabla 1,9,0))), 0)+($.

SET TYPEAGGAD TO 10

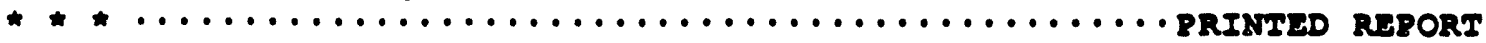

CASE REPORTER=2

RON ISITON

SET PRINT ON

? HEADI +HEAD2

? HEAD 3

SEARCHISEARCH+[ .AND. QUANTITY>O .AND. VALUE>O]

? [

REPORT FORM E3B REST FOR ESEARCH WHILE ESPEEDOPI

$?$

[ Note: Totals and weighted average exclude records with zero]

? [ quantity or amount values. ]

[ ICSD Coal Types : 1 - steam 2 - Motallurgical 3 - Other]

[ ICSD Regional Ports : 1 - Eastern 2 - Southern 3 - Mestern]

[ 4 - Northern]

[ ICSD Conl Destination Regions : 1 - Canada 2 - South America]

l

SET PRINT OFE

CLOSE AII

WAIT [Hit any koy to seturn to ICSD menus.... ]

* *.............................................. report

CASE REPORTER-3

SET ALTERNATE TO E3.TXT

SET ALTERNATE ON

? HEAD1 + HEAD2

$?$ HEAD 3

SEARCHISEARCH+[ .AND. QUANTITY>O .AND. VALUE $>0]$

$?$ [ 


\section{REPORT TORM E3A REST FOR GSEARCH WHILE GSPEEDUR 1}

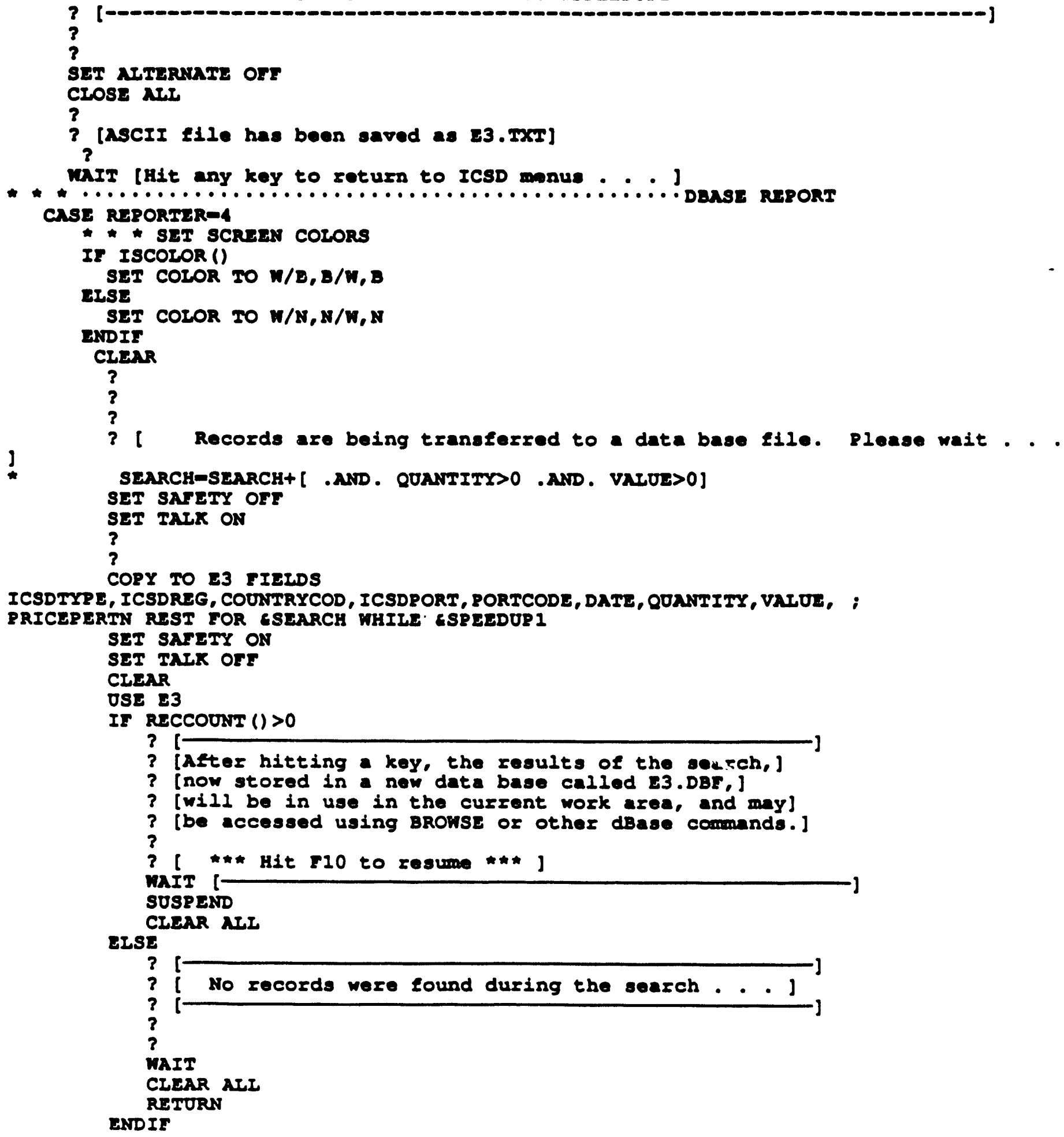




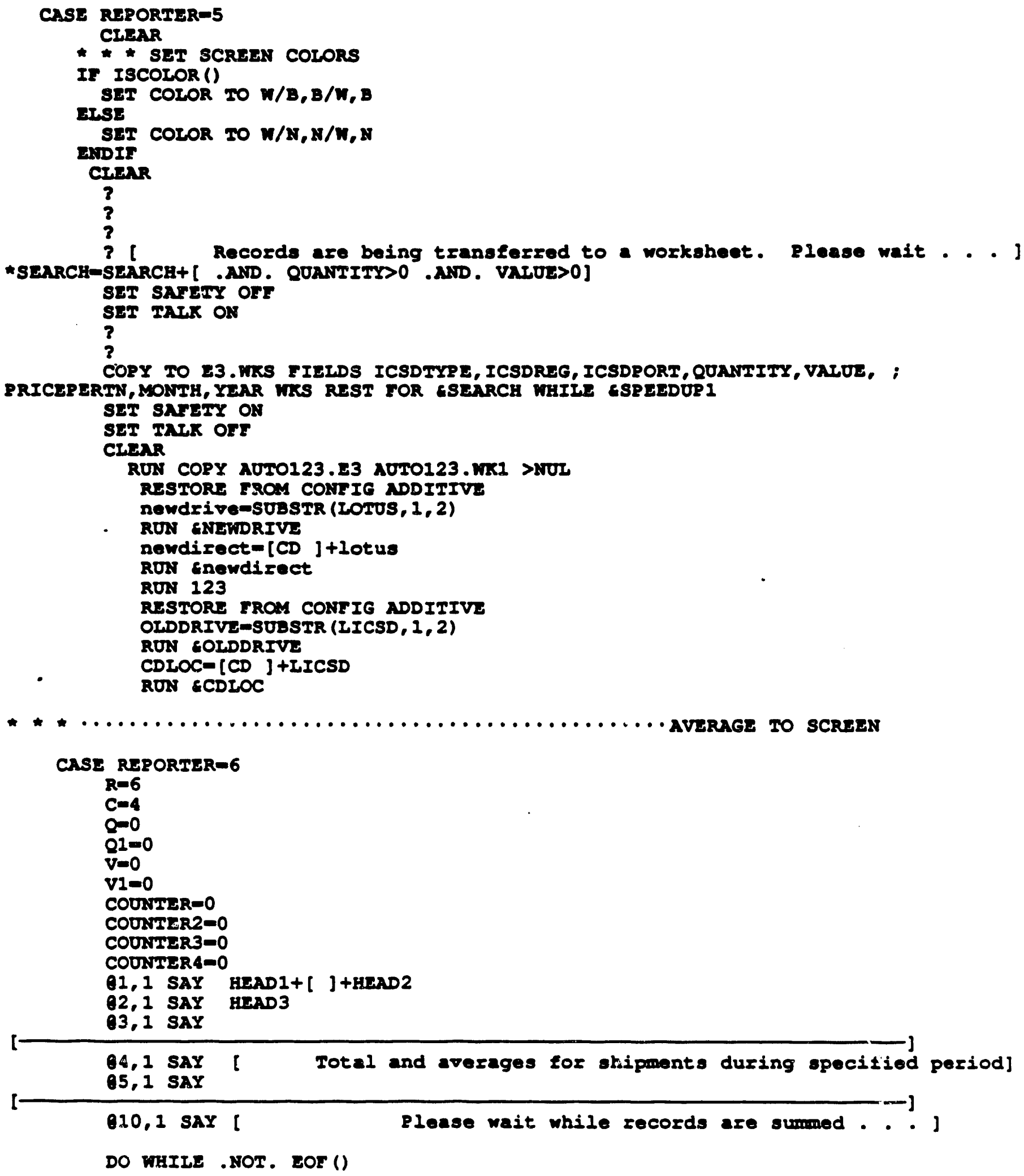




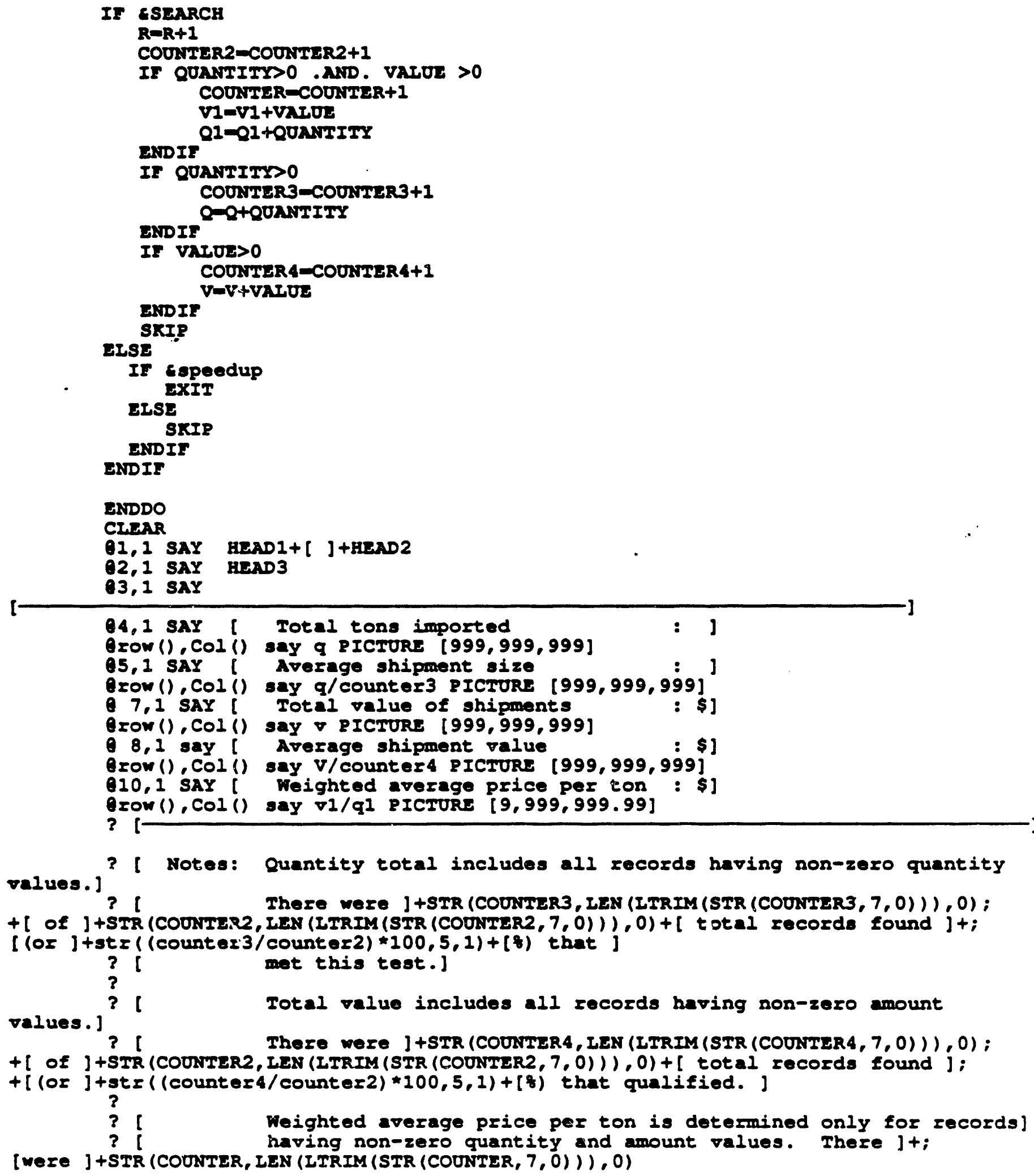


3 [ OF ]+STR (COUNTER2, LEN (ITRIM (STR (COONTLR2, 7, 0))), 0) ;

$+[$ total records found (or $]+\operatorname{st} x(($ counter/counter $) * 100,5,1)+[$ ( ) ;

where this condition]

3 [ applied, with a total quantity of ];

$+\operatorname{STR}(q 1, \operatorname{LEN}(\operatorname{LTRIM}(\operatorname{STR}(q 1,9,0))), 0)+[$ tons and ]

? [ value of $\$]+\operatorname{STR}(\nabla 1, \operatorname{LEN}(\operatorname{ITRIM}(\operatorname{STR}(\nabla 1,9,0))), 0)+[$.]

SET TYPEAHEAD TO 0

$\operatorname{maIT}[]$

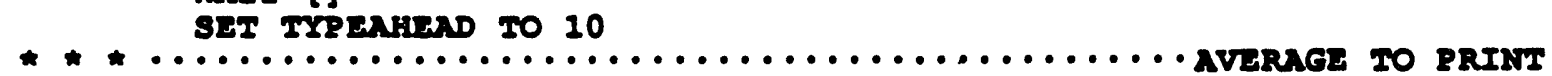

CASE REPORTER-7

$R=6$

C.4

$0=0$

Q1=0

$v=0$

$\mathrm{VI}=0$

COUNTER-O

COUNTER2=0

COUNTER 3=0

COUNTER 4-0

Q1,1 SAY HEAD1+[ ] HEAD2

02, I SAY HEAD3

03,1 SAY

[ 04,1 SAY [ Total and averages for imports during specified period]

05,1 SAY

010,1 SAY I

Please wait whlle records are summed . . .

DO WHILE . NOT. EOT()

IF ESEARCH

$R=R+1$

COUNTER2-COUNTER2+i

IF QUANTITY>0 . AND. VALUE >0

COUNTER-COUNTER+1

V1-V1+VALU2

ENDIF

Q1-Q1+QOANTITY

IF QUANTITY>0

COUNTER3-COUNTER3+1

ENDIF

Q-Q+QUANTITY

IF VALUE>O

COUNTER4-COONTER4 1

ENDIF

$\mathrm{V}-\mathrm{V}+\mathrm{VALUE}$

ELSE

If Espeedup

ExIT

EISE

SKIP

FNDIF

ENDIF

ENDDO

SET DEVICE TO PRINT 


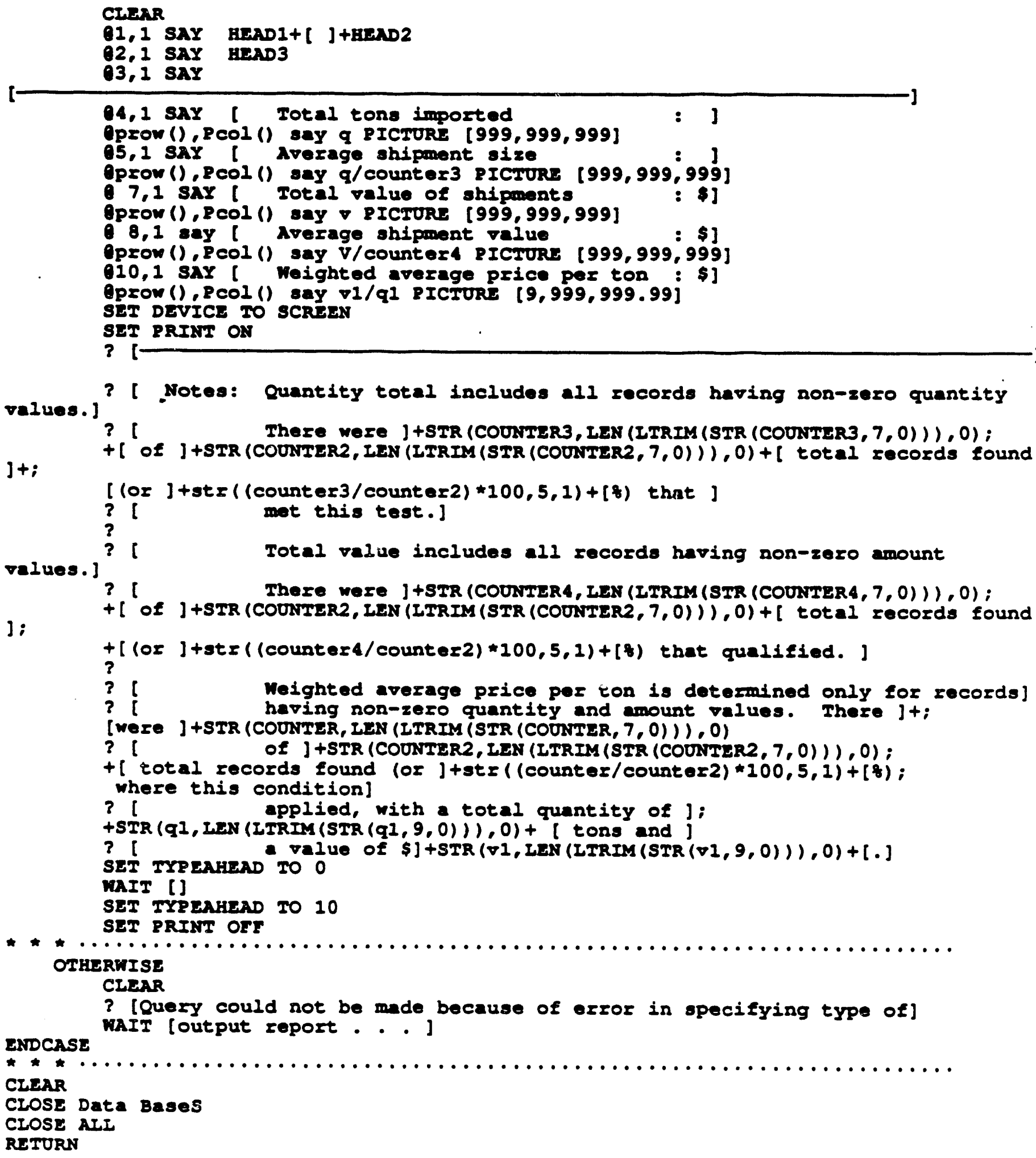




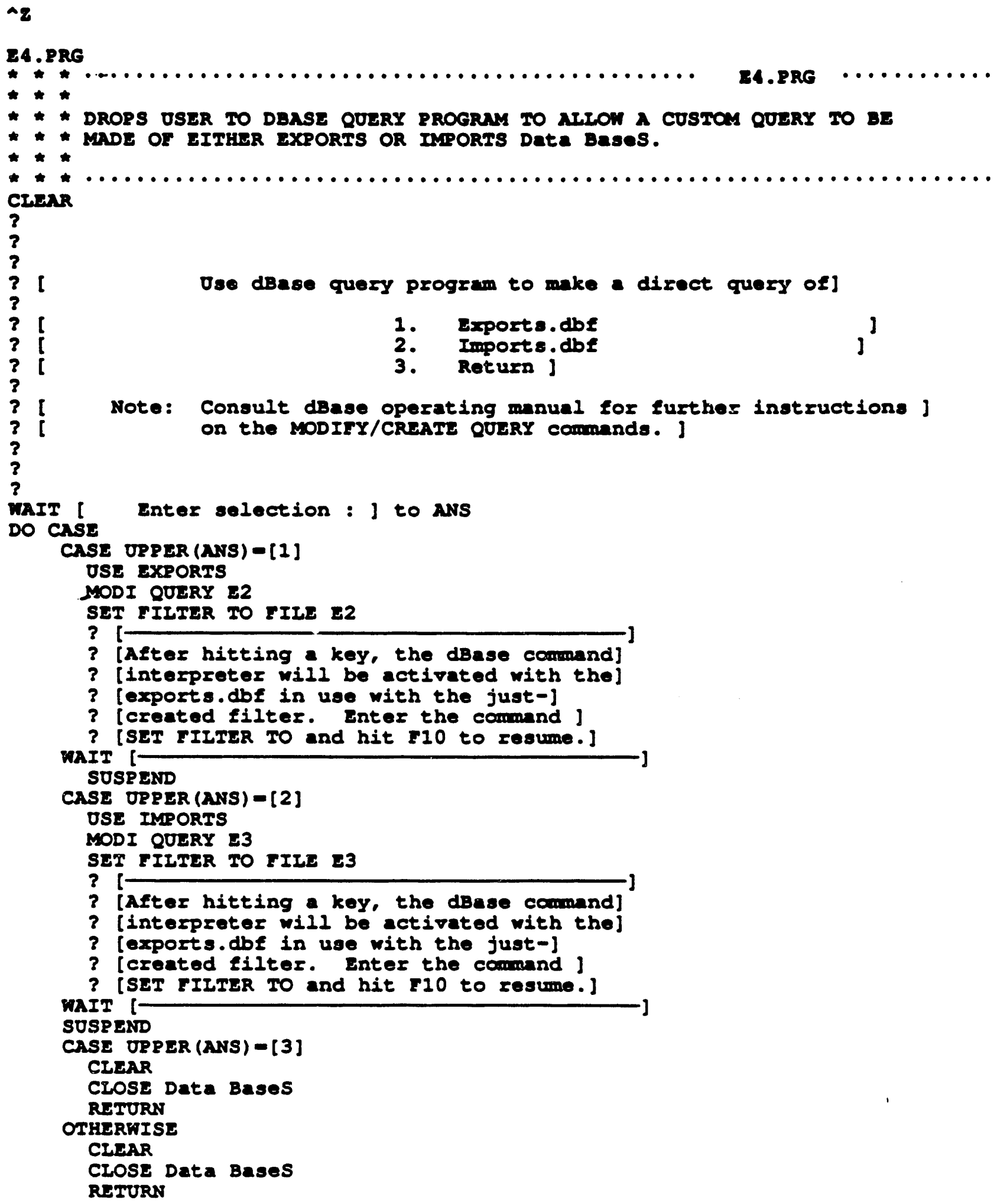




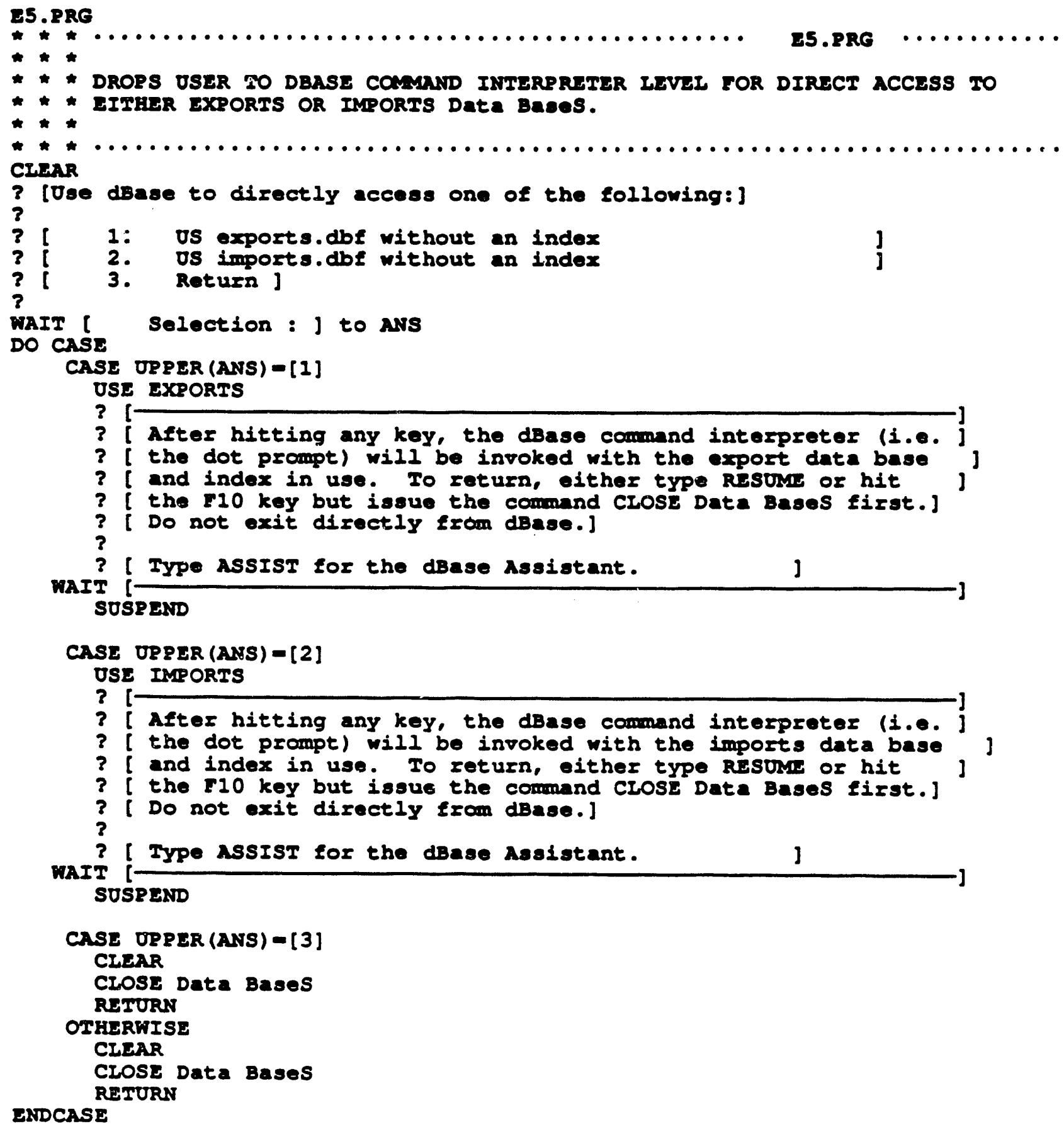


CIOSE Data Bases

RETURN

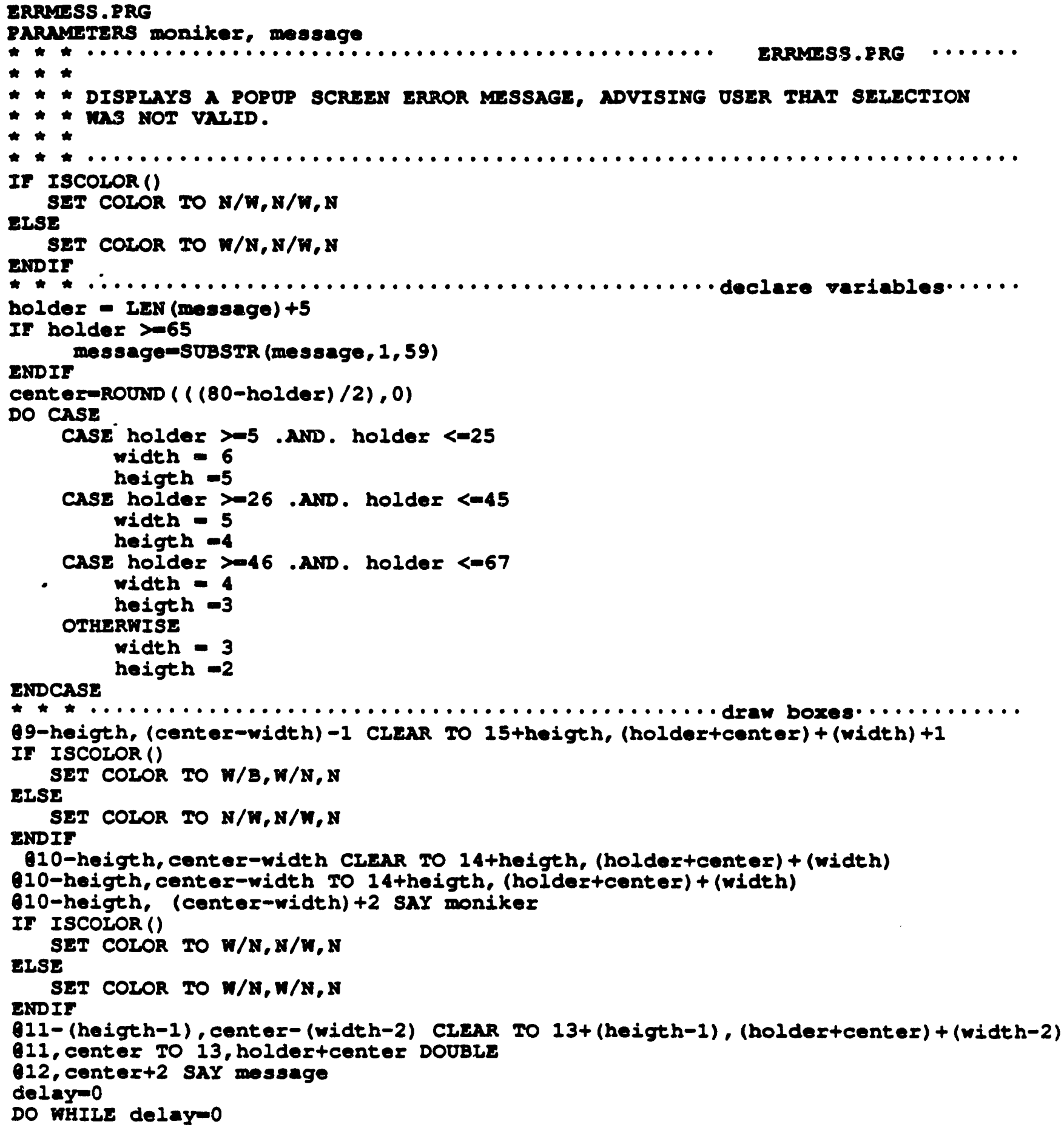


delay-INKEY ()

RETURN

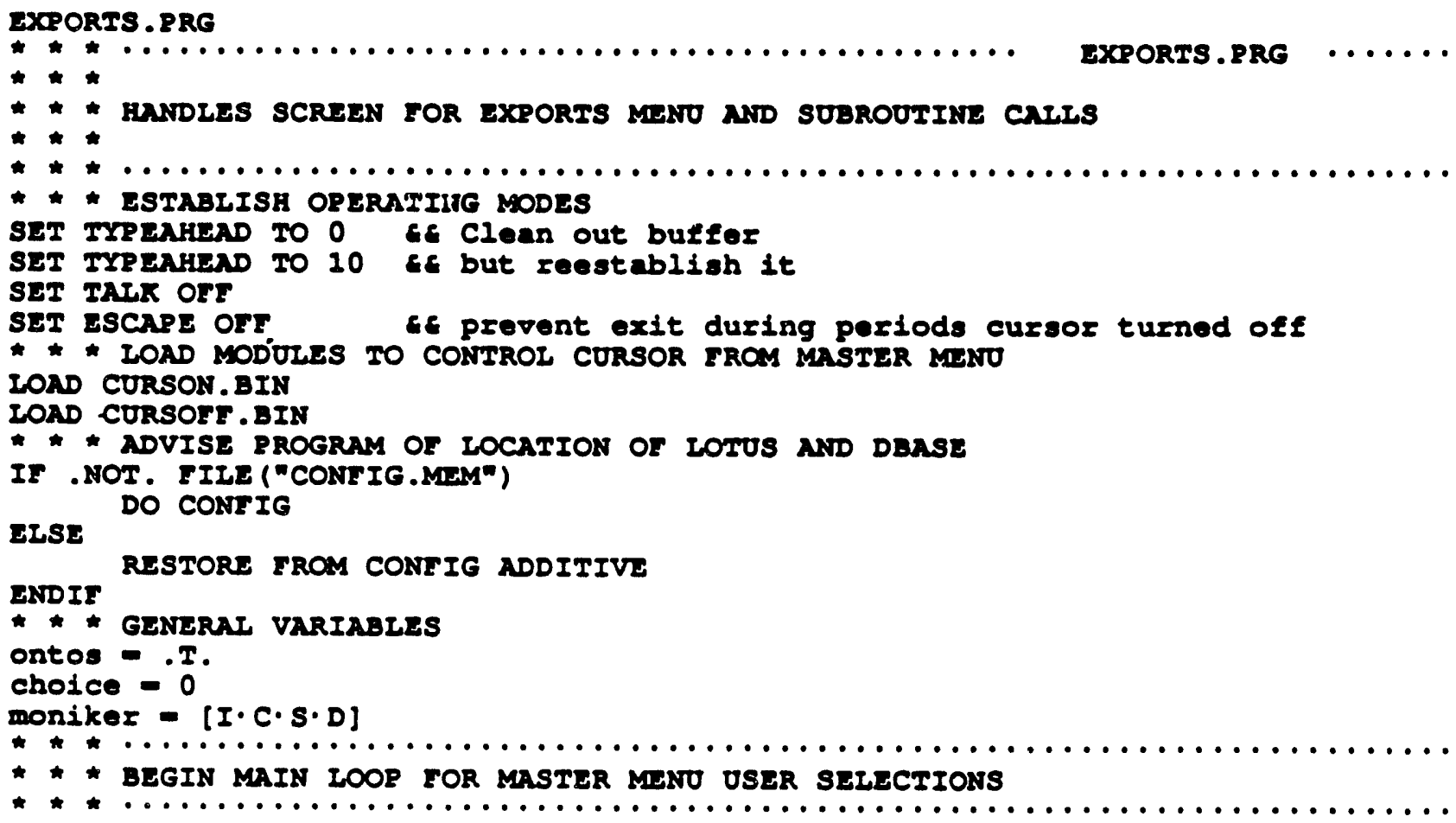




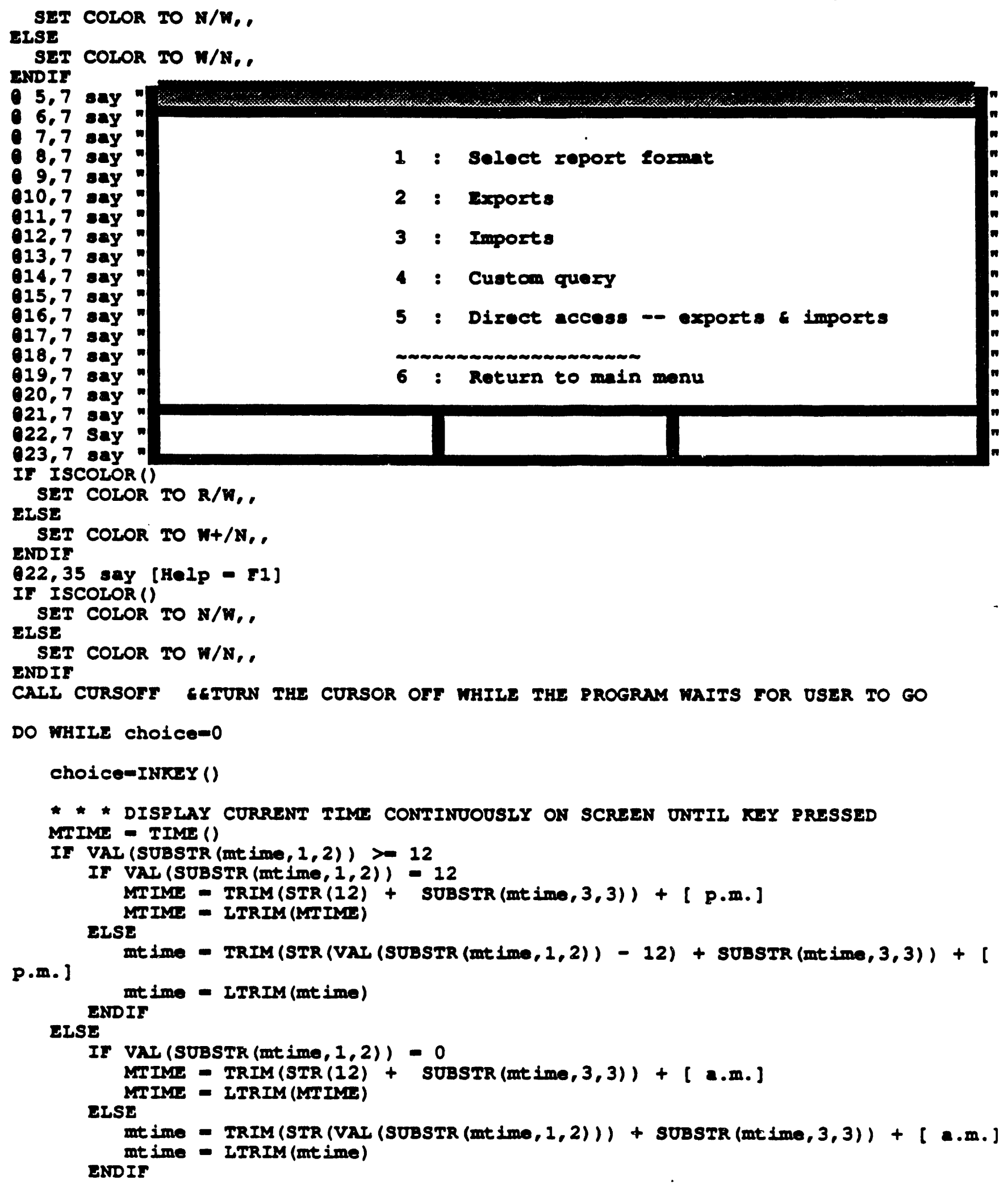


FNDIF

022,16 say date ()

022,57 say mtimot [ (E) ]

022,46 SAY CRR (choice)

ENDDO GE HND OT IOOP TO GIT OSER MINO CHOICE

CAI CURSON CE TURN THE CURSOR BACK ON

SET ESCAPE ON ON ESCAPE RETURN GE SINCE CURSOR IS BACK ON, ESCAPE IS RERMISSIBLE

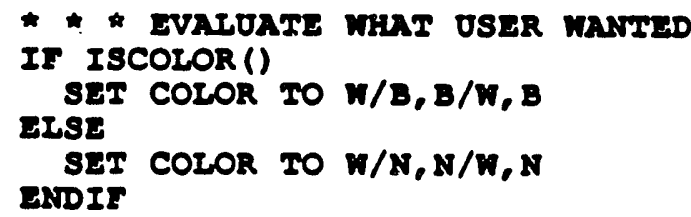

DO CAsE

CASE CHR (choice) \$[^l] if Oaer pressed Fl help key

helpl-[SEIECT FORMAT specifies acreen, printer, file or aumary ] help2-loutput. File output types include data bases, worksheets, ] help3-[ASCII text. EXPORTS / IMPORTS queries respective data bases] help4-lon $0 . S$. transactions ............. CusTOM OUURY loads the help5-[dBase III guery program to permit the construction of ueer-] help6-[deaigned query. DIRECT ACCess dropa to the dBese cowmand] help7-[interpreter (the dot prompt) with either exports.dbf or ] help $8=$ [imports. dbe in use. ]

DO help VITH moniker, helpl, help2, help3, help4, help5, help6, help7, help8

CASE CHR (ChOice) \$ [1]

DO $E 1$

\&6 Subroutine call

CASE CHR (choice) \$ [2]

DO $\mathbf{E 2}$

\&f Subroutine call

CASE CHR (choice) \$ [3]

DO 53

es subroutine call

CASE CHR (choice) \$ [4]

DO 24

sf subroutine call

CASE CHR (choice) \$ [5]

DO 55

se subroutine call

CASE CHR (ChOice) \$ [6]

CISAR

RETORN 
OTHERTISE

mesaggo-[Invalid selection . . try again] DO ERRYLSS VITH moniker, message IOOR

\section{HNDCNSE}

ENDDO

RETURA
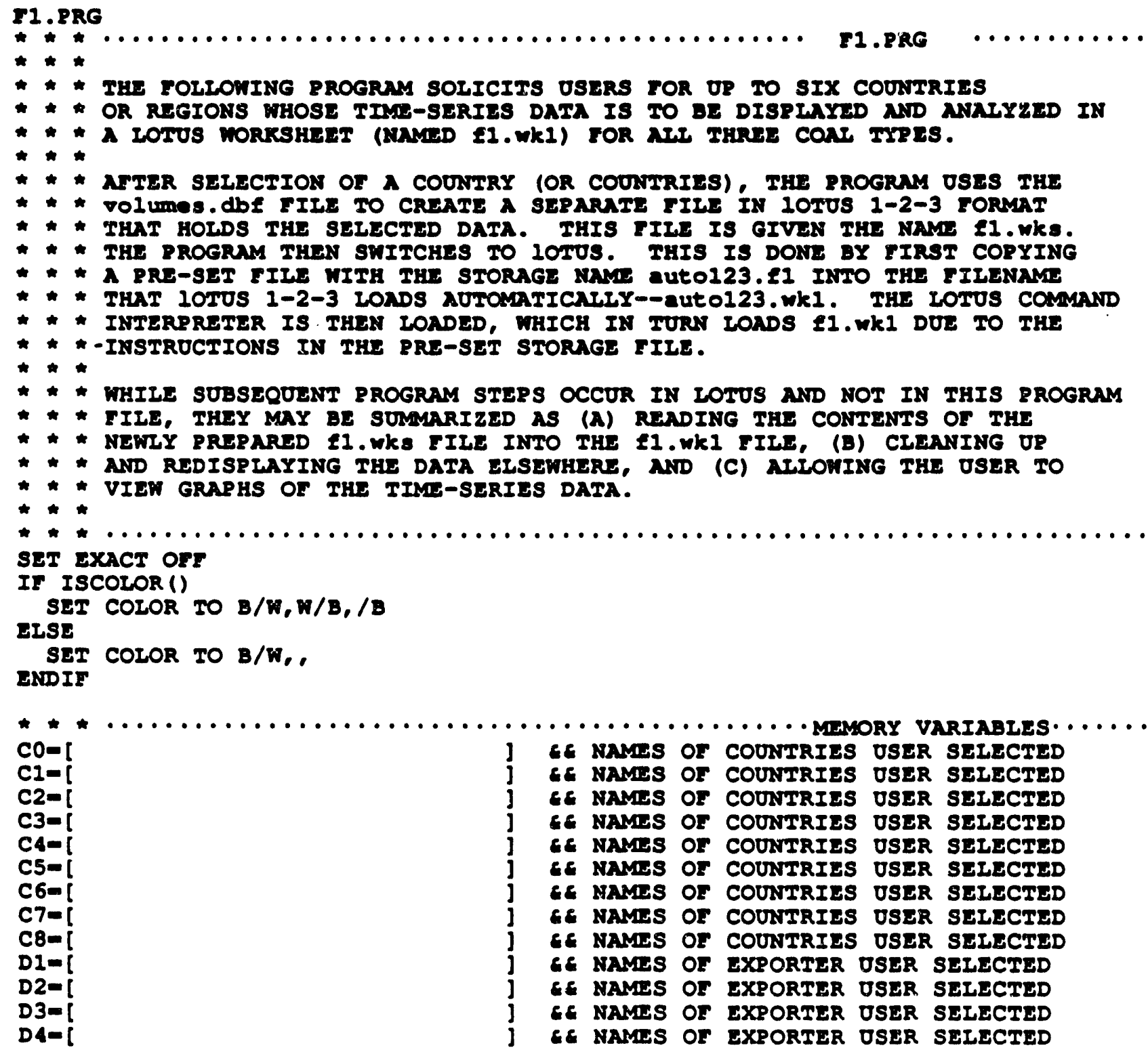


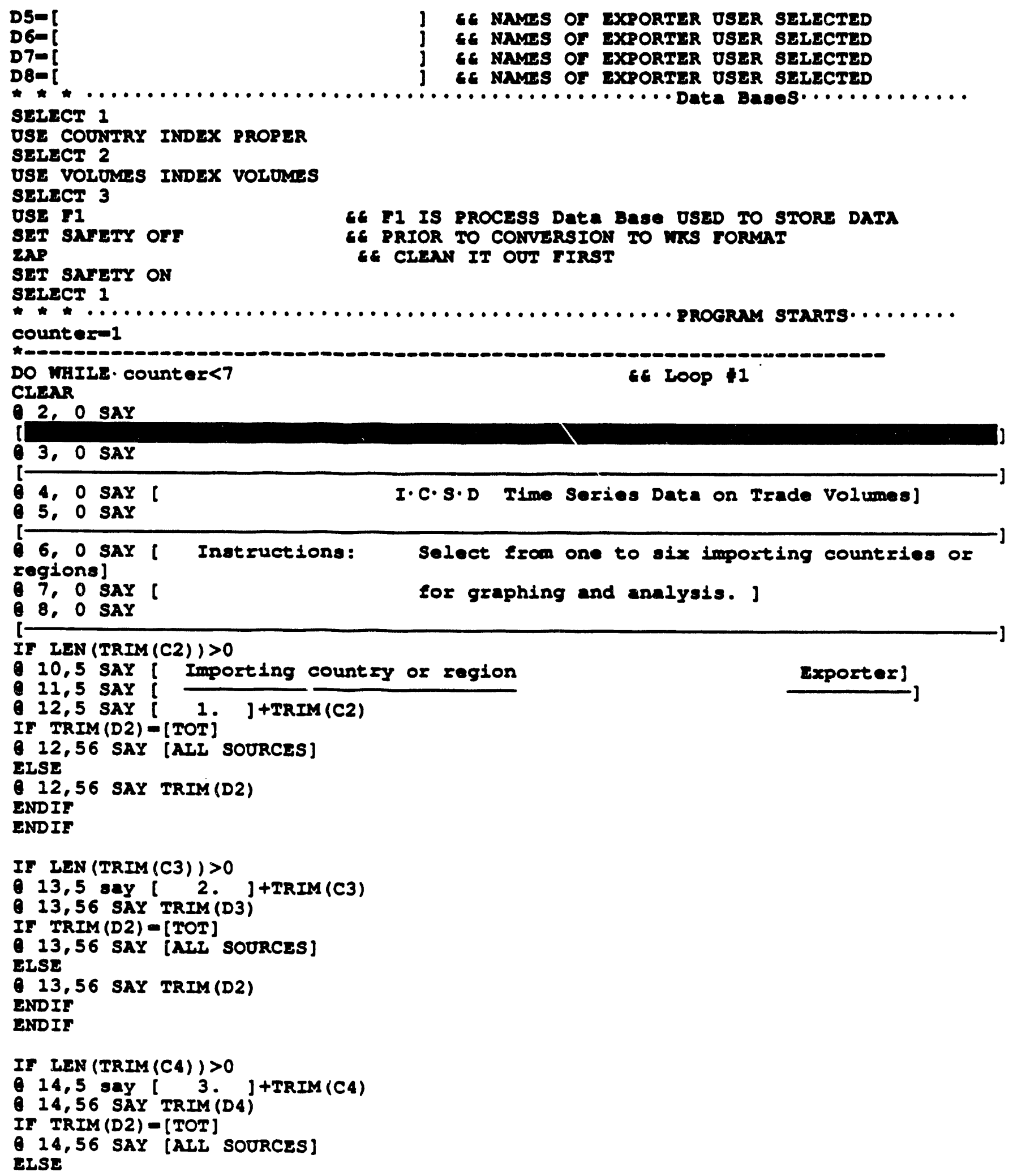




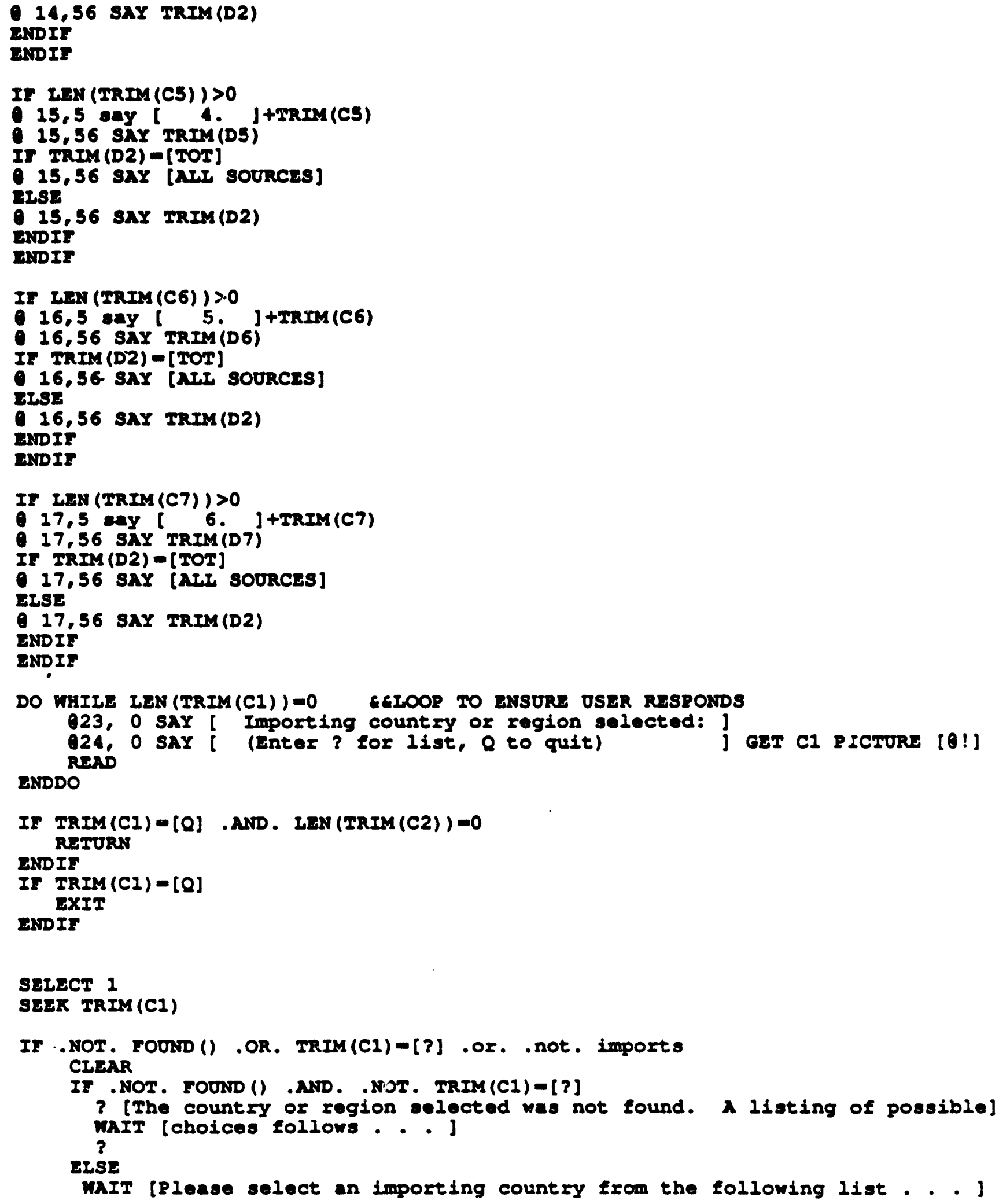




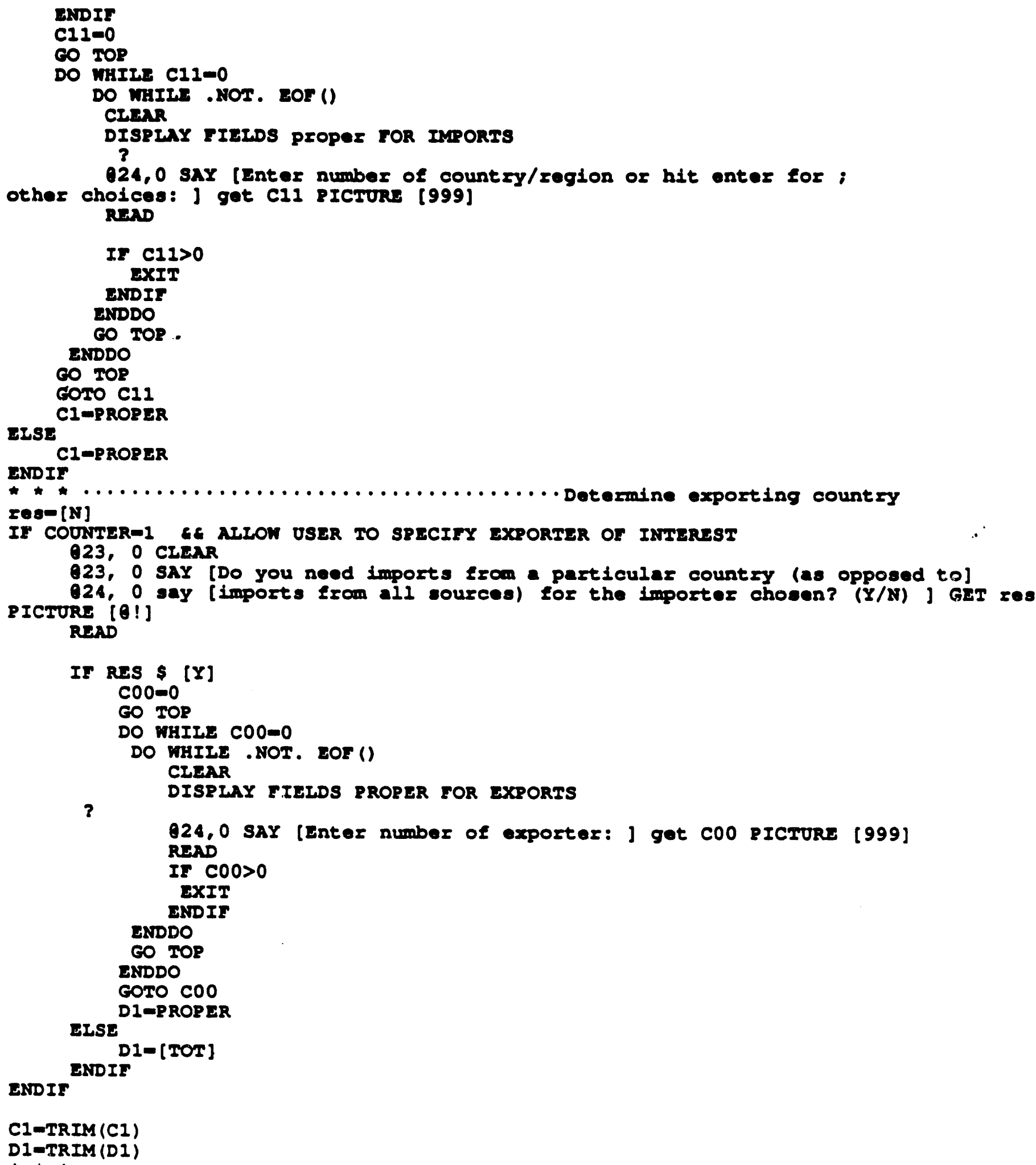




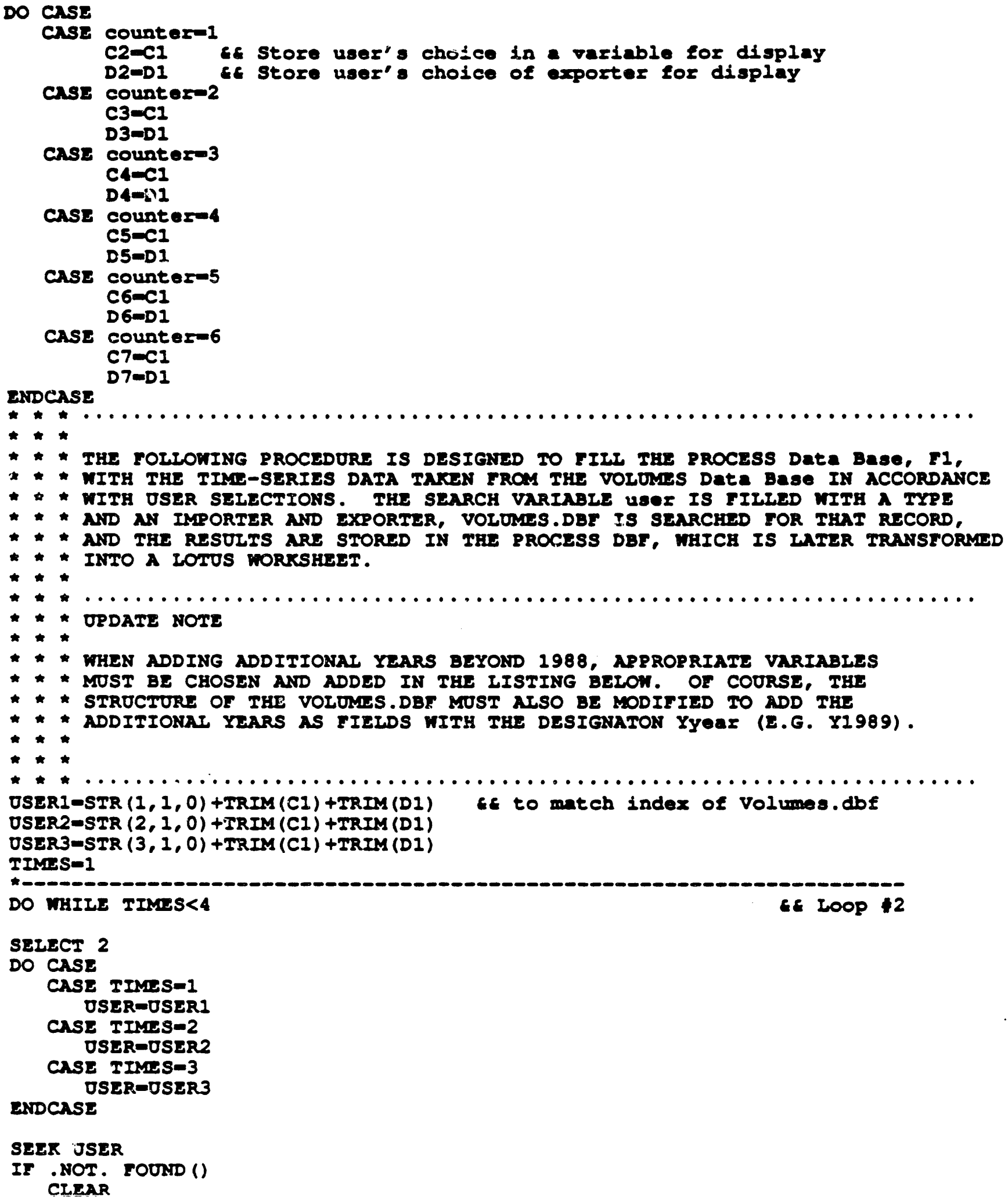

fe to match index of Volumes.dbf 

ENDIF

WAIT [No data was found in reponse to your query . . . ]

$X$ IMP

$x \times-\operatorname{ExP}$

XCX-TYRE

X1980-Y1980

X1981-Y1981

X1982-Y1982

X1983-Y1983

X1984-Y1984

X1985-Y1985

X1986-Y1986

X1987-Y1987

X1988-Y1988

SELECI 3

APPEND BIANR

REPIACE IMP NITH $X$

REPIACE EXP VITH $X \times$

RGPIACE TYRE NITH XCXX

RSPIACE Y1980 WITH X1980

REPIACE Y1981 WITH X1981

REPLACE Y1982 VITH XI982

REPIACE Y1983 WITH X1983

RIPIACE Y1984 WITH X1984

REPIACE Y1985 WITH X1985

REPIACE Y1986 WITH X1986

REPLACE Y1987 NITH X1987

REPIACE Y1988 WITH X1988

TIMSS-TIMS +1

SE INCRMMENT COONIER

ENDDO

CE LOOP $\$ 2$

CI-[
COI-[

ENDDO

66 LOOP 1

CIEAR

$?$

$?$

$?$

? [ Records are being retrieved for selected importers and exporters.]

? [ Please wait . . ]

SELECT 3

SET SAFETY OFE

CORY TO El.WRS WRS

SET SATETY ON

CIEAR

CIOSE Data Bases

RON COPY AUTO123.FI AUTO123.WRI >NOL

RESTORE TROM CONTIG ADDITIVE

newdrive-SUBSTR (IOTUS, 1, 2)

RUN ENEWDRIVE

newdirect $=[C D]+$ lotus 
Ror snewdirect

RON 123

RASTORS FROM CONFIG ADDITIVE

OLDDRIVS-SUBSTR (IICSD, 1, 2)

RUN COLDDRIV

CDIOC- [CD ] IIICSD

RUN $S$ CDIOC

RETURA

* * Modified by B. de B. on 09/21/90

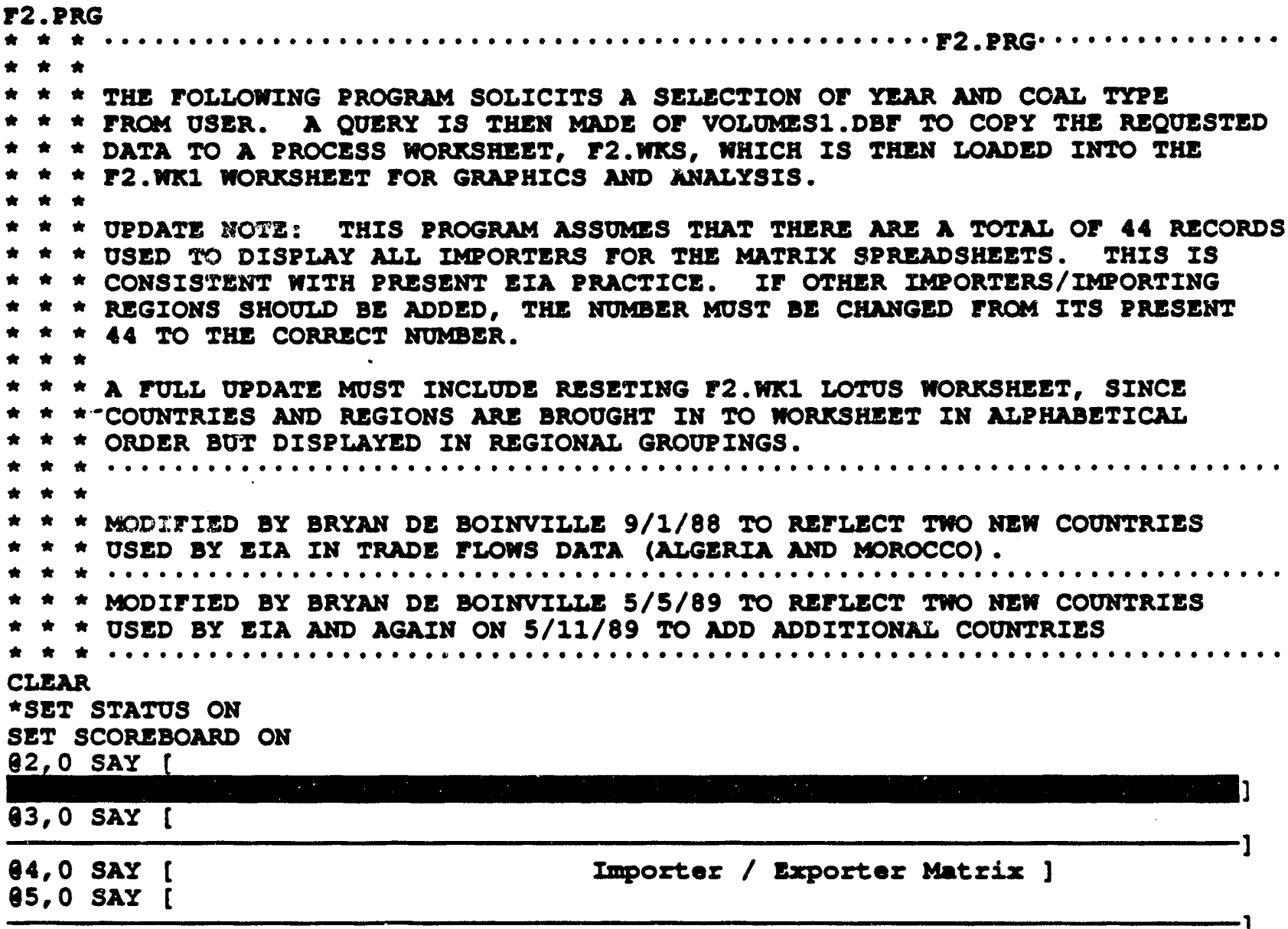

Orow ()+2, 0 sey [ The matrix view shows trade volumes between individual and] Orow () +1 , 0 say ( regional coal importers and exporters, as well as relativel Qrow ()+1, 0 say [ market shares.]

exow $(1+1,0$ say

Orow ()+2, 0 say [ A year and coal type must be specilied: ]

CYEAR-1987

CTYPE=3 
Qrow $(1+2,0$ say [

[9999]:

RANGE 1980,1988

Grow (1)+2, 0 say [

GET CIYPE PICTURS

READ

SELFCT 1

OSE VOLOMES1 INDEX $\mathrm{F}_{2}$

MARKERESTR (CTYPE, 1, 0) +STR (CYEAR, 4, 0)

SEEK MARRTR

* * NOTE, Thers ARE FORTY ONE IMPORTERs OR REGIONS IN tHE MATRIX

SET SATETY OFF

COPY NEXT 44 TO F2.WKS MRS

SET SATETY ON

* * ShITCH INTO IOTOS TO PICKOP F2. Whs FROA F2. WKI

crear

RUN CORY AUTO123.F2 AUTO123. MRI >NUL

RESTORE FROM CONEIG ADDITIVE

newdrive-SUBSTR (IOTUS, 1, 2)

RON ENEWDRIVS

newdirect $=[C D]+10 t u s$

RON Enewdirect

RUN 123

OLDDRIVS-SUESTR (IICSD, 1, 2)

RUN COLDDRIVE

CDLOC-[CD ]+IICSD

RON ECDIOC

RETURN

F3.PRG

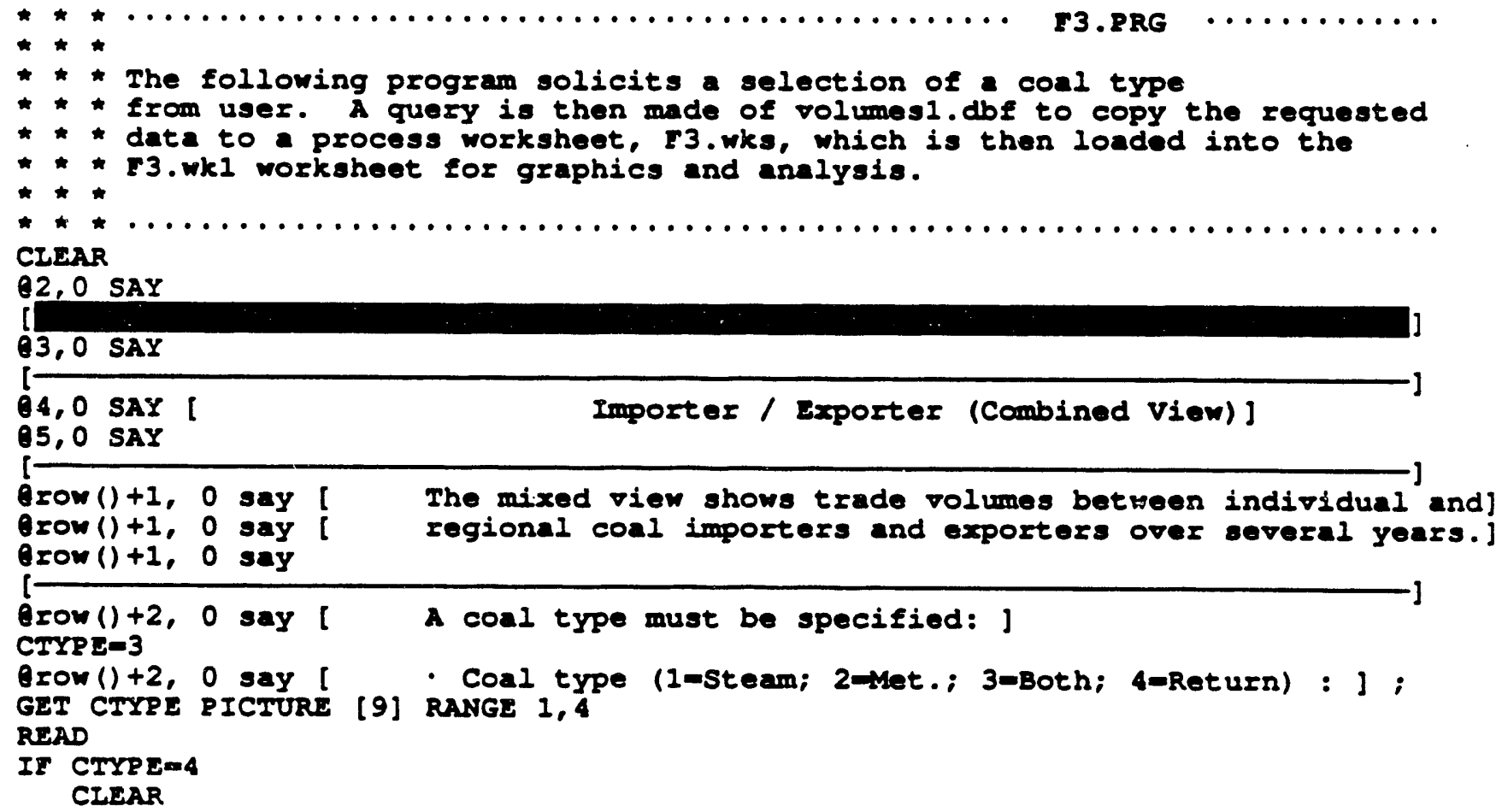




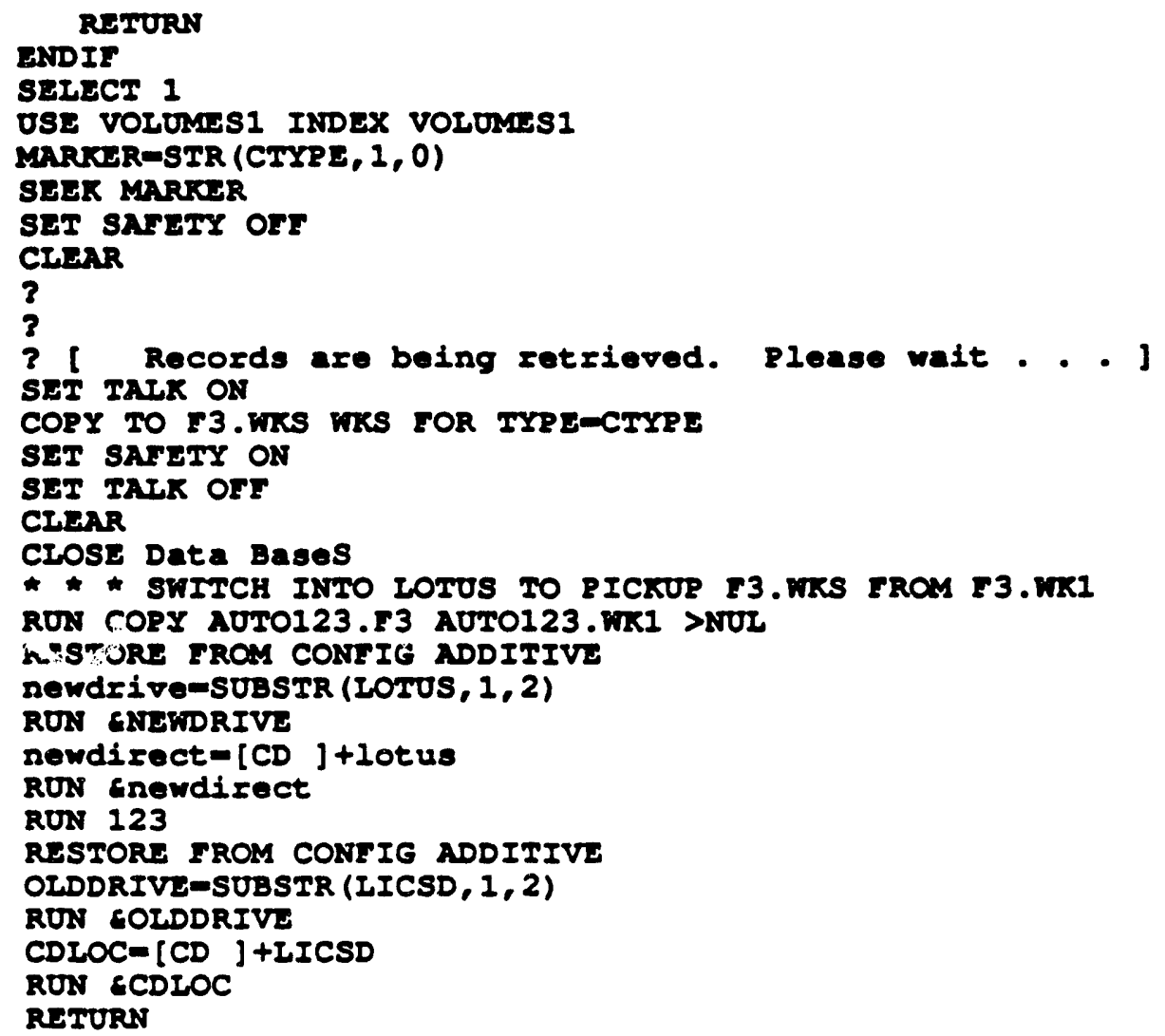




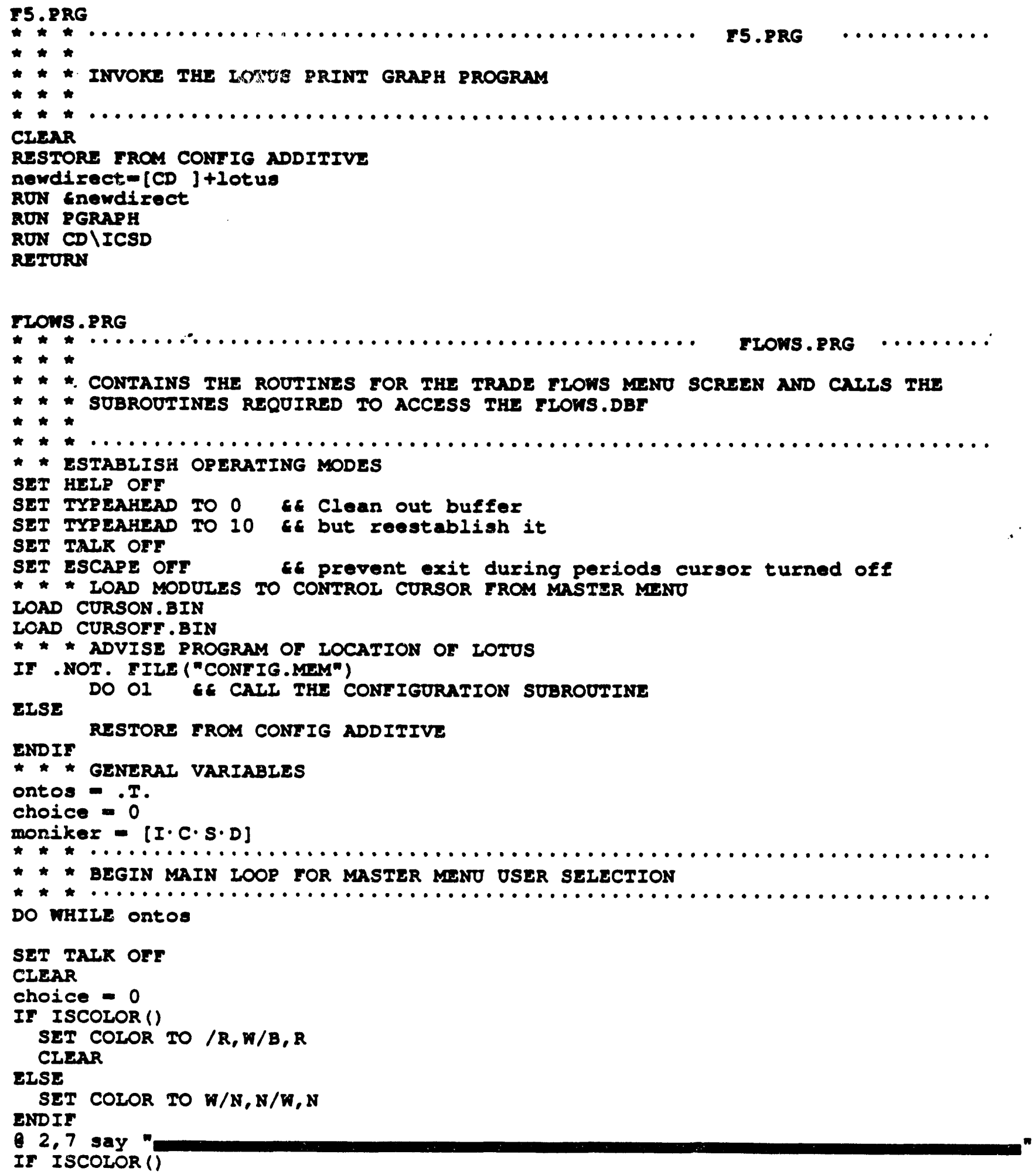




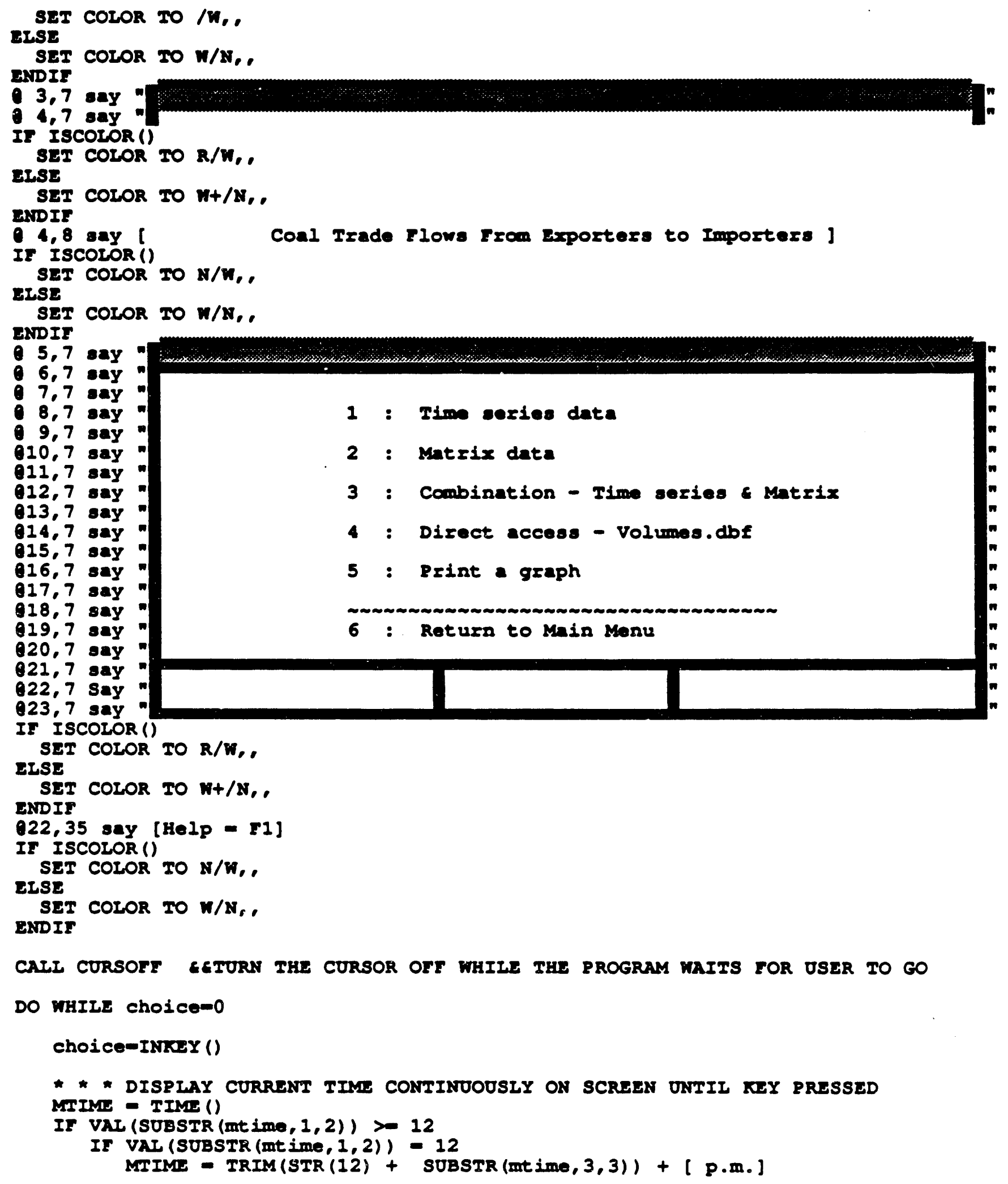




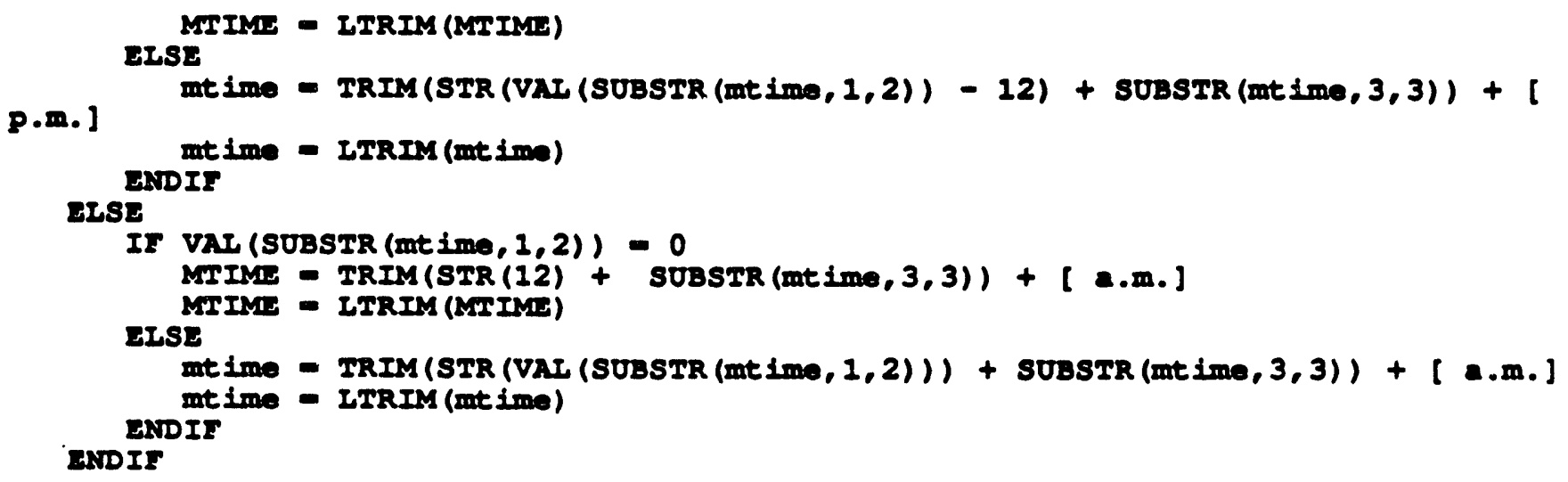

CASE CHR (ChOice) \$ [3] 
IF VAI (SUBSTR (mt ime, 1, 2)) $=0$

MTIML - TRIM(STR (12) + SUBSTR (mime,3,3)) + [a.m.]

MTIME - ITRIM (MTIME)

ELSE

mt ime - TRIM (STR (VAL (SOBSTR (mt Ime, 1, 2))) + SUBSTR (mt Ime, 3, 3)) + [a.m.]

mtime - ITRIM (mtime) ENDIF

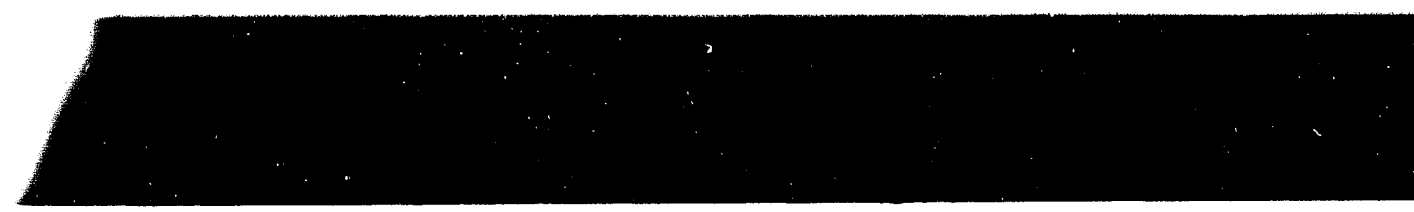

ICSD Program Source Code

DO F3

CAsE CHR (ChOiCo) \& [4]

DO I4 $^{4}$

CASE CHR (ChOice) \& [5]

DO $\mathbf{F 5}$

CASE CHR (choice) \$ [6]

CLEAR

ROTURN

OTHERHISE

message-[Invalid • DO Try again]

DO ERRMESS MITH moniker, message

IOOP

ENDCASE

ENDDO

RETURN

HELP . PRG

PARAMETERS mORiker, help1, help2, help3, help4, holp5, holp6, help7, help8

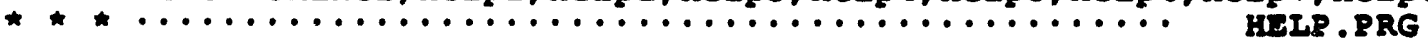

$\star * *$

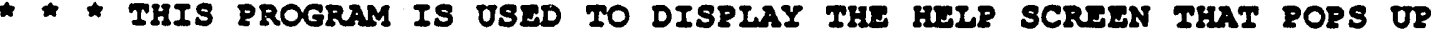

* * over the meno scremes.

* * Iatabliar

eoloring

ISCOLOR ()

SET COLOR TO $N / H, H / B, N$

ELSE

SET COLOR TO $N / N, N / N, N$

ENDIF

holder - IWN (helpl) +2

IF bolder $>65$

ENDIF

helpl-SUBSTR (help1, 1, 59)

center-ROUND ( ( (80-holder $) / 2), 0)$

DO CASE

CASE holder >-5. AND. holder $<-25$

width -6

heigth -5

CASE holder $>-26$. AND. holder $<-45$

width $=5$

heigth $=5$

CASE holder $>=46$. AND. holder $<=67$

width $=4$ 


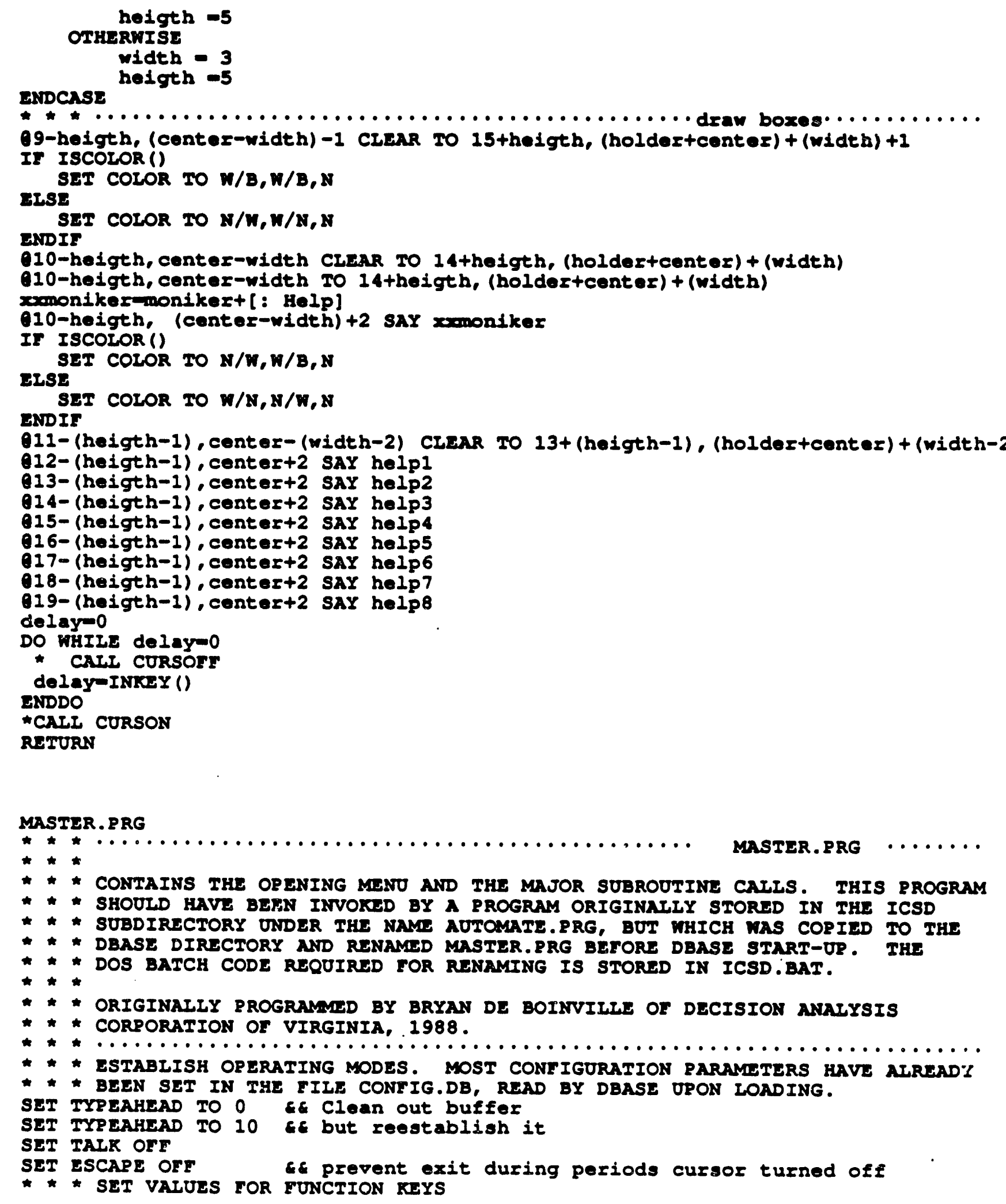




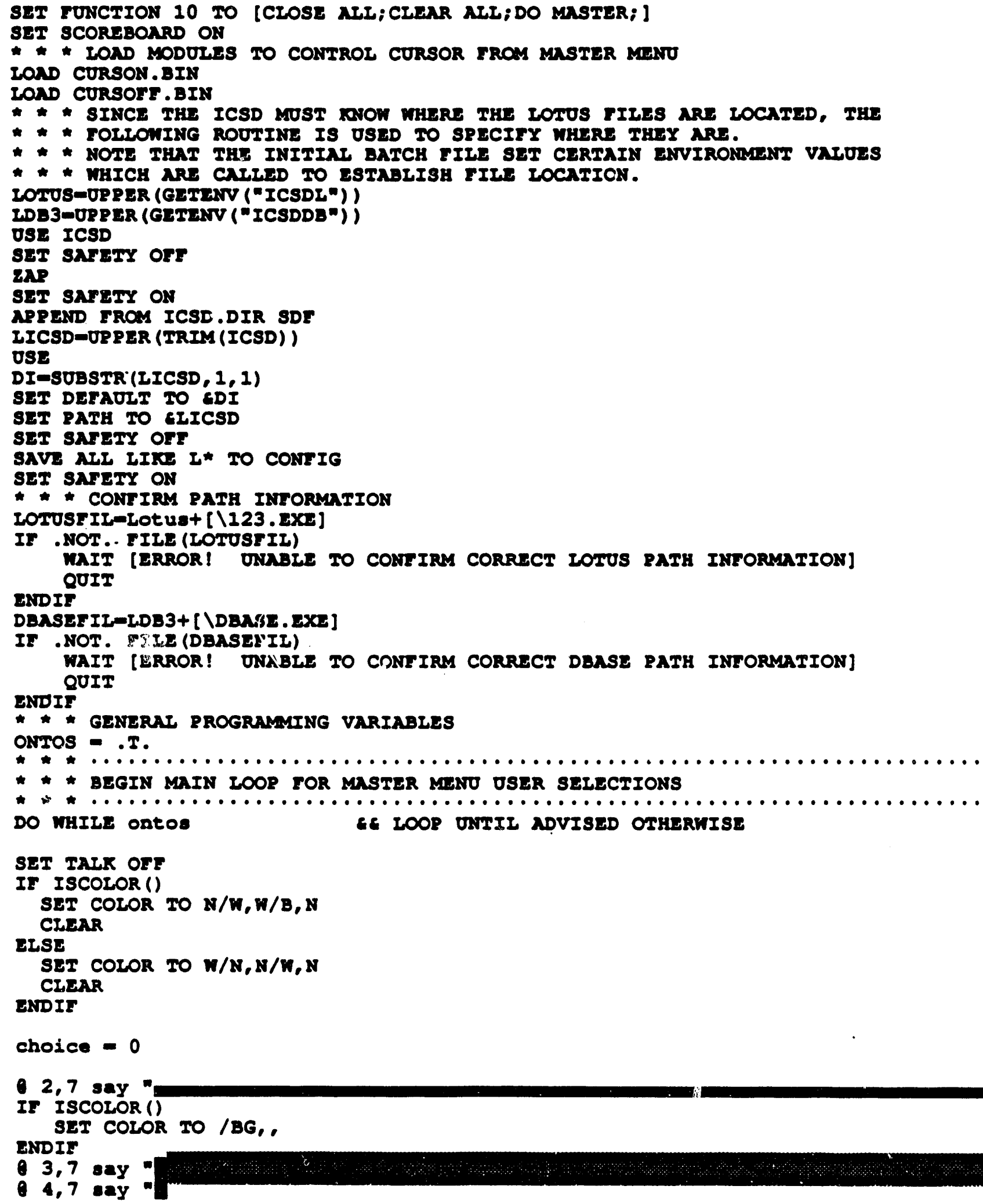


IF ISCOLOR()

SET COLOR TO N/BG,.

EISE

SET COLOR TO $\mathrm{N+} / \mathrm{N}$, ANDIF

- 4,8 say l

IF ISCOLOR()

International Coal statistics Data Base

EISE

SET COLOR TO M/N,,

ENDIF

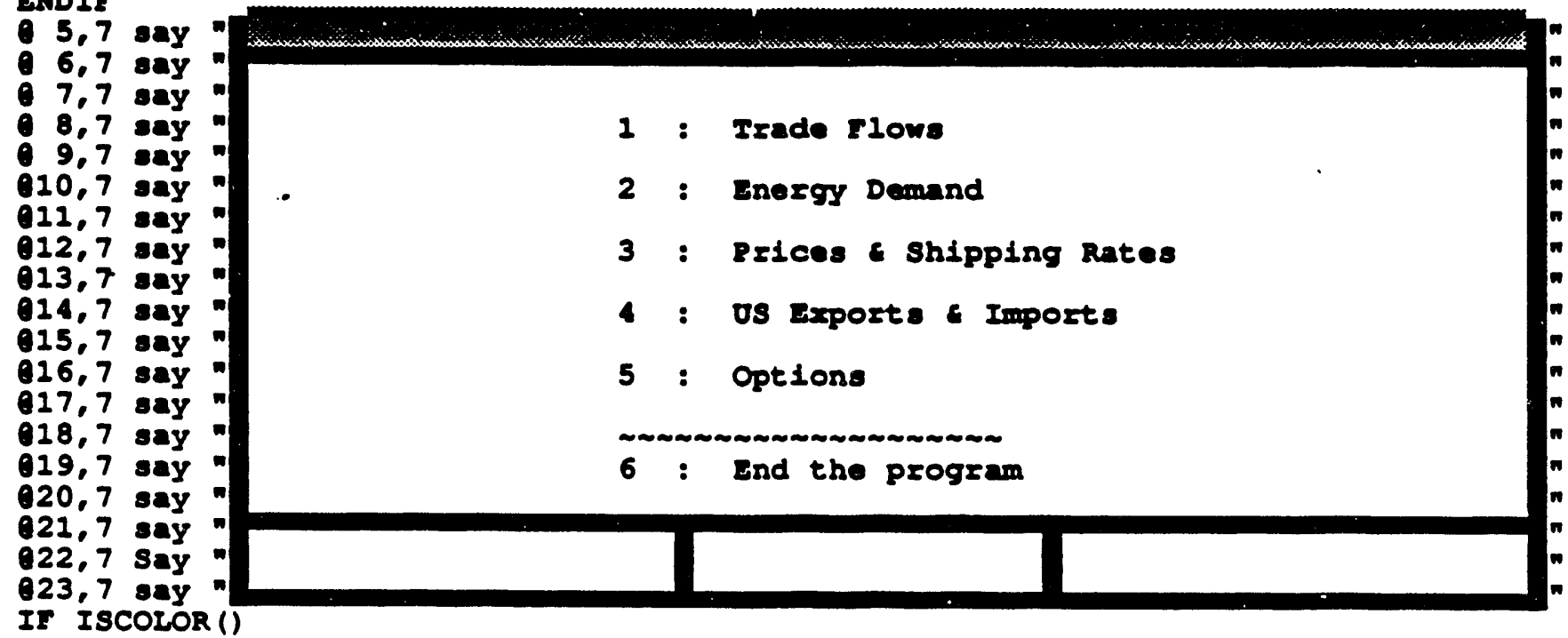

SET COLOR TO R/BG, ,

ELSE

SET COLOR TO $\mathrm{W}+/ \mathrm{N}$, ,

\section{ENDIF}

022,35 say [Help - [1]

IF ISCOLOR()

SET COLOR TO N/BG, ,

EISE

SET COLOR TO $M / \mathrm{N}$, ,

ENDIF

CALI CORSOTF GETURN THE CURSOR OFT WHILE THE PROGRAM WAITS FOR OSER TO GO * * MaIT FOR, THEN EVALUATE OSER INPUT

DO WHILE choice-0

choicemabs (INkeY ())

* * DISPIAY CURRENT TIME CONTINOOUSLY ON SCREEN UNTIL REY PRESSED

MTIME - TIME ()

IF VAL (SUBSTR (mtime, 1, 2)) > 12

IF VAL (SUBSTR (mt ime, 1, 2)) -12

MTIML $=\operatorname{TRIM}(\operatorname{STR}(12)+\operatorname{SUBSTR}($ mtime,3,3)) $+[$ p.m.] MIIME - ITRIM (MIIML)

ELSE

P.m.]

mtime - $\operatorname{TRIM}(\operatorname{STR}(\operatorname{VAL}(\operatorname{SUBSTR}(m \mathrm{~m} i m e, 1,2))-12)+\operatorname{SUBSTR}(m t i m e, 3,3))+($ ENDIF

mtime = IIRIM (mtime)

EISE 


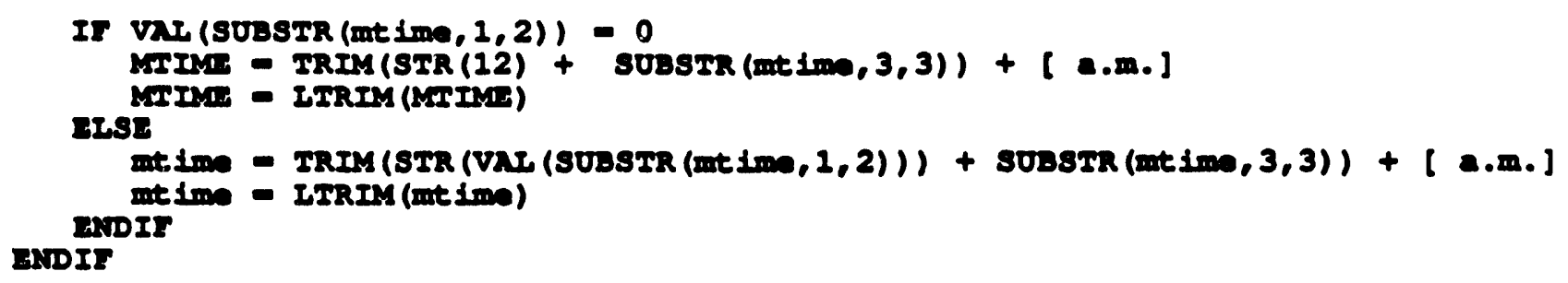

\section{2,16 aay date ()}

022,57 ang antim

022.46 say car (cholee)

INDDO GA END OF IOOP TO GET OSER MENO CHOICE

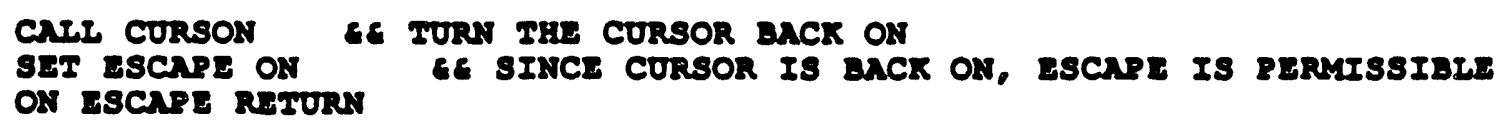




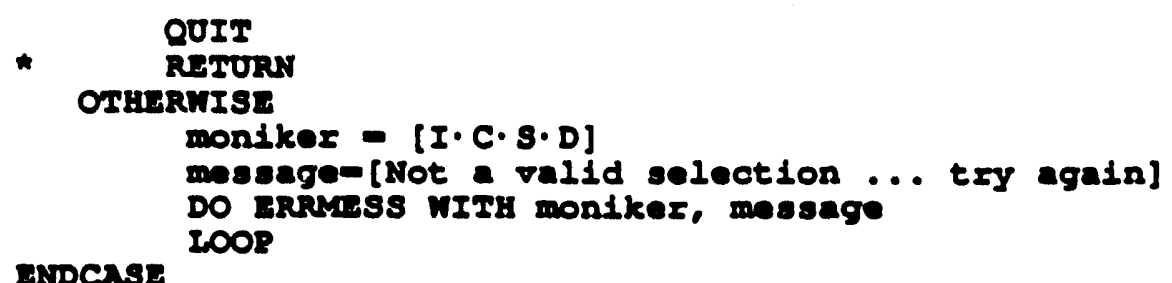

INDDO

RבMUN

ag

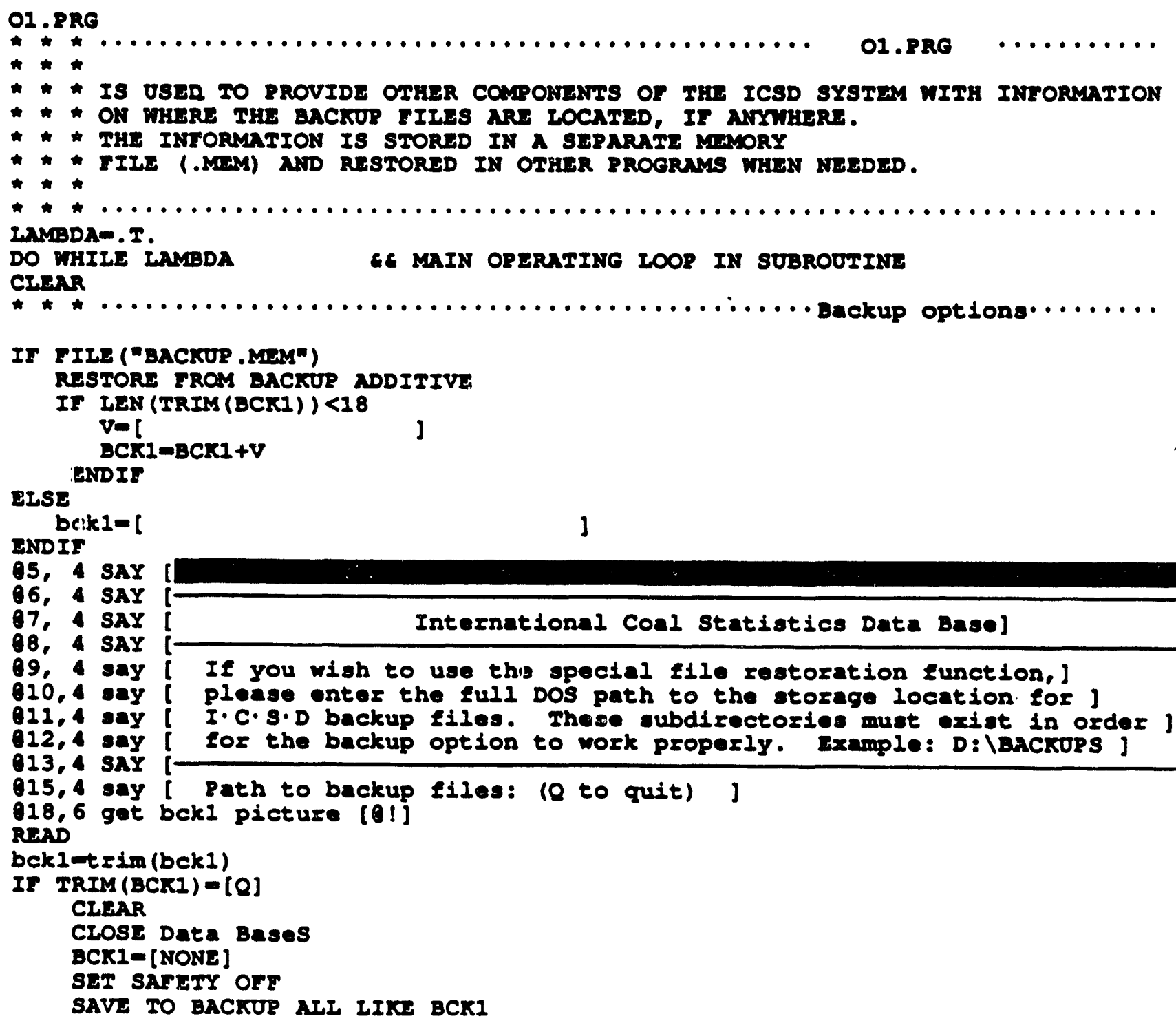




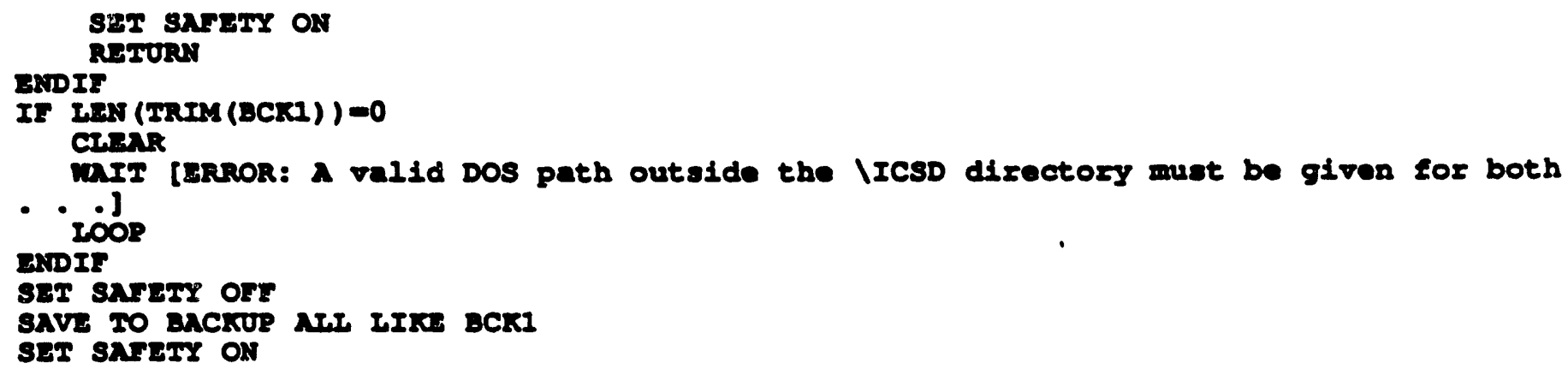

RETORA

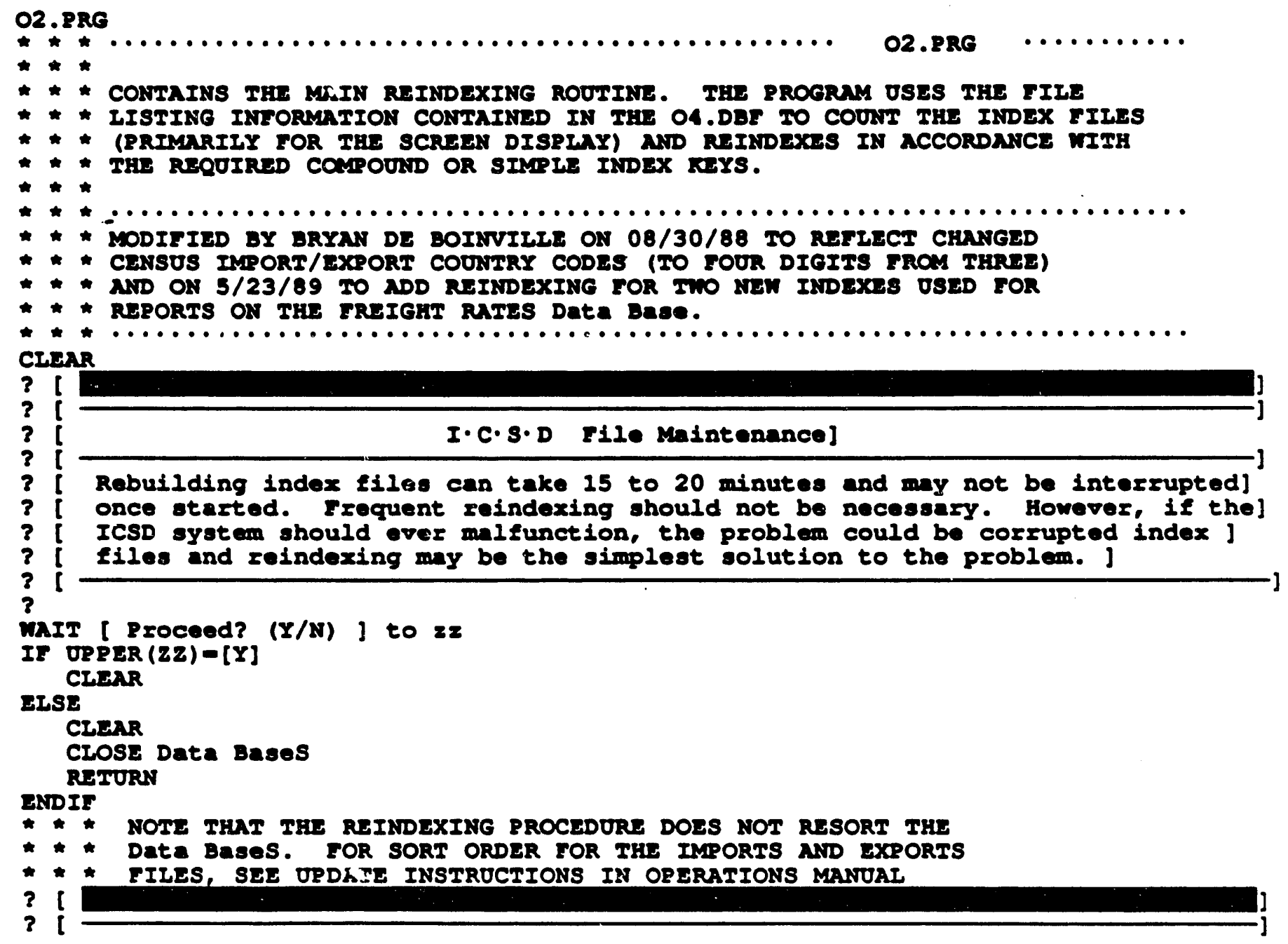




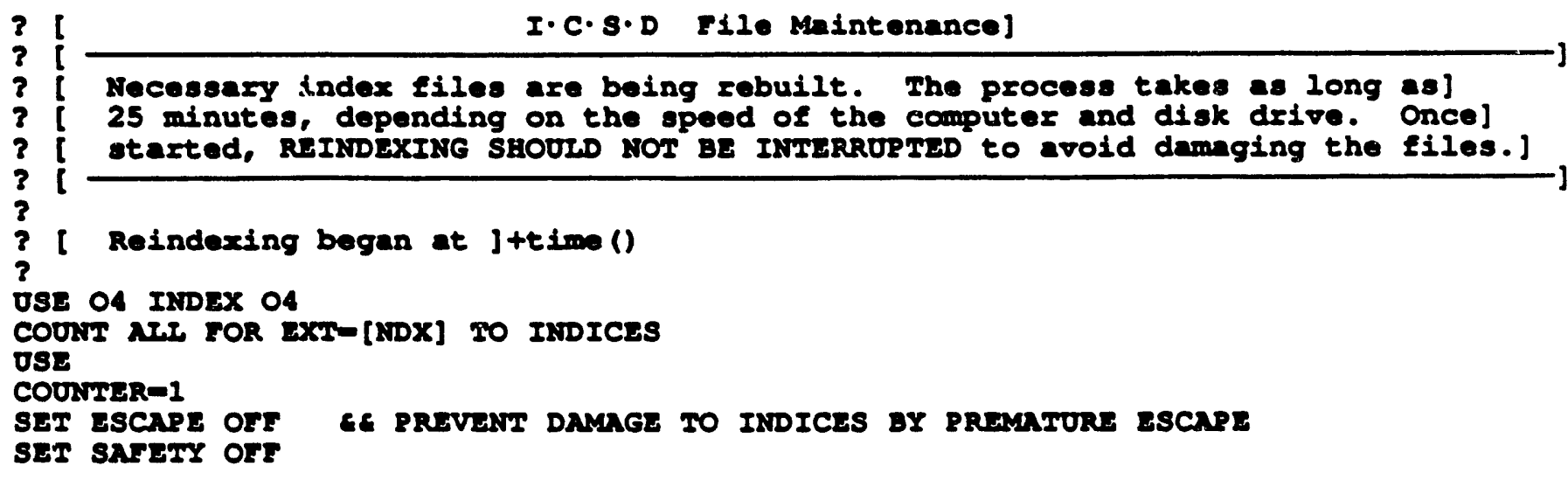

\section{DO WAILE COONTER<MINDICES}

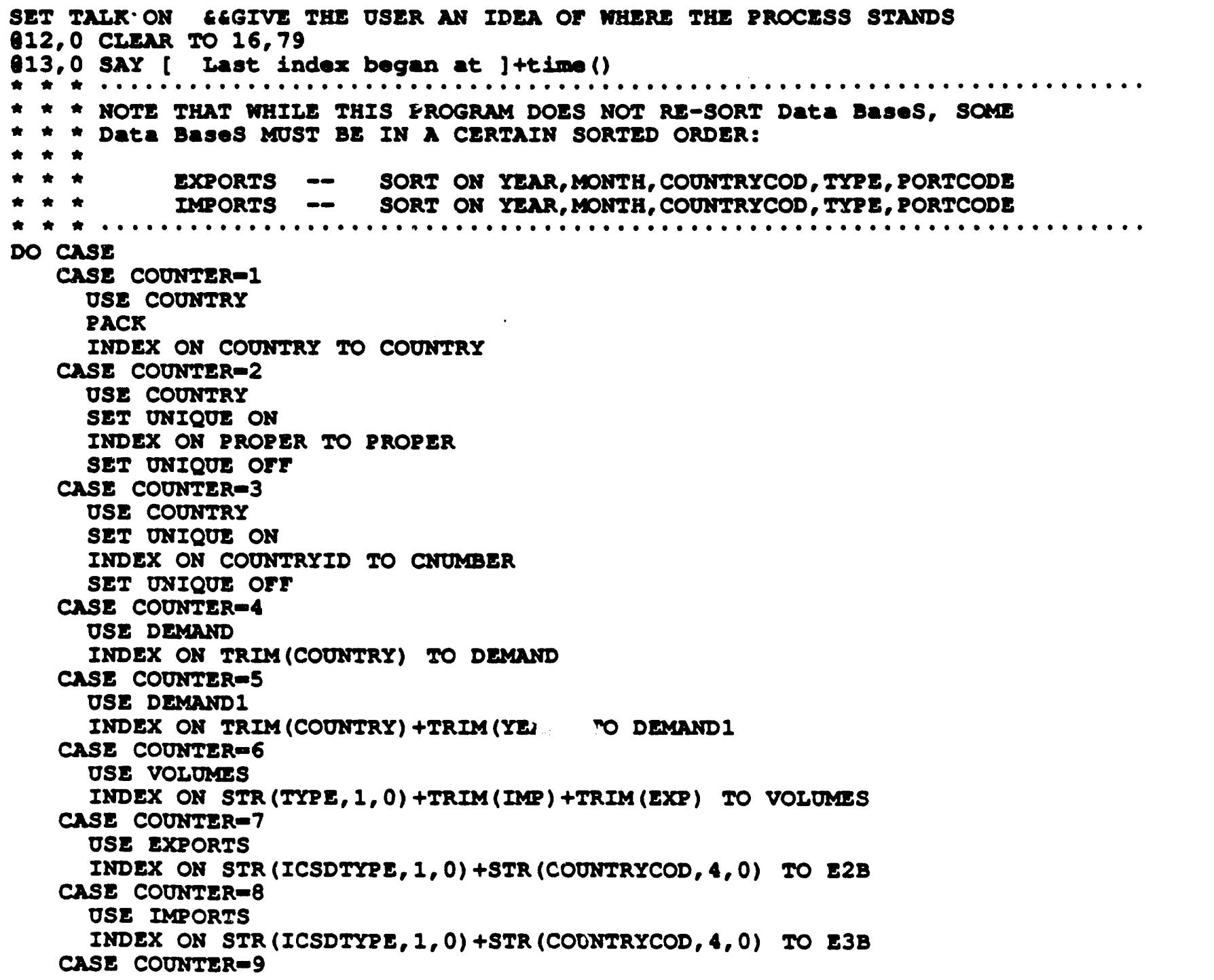


OSE VOLUNDSI

INDEX ON STR (TYPE, 1, 0) +TRIM (IMPORTER) + IRIM (YEAR) TO VOLUMESI

CASE COUNTIER=10

OSE PORTS

INDEX ON RORT TO PORTS

CASE COONTIER-11

OSE PORIS

INDEX OIS IDNOMBER TO RORTYO

CISE COONHER=12

OSE VCOUITRY

INDEX ON EXPORTER TO VCOUNIRY

CASE COUINIER-13

OSE EXPORTS

INDEX ON STR (ICSDTYRE, 1,0) +STR (TEAR, 2,0) TO E2A

CASE COONIER 14

OSE IMPORTS

INDEX ON STR (ICSDTYRE, I, 0) + STR (IRNR, 2, 0) TO E3A

CASE COUNTER 15

USE VOLOMESI

INDEX ON STR (TYRE, 1,0) + TRIM (YEAR) + TRIM (IMPORTER) TO $\mathrm{F} 2$

CASE COONHER 16

OSE PRICES

INDEX ON STR $($ TYPE, 1, 0) +STR $(Y 1,2,0)$ TO RRICES

CASE COONIIER=17

OSE FRIGIGT

INDEX ON $\operatorname{STR}(Y 1,2,0)+\operatorname{STR}(M 1,2,0)$ TO FREIGET

CASE COUNTER-18

OSE 04 INDEX 04

RIINDEX

CASE COUNTER-19

OSE VOLUNES1 INDEX F2

RSINDEX

CASE COUNIIER -20

- SET UNIQUE ON

OSE FRIIGHT

INDEX ON RECOFORIG TO P3A

SET UNIQUE ORF

CASE COUNTER-21

SET UNIQUE ON

OSE FRUIGHT

INDEX ON REGOTDEST TO P3B

SET ONIOUS OFE

CASE ,OONTIR-22

SET UNIQUE ON

USE prices

INDEX ON country TO 22

SET ONIQUE OFF

OTHLRWISE

ENDCASE

EXIT

017,2 SAY [Index ] +STR (COONTER, 2,0)+[ of ]+STR (INDICES, 2, 0) +[ completed]

SET TALK OEF

COUNTER-COUNTER+1

ENDDO

Crose Data Bases

Q12,0 ciear to 16,79

Q13,0 SAY [ Reindexing was completed at ]+time() 
SET TAIK ORF

COUIISR2-1

DO MHILE COONTER $2<800$

COONTIER2-COUNTER2+1

ANDDO

IF COONTER

3 [ Only the original ICSD indices have been reindexed. It appenrs]

$?$ [ that there are user-created indices that may have to be reindexed ] ENDIF

WAIT [ manually. Do this Erom the dBase dot prompt (Mise. options) . . ]

SET SATETY ON

SET ESCNPE ON

RETURA

$\wedge \mathbf{2}$

03.PRG

$\rightarrow *$

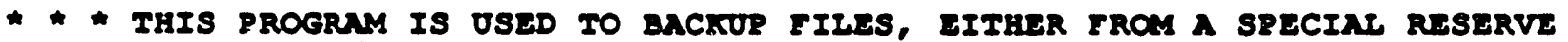

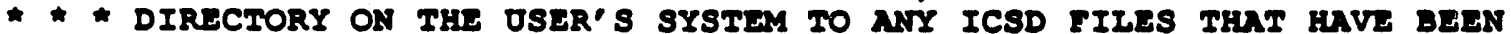

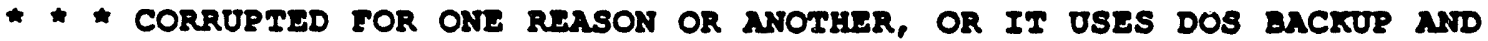

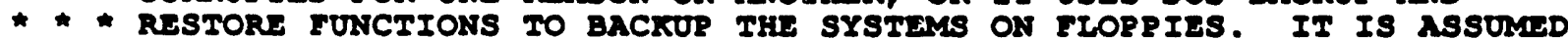

* * THAT FLOPPY DISK DRIVI A: MIII BE USED FOR THIS PROCESS. IF FOR

* * SOME REASON DRIV A: ShOULD NOT BE OSED, THE OSER MOST EDIT THIS

* * progray to surply the correct drivs.

$\star \omega$

$\pitchfork *$

ontog=.T.

t--

DO MAILE ontos

Q3,0 SAY

[

Q4,0 SAY

[1,

Q5, 0 SAY

Q6,0 SAY

[ 7,0 say [ File backup either (a) copies key files from their present location]

0 9,0 say [ files in the IICSD directory; or (b) usus the Dos backup prograra to copy]

010,0 say ( key files to Eloppy disks loadec into drive $A$. The present I

011,0 say [ path to the storage directory for option (a) is: ]

IF FIIS ("BACKOP . MMM")

ELSE

RESTORE FROM BACKUP ADDITIVE

WAIT [Necessary configuration information is missing. Please provide it. . .] DO Config

RESTORS FROM BACKUR ADDITIVE

IOOP

ENDIF

Q13,0 say [ Storage directory for original fileso ]+bckI

Q14,0 aay [ ]

Q16,0 sAY [ If this is not the right storage location for option (a), reconfigure]

Q17,0 say [ the system before running this program again. Option (b) requires at ] 
018,0 sAY [ least 14 floppies (formatted $360 \mathrm{~K}$, less if $1.2 \mathrm{mag}$ diskettes are used) . ]

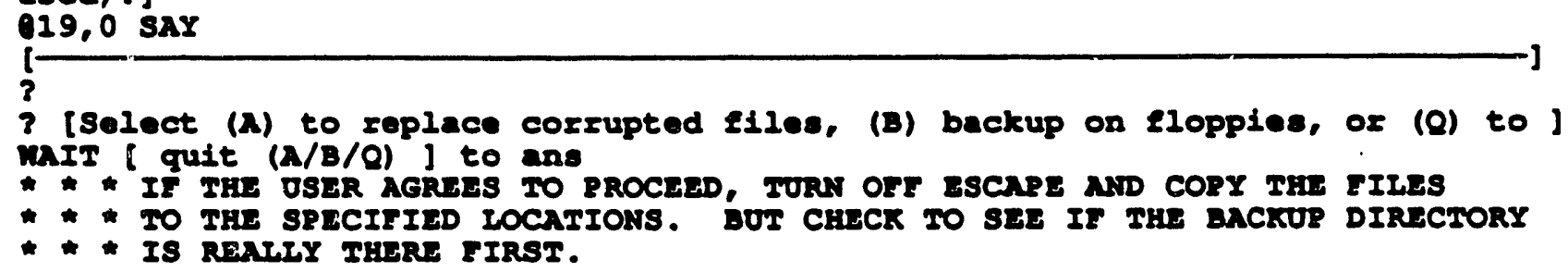




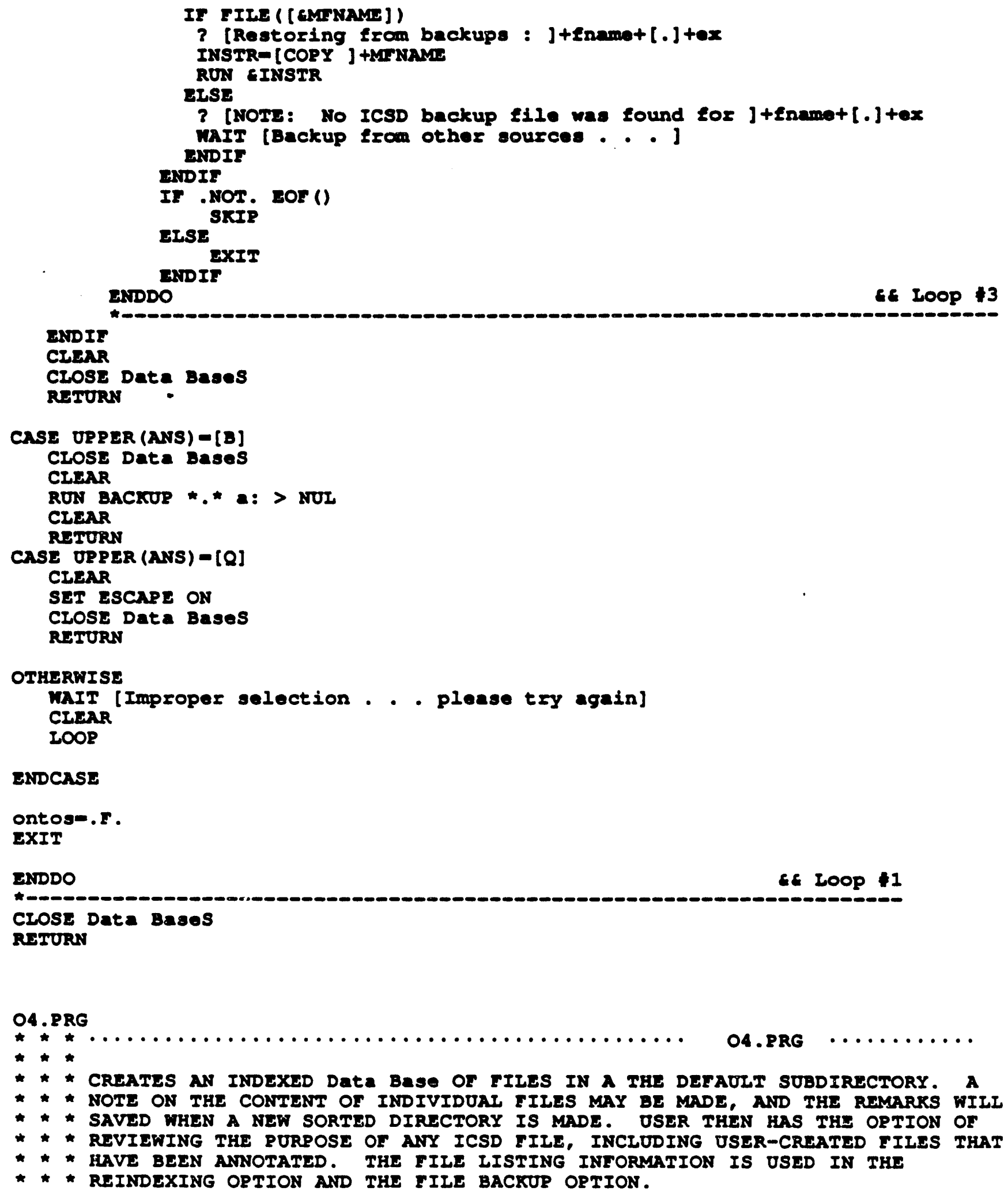




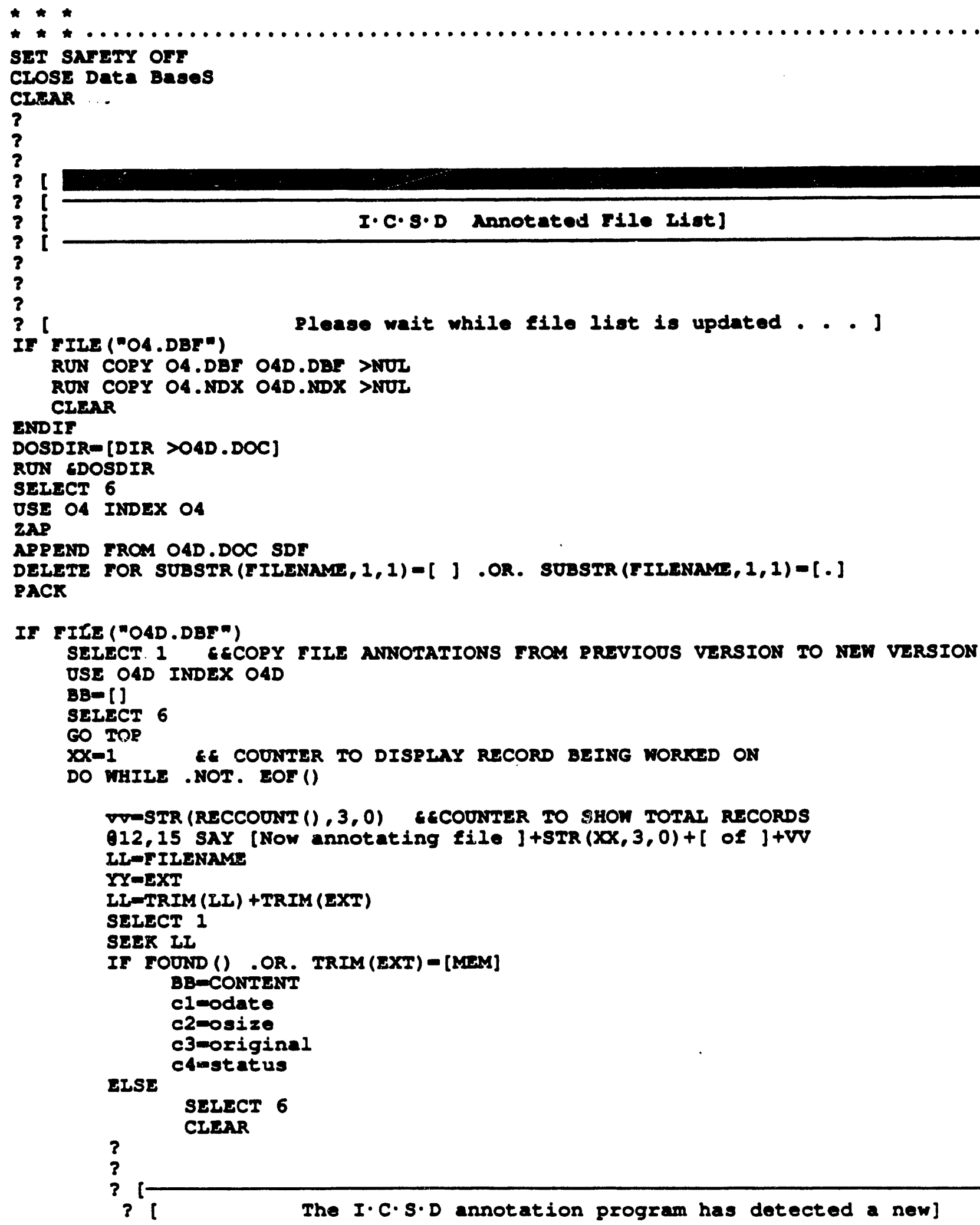


ICSD Program source Code

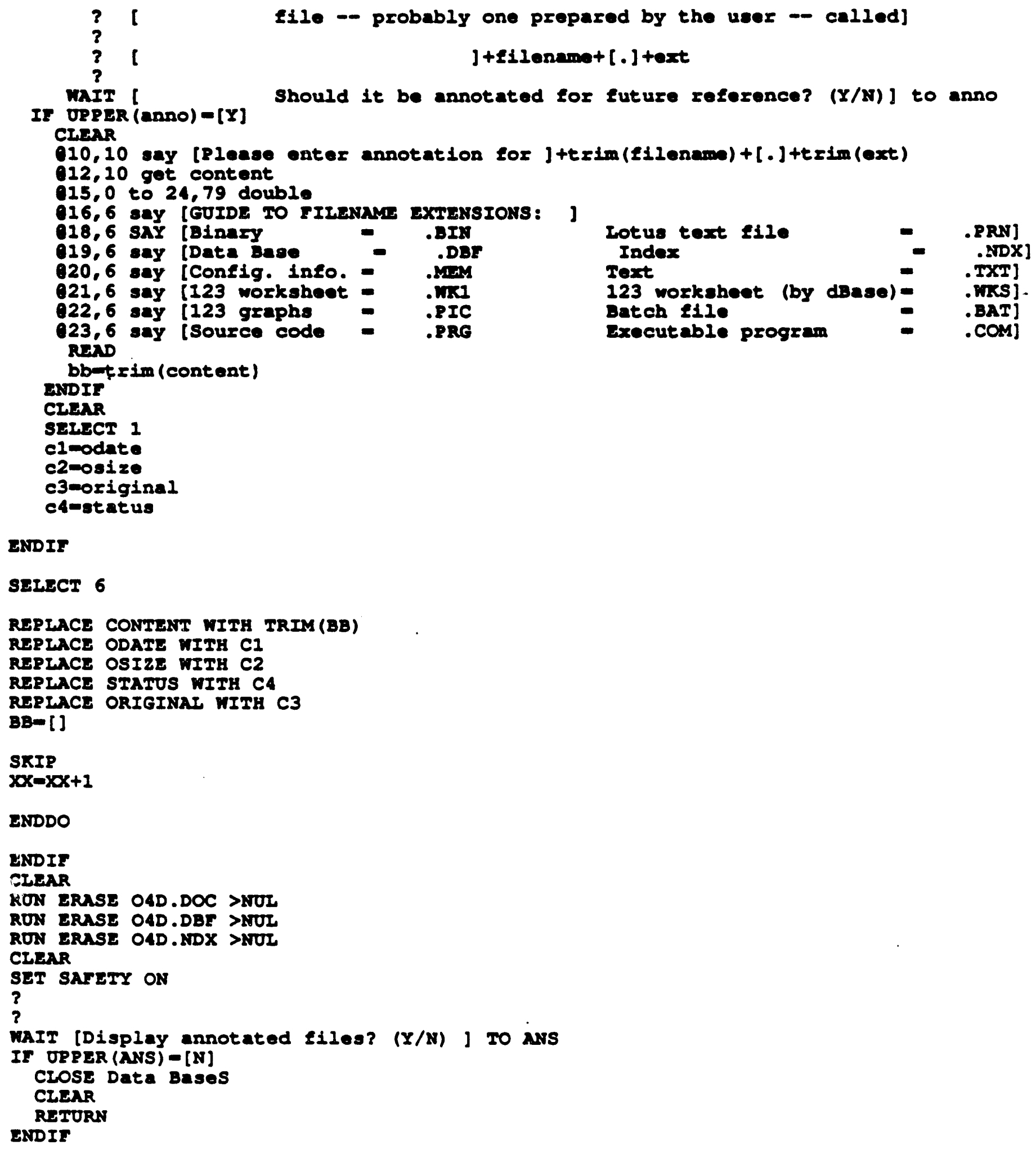




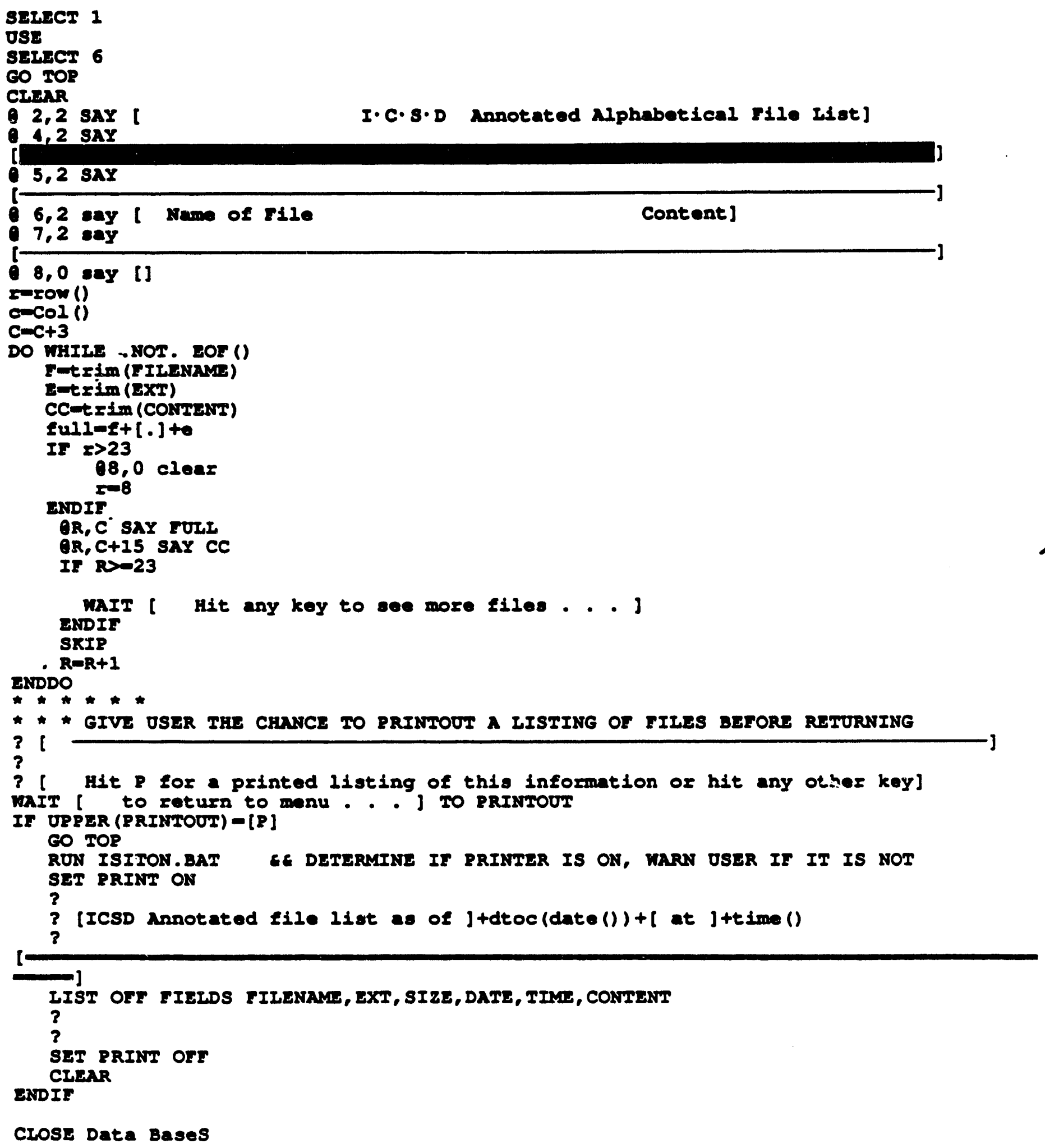




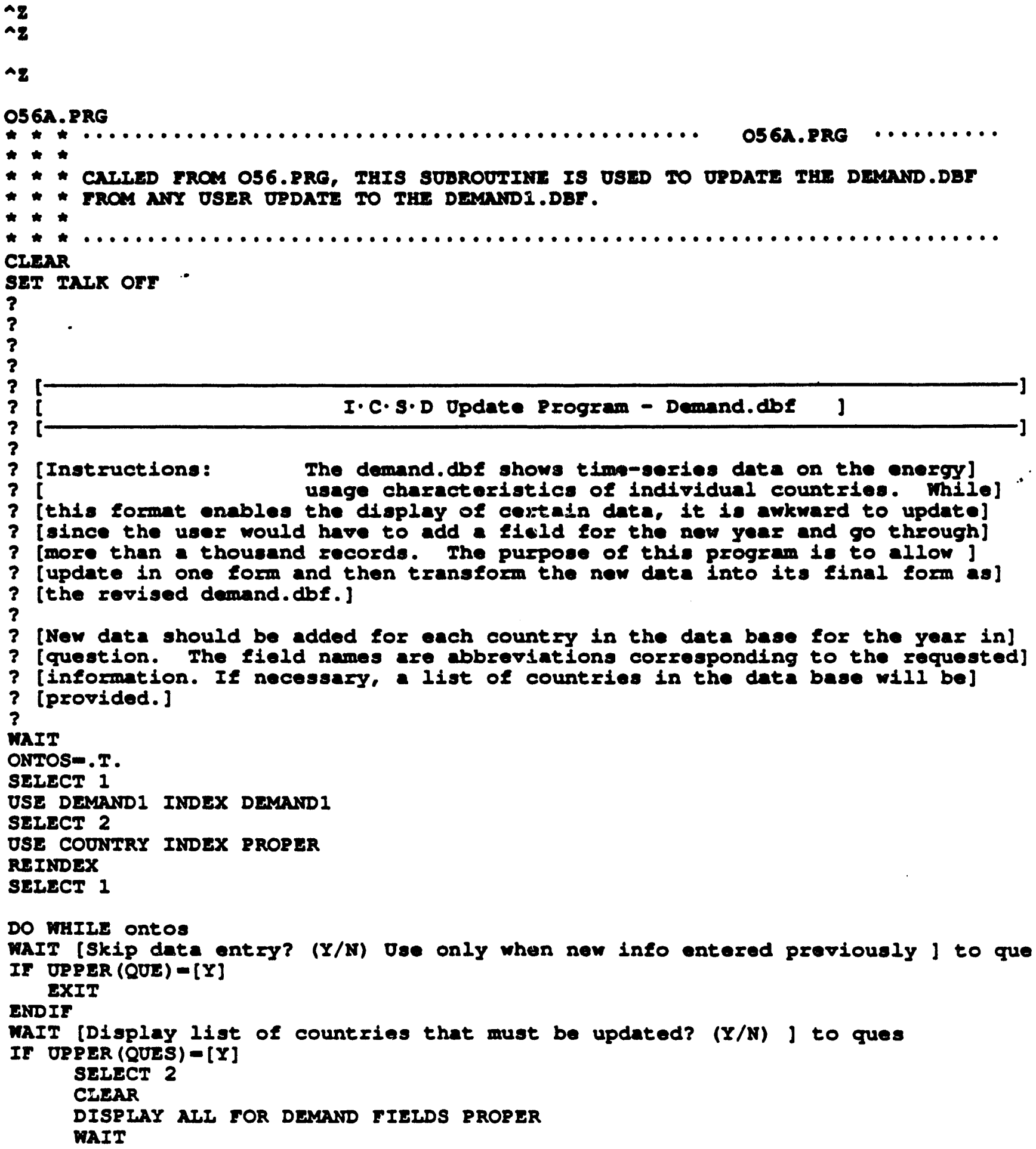


ENDIF

SELECT 1

CLEAR

APPEND BIANKK

Qrow (), 1 any [Country :

] got country

Oron () +1 , 1 any (Year

OrON() $+1,1$ aAY (PRIMNRY GNERGY CONSUNPTION

Erow () +1, I aay ( (Quadrillion Dtu)

exon ()+1, 1 any [-

$\operatorname{erow}(1+1,1$ any

(1, 1 ang

erow ()$+1,1$ any

$\operatorname{erom}(1)+1,1$ gay

[Retroleum

liatural Gas

] got REC OII

get $P=C$ NG

get $P \Sigma C-C$

get PEC-NOC

erow ( $+1,1$ say [Aydro

get $\mathrm{PEC}-\mathrm{H}$

Oxow () $+1,1$ say lother

get pec-ors

Oxow ( $)+1,1$ say []

Orow ()+1, 1 say [Total-

get PEC TOT

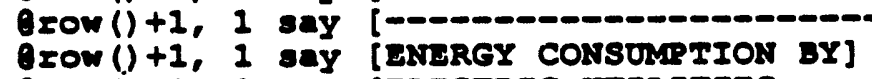

Oxow () +1 , I any [EIECTRIC UTIIITIES ]

Erow () $+1,1$ any [(Quadrillion Btu)]

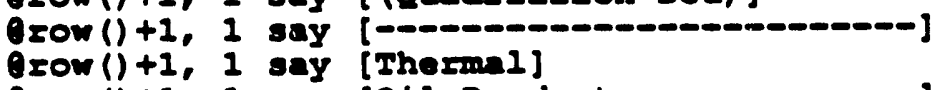

Erow ()$+1,1$ say [Oil Products

erow () $+1,1$ aay (Natural gas

erow () +1 , 1 say (Coal

get yoar

$\operatorname{erow}(1)+1,1$ say []

Erow ()+1, 1 say [subtotal-]

READ SAVS

CIEAR

Erow () $+1,1$ ay (Nuclear

erow () $+1,1$ say [Hydro

Orow $(1)+1,1$ say lother

get

get $\mathrm{soC- \textrm {H }}$

get EOC_OIL

got WOC_NG

] got roc-C

Orow () +1 , 1 say (Total-

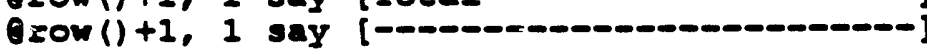

erow ()$+1,1$ say [INDUSTRIAI ENGRGY CONSUMR.]

Orow () +1 , 1 say ( (Quadrillion Btu)

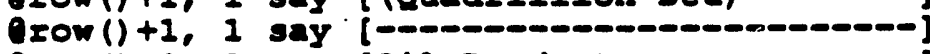

Grow ()$+1,1$ any l011 Products

Orow () +1, 1 say [Natural gas

Srow () +1, I say [Coal

erow ()$+1$, I say [rlectricity

erow () $+1,1$ say lother

erow () $+1,1$ say (Total=

$\operatorname{\theta row}()+1,1$ say

erow (1) +1 , 1 gay

$\operatorname{erow}(1)+1$, 1 say

erow ()$+1,1$ say

Orow ()$+1,1$ say

erow ()$+1$, 1 say

erow () $+1,1$ say

trornI cons conson.

(Millions of Metric Tons)

[Electric utilities

[Hard Coal

READ SAVS

CLEAR

Orow () +1, 1 say (Subtotal-

eron() +1 , 1 say (Industry

erow () $+1,1$ say [Iron and steel

orow () +1 , 1 say lother

j get EOC_OTH

get EDC_IOT

j

get IEC OII

get IEC NG

get IEC-C

got IEC-E

get IEC-OTH

get IEC_IOT

j get ICC_EUC

I get ICC_EU.

] get TCC_EOS

j get ICC_IM

(




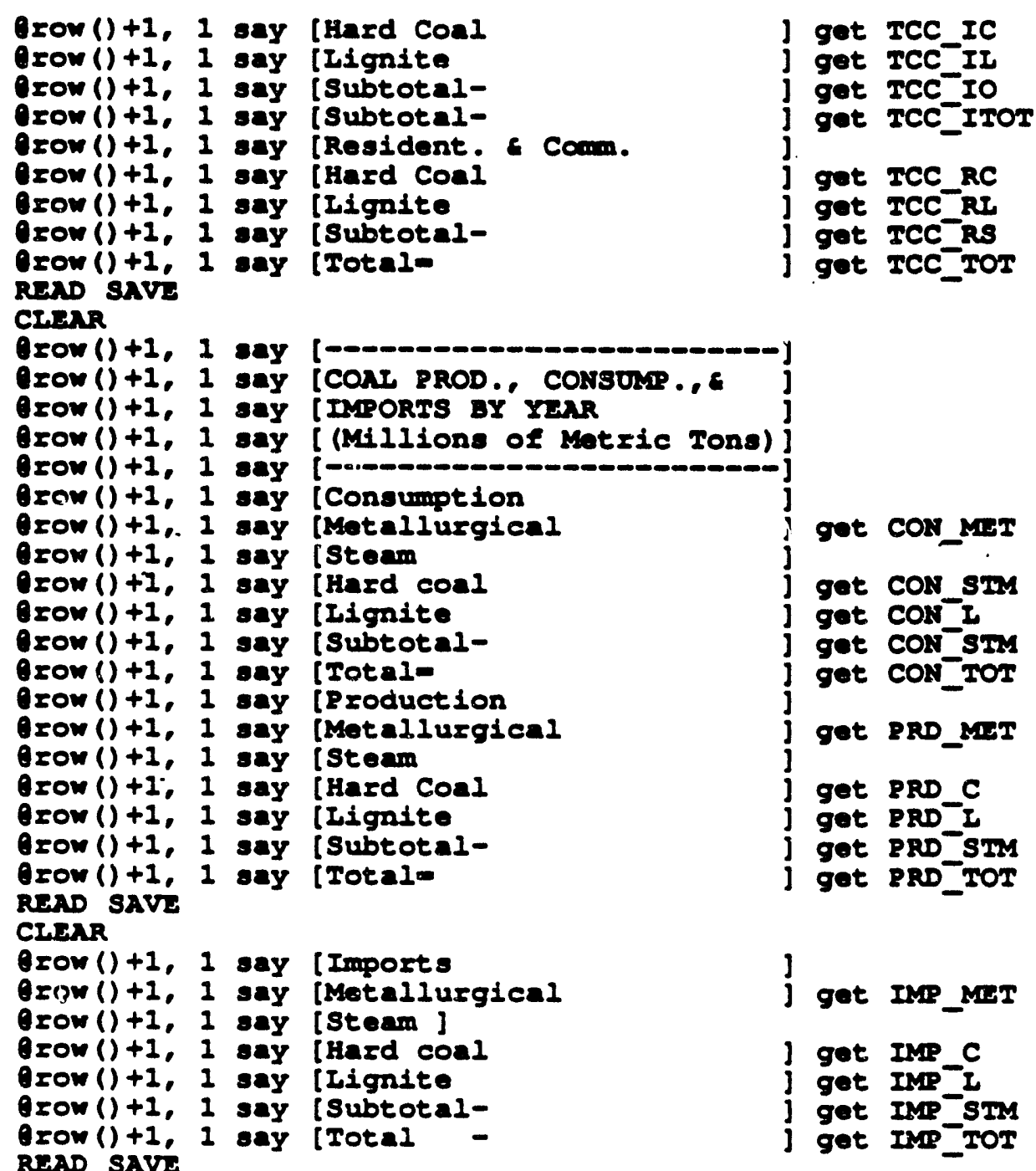
DAV

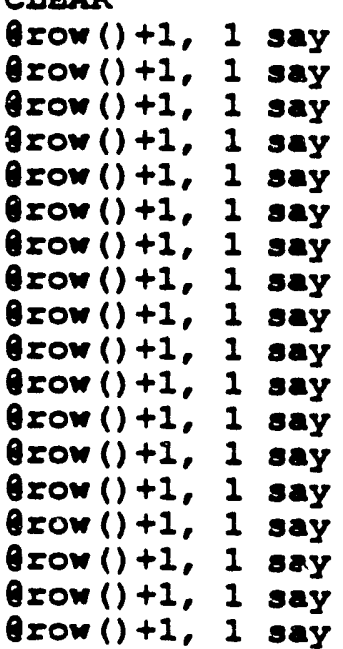

[Electricity

Capacity (GW) by Fuel Type ConI

Oil

Gas

Nuclear

Hydro/Geo

otber

TOTAL

Generation (TWM) by ruel Conl

Oil

Gas

Nuclear

Hydro/Geo

other

TOTAI

get ECAP_COAI
get ECAP_OII
get ECAP_GAS
get ECAP_NOC
get ECAP_HYDRO
get ECAP_OTHER
get ECAP_TOTAI
get EGEN_COAI
get EGEN_OIL
get EGEN_GAS
get EGEN_NOC
get EGEN_HYDRO
get EGEN_OTHER
get EGEN_TOTAI




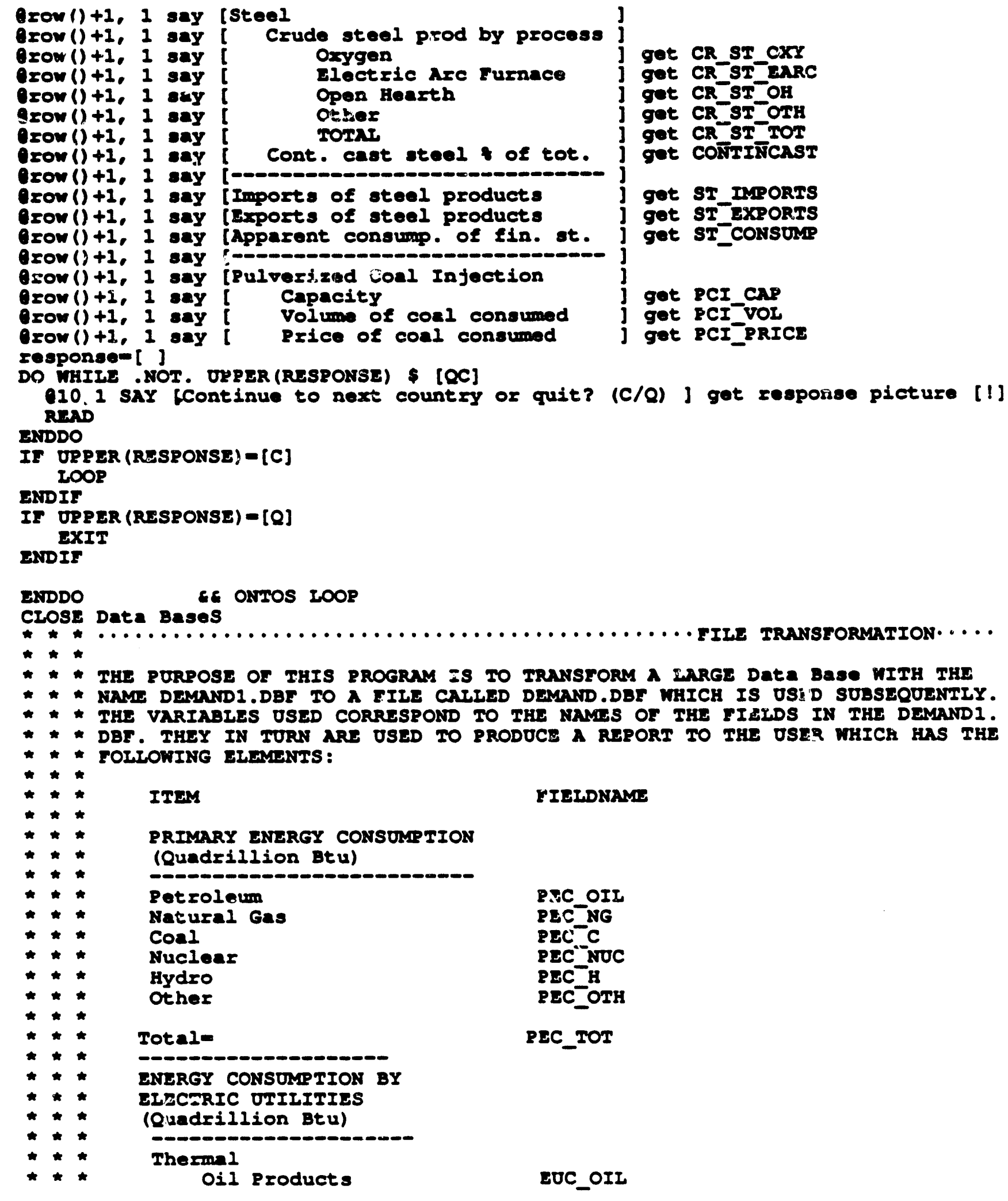


Natural gas

Conl

Subtotal-

Nuclear

Hydro

Other

Total-

INDOSTRIX MVRGY cONSUM. (Quadrillion Btu)

Oil Product:

Hatural gas

Conl

rectricity

Othex

Tota.1-

TOTAI COAL CONSONR.

(Millions of Metric Tons)

slectric utilities

Hard Coal

Iigsite

subtotal-

Industry

Iron and steel

Other

Hard ConI

Iignite

Subtotal-

subtotal-

Resident. Comm.

Hard Cos 1

Iignite

subtotal-

Tota1-

--m--0-m-

COAT PROD.. CONSOMP., E

IMPURTS BY YEAR

(Mililions of Metric Tons)

Consumption

Metallurgical

Steam

Hard coal

Iignite

subtota1-
BOC NG

soc-C

EOC NOC

EOC

atc-ore:

EOC IOI

IEC OII

IEC 11

IsC C

I.C

IEC OTH

IEC TOT

TCC $\mathrm{IOC}$

TCC_EUL

ICC_EOS

ICC_IM

ICC IC

ICC-II

ICC_IO

TCC_ITOI

TCC RC

TCC_R

ICC_Rs

ICC_IOI

CON_MET

CON STM

cONII

CON_SIM 


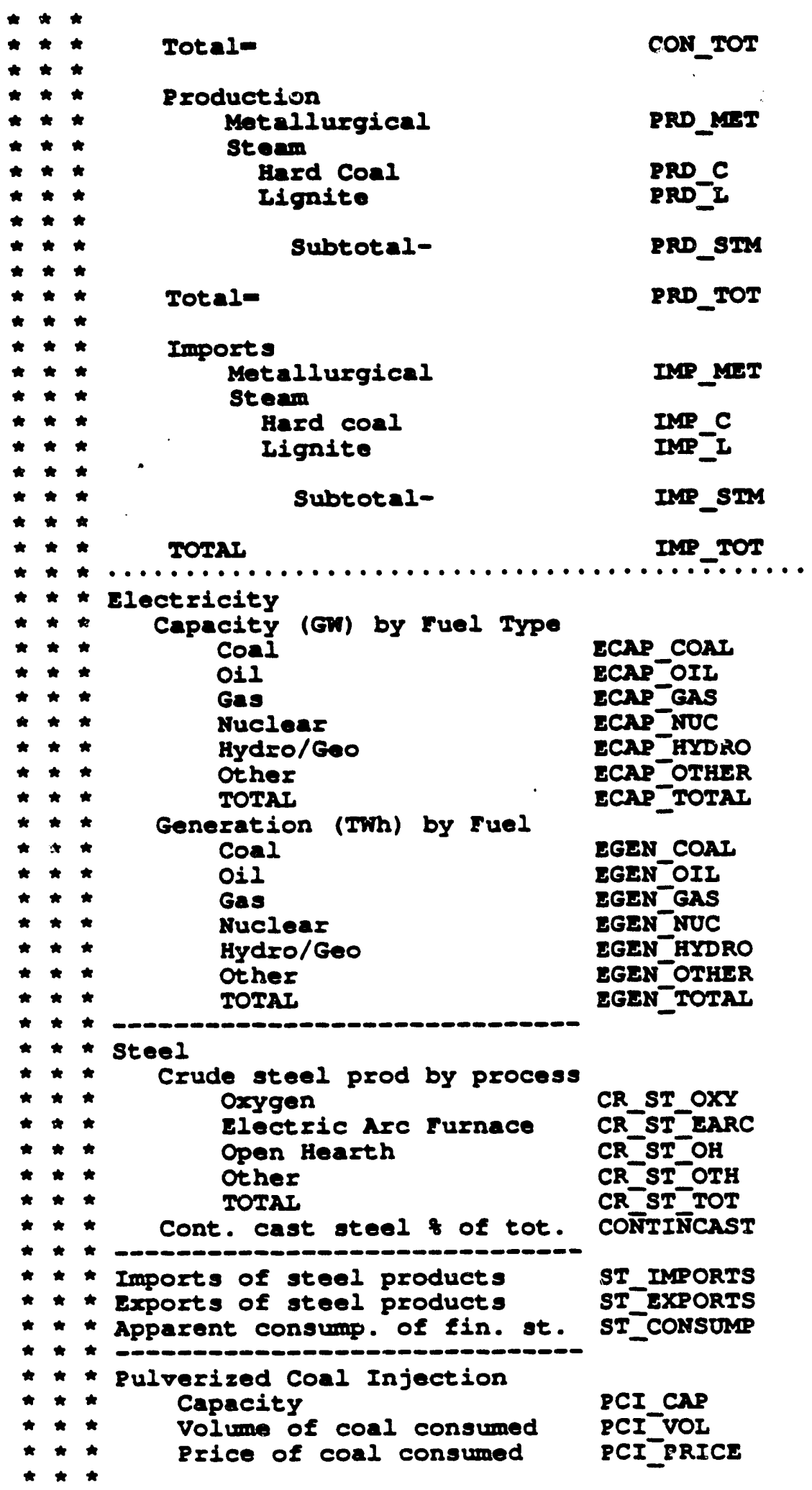




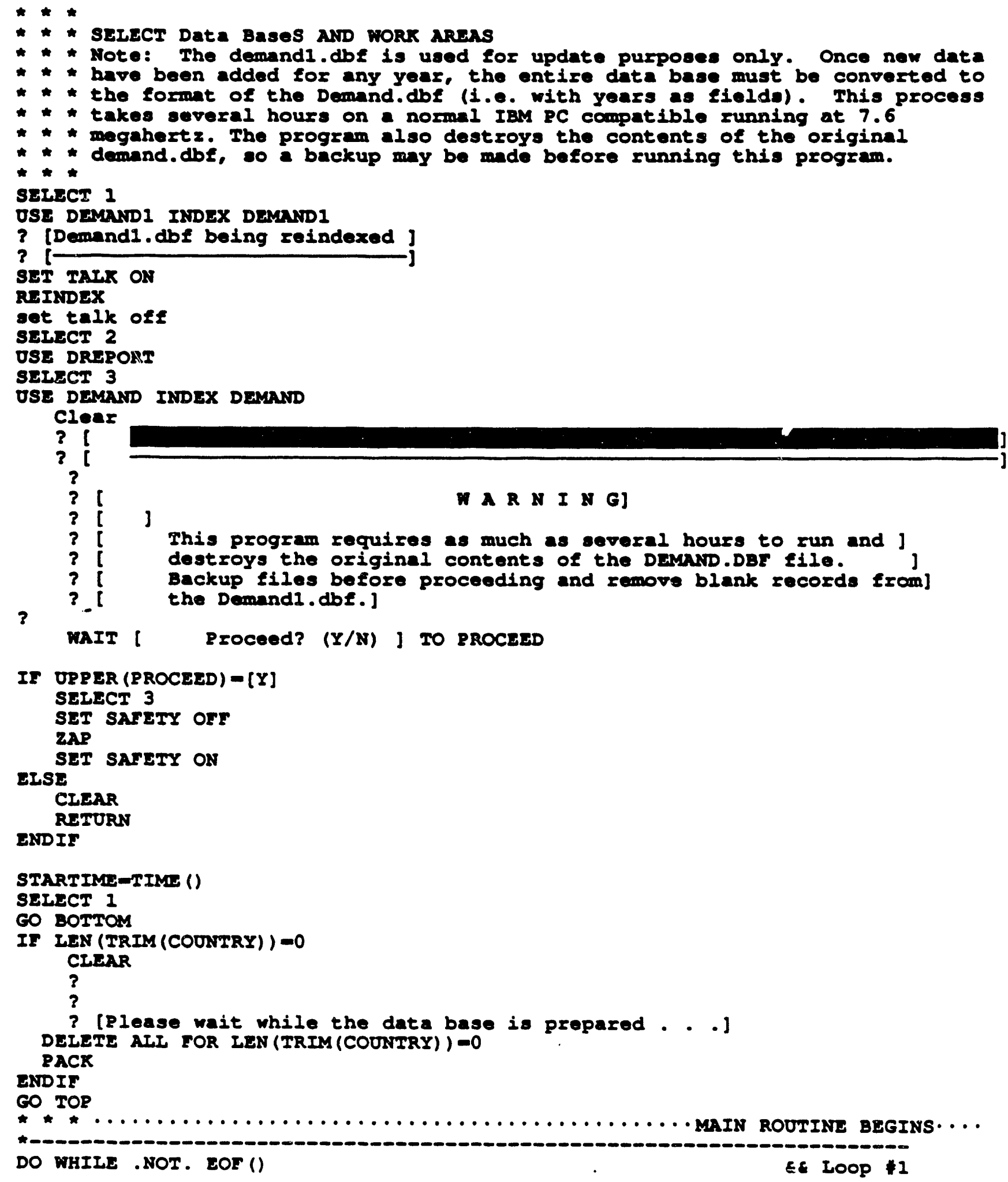




\section{CLEAR}

SEIECT 1

ICOONIRY COUNIRY

3 [Now working on: ]+COONIRY

$?$

3 [The program atarted at ]+startime

nowtime-time ()

$?$ [Work on the current country began at J fnowtime

$\star \star *$

* * houygars hotdos the stomber of rjcords (ONe for mach year) in the

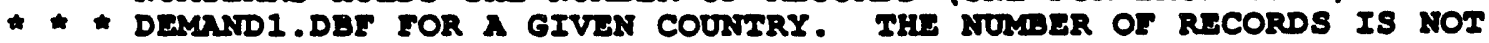

* * the save for mach country.

$\star \star \star *$

piacemericho ()

COUNT FOR COUNTRY-LCOONTRY TO NOMYENRS

GO PIACE

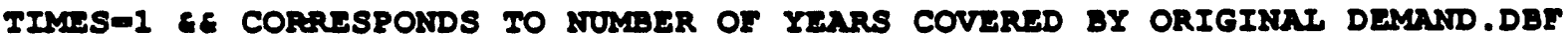

DO WHIIE TIMES<-NOMYMARS

GE RIPPIE THROUGH DFMNND.DBE

MCOONIRY-COONITRY

MYEAR -YEAR

SEIECT 2

OSE DREPORT GE REESTABIISHED BECAOSE CLOSED ON IAST IOOR

RYEAR- [Y] + TRIM (MYEAR) GEFIEID WAMS FOR YEARS BEGIN VITH "Y" THEN YWAR

DO MHILE .NOT. EOF() EERIPRLE TAROUGH DREPORT.DBY

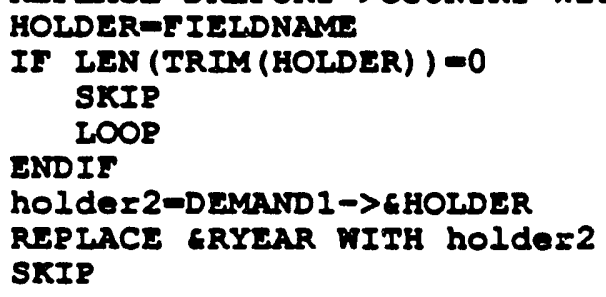

INDDO

GO TOR GE TO PRGPARE DREPORT Data Bage FOR NEXT PASS THROUGH

OSE GE CIOSE DREPORT.DBF ONIII NEXT LOOP TO PERMIT APPEND TO DEMAND

SELECT 1 GERETURN TO DEMANDI.DBF

SKIP IE GO ON TO NEXT RECORD IN DEMANDI.DBE TO PICK OP NEXT YEAR TIMST-TIMSS 1

ENDDO GE END RIPPIE THROOGH DEMANDI.DBF FOR TEAR YEAR

SEIECT 3

APPEND FROM DREPORT

SEIECT 1

ENDDO

44 LOOP $\$ 2$

cLgar all

SELECT 3 
OSE DEMAND INDEX DEMAND

REINDEX

CIENR AI.

RETURN

$a \mathbf{z}$

OS6B.PRG

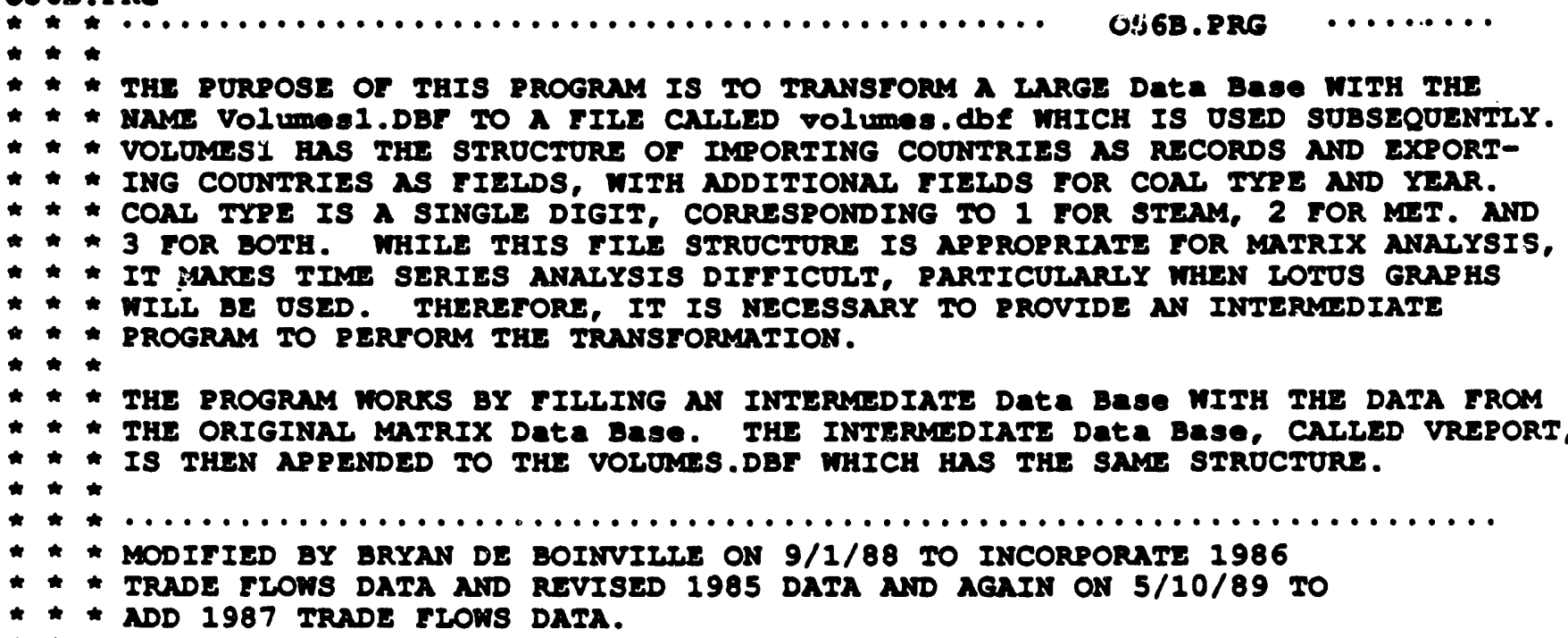

* * variabies in volungusi. Dbe:

* * year yhar (entergd is a string/uabel rather mhan as a vumber)

* * importer m mame of importivg cotitry

* * australia -exporting countray

* * canada exporting country

* * china -exporting country

* * colorbia exporting coutray

* * other mexporting country

* * polunid mexporting country

* * sarrica eExporting coUNTry

* * ossr exporting country

* * UR -EXPORTING COUNTRY

* * USA mXPorting country

* * mgermany exporting country

* * total total for all exporters

* * TYPE COAI TYPE (1-STEAM, 2-ULT, 3-BOTH)

* * variables in VRgport and volones.dBr:

* * Imp gename or importing coontry

* * exp esName or exporting country

- * MYPS

* + Y1980

* $\mathbf{1 9 8 1}$

- $\quad$ Y1982

* $\quad \mathbf{1 9 8 3}$

$\star \star \star \quad Y 1984$

* * $\quad$ ×1985

* * Y1986

- * $\mathbf{1 9 8 7}$ ESCOAI TYPE (1-STREAM, 2-MLT, 3-BOTH)

GEVOLOME TRADED IN SHORT TONS FOR YMAR GEVOLOM TRADED IN SHORT TONS FOR YEAR CEVOLONL TRADED IN SHORT TONS FOR YEAR EEVOLUNE TRADED IN SHORT TONS FOR YEAR GEVOLOML TRADED IN SHORT TONS FOR YGAR EEVOLUMI TRADED IN SHORT TONS FOR YGAR GEVOLOME TRADED IN SHORT TONS YOR YLAR GEVOLOME TRADED IN SHORT TONS TOR YLAR 


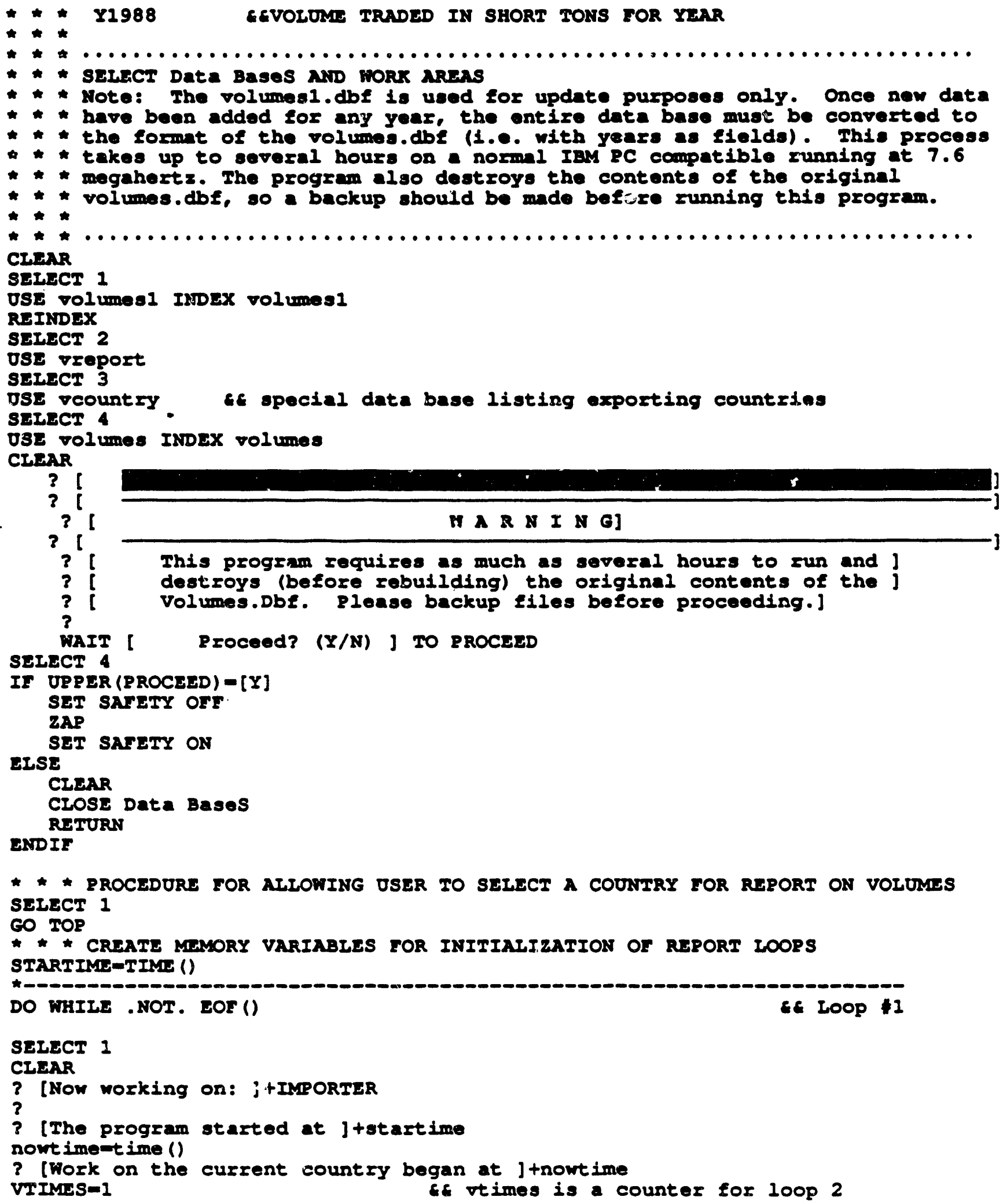




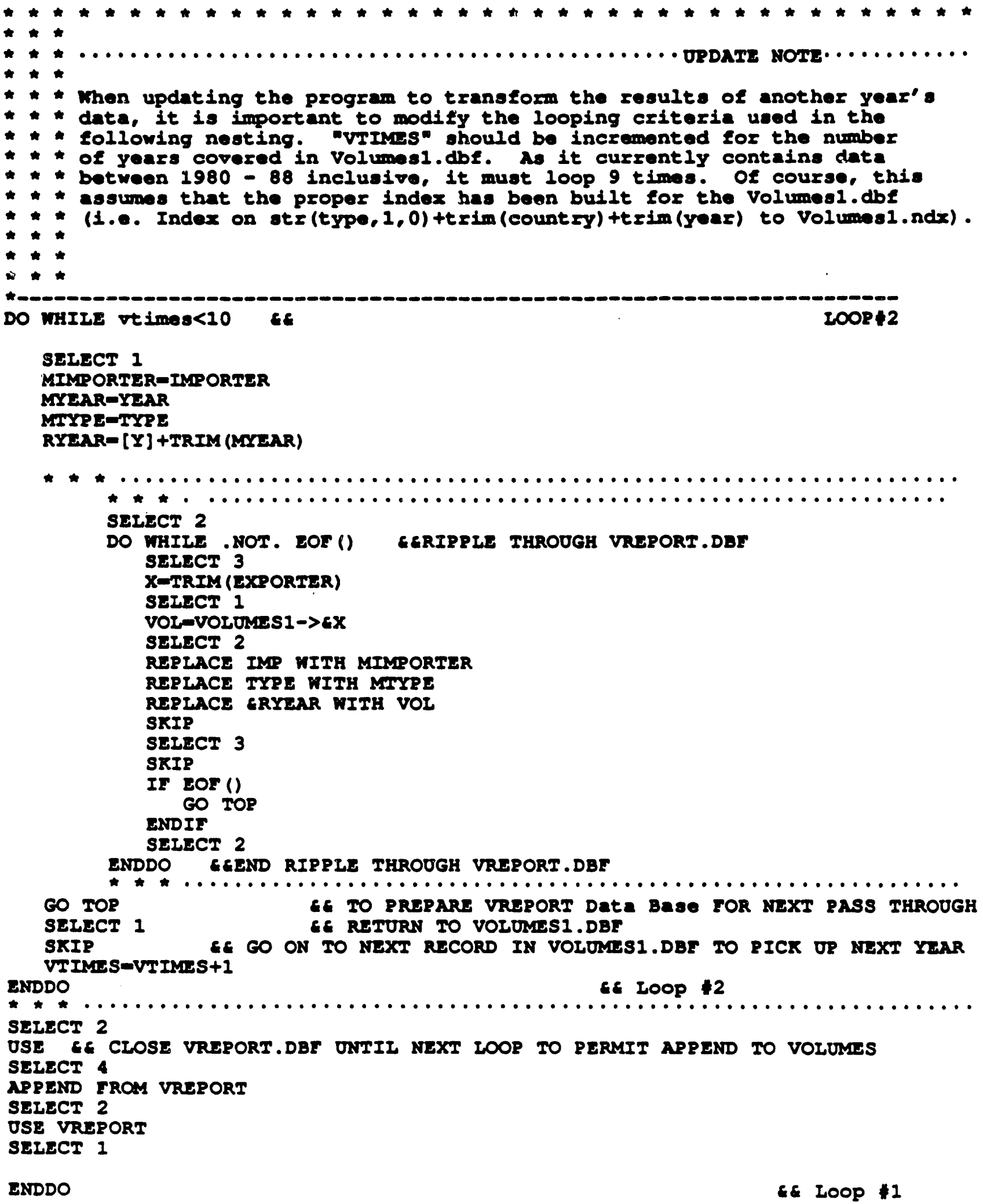




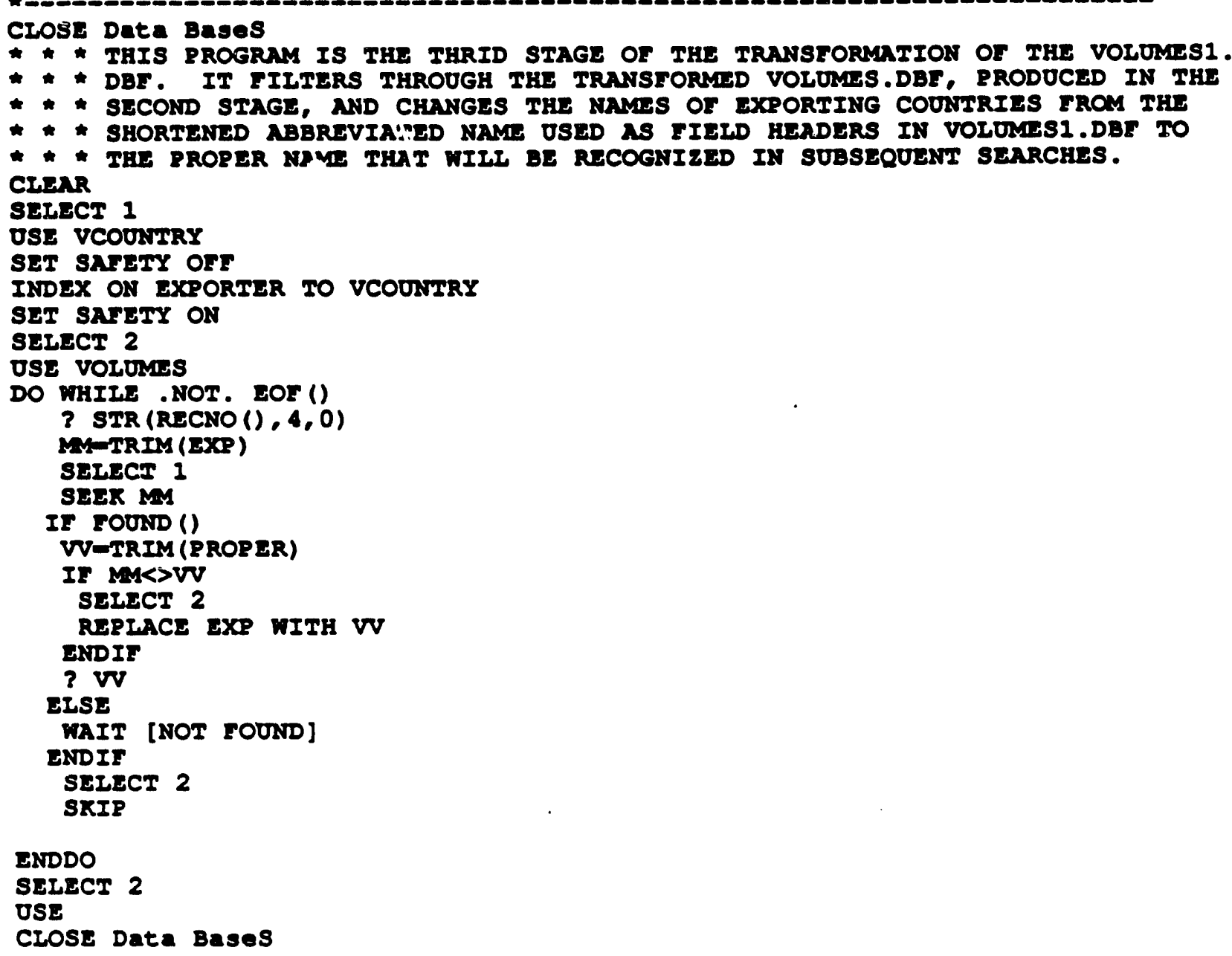

RUTURN

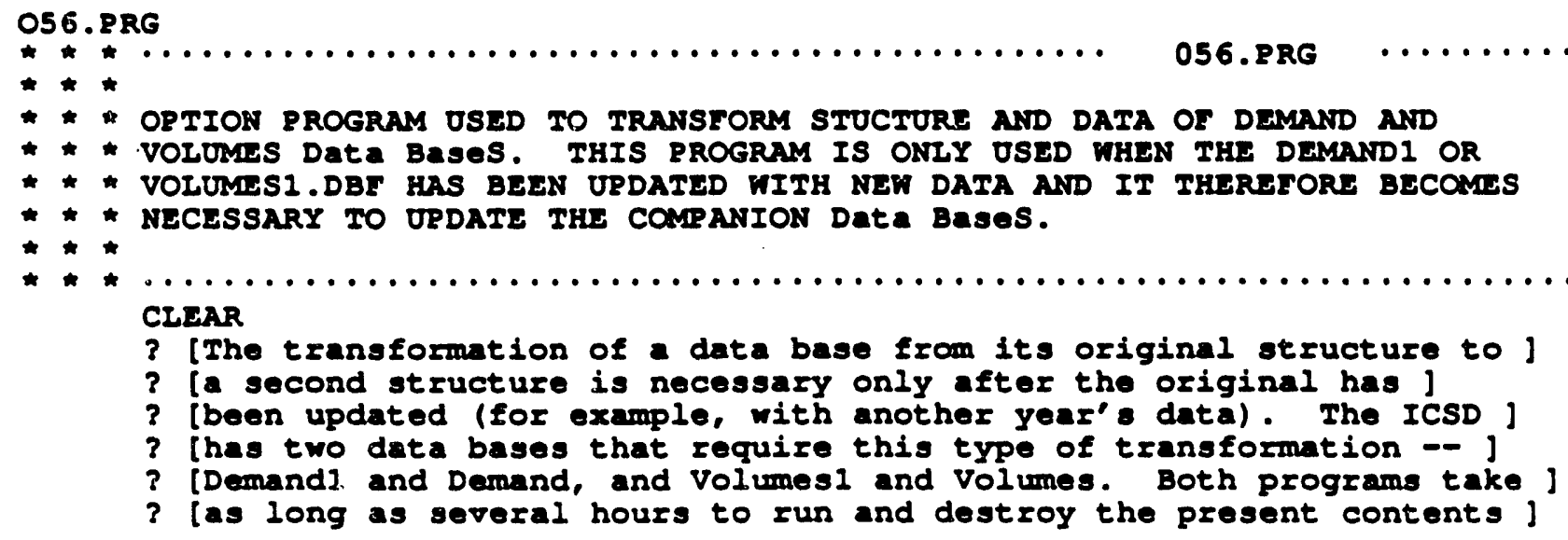




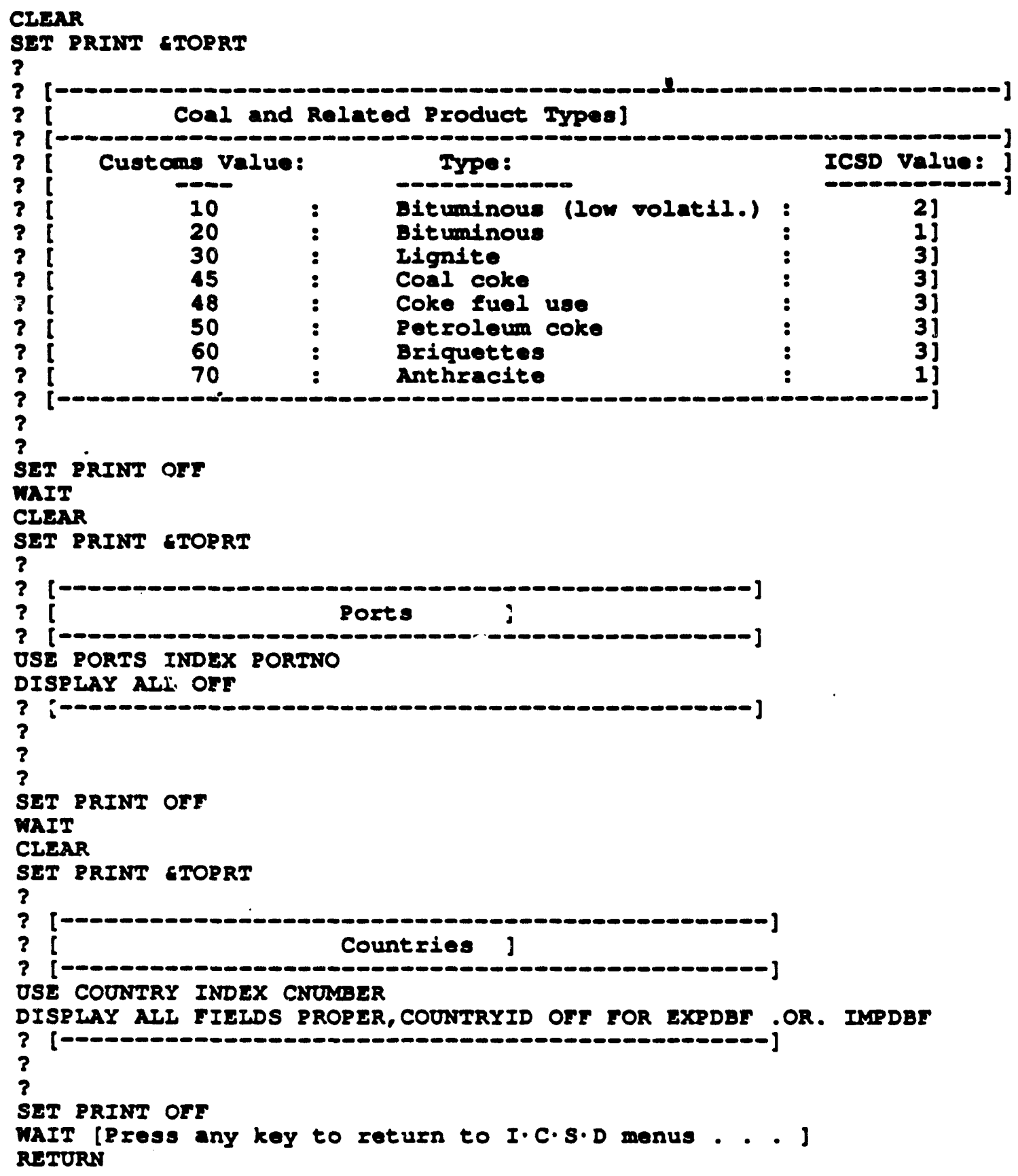

O5.PRG

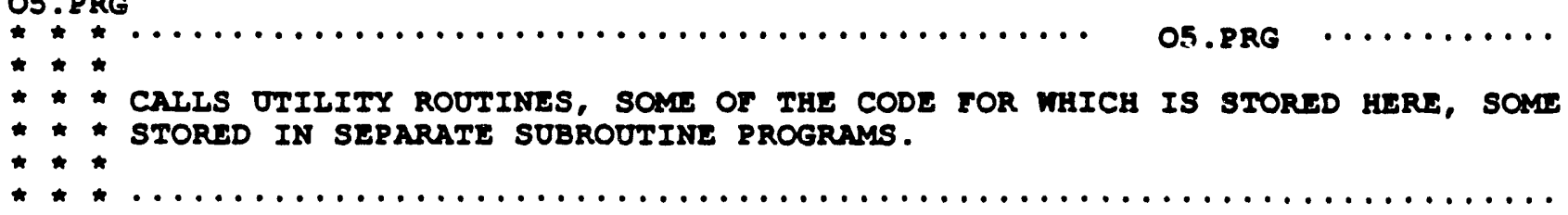




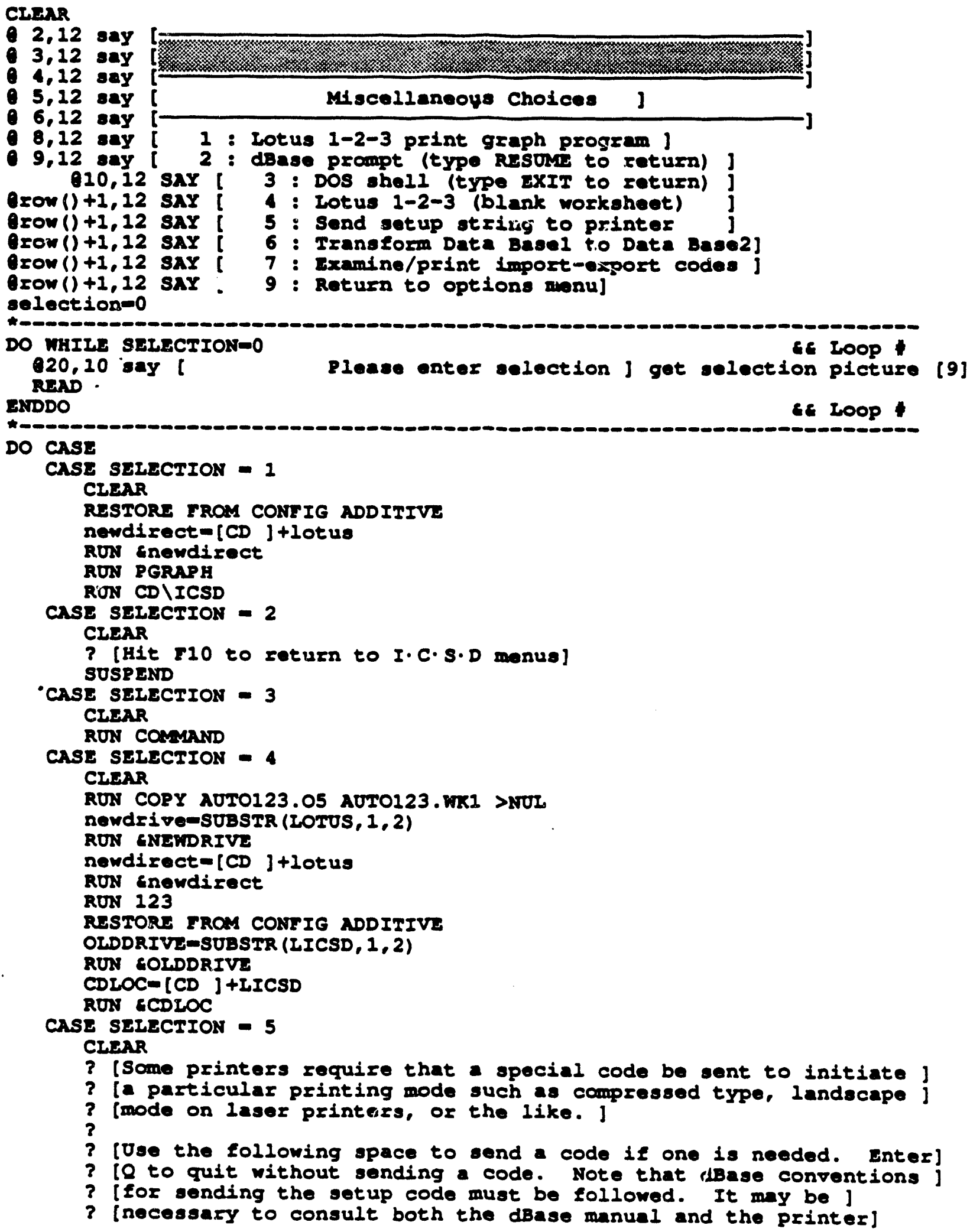


IF FILE ("PRINTER.MHM")

ELSE

RGSTORS FROY PRINTER ADDITIVL

ENTI

STORs apace (200) TO SETURCD

Orow ()+1, \& GTS setuped PICIUR: "OS45"

Orow ()+2,4 eay [Example: Compreseed mode on many printers -- ]
Orow ()+1,4 aay [

erow ()$+1,4$ say

exow ( $+1,4$ any

erow () $+1,4$ aay

Orow () $+1,4$ ony

erow $(1)+1,4$ any

RAND

IF UPPER (IRIM (SETUPCD) ) - [Q] .OR. IEN (IRIM (SEIURCD) ) $=0$

CIOSE Data Bases

CLEAR

ENDIF

RETUtis

IF UPPER (IRIM (SEIUPCD)) - [IJ]

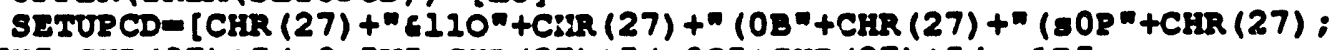

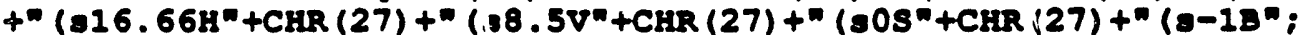

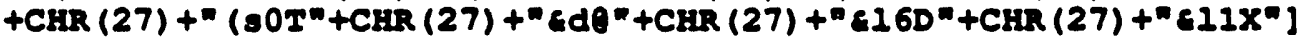

ENDIF

SET SAFETY OFF

SAVE TO RRINTER ALI IIKE SETUPCD

SET SAFETY ON

RTN ISITON

SET PRINT ON

?? ESETYOCD

SET PRINT ORE

CIJAR

WAIT [Test result? $(Y / N)$ ] to TRYIT

IF UPPER (TRYIT) $-[Y]$

SET RRINT ON

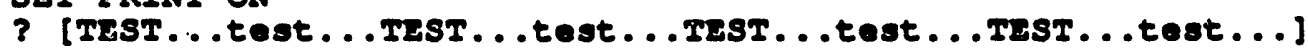

?

? [The sole purpose of the Internatianal Coel statiatics Data Base ]

$?$ [is to further understanding of world conl flows.]

$?$

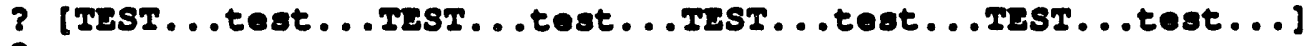

$?$

SET RRINT OFF

FNDIF

CLEAR

RSTORN

CASE SELECTION - 6

DO 056

CASE SEIECTION -7

DO 057

CASE SELECTION $=9$

CIEAR

RETURN

OTHERGISE

WAIT [That choice is not available... . ] 
CIFAR

RETURN

ENDCASE

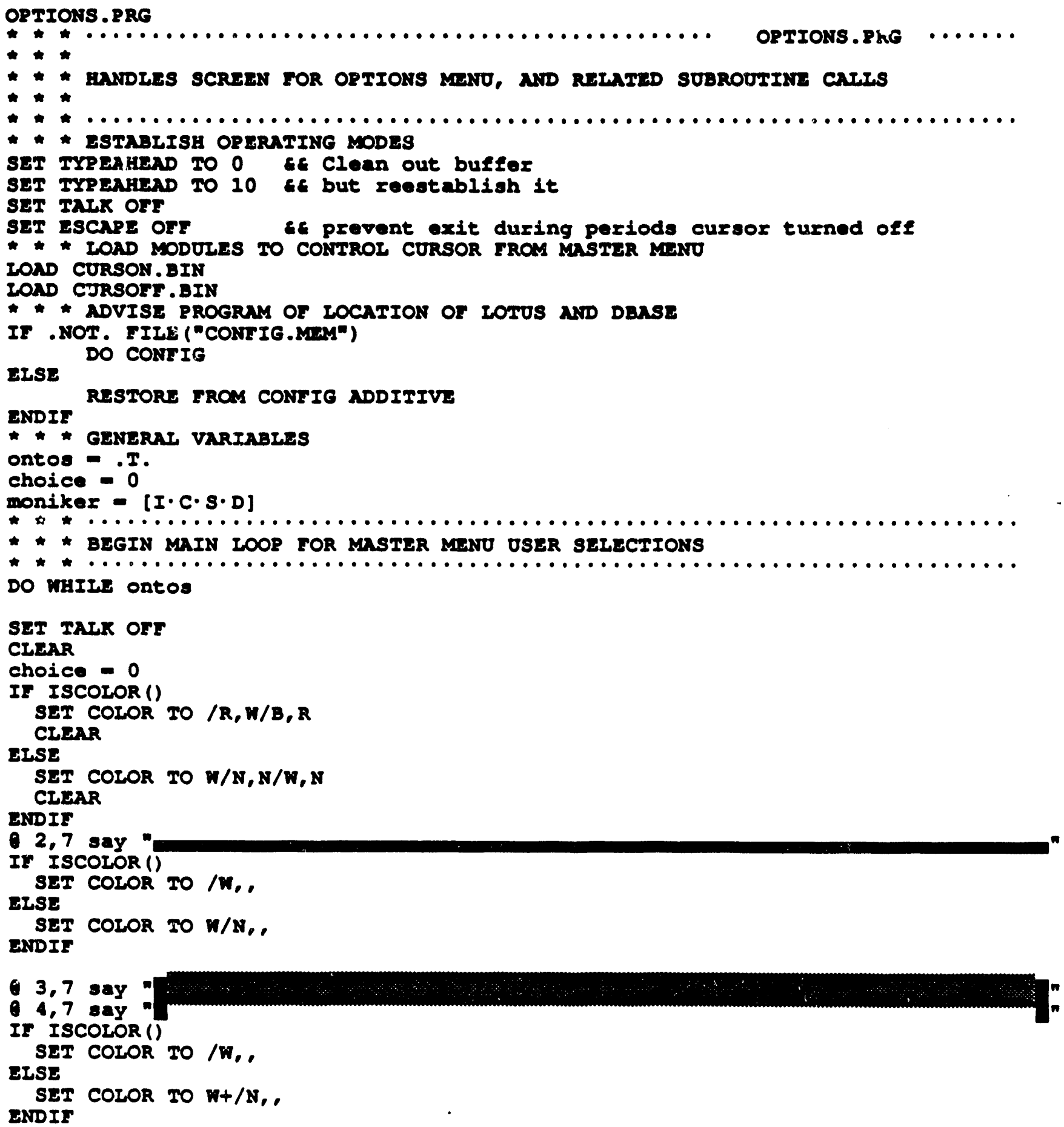


Q 4,8 say (

IF ISCOLOR ()

SET COLOR TO /W,

EISE

SET COLOR TO $w / N$,

ENDIF

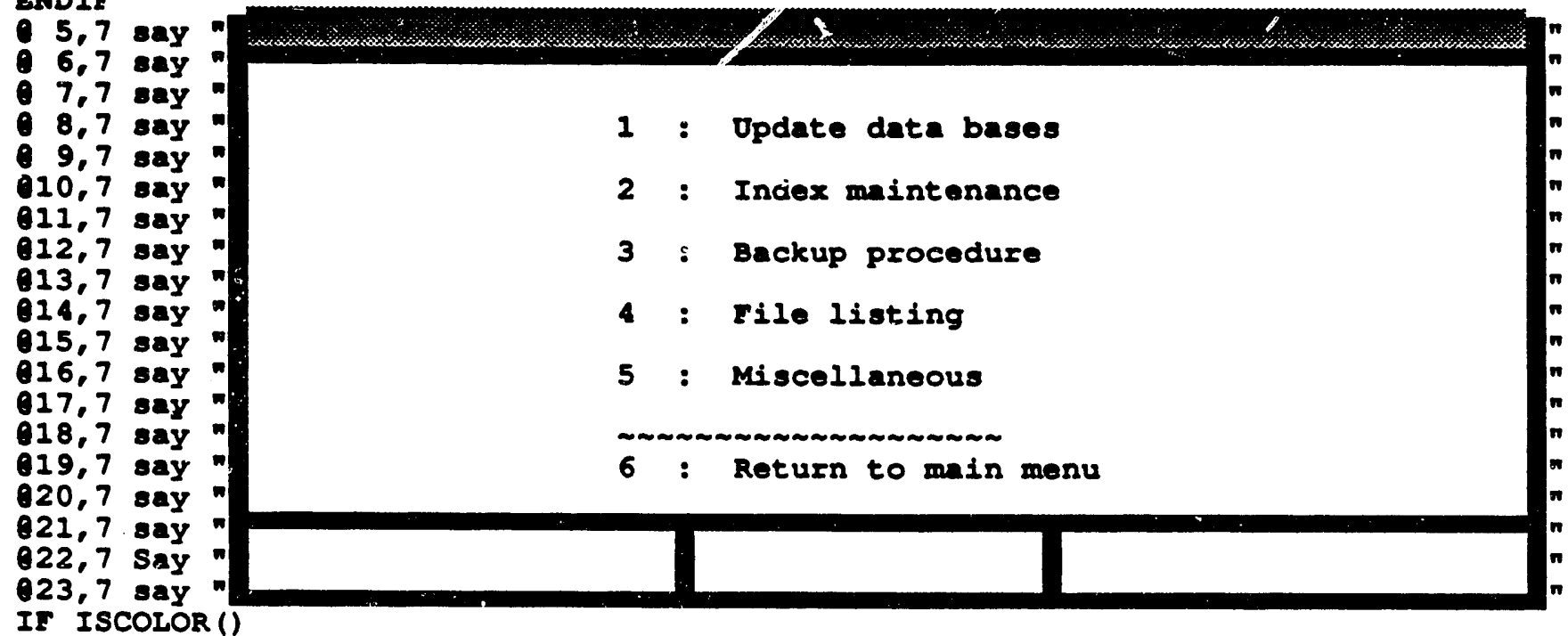

Options

]

SET COLOR TO $/ \mathrm{W}$,

EISE

SET COLOR TO $\mathrm{W}+/ \mathrm{N}$, ,

ENDIF

022,35 say [Help = F1]

IF ISCOLOR ()

SET COLOR TO $/ \mathrm{W}$, ,

EISE

SET COLOR TO $\mathrm{N} / \mathrm{N}$, ,

\section{ENDIF}

CAII CURSOTF EETURN THE CURSOR OFF WHILE THE PROGRAM MAITS FOR OSER TO GO

DO WHIIJ choice=0

choice-INEEY ()

* * DISPLAY CURRENT TIME CONTINUOUSLY ON SCREEN UNTII KEY PRESSED

MIIME - TIME ()

IF VAI (SUBSTR (mtime, 1,2)) >- 12

IF VAI (SUBSTR (mt ime, 1,2$)$ ) $=12$

MTIME $-\operatorname{TRIM}(\operatorname{STR}(12)+\operatorname{SUBSTR}(m t i m e, 3,3))+[$ p.m.] MTIME - ITRIM (LMTIMI)

ELSE

P.m. ]

ELSE

ENDI

mt ime - $\operatorname{TRIM}(\operatorname{STR}(\operatorname{VAL}(\operatorname{SUBSTR}($ mt ime, 1,2)) - 12) + $\operatorname{sUBSTR}($ mt ime, 3, 3)) + l

mt ime = ITRIM (mt ime)

IF VAI (SUBSTR (mtime, 1,2)) $=0$

MIIML $=\operatorname{TRIM}(\operatorname{STR}(12)+\operatorname{SUBSTR}(m \mathrm{~m}$ ime, 3,3)) + [a.m.]

MTIME = ITRIM (MTIME)

ELSE

mtime $=\operatorname{TRIM}(\operatorname{STR}(\operatorname{VAI}(\operatorname{SUBSTR}(m t i m e, 1,2)))+\operatorname{SUBSTR}(m t i m e, 3,3))+[$ a.m.] 

GNDIF

$$
\text { mt ime - ITRIM (mtime) }
$$

022,16 say date ()

$$
022,57 \text { say mtime+[ (0) ] }
$$

022, 46 SAY CHR (Choice)

ENDDO $C$ END OF IOOP TO GET OSER MENU CHOICE

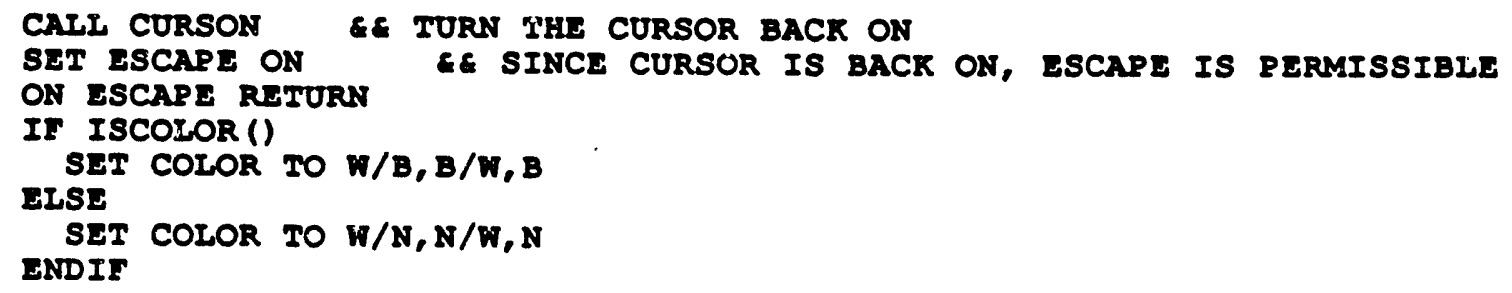


RETURN

\section{OTHERWISE}

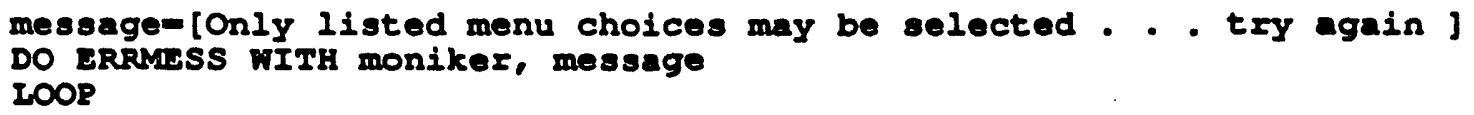

ANDCASE

ENDDO

REIURN

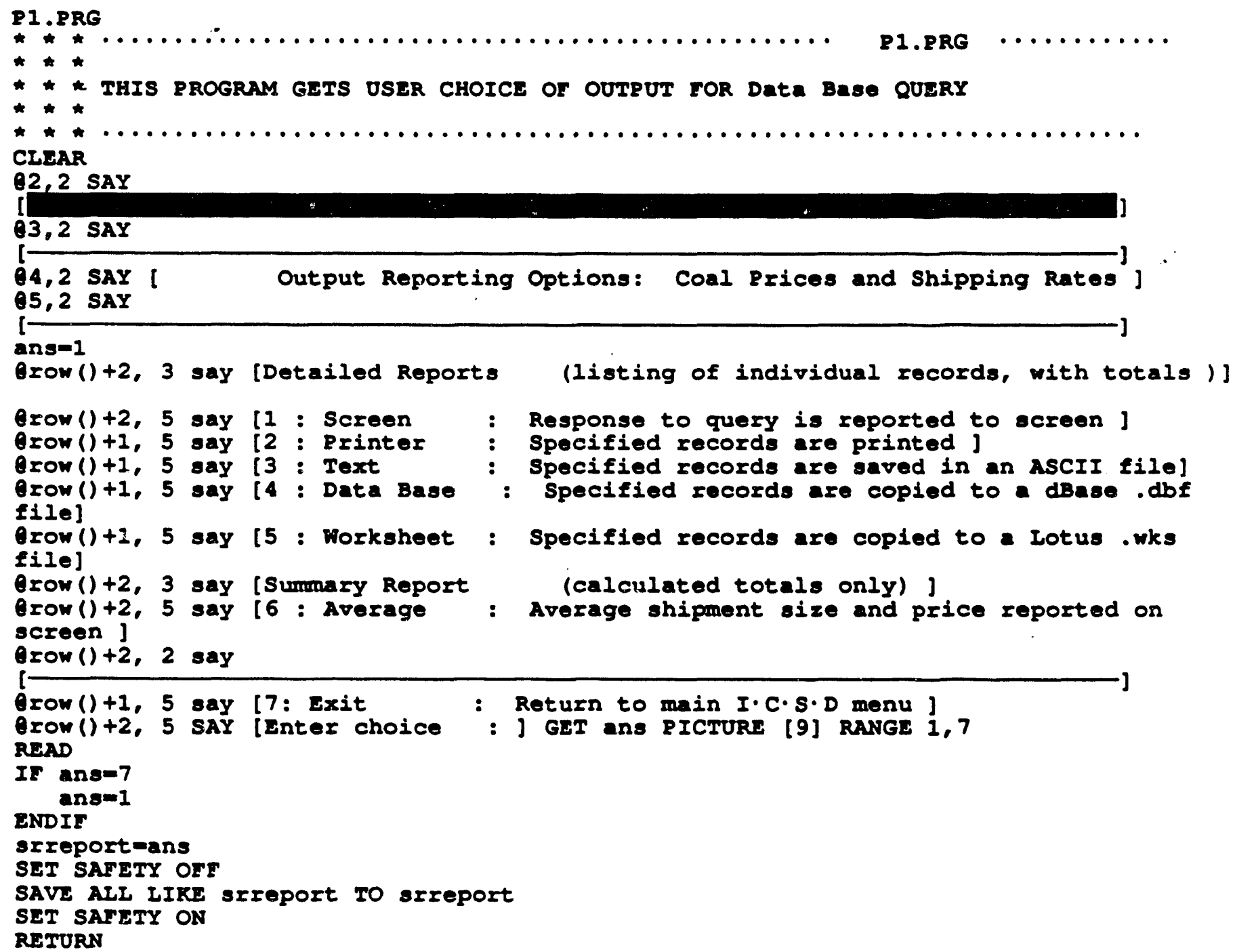




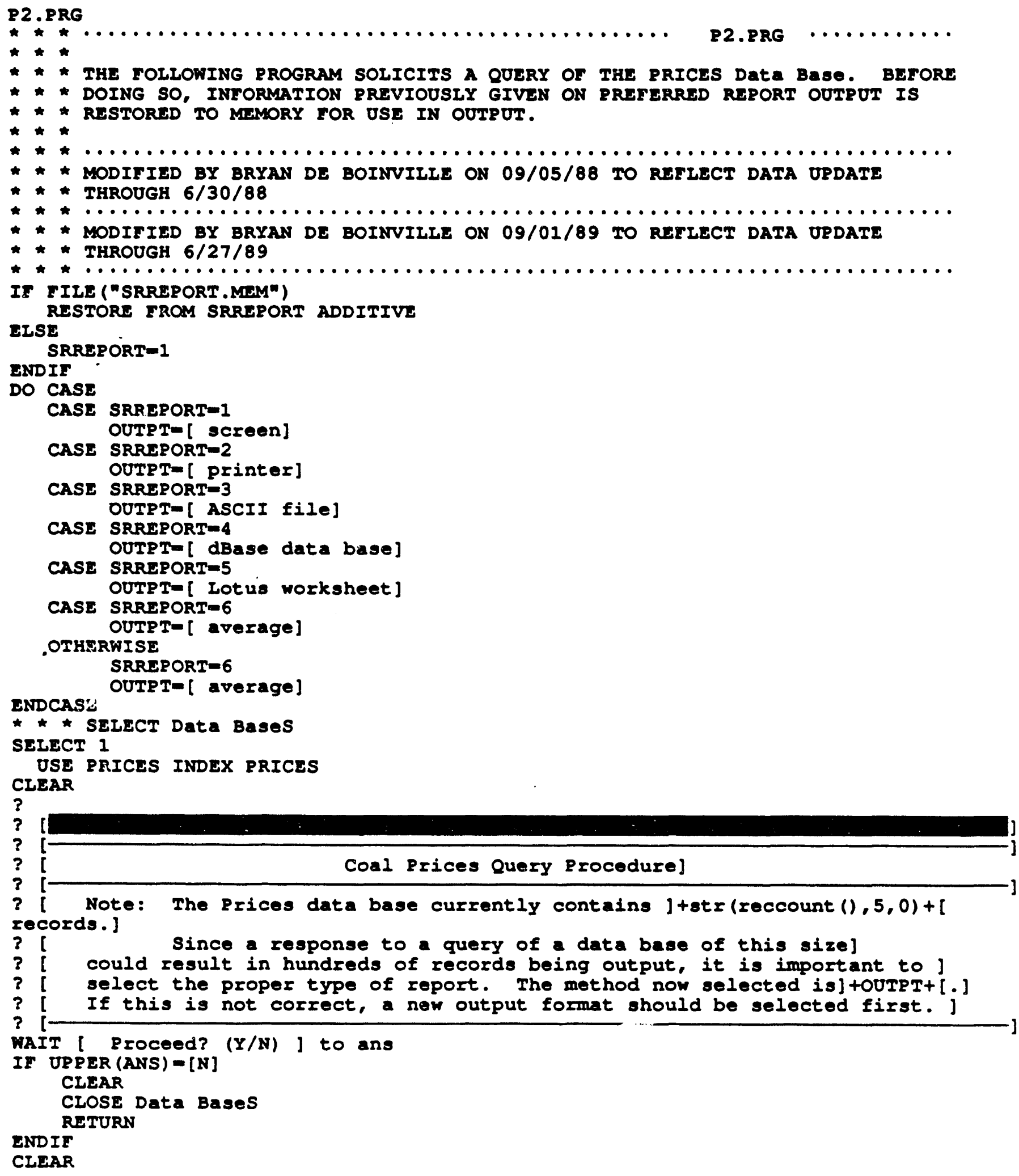




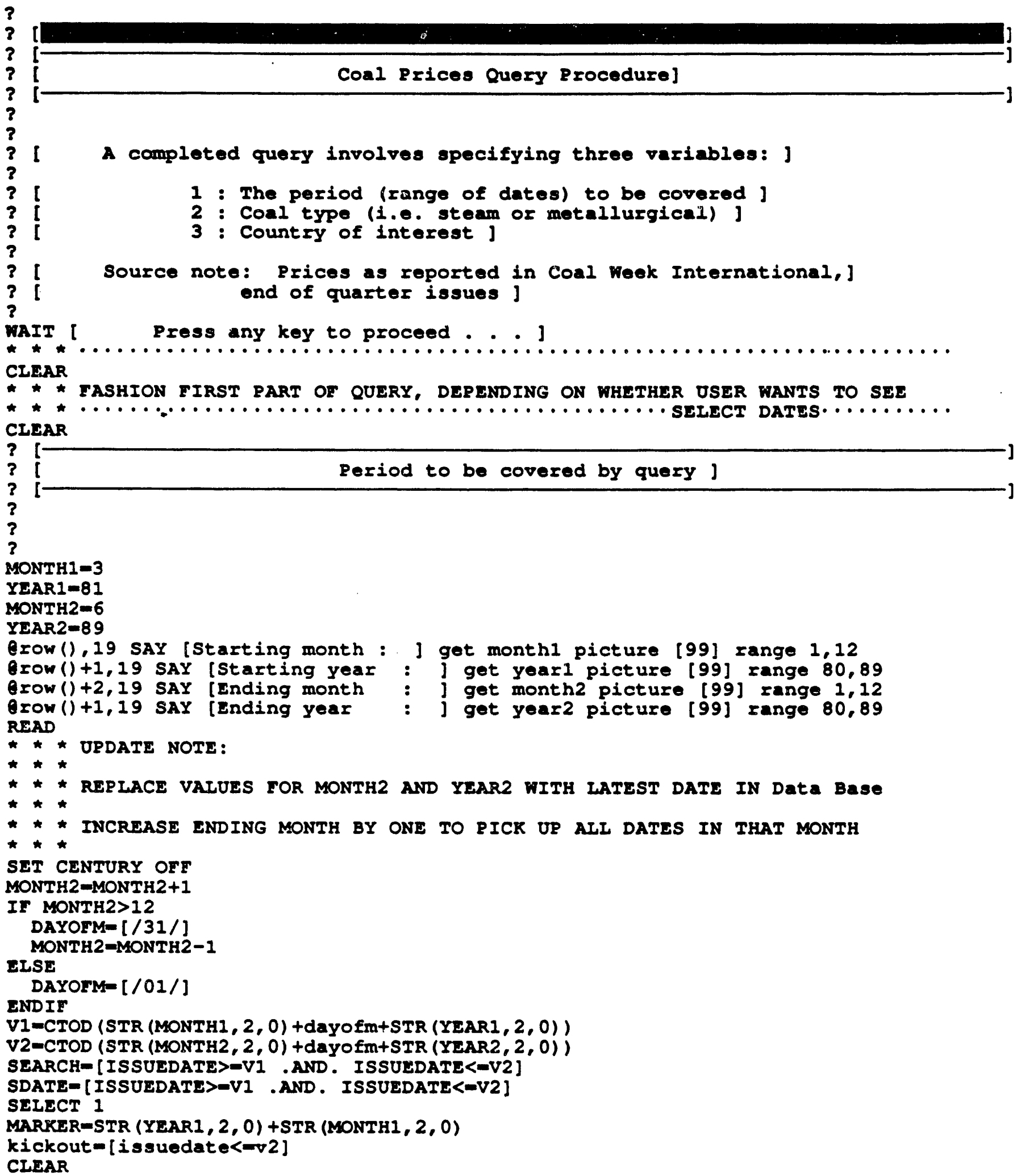




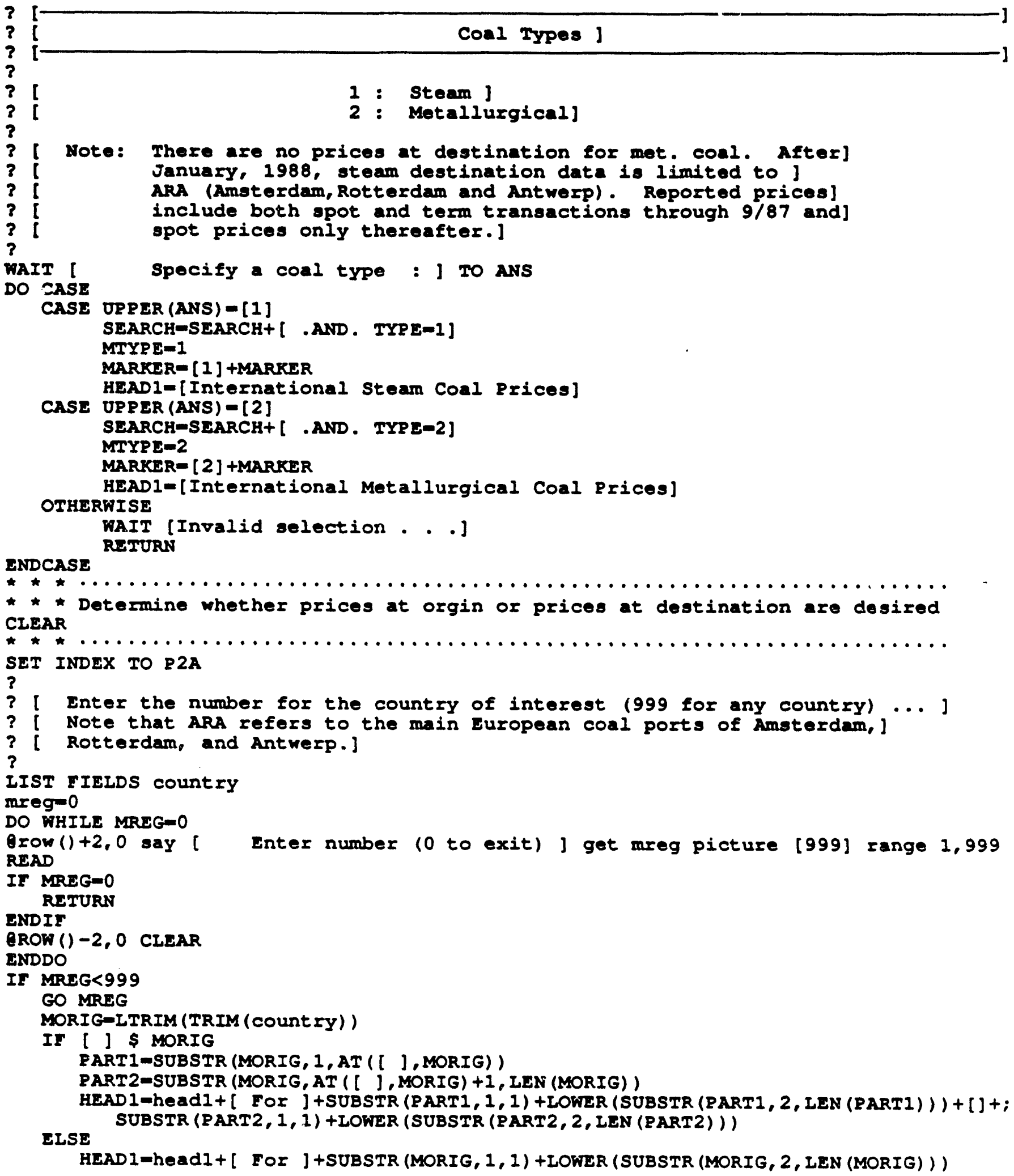


ELSE

ENDIF

MORIG -[]

HGADI-headl+ [ For Al] Countries]

ENDIF

IF IEN (TRIM (MORIG) ) $=0$

SORIG-[]

EISE

SORIG=" .AND . COONTRY= [GMORIG]"

ENDIF

CILAR

SEARCHESEARCH+SORIG

SET INDEX TO prices

ok-.t.

if. not. ok

31

31

3

3

1

[ Note: There are no prices at destination for met. coal]

$?$

mAIT [ Specify a price type : ] TO NS

DO CASE

CASE UPRER(NS) $=$ [1]

SEARCH=SEARCH+ [ .AND. O_D-1]

PTYPE $=\left[0 \_D=1\right]$

MO $D=1$

HEADI-HEADI+[ at Port of Origin]

CASE UPPER (NS) = [2]

SEARCH-SEARCH+ [ .AND. O_D=2]

PTYP E- $\left[\begin{array}{ll}0 & D=2\end{array}\right]$

MO $D=2$

OTHERWISE

HEADDI-HEADI+ [ at Destination]

WAIT [Invalid selection... .]

ENDCASE

endif

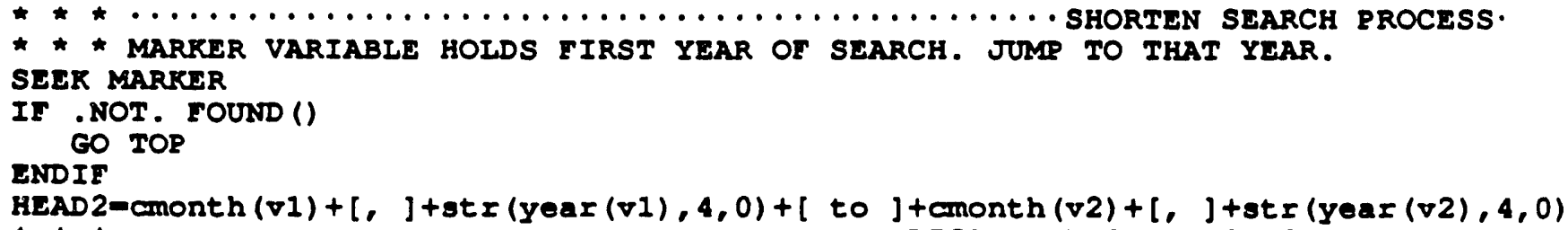

DO CASL

CASE SRREPORT $=1$

CLEAR

wait [Use pause key (or CTRI + Num Lock) to stop display... .] CLEAR 


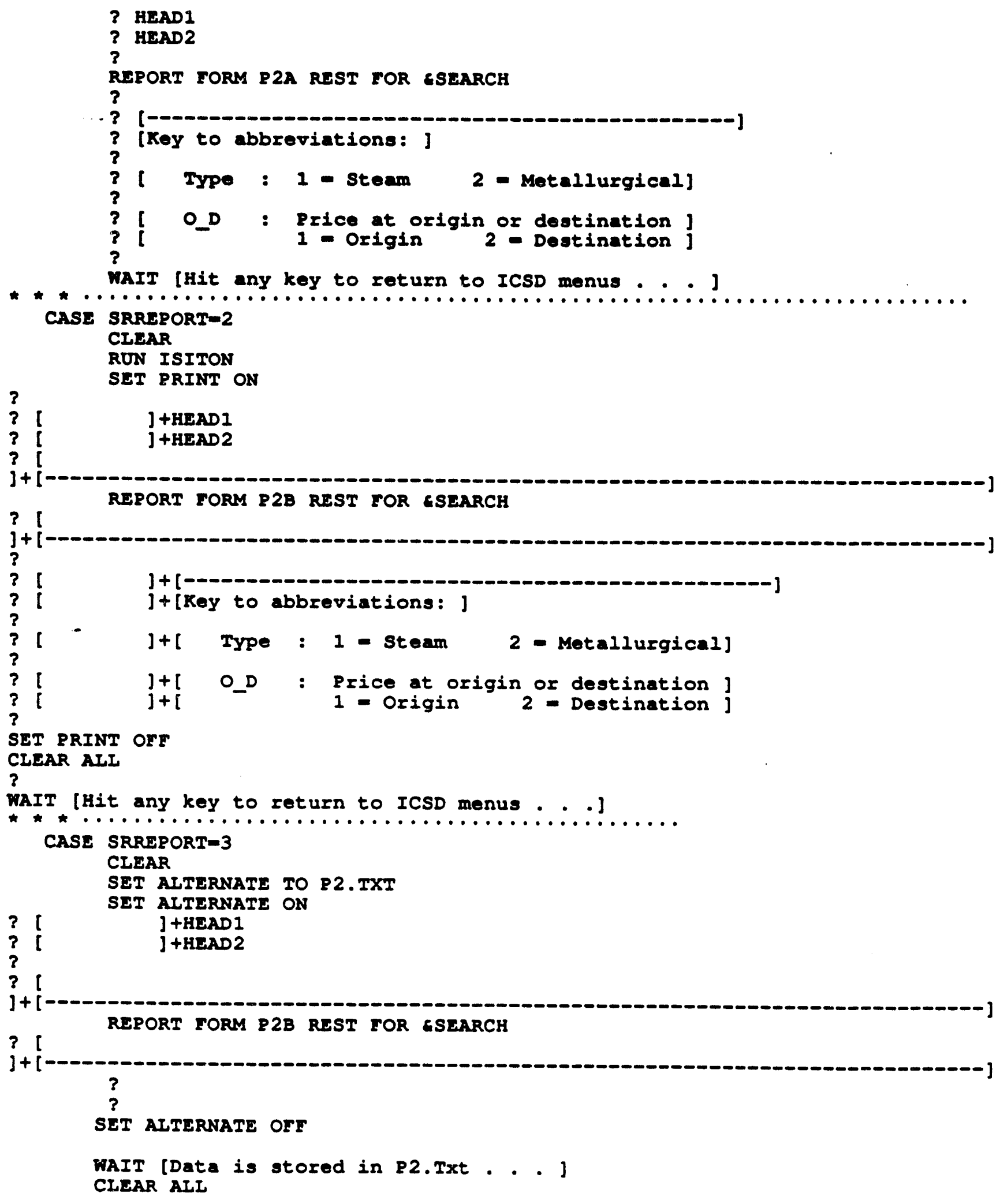




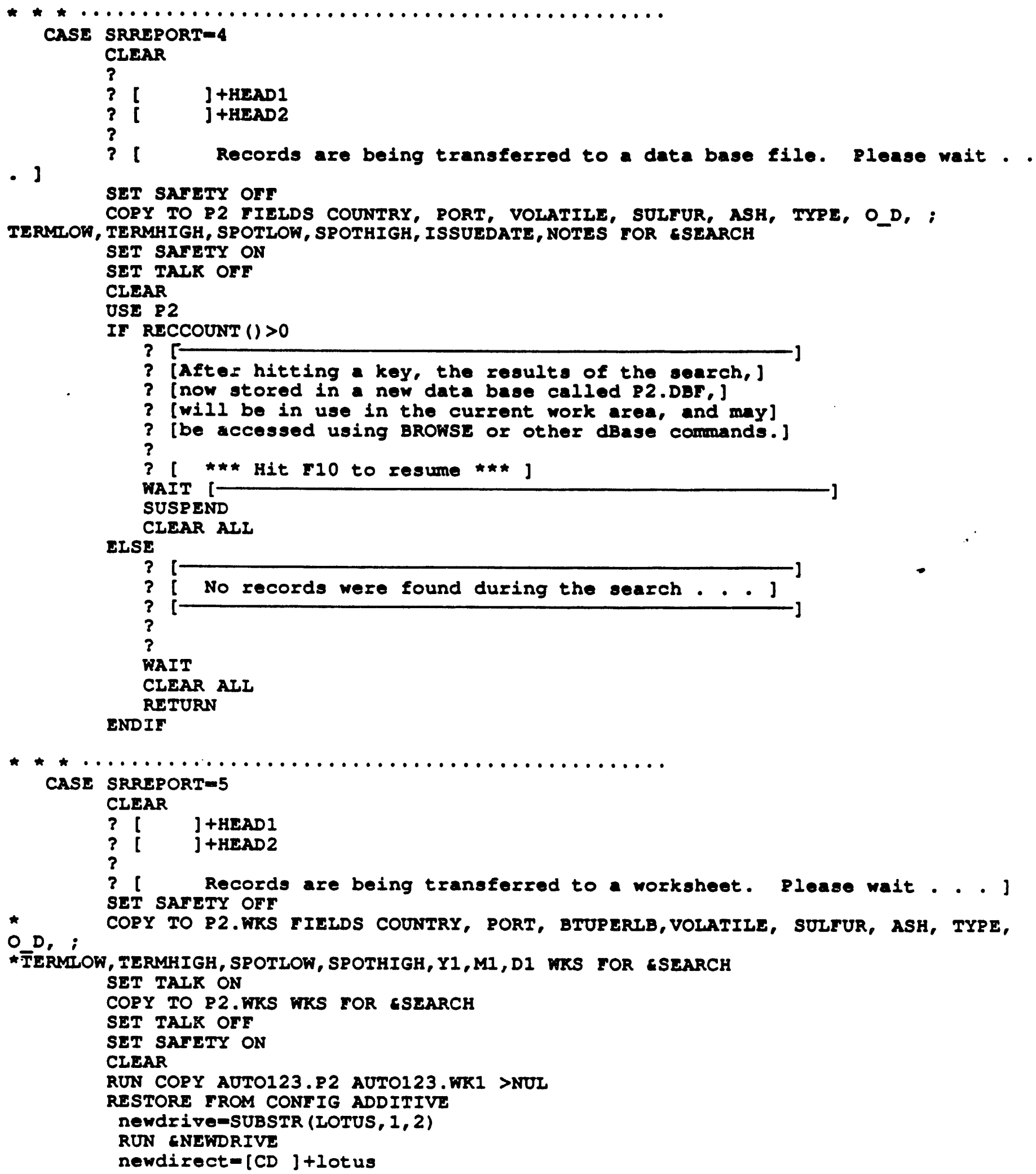


RUN cnewdirect

RUN 123

RESTORE FRGA 、ONFIG ADDITIVE

OLDDRIVS-SUBSTR (IICSD, 1, 2)

RUN COLDDRIV

CDIOC $=[C D]+I I C S D$

RON GCDIOC

CASE SRRSPORT-6

CLEAR

$?$ [

$?$

3 [

31

$?$

] HISAD2

NOTZERO1-SEARCK+ [ .AND. TERMLOW>0 . AND. TERMHIGH>0]

NOTZERO2-SEARCH+ [ .AND. SPOTLOW>0 .AND. SPOTHIGH>0]

SEIK MARKER

IF . NOT. FOUND()

ENDIF

GO TOR

COUNT REST TO Cl FOR ENOTZERO1 while Ekickout

SEEK MARKER

IF . NOT. FOUND ()

GO TOP

INDIF

AVGRAGE REST TERMIOW, TERMHIGH TO A1,A2 FOR ENOTZERO1 While Ck1CkOUt SELK MARKER

IF . NOT. FOUND()

ENDIF

SO TOP

COUNT REST TO C2 FOR ENOTZERO2 while \&kickout

SEEK MARKER

IF . NOT. FOUND ()

GO TOR

ENDIF

AVEREGE SPOTLOW, SPOTHIGH REST TO A3,A4 FOR ENOTZERO2 while GkickOut

$?$

$?[$

3

? 1

【

[

[

[

[

Average term price - Low bound - \$J+STR $(A I, 8,2)$

Average term price - High bound - $\$$ J $+\operatorname{STR}(\mathrm{A} 2,8,2)$

]$+\operatorname{stc}(c 1,8,0)+[$ observations $]$

Average spot price - Low bound - \$1+STR $(A 3,8,2)$

Average spot price - High bound - $\$$ j+STR $(A 4,8,2)$

]$+\operatorname{St}[(c 2,8,0)+[$ observations $]$

Note: Averages based on records with non-zero value: for] both the high and low bound of either the spot or term] price.]

WAIT [

Hit any key to return to ICSD menus.... ]

OTHERHISE

CLEAR

? [Query could not be made because of error in specifying type of] INDCASE

MAIT [report output... ] 
CLOSE Data Bases

RETURN

A

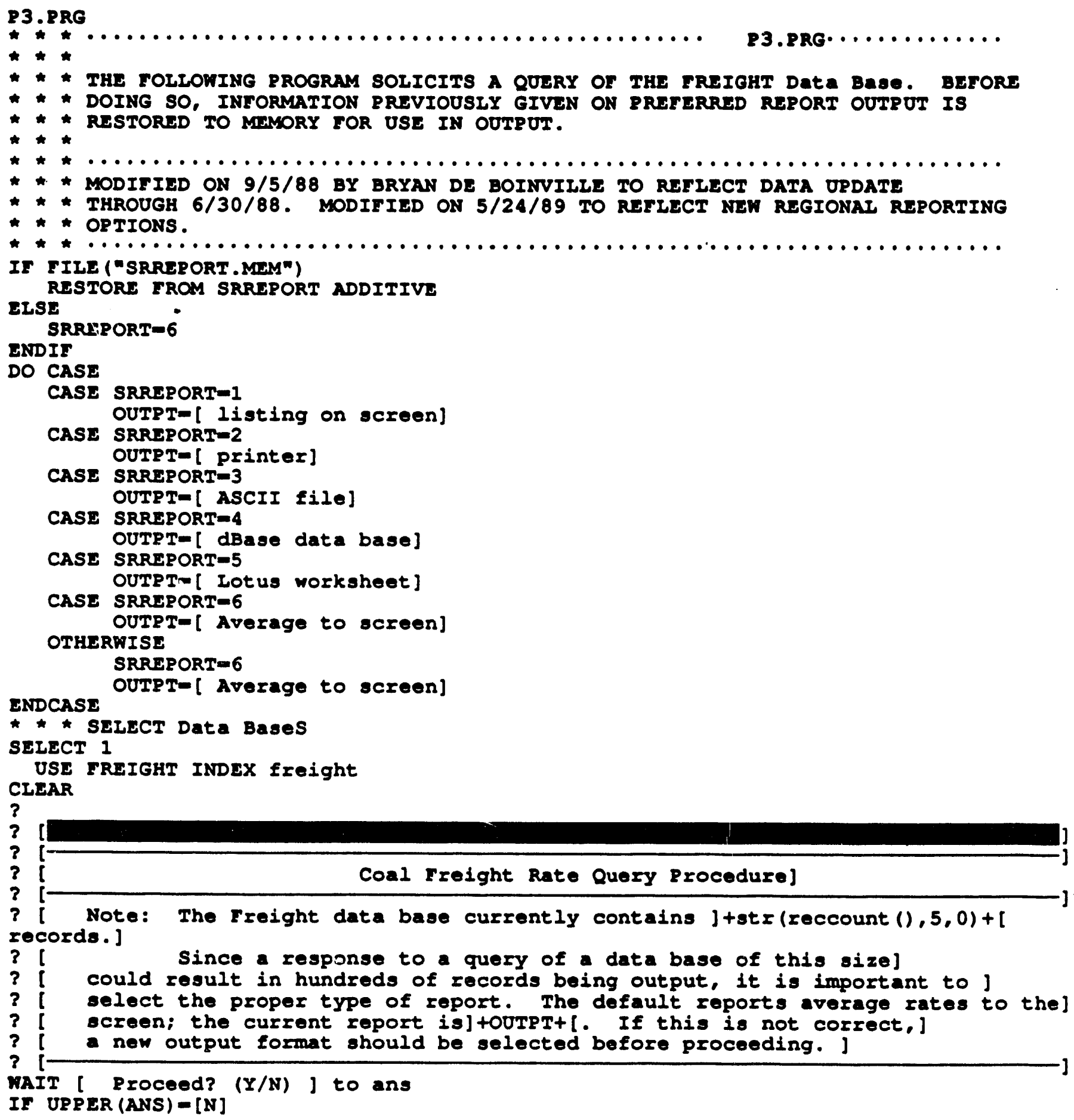




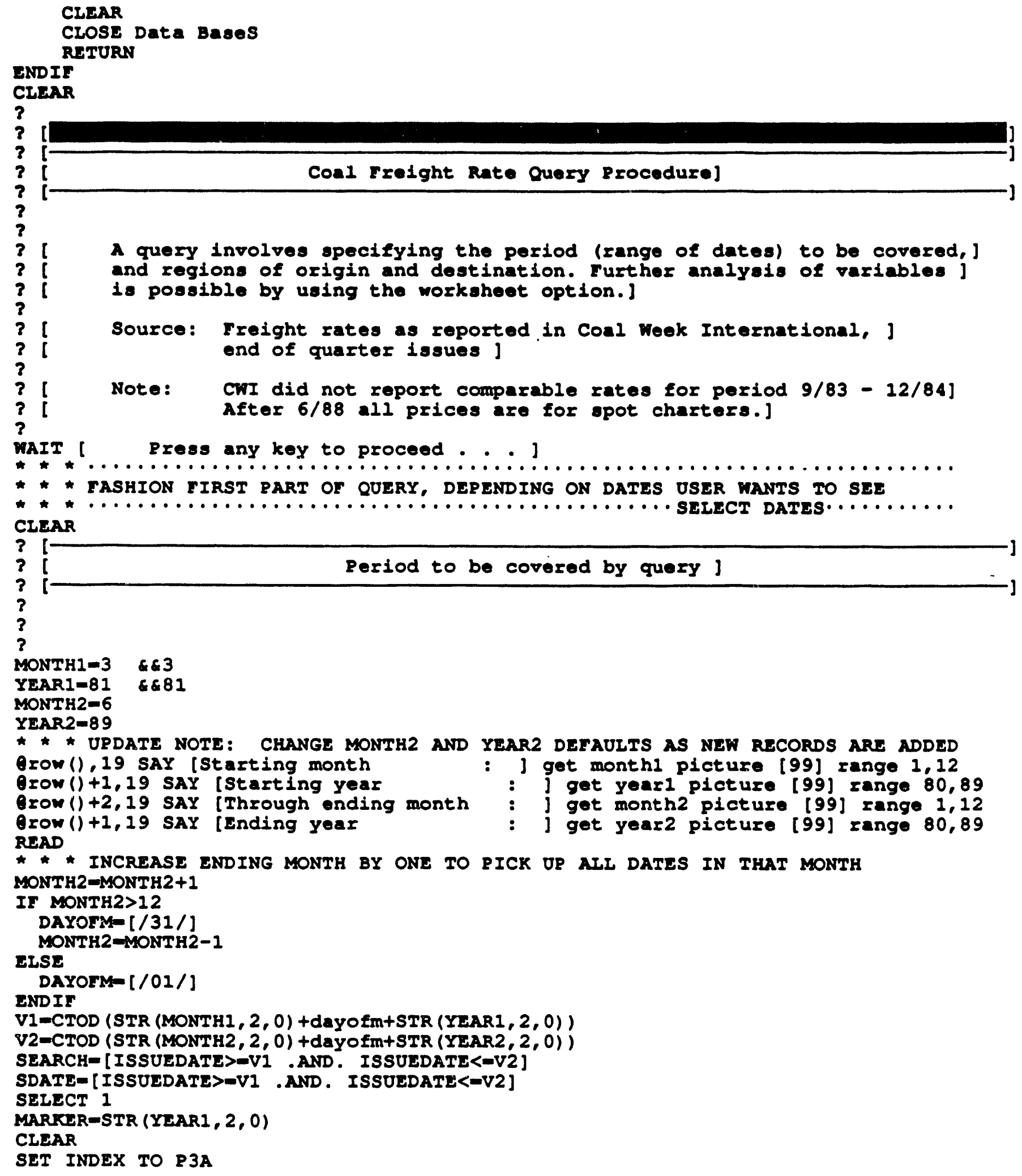




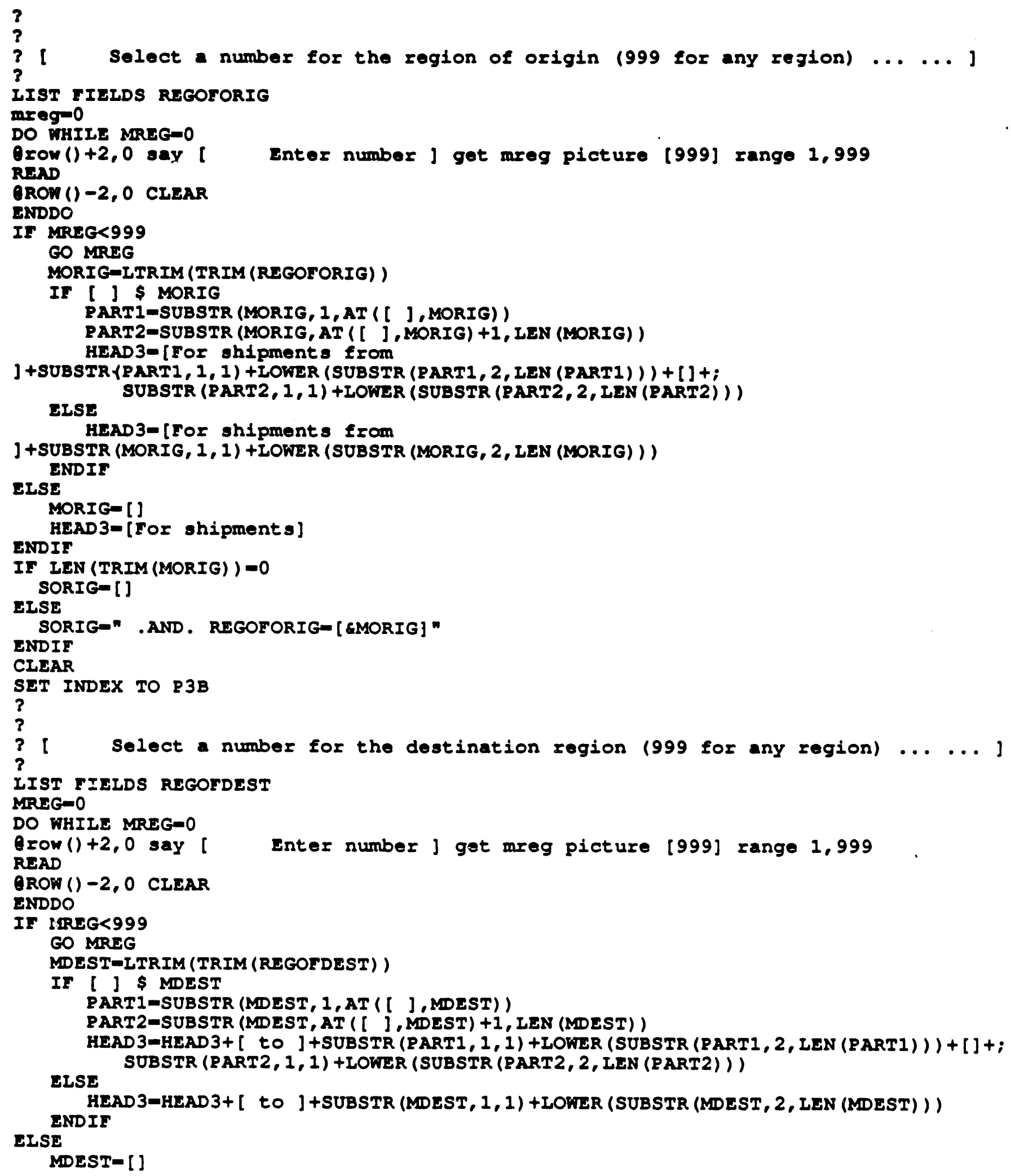




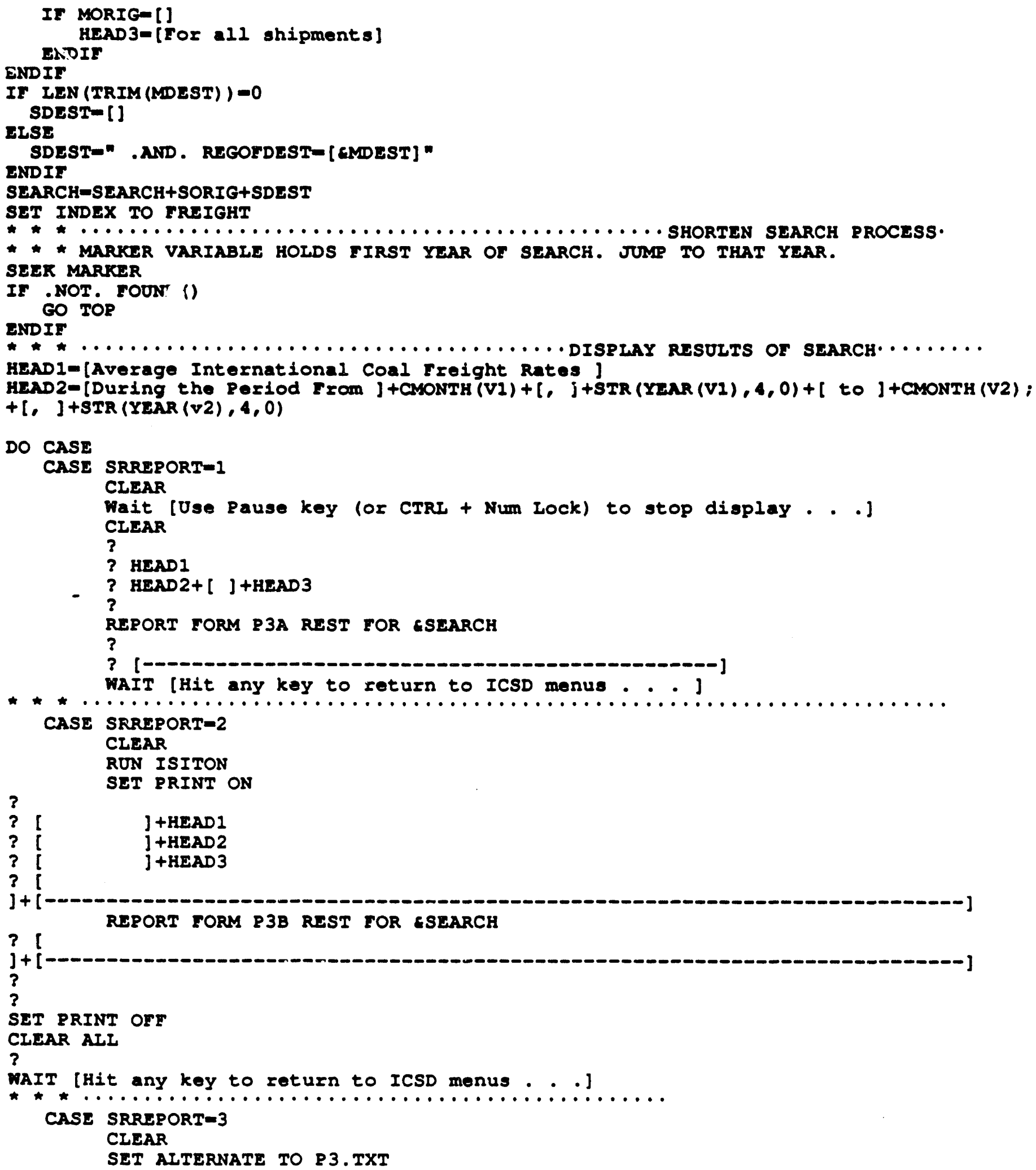




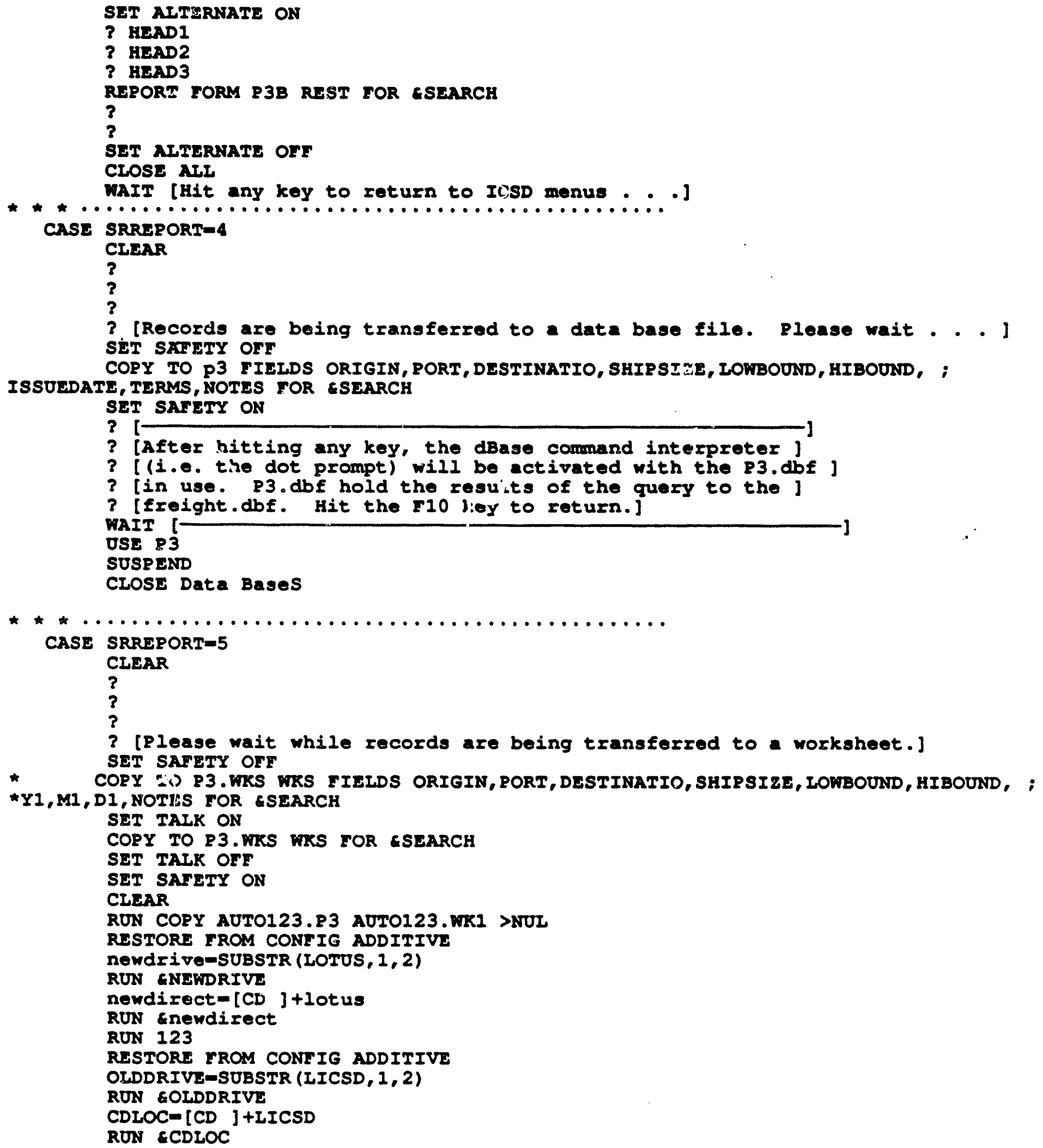




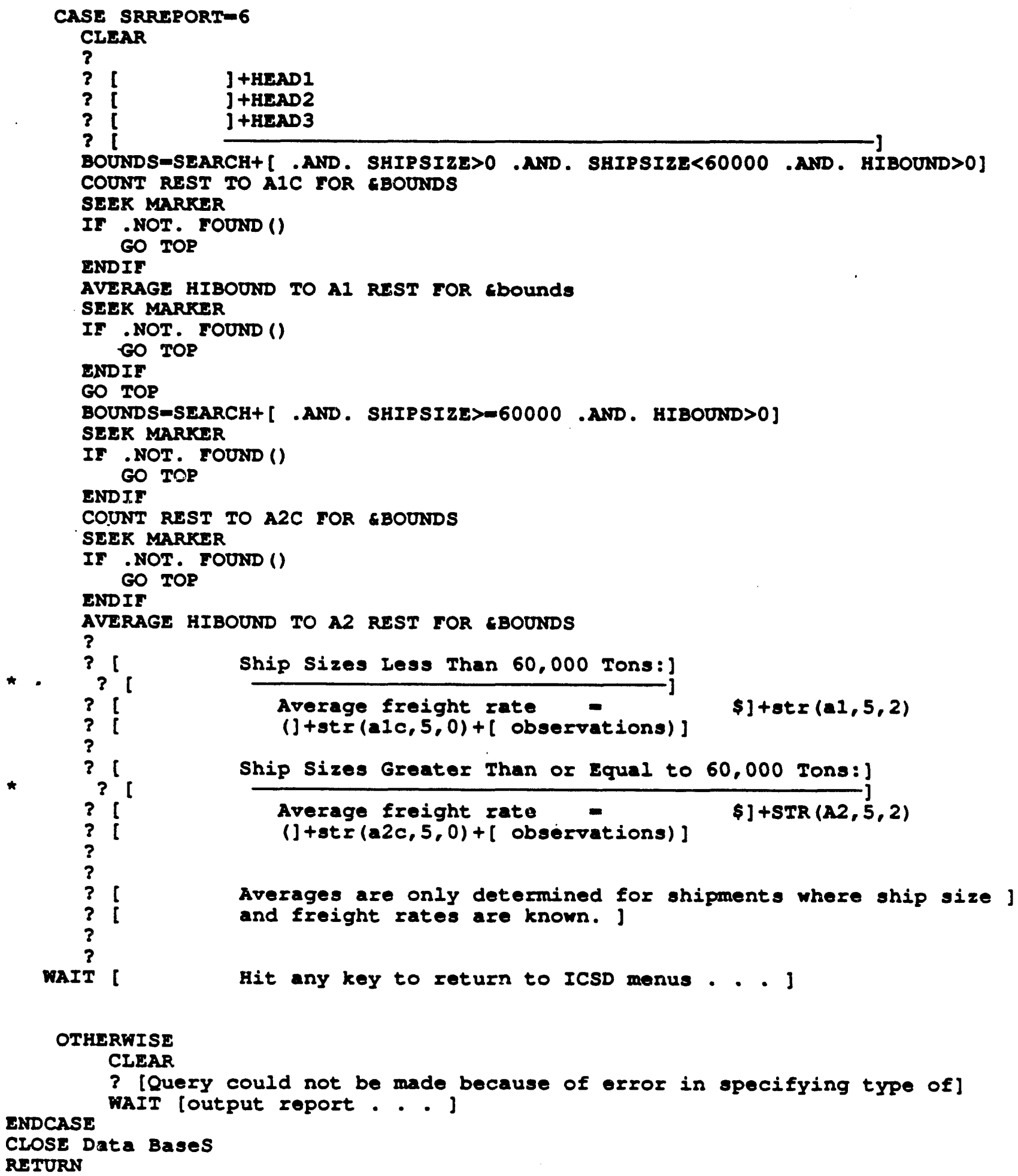




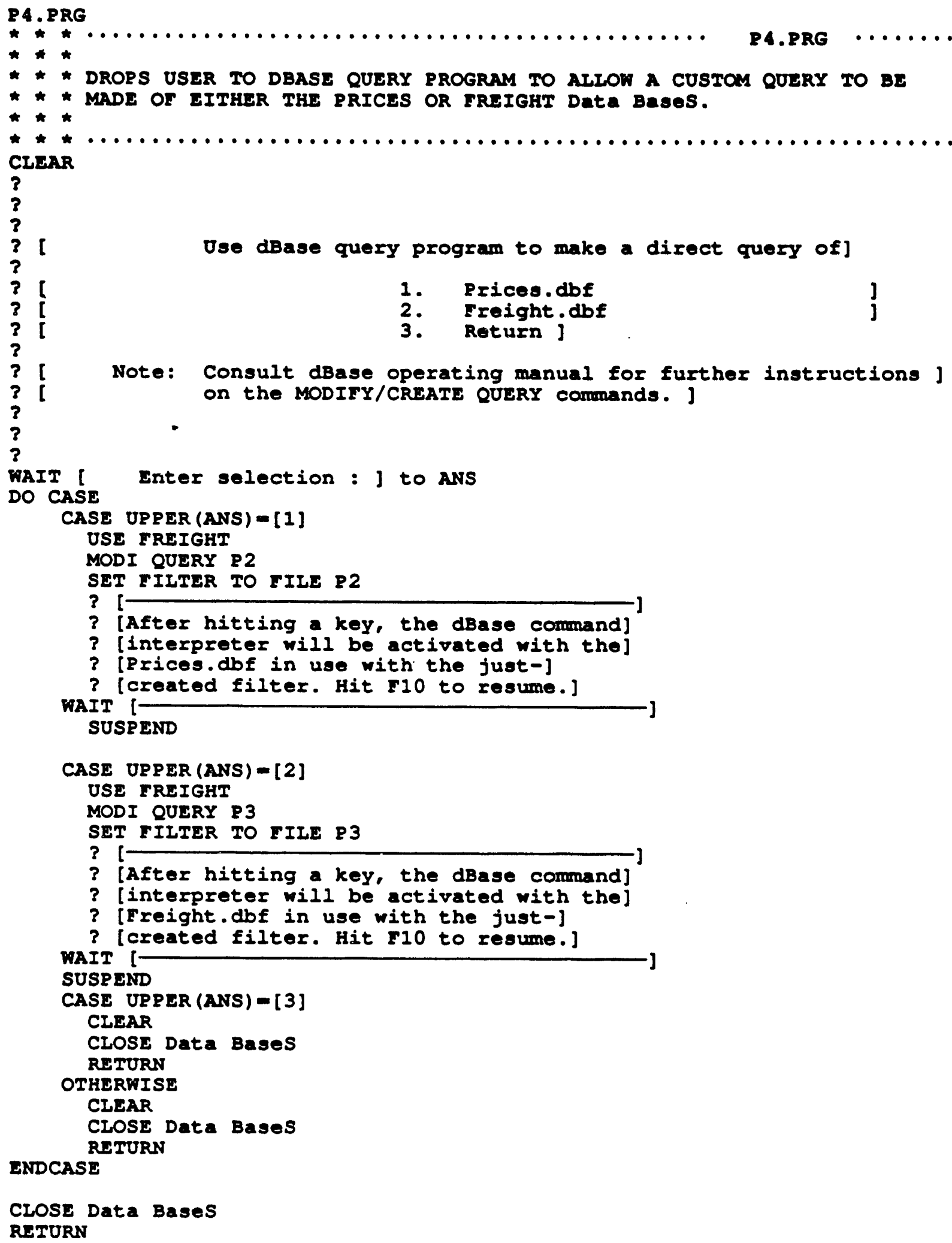




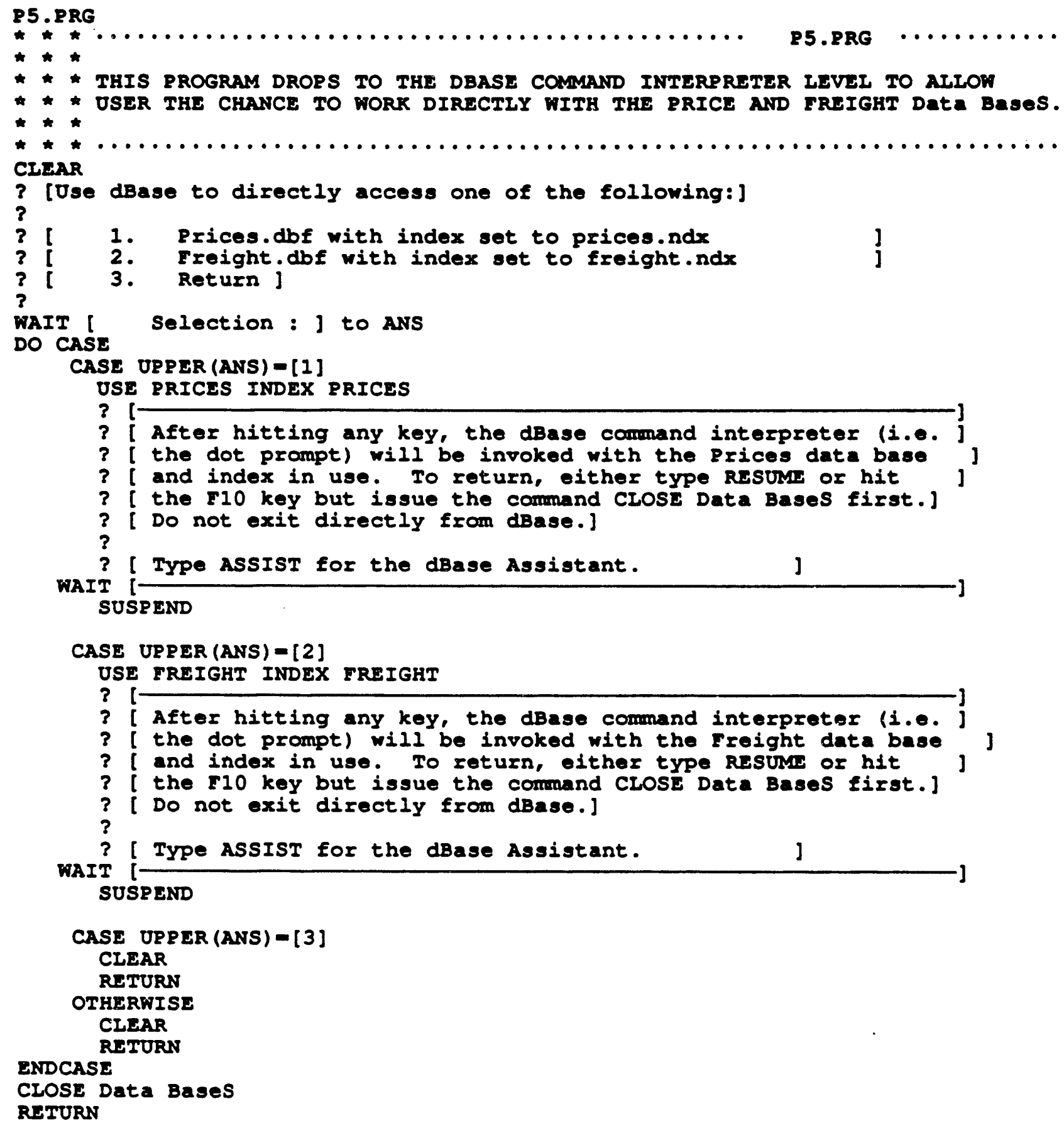

PRICES.PRG 


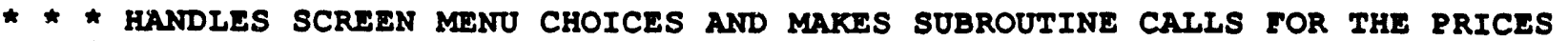




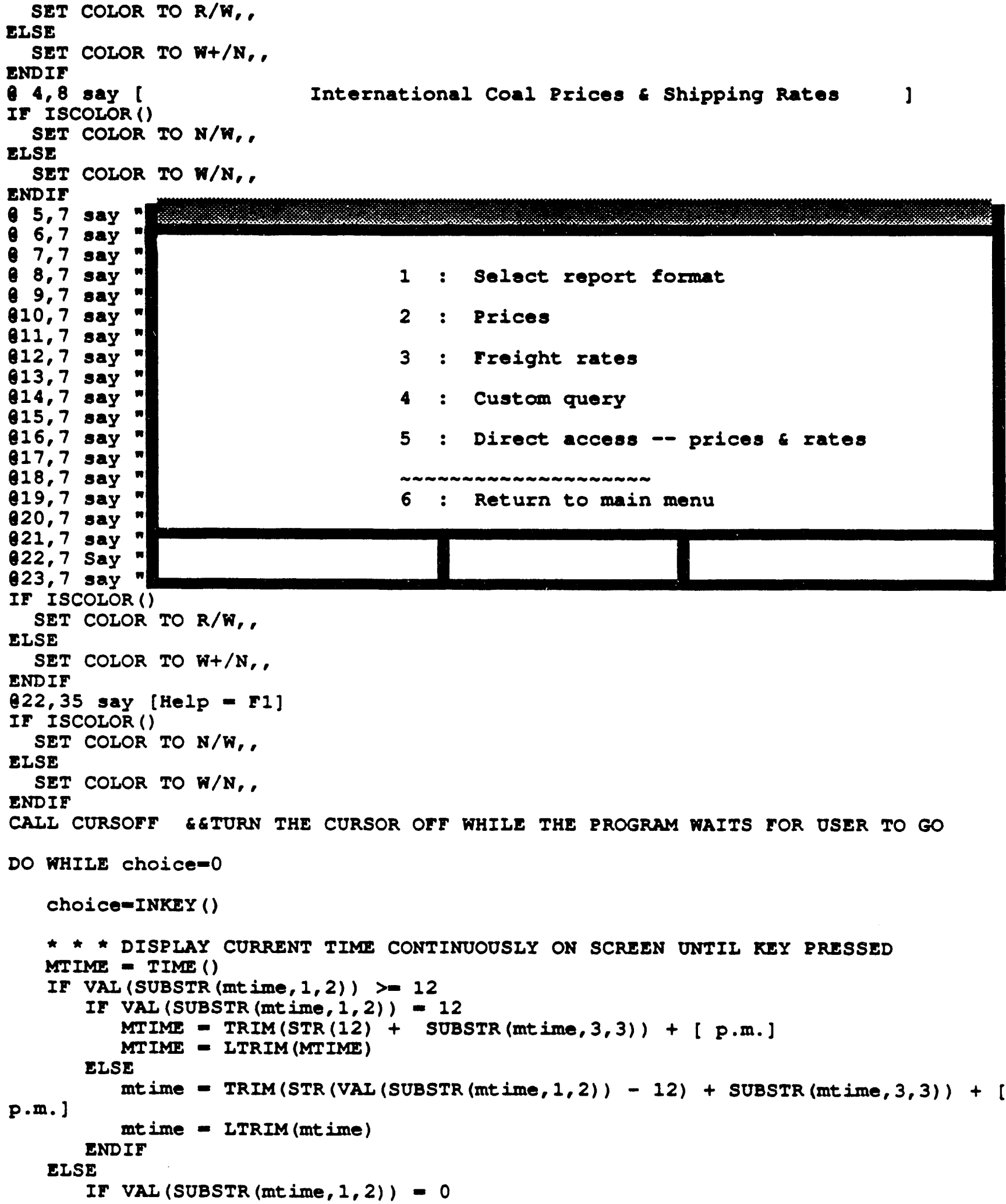




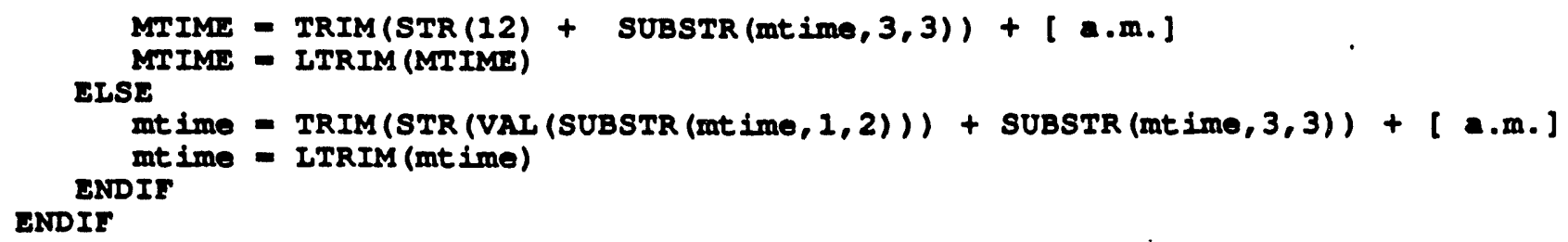

CASE CHR (choice) \$ [2]

DO 82

Ge Subroutine call

CASE CHR (ChOice) \$ [3]

DO $P 3$

\&\& Subroutine call

CASE CHR(choice) \$ [4]

DO 84

fe Subroutine cail

CASE CHR (choice) \$ [5] 
DO P5

cif Subroutine call

CASE CHR (choice) \$ [6]

CLEAR

RETURN

\section{OTHERWISE}

message-[Only listed menu choices are valid . . .] DO LRRMLSS WITH moniker, message LOOR

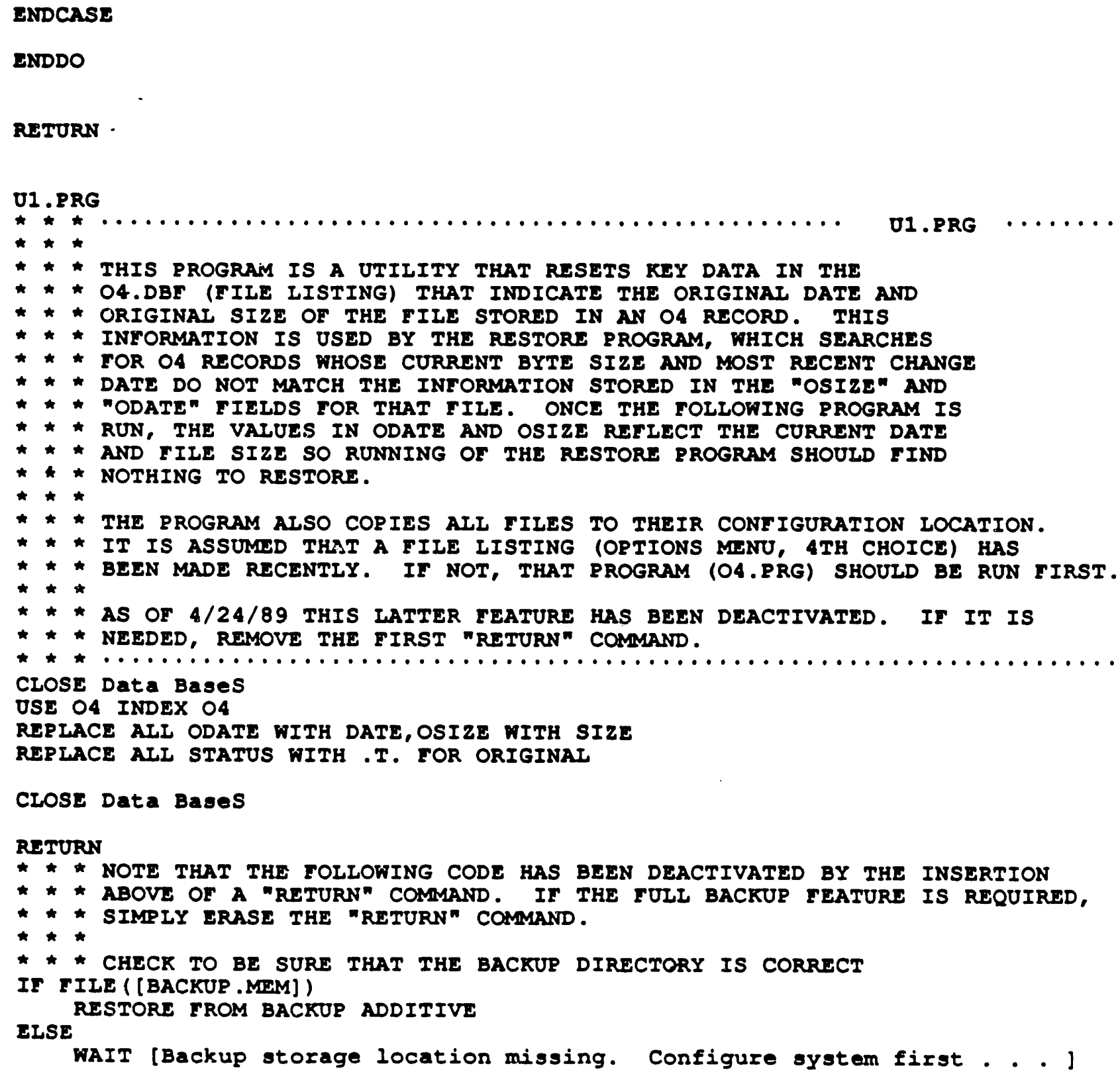




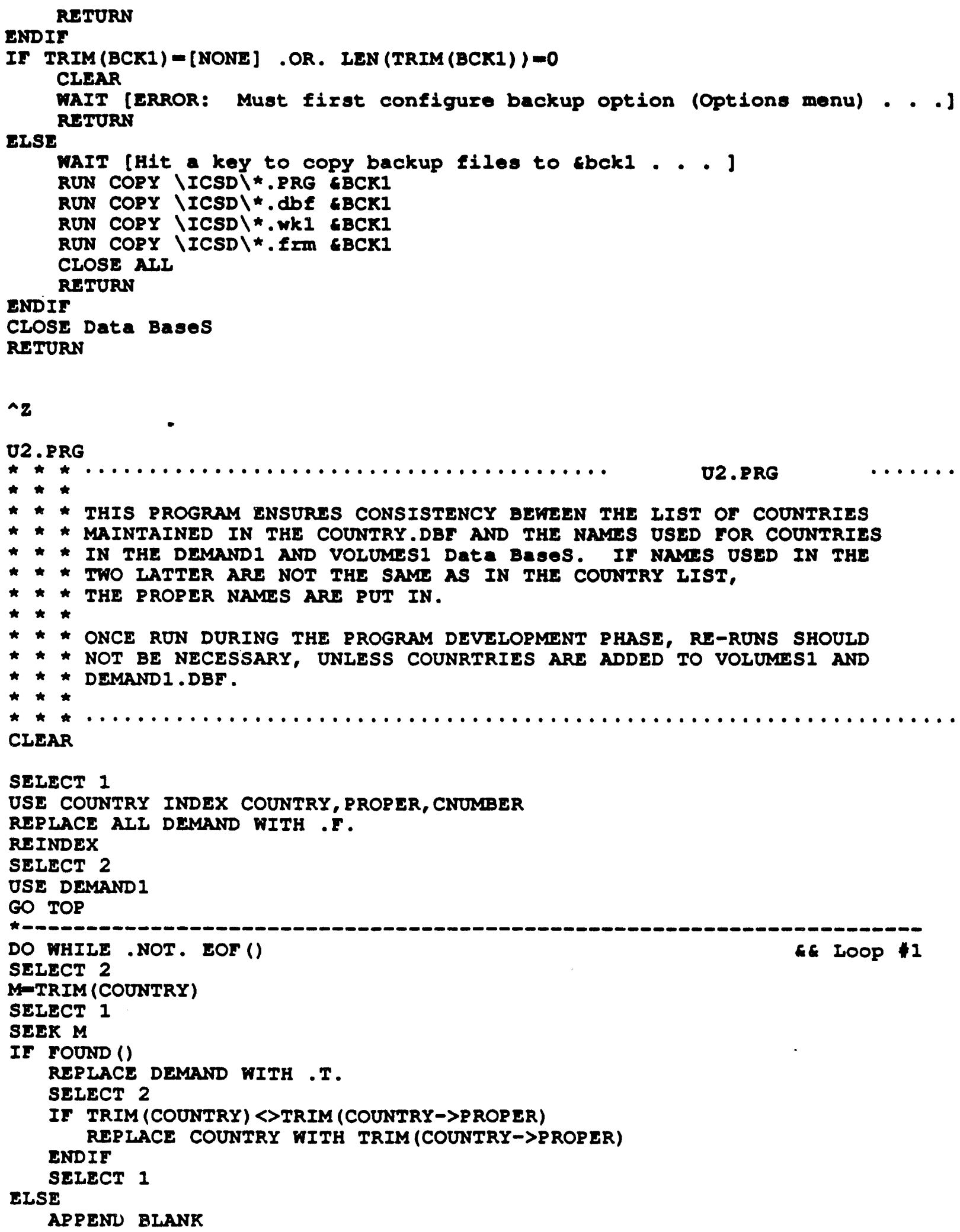




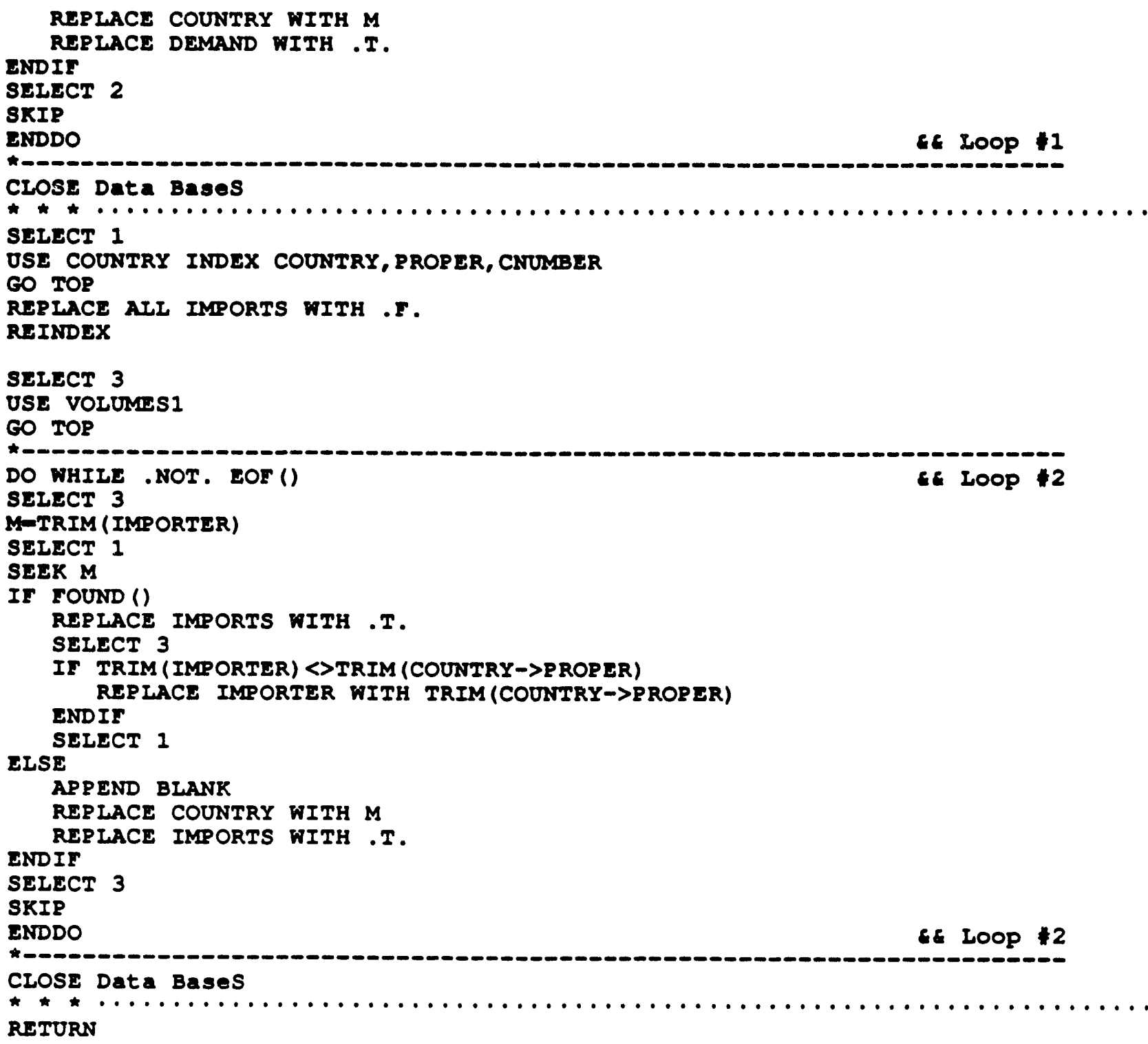




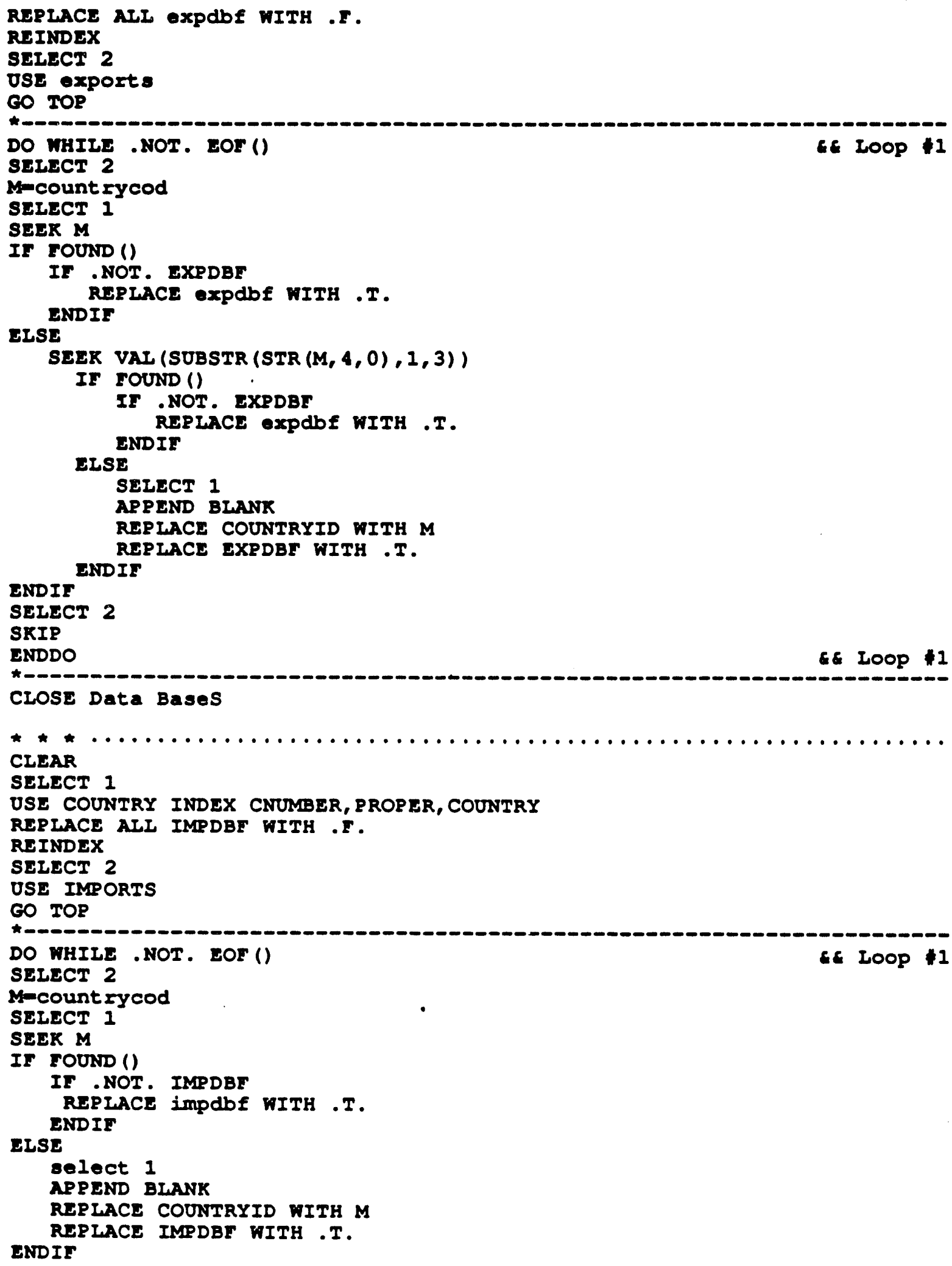


SELECT 2

SKIP

ENDDO

GE LOOP I

cLEAR asi

CLEAR

? [THE RROGRAM FINISHED RONNING AT ]+TIME()

RETURN

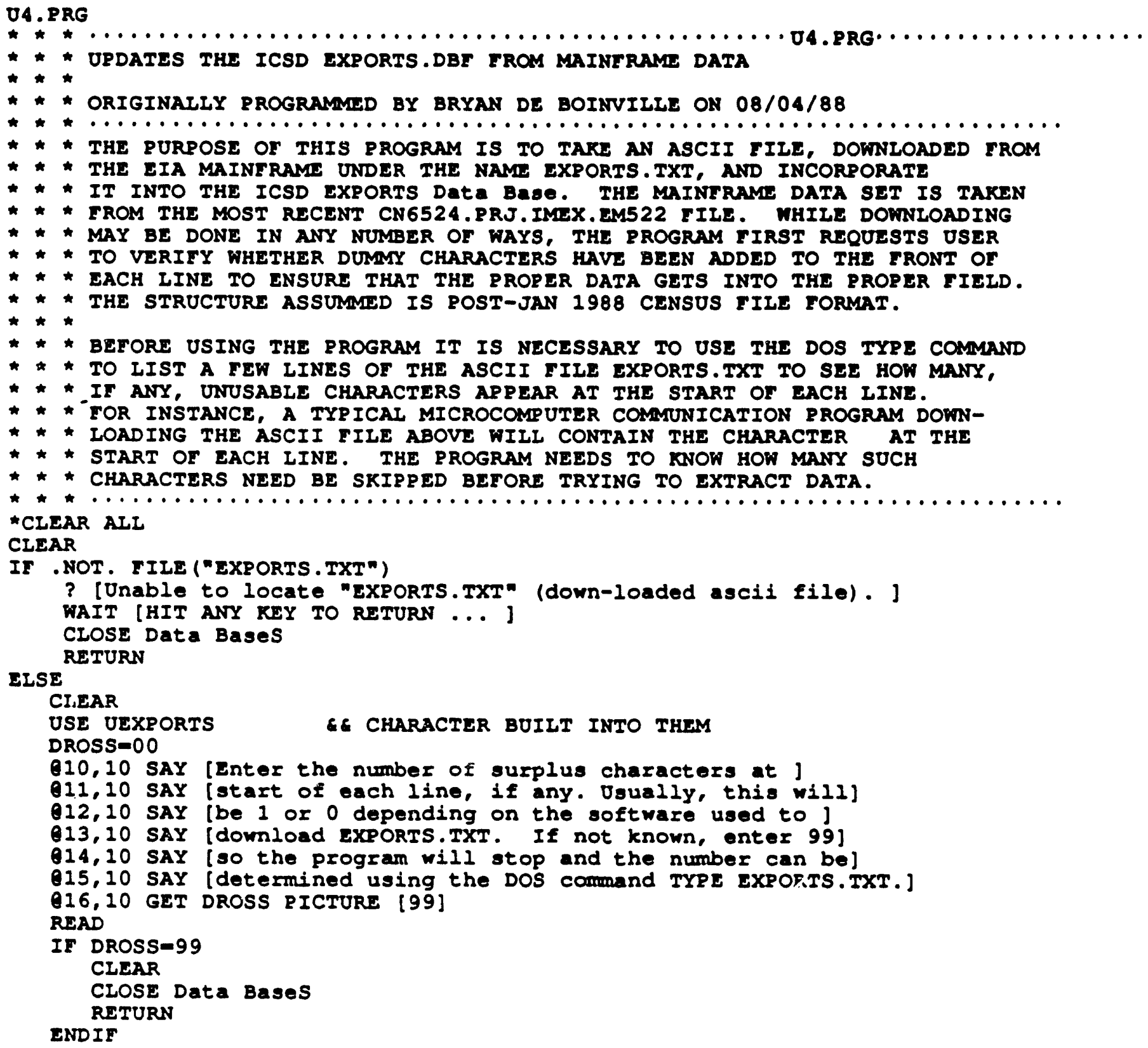


DROSS-DROSS-1

SET BAFEIY OTF

RAP

BET BATEIY ON

8LT TALK ON

CITAR

$?$

$?$ [Records are being added from the Export. Ixt 211e]

3 [

APPEND FROM EXPORTS. TXY SDT

8ET TMIN OFT

CO TOP

OSE

RUN zename EXPORTS.TXY oexporta.txt

ADIF

CIRNR

OSI U2xports

nnerecount () .

010,10 SAY [Update of the Usxports.Dbf has reached record \$]

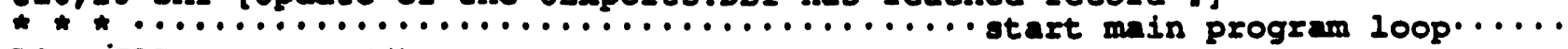

Do wirs . MOT. EOr ()

010,57 eay atz $($ recno ()$, 5,0)+[$ of $]+\operatorname{atc}(n n, 5,0)$

CHO-SUBSTR (EXPORTS, DROSS $+9,2$ )

REPLACE type MITH VAL (CHO)

CHI-SUBSTR (EXPORTS, DROSS + 14,4)

IF VAI (CAI) $>999$

REPIACE countrycod MITH VAL (CHI)

EISE

REPIACE countzycod WITH VAL (CHI) *10

\section{INDIF}

CH2-SUBSTR (EXPORTS, DROSS + 26,12)

REPHACE quantity2 WITH VAL (CH2)

CH3-SUBSTR (EXPORTS, DROSS + 18,2)

RIPIRCE portcode WITH VAL (CH3)

CHA-SUBSTR (EXPORTS, DROSS $+20,2$ )

RERIACE month VITH VAI (CH4)

CHS-SUBSTR (EXPORTS, DROSS + 22,2)

REPIACE year NITH VAI (CH5)

CH6-SUBSTR (EXPORTS, DROSS + 38, 12)

REPIACE Cardcount WITH VA工 (CH6)

CA7-SUBSTR (EXPORTS, DROSS + 50,12)

REPIACE quantity WITH VAI (CH7)

CH8-SUDSTR (EXPORTS, DROSS + 62,12)

REPLACE value WITH VAL (CH8)

IF QONNTITY > 0

RGPIACE PRICEPERIN NITH VALUE/QOANTITY

EISE

RGPIACE PRICEPERTN WITH 0

MNDIE

CH9-SUBSTR (EXPORTS, DROSS + 74, 12)

REPLACE shipweight VITH VAI (CH9)

CH10 $=$ STR (KONTH, 2, 0) + [/01/]+STR $($ YMAR, 2, 0)

REPIACE date NITH CTOD (CHIO)

CAII-SUBSTR (EXPORTS, DROSS + 86,12)

REPLACE ahipvalue WITH VAL (CHII)

010,56 CLEAR TO 10,79

SKIP 
ENDDO

* * cusar

$?$

[The file just created, UEXPORTS.DBF, must now be edited to delete]

? [extraneous material at the begining and end of the elle. After]

? [pressing a key, the BROWse command will be used for this purpose.]

3 [Use CTRI + 0 to mark record for deletion. Jse CTRI + HOMS to move]

? [from the top to the bottom of the file.] CIEAR TYP EAHEAD

$?$

WAIT [Read these instructions before going on ....]

BRONSE

SET TALK ON

PACK

SET TAIK OFE

OSE

CLEAR

TEXT

UEXPORTS.DBF is now ready to be appended to EXPORTS.DBF.

The next section of the program does this for you. If you wish to do it manually, enter $x$ to exit.

If you want the program to update the exports file, enter 2 if all of the old sxports.Dbf records should be erased and replaced with the new data.

If the old records should be retained and the new ones added at the end, enter $A$.

ENDTEXT

SET TAIK ON

CLEAR TYPEAHEAD

WAIT [- ] to choice

DO CASE

CASE UPRER (CHOICE) $=[\mathrm{X}]$

CLEAR

RETURN

CASE UPRER (CHOICE) = [A]

USE EXPORTS

APPEND FROM UEXPORTS

USE

CASE UPRER (CHOICE) = [z]

USE EXPORTS

SET SATETY OFE

ZAP

SET SAFETY ON

USE

OTHERWISE

CLEAR

RETURN

ENDCASE 
CLIAR

? [The new EXPORTS.DBF file is now complete and reindexed. ]

$?$

WAIT

CIEAR

RETURN

\section{U6. PRG}

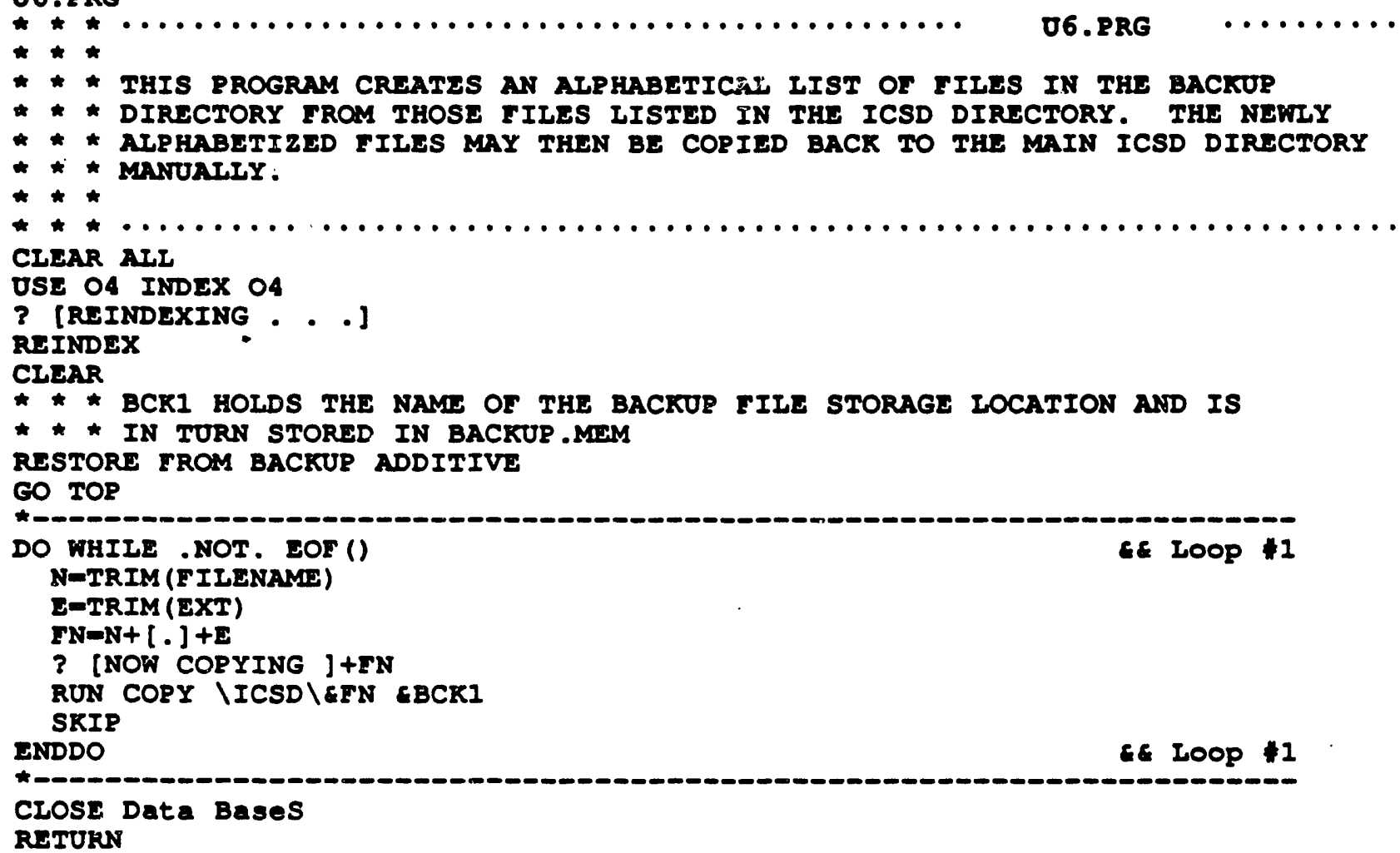

$\hat{n z}$

$\sim \mathbf{z}$

07. PRG

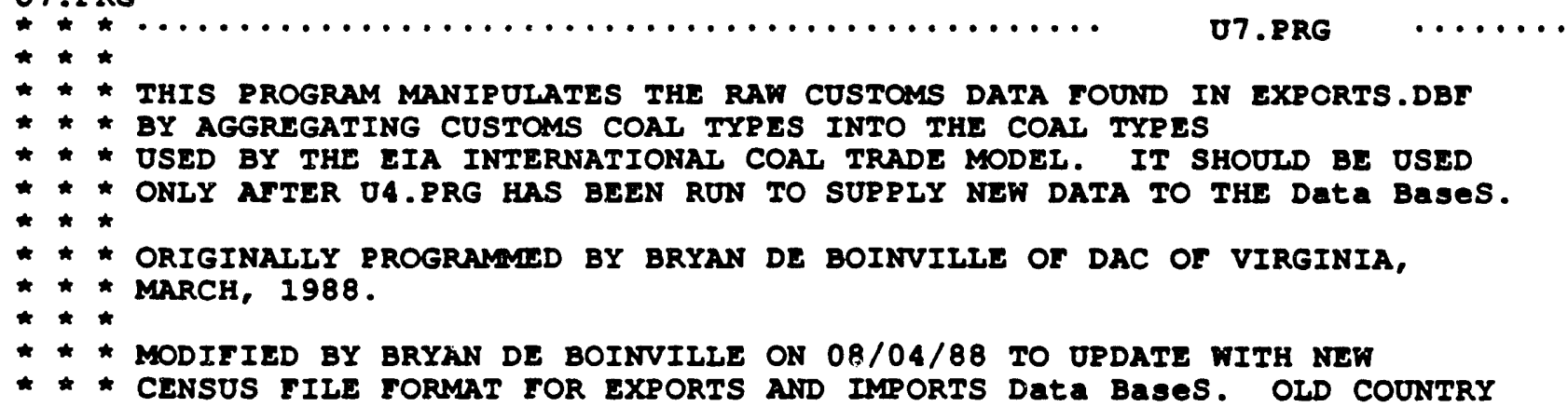




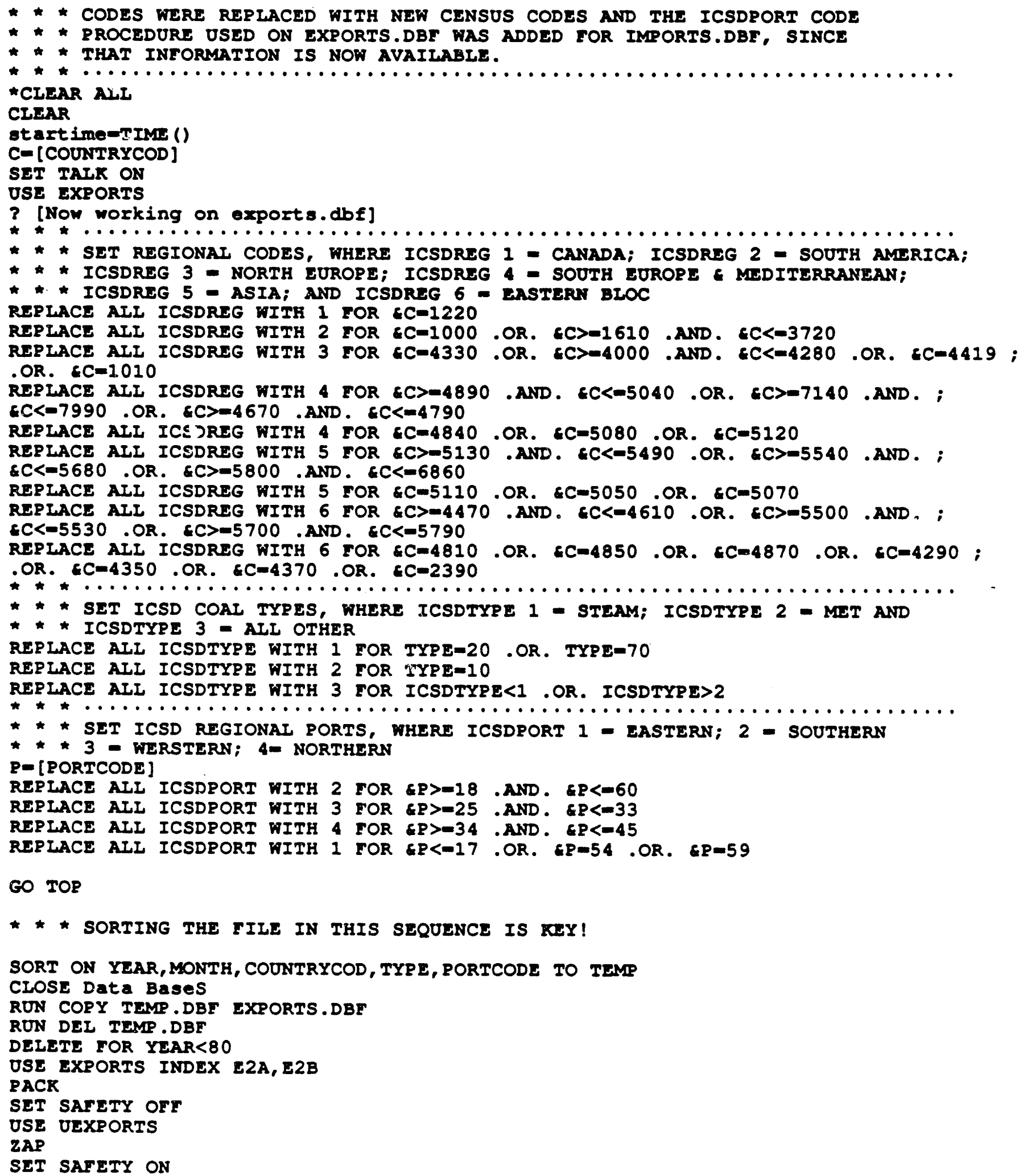


USE EXPORTS INDEX E2A, E2B

REINDEX

CLEAR

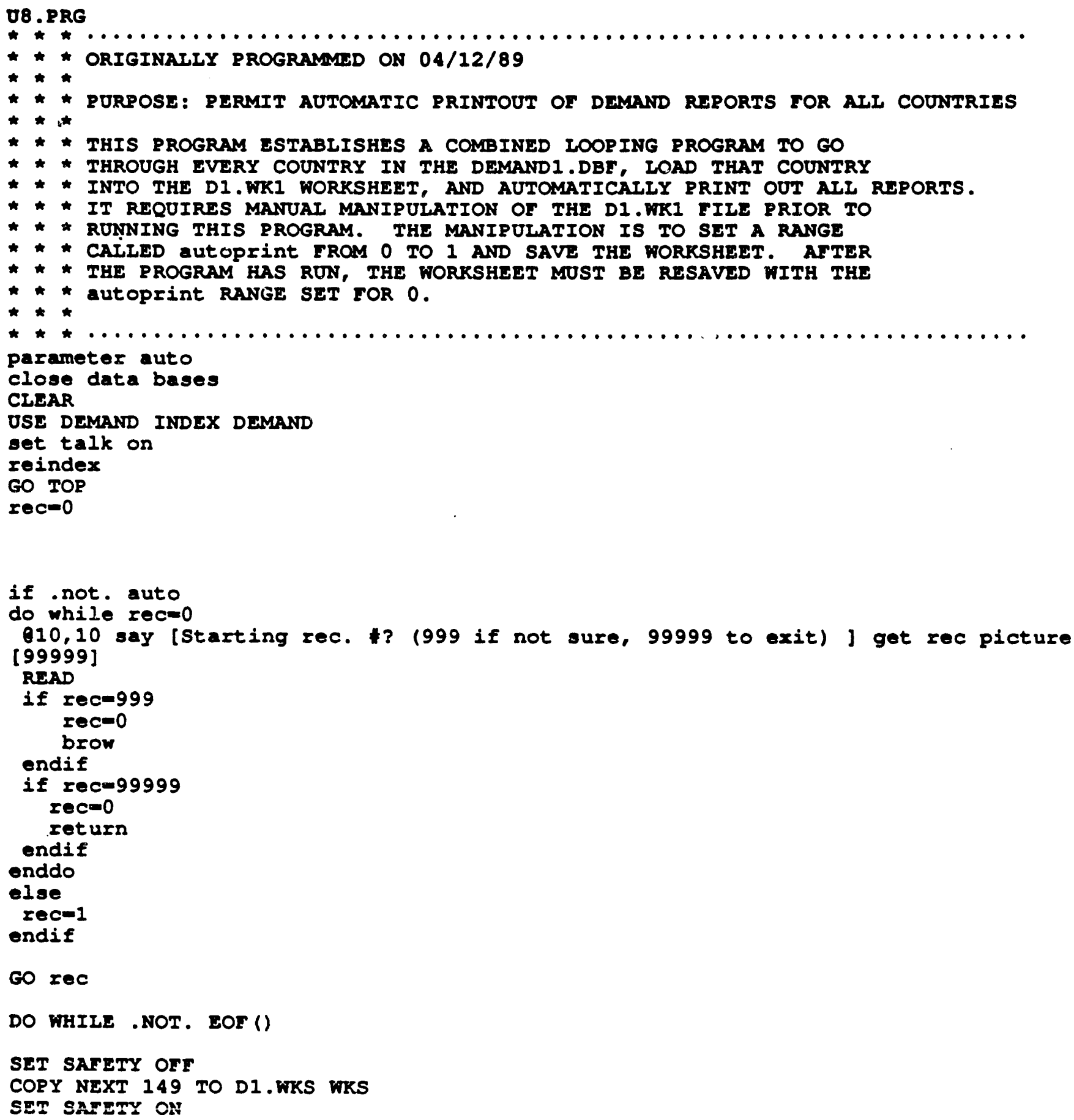


RUN CORY AUTO123.DI AUTO123. WK1 >NOL

RESTORE FROM CONFIG ADDITIVE

newdrive=SUBSTR (LOTUS, 1, 2)

RUN GNEWDRIVS

newdirect $=[C D]+$ lotus

RUN Gnewdirect

RON 123

RESTORE FROM CONFIG ADDITIVE

OLDDRIVE=SUBSTR (IICSD, 1, 2)

RUN COLDDRIVS

CDLOC=[CD ] +LICSD

RUN \&CDIOC

$?[$

SRIR 1

ENDDO

RETURN

\section{UCOUNTRY . PRG}

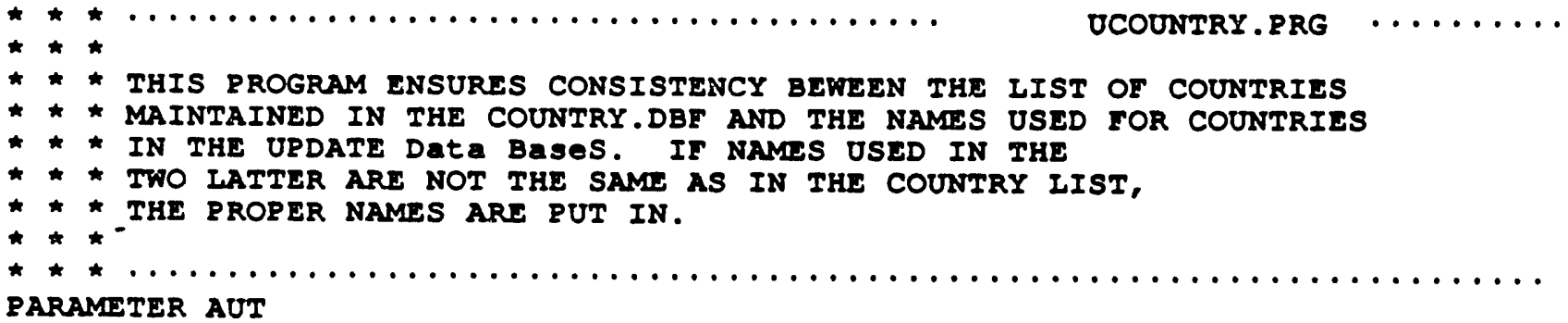

SELECT 1

SET TALK OFF

IF FILE ( [UDMD . MEM])

REST FROM UDMD ADDITIVE

ENDIF

ip-TRIM (MPATHICSD) + [ ]

dn=IP + [ COUNTRY]

USE EDN

DNI $1=I P+[$ COUNTRY $]$

DNI2=IP + [PRORER]

DNI $3=I P+[$ CNUMBER]

SET INDEX to EDNI1, EDNI2, GDNI3

REINDEX

GO TOP

SELECT 3

IF .NOT. AUT

FILENAME =

OROW() +1, I SAY [Name and path of file to check ] get filename

READ

FNAME $=$ [

erow () $+1,1$ say [Name of field holding countries? ] GET FNAME

READ 


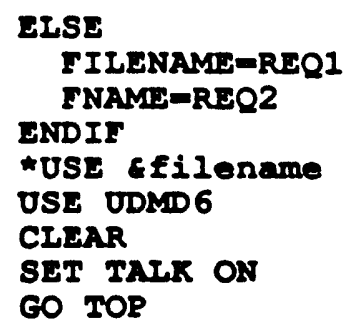

UDEMAND. PRG

* * THIS PROGRAM CONTROLS UPDATE OF THE DEMANDI.DBF OF THE ICSD. clear ali

ISITAUTO- T.

SET ESCAPE ON

CLEAR

TEXT

URDATING THE DEMAND Data Base

This program controls access to the six programs that update the DEMANDI.DBF:

1. UDMD1.PRG uses decompressed IEA data to build UDMD1 for the non-IEA countries - units : metric tons. Uses INDIVIDUAL COUNTRY files

2. UDMD2.PRG uses decompressed IEA data to build ODMD2 for the IEA countries units : metric tons Uses INDIVIDUAI C.OUNTRY files

3. ODMD3.PRG uses the intermediate file DDMD2 to update data in DEMAND1.DBF

4. UDMD4.PRG uses a data base, UDMD4.DBF, created by translating the DBASE range of UDMD. WK1 from Lotus format to dBase format, to update the outyear forecasts contained in DEMANDI.DBF.

5. UDMD5.PRG uses the intermediate file UDMD1 to update data in DEMAND1.DBF. 
(Check units)

6. UDMD6.PRG builds ODMD6.DBF from decompressed IEA BES

files. Covers both IEA and NON-IEA countries, unitgm actual metric

7. ODMD7.PRG updates DHMAND1 using UDMD6 data = metric actual

8. UDMD8.PRG creates DEMAND.DBE from DEMAND1.DBE

9. UDMD9.PRG builds UDMD6.DBE from decompressed IEA BAL

files. Covers both IEA and NON-IEA countries, unitse MTOE ENDTEXT

WAIT

MPATHICSD=SPACE (35)

IF $\operatorname{FIIE([UDMD~.~MIMU])~}$

ENDIF

REST FROM UDMD. MAM ADDITIVE

CLEAR

Q 10, 10 SAY [Where are ICSD files stored: full path, do not end with 'l' ] - 12, 10 GET MPATHICSD PICTURE [Q!]

READ

SET SAFETY OFF

SAVE AIL TO UDMD

close all

SET ESCAPE ON

^DO UDMDI WITH ISITAUTO

*DO UDMD2 WITH ISITAUTO

*DO UDMD3 WITH ISITAUTO

^DO UDMD.4 WITH ISITAUTO

•DO UDMD 5 a WITH ISITAUTO

DO UDMD 6 WITH ISITAUTO

DO UDMD7 WITH ISITAUTO

quit

UDIR.PRG

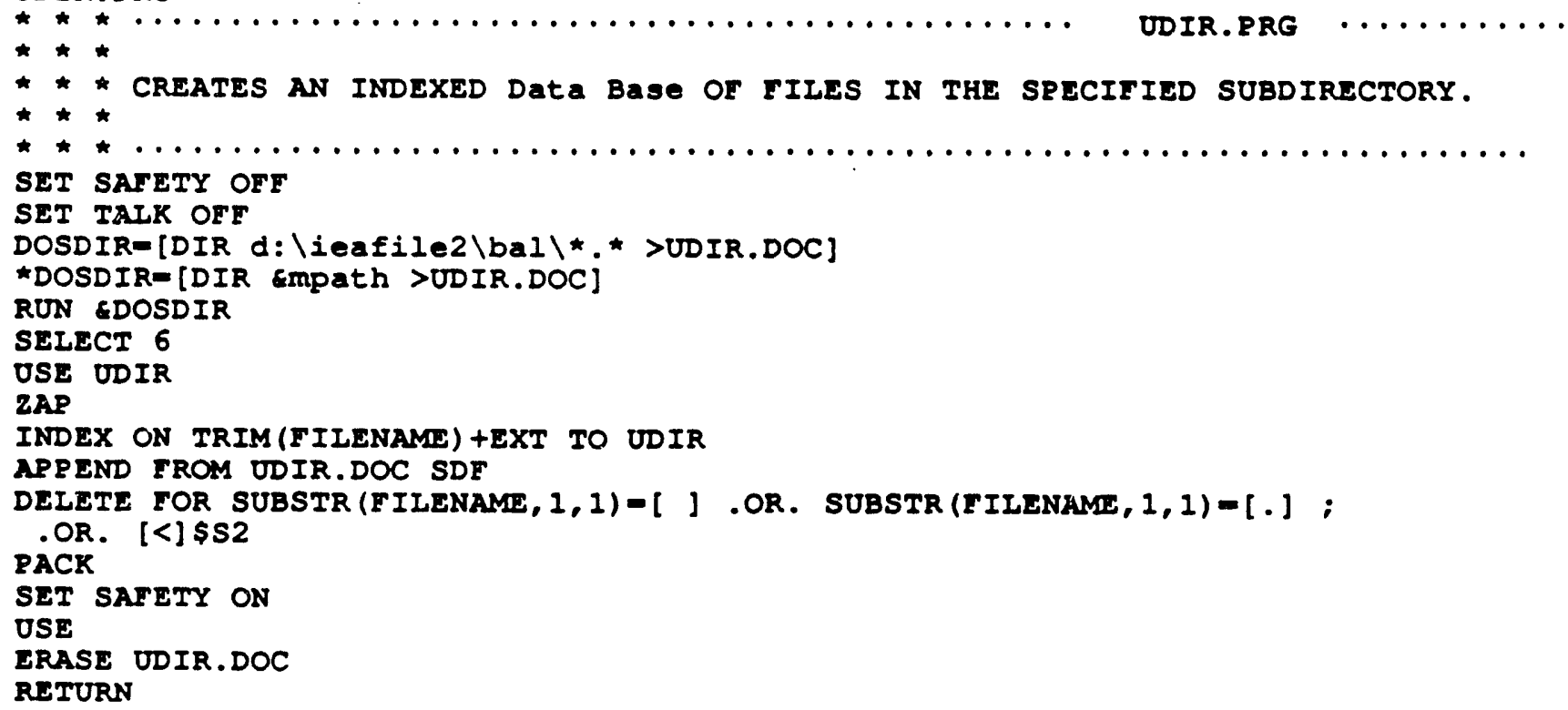




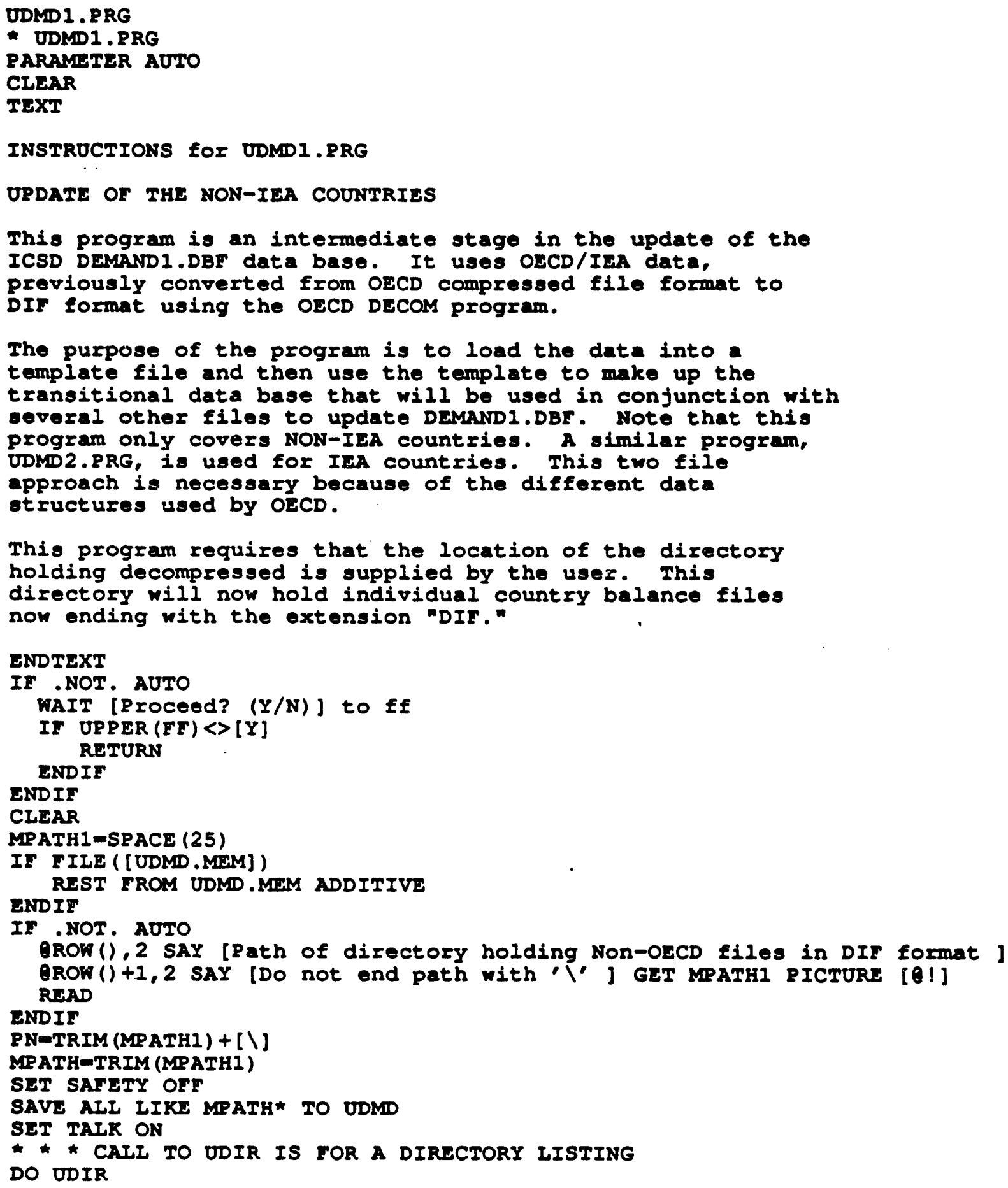




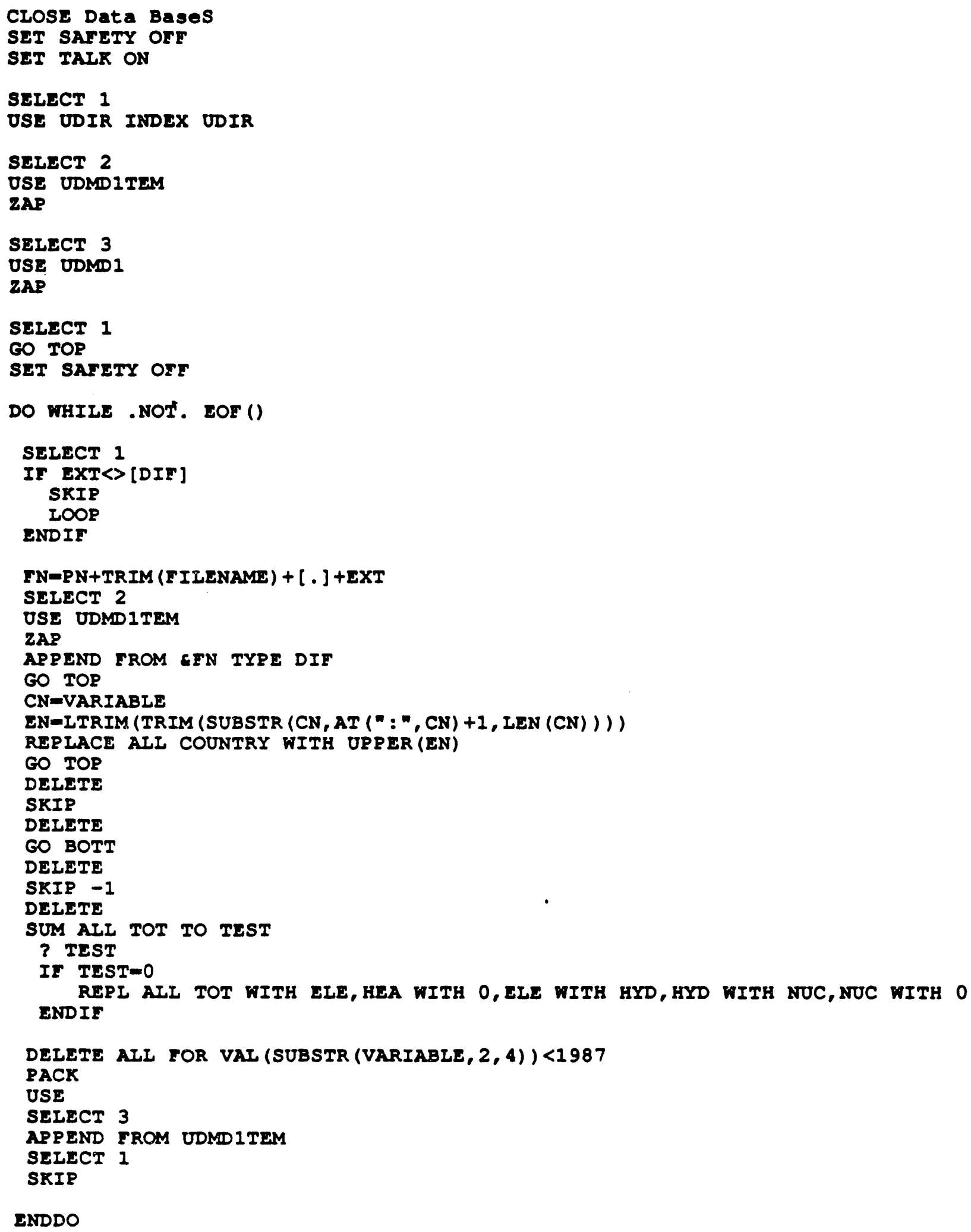

ENDDO 


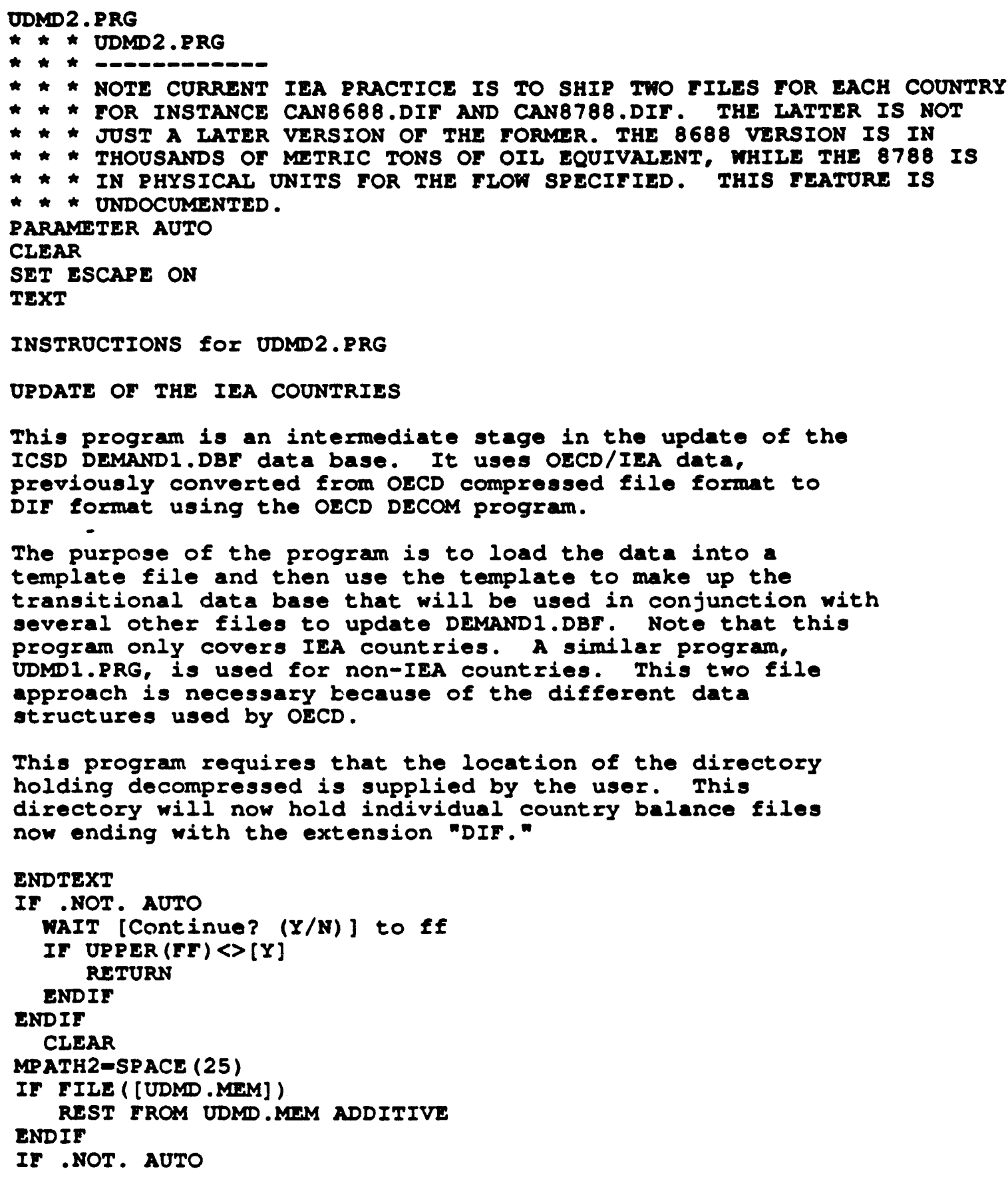




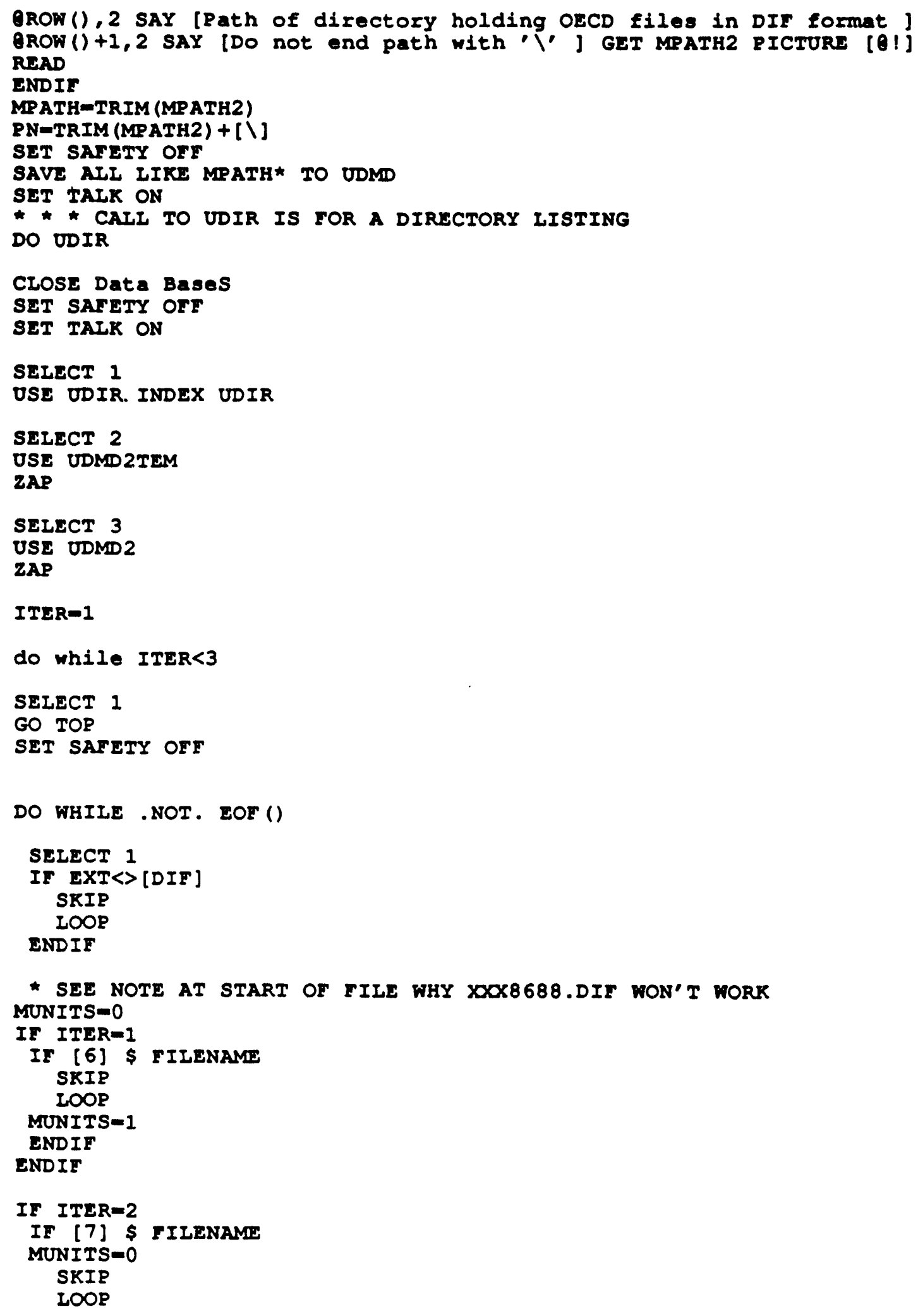


ENDIF

ENDIF

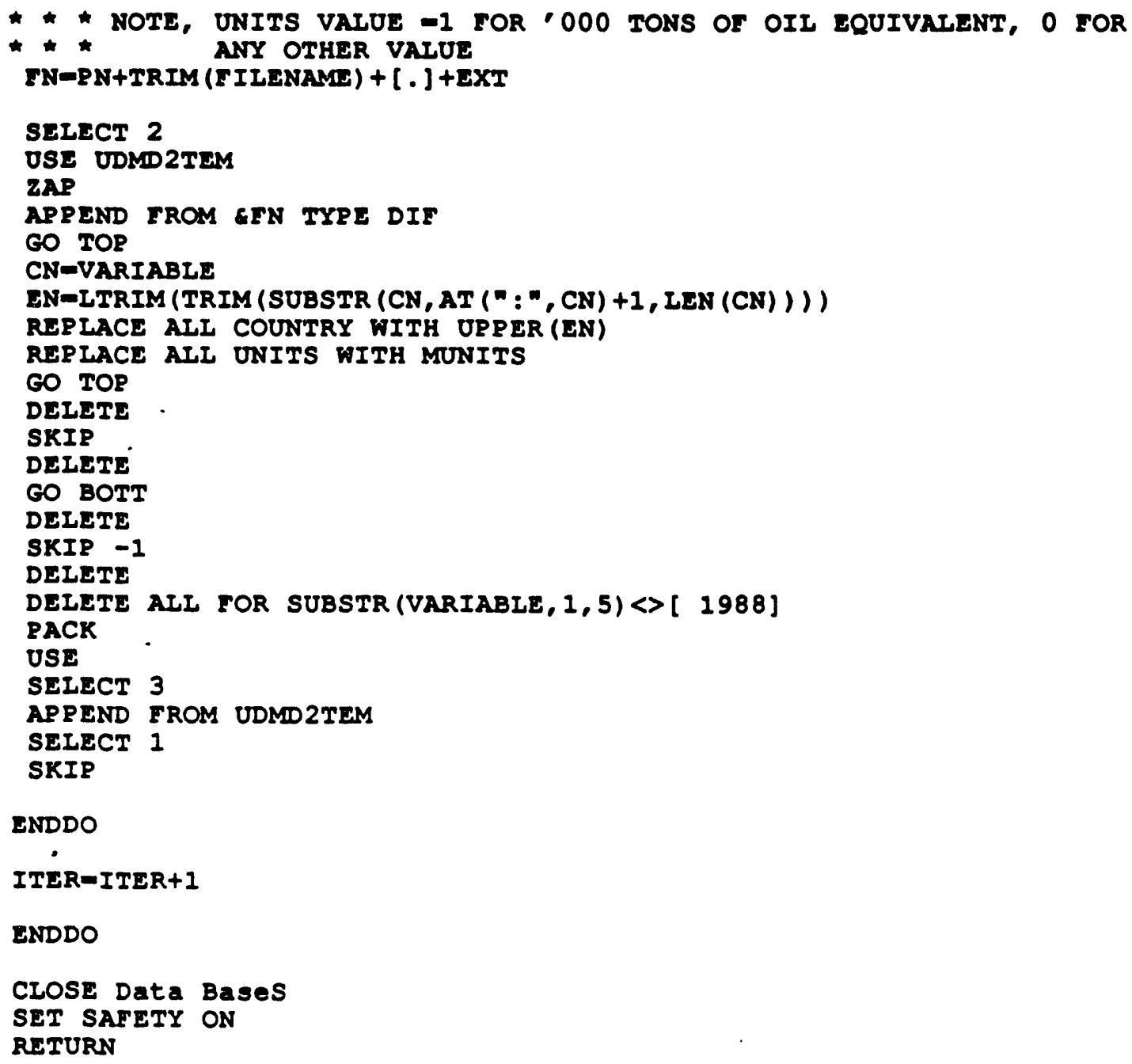

ENDDO

$I T E R=I T E R+1$

ENDDO

CIOSE Data Bases

SET SAFETY ON

RETURN

ODMD3 . PRG

* * UDMD3.PRG

parameter aUto

CLEAR

SET SAFETY OFF

TEXT

Opdating DEMAND1.DBF STEP 3

This program uses the values stored in UDMD2.DBF to update the national demands stored in DEMAND1.DBF of the ICSD. The former file must have been created prior to running this program. In essence, 
It holds the values from the most recent IEA data fiels, decompressed, and loaded into dBase format by UDMD2.PRG. The values are for IEA / OECD countries.

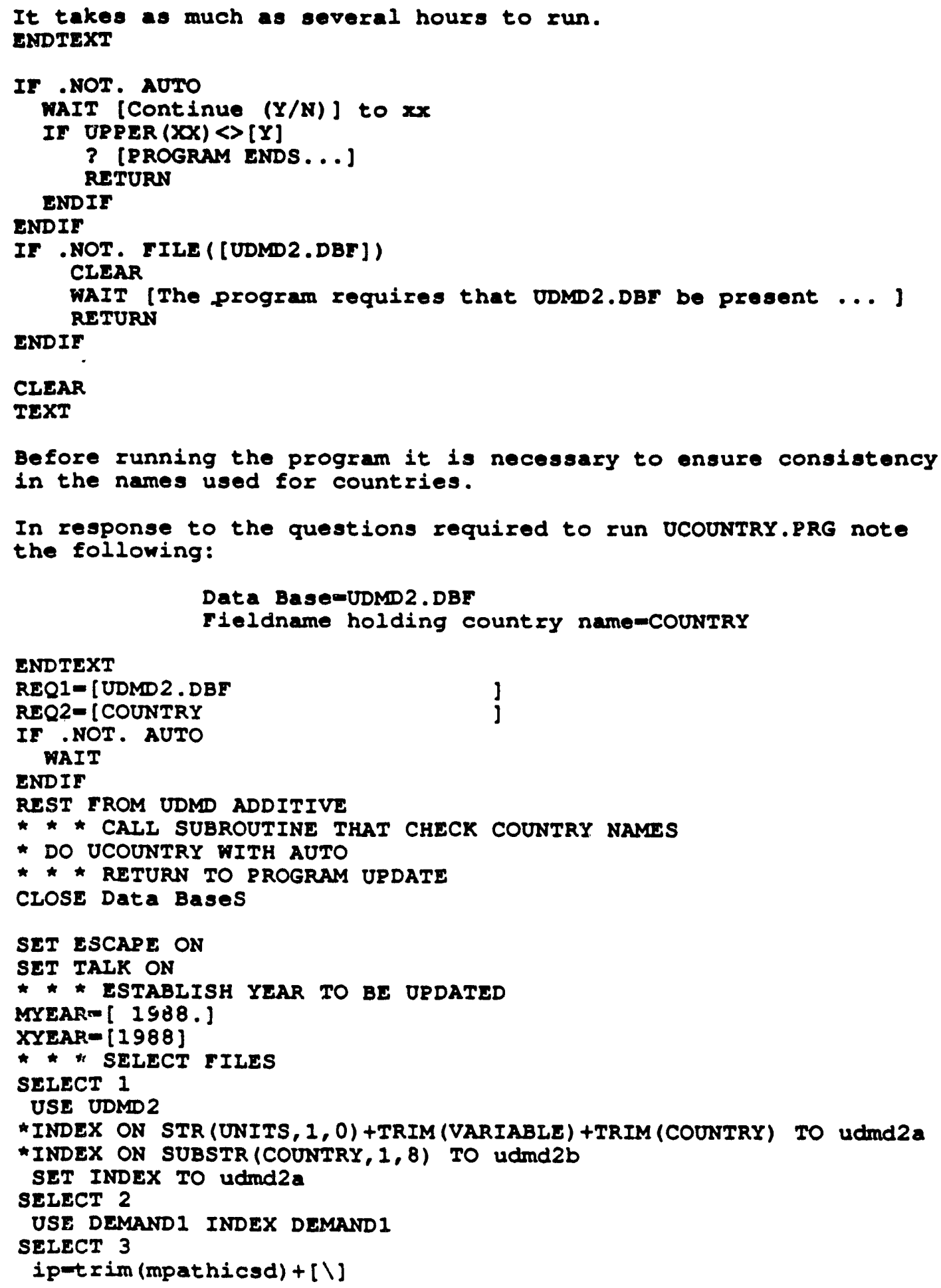




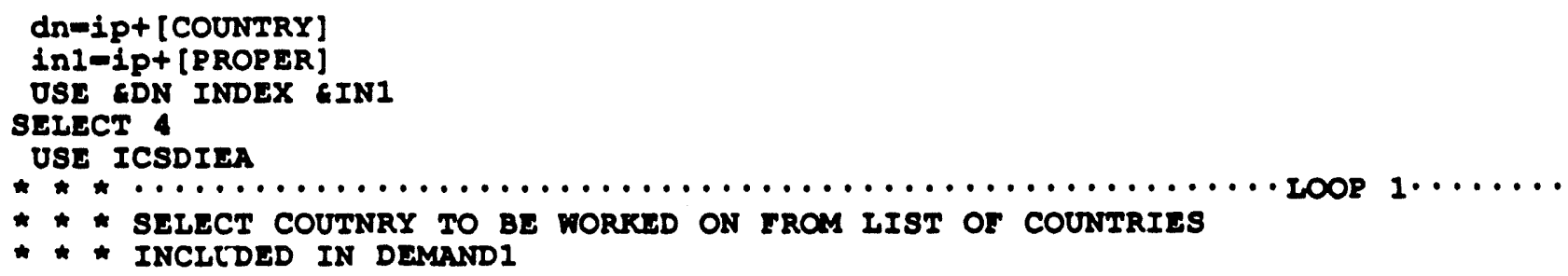

- CNAME2-COUNTRY

CNAME-SUBSTR (UPPER (PROPER) , 1,8)

CNAME2-PROPER

CNAME-TRIM (CNAML)

* * *ITH COUNTRY SELECTED, GO TO IEA DATA AND SEE IF

* * THAT COUNTRY IS INCIUDED FOR THE YEAR IN QUESTION. 


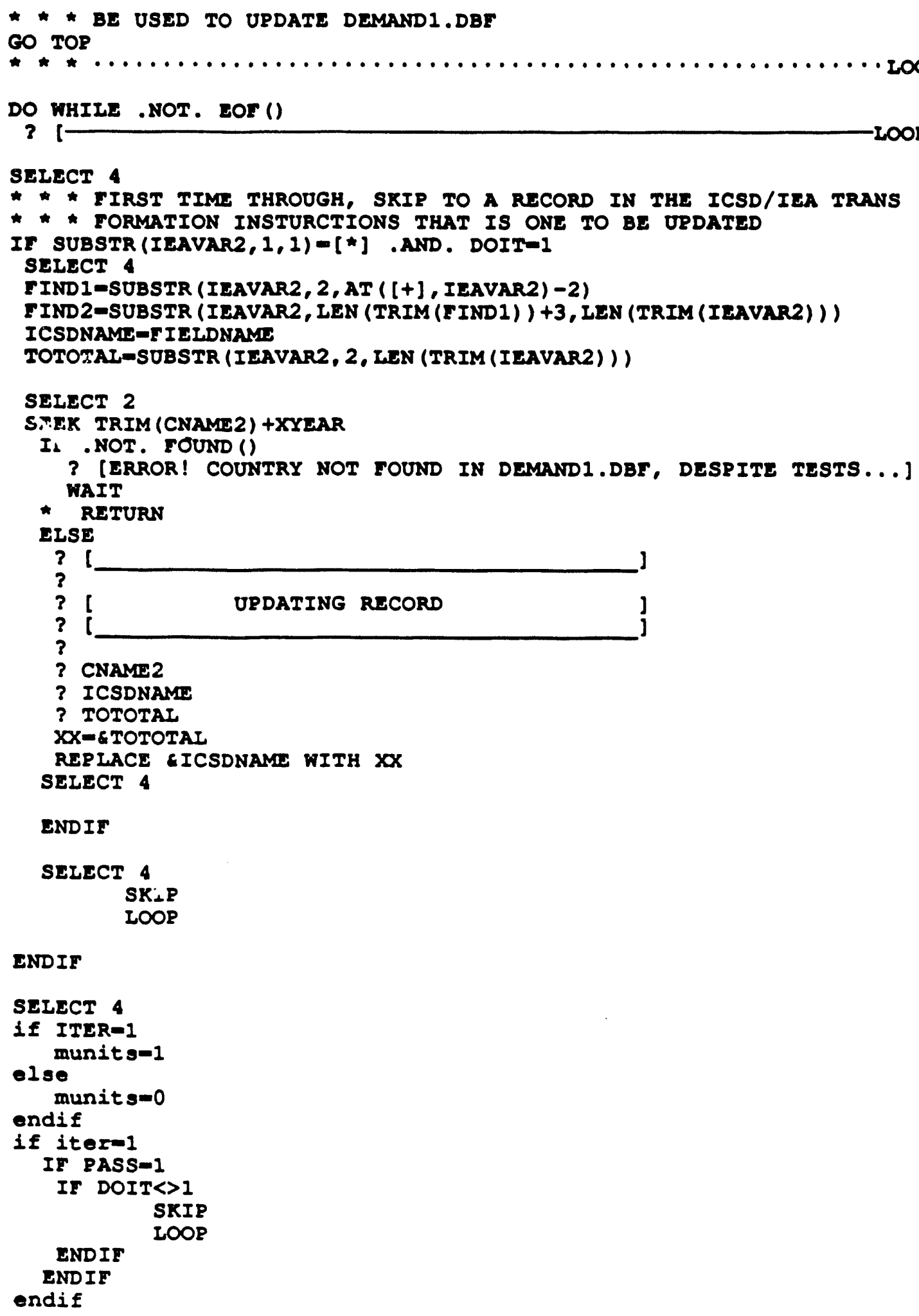




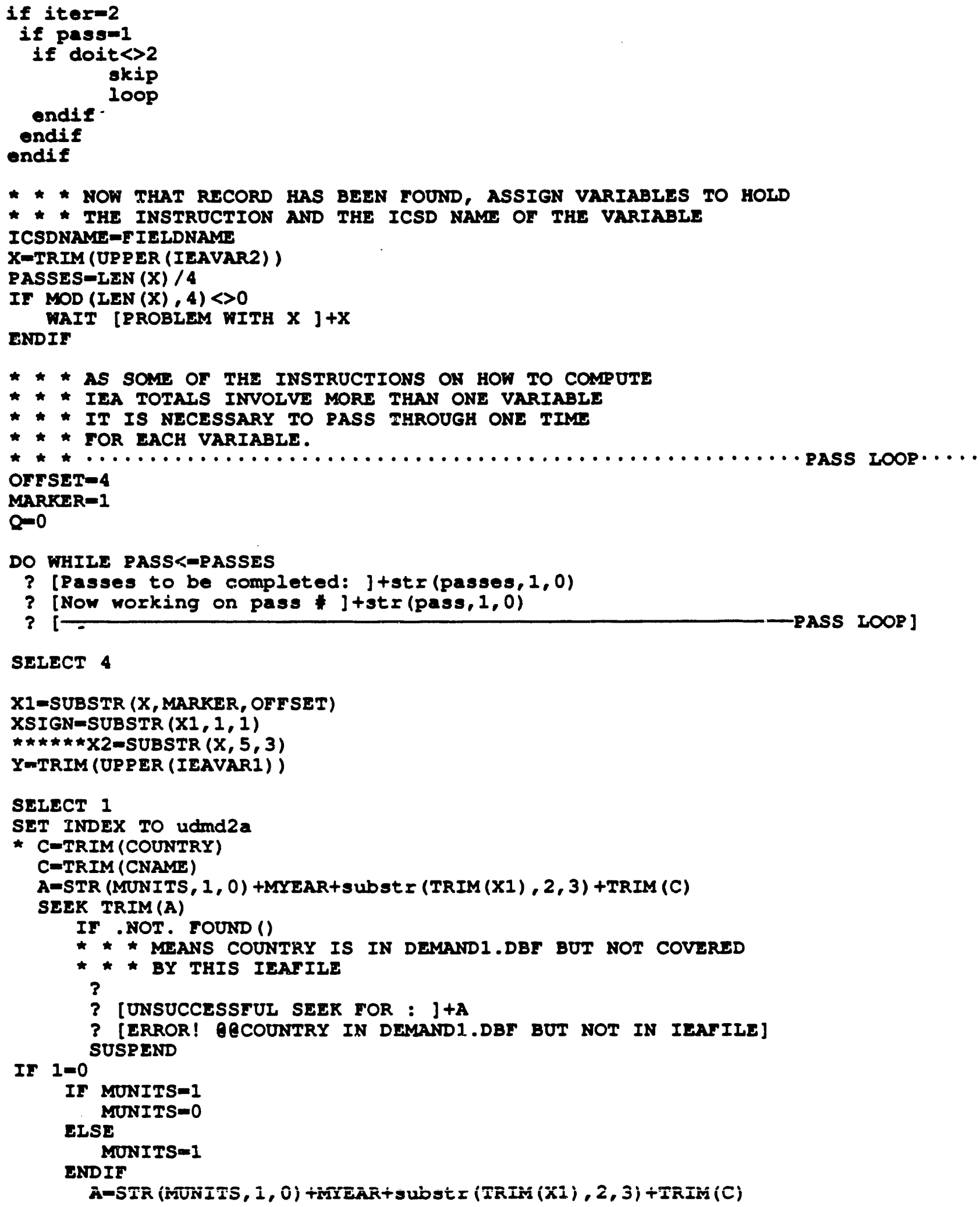




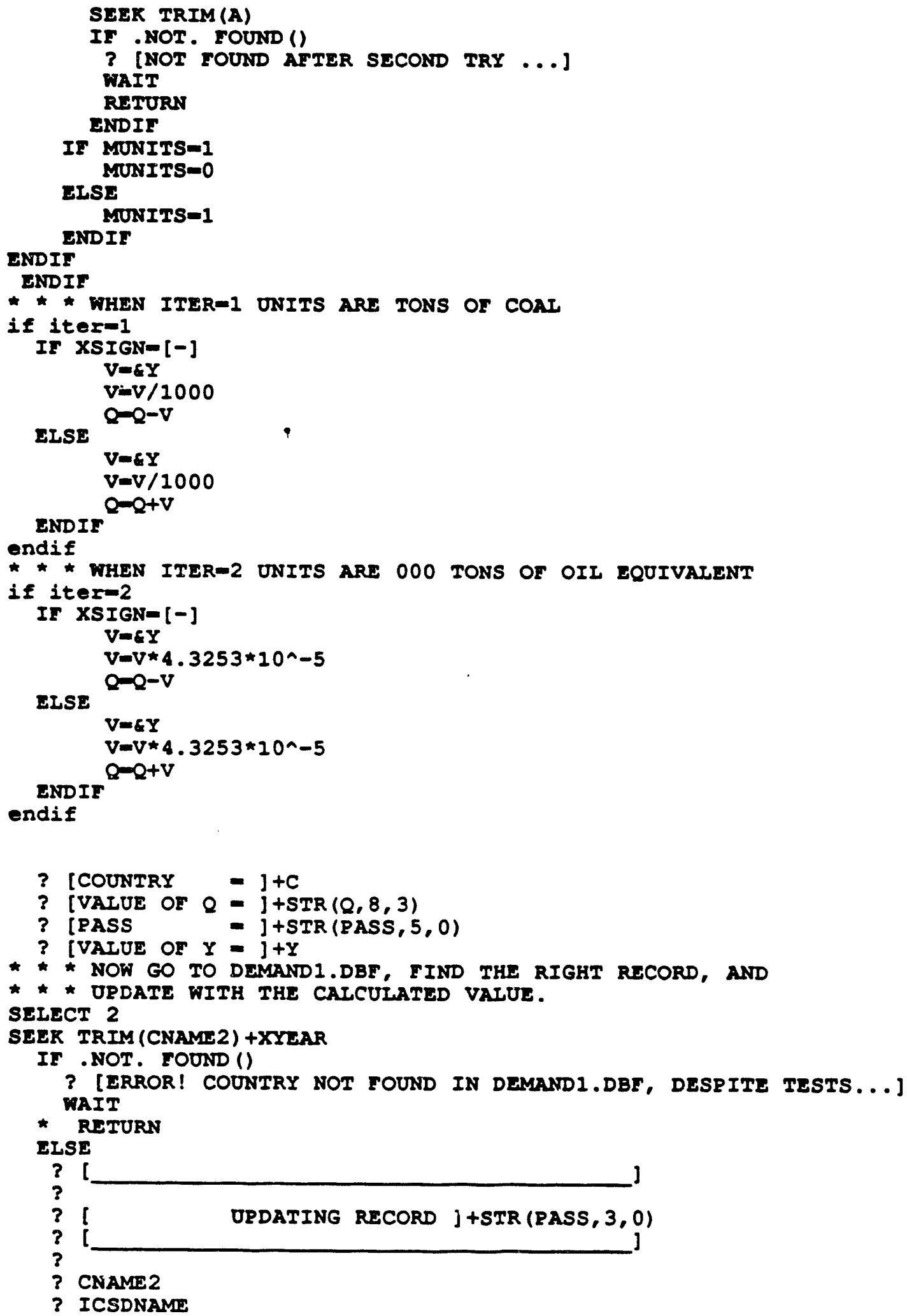


REPLACE EICSDNAME WITH $Q$

ENDIF

SELECT 4

PASS-PASS+1

MARKUR-MARKERTOFTSET

* IF MARKUR I IEN (X)

* markiraral

* MaIt [LEAVING pass IOOR BEcadse OF NOThING ELSE TO DO]

$\star \quad$ EXIT

* BNDIF

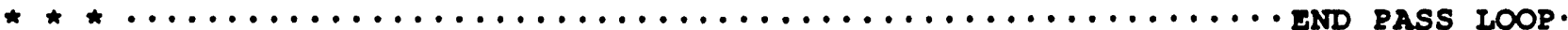

ENDDO

PASS=1

SELECT 4

SKIP

SNDO

SELE 3

SKIP

$\star \star$

ENDDO

$I T E R=I T E R+1$

ENDDO

RETURN

UDMD4 . PRG

* PROGRAM TO UPDATE THE FORECAST VALUES OF DGMAND1.DBF OF THE ICSD. parameter auto

ClOSE Data Bases

CLEAR

TEXT

INSTRUCTIONS

This program updates the forecast values for the years 1995, 2000, 2005, and 2010 that are contained in the ICSD data base,

DIMAND $1 . D B E$.

Before running it, the file UDMD4.DBF must be present after having been created by the special worksheet UDMD.MK1. ODMD4.DBF results after using the Lotus TRANSIATE program to convert the UDMD. WKI range DBASE from Lotus file format to dBase III format. This UDMD. WK1 worksheet uses Lotus macros to process approximately two dozen files that hold forecasts for key coal economies. IF THESE 
FIIES HAVE NOT BEEN PRERARED, DO NOT RUN THIS PROGRAM....

This program will take approximately a half hour to complete.

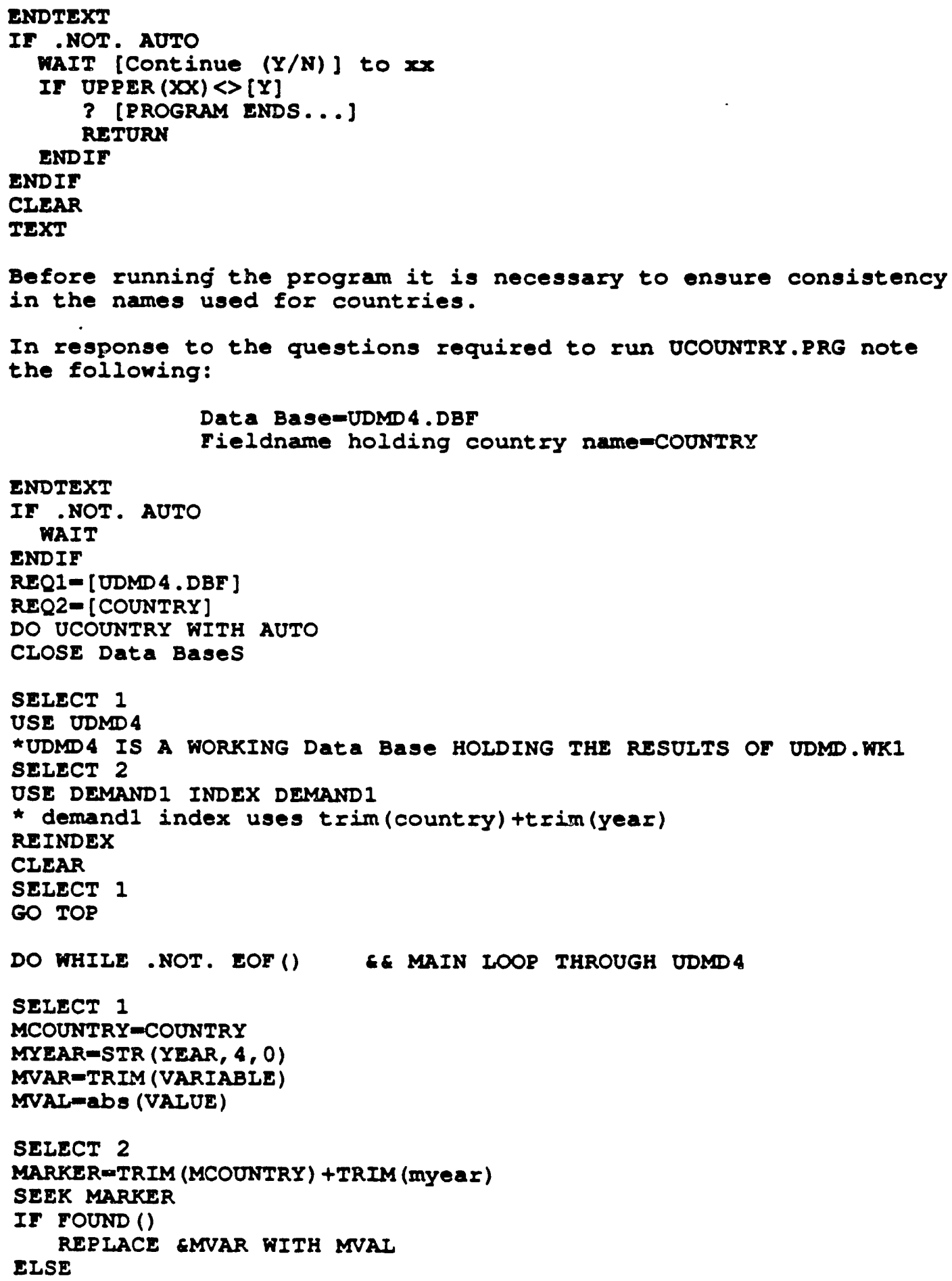




\section{CLGAR}

\section{ENDIF}

$?$ [MARKER = ] HMARKER

1

WAIT [ERROR! VAIUE NOT FOUND]

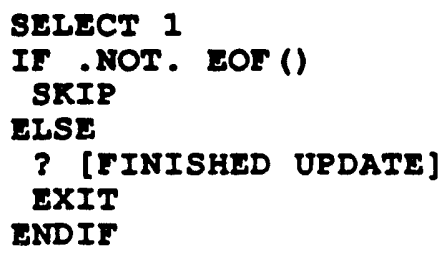

SELECT 1

IF . NOT. EOT ()

SKIP

ELSE

$?$ [FINISHED UPDATE]

EXIT

ENDIF

ENDDO

6E MAIN IOOR THROUGH UDMD4

RETURN

$\star \star \star$ Modified by B. de B. on $09 / 20 / 90$

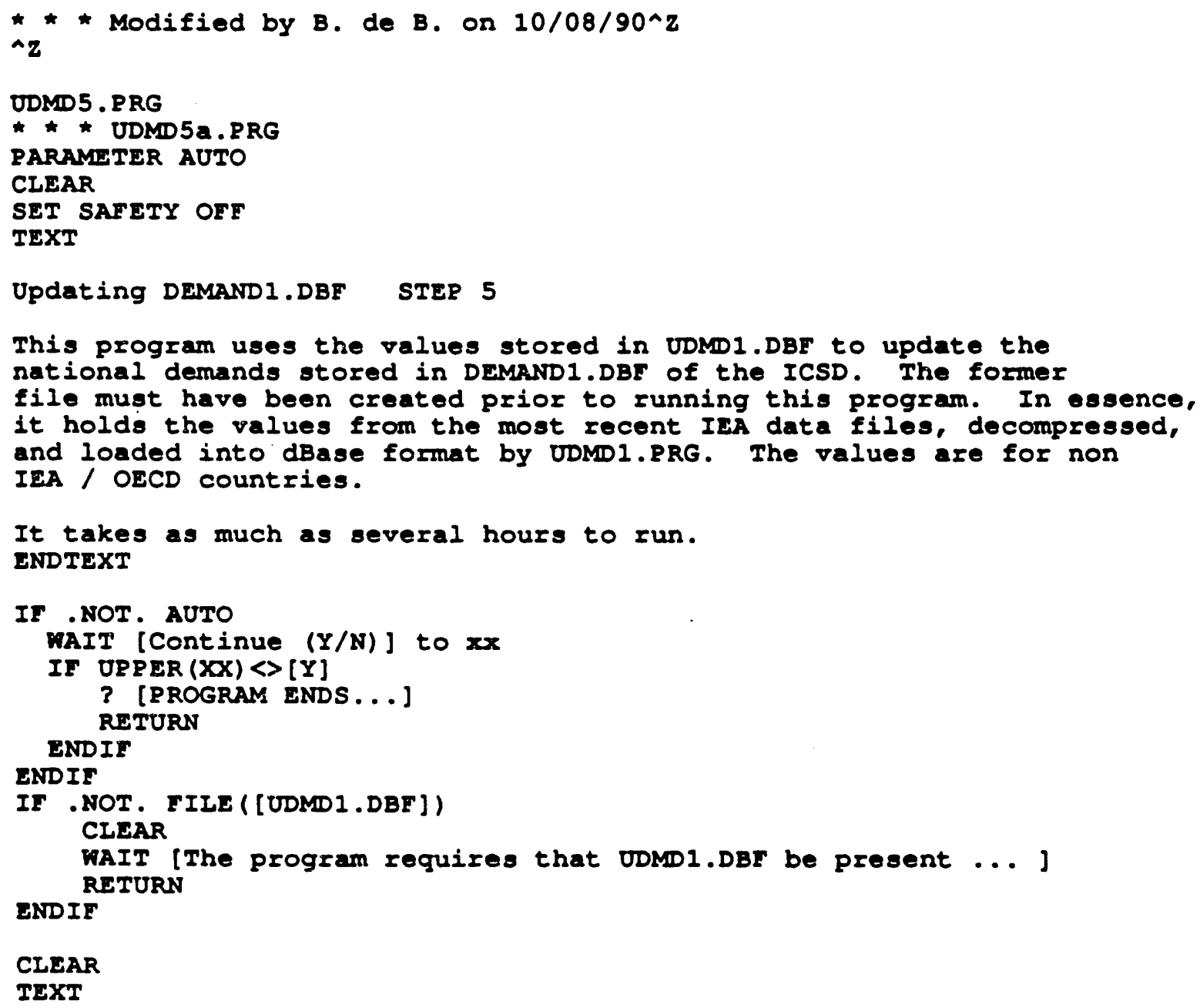




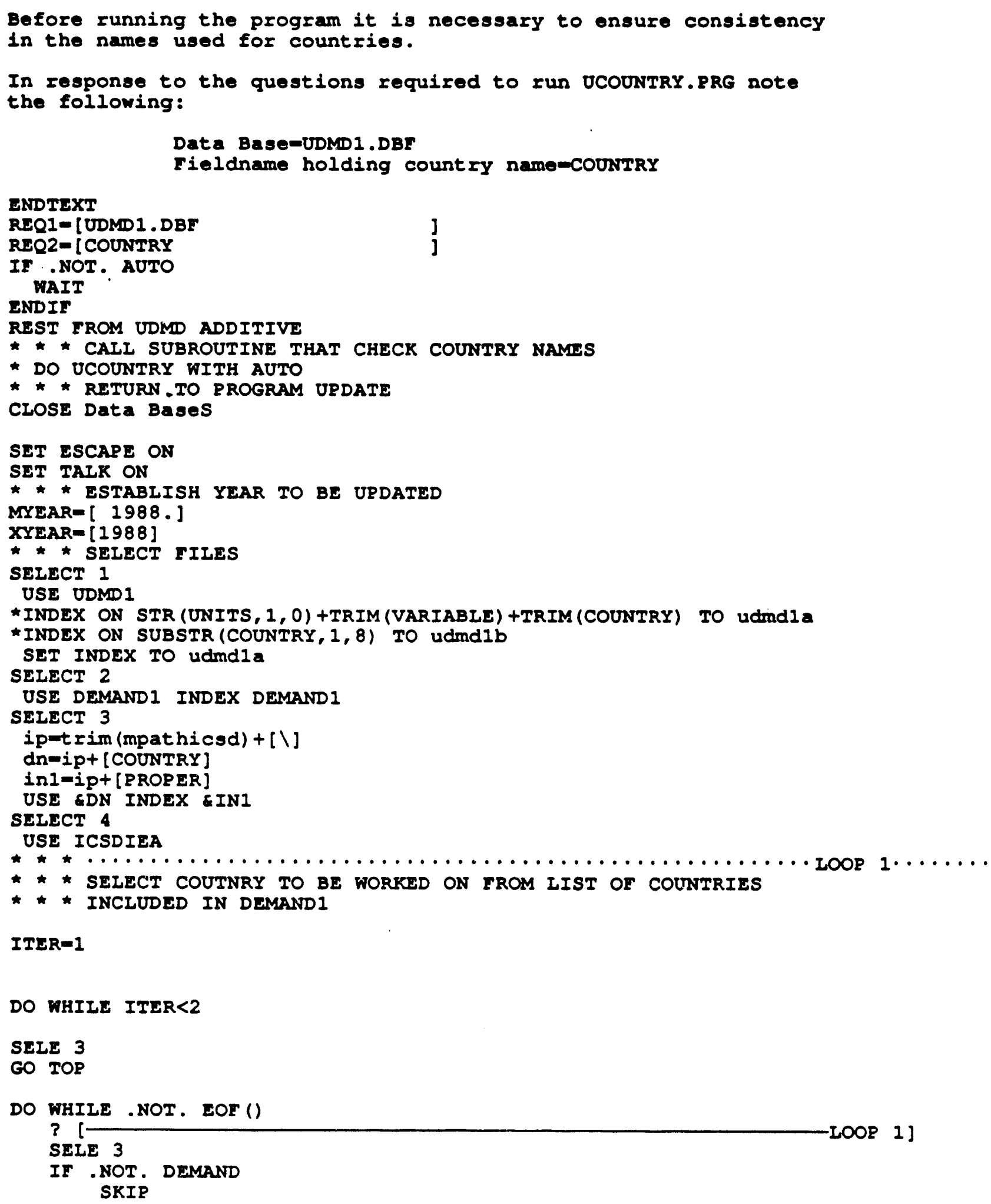




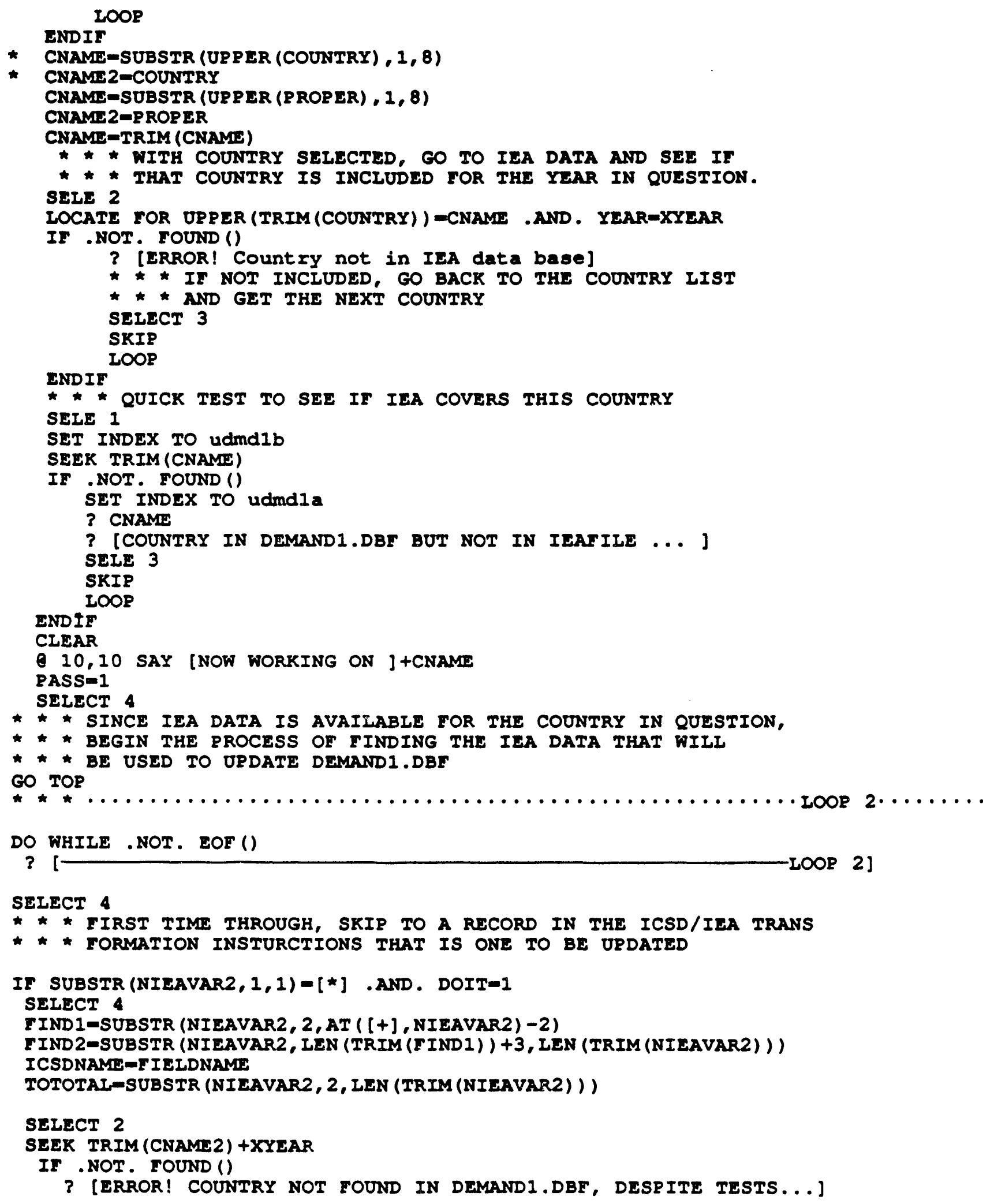




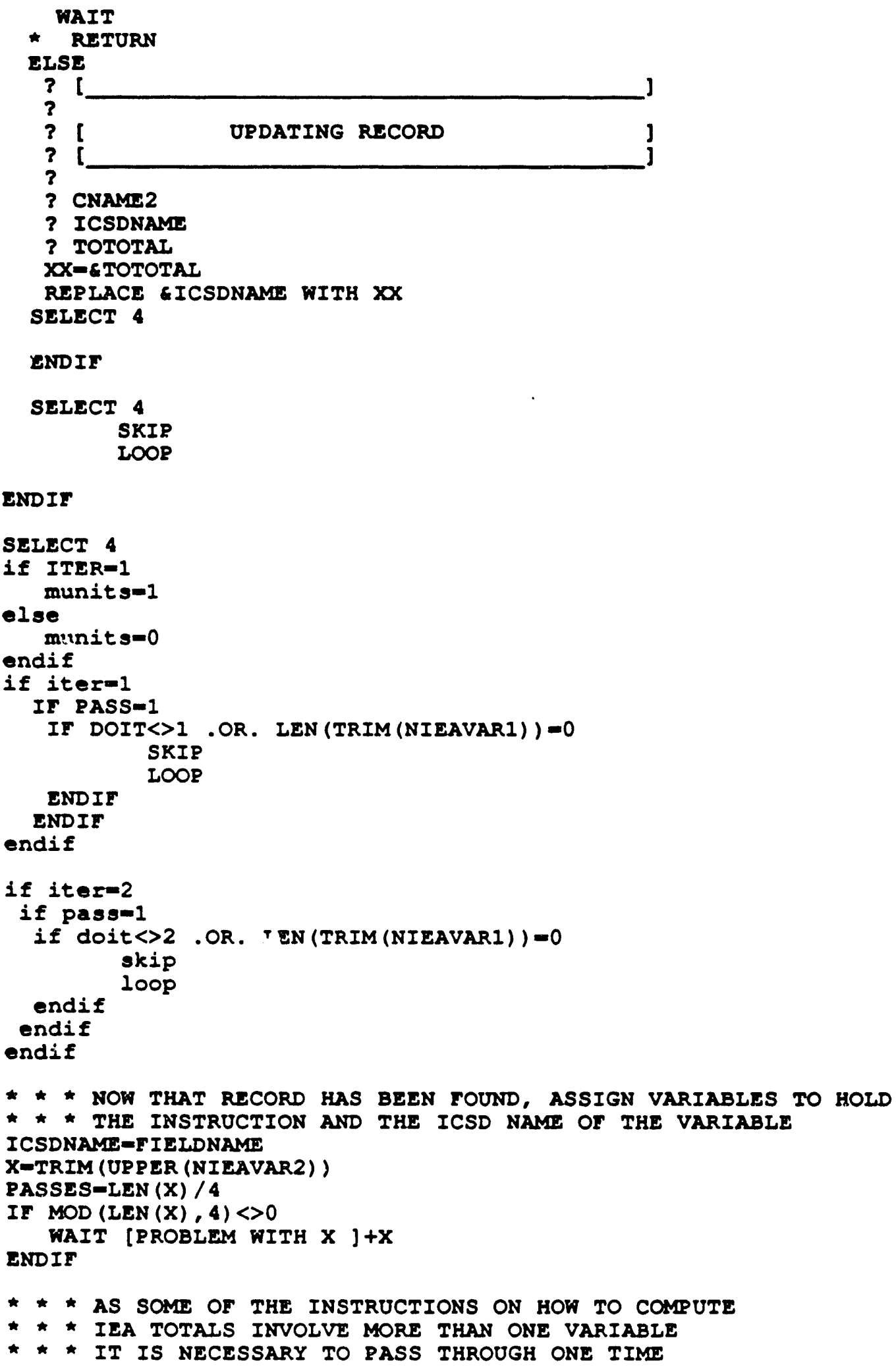




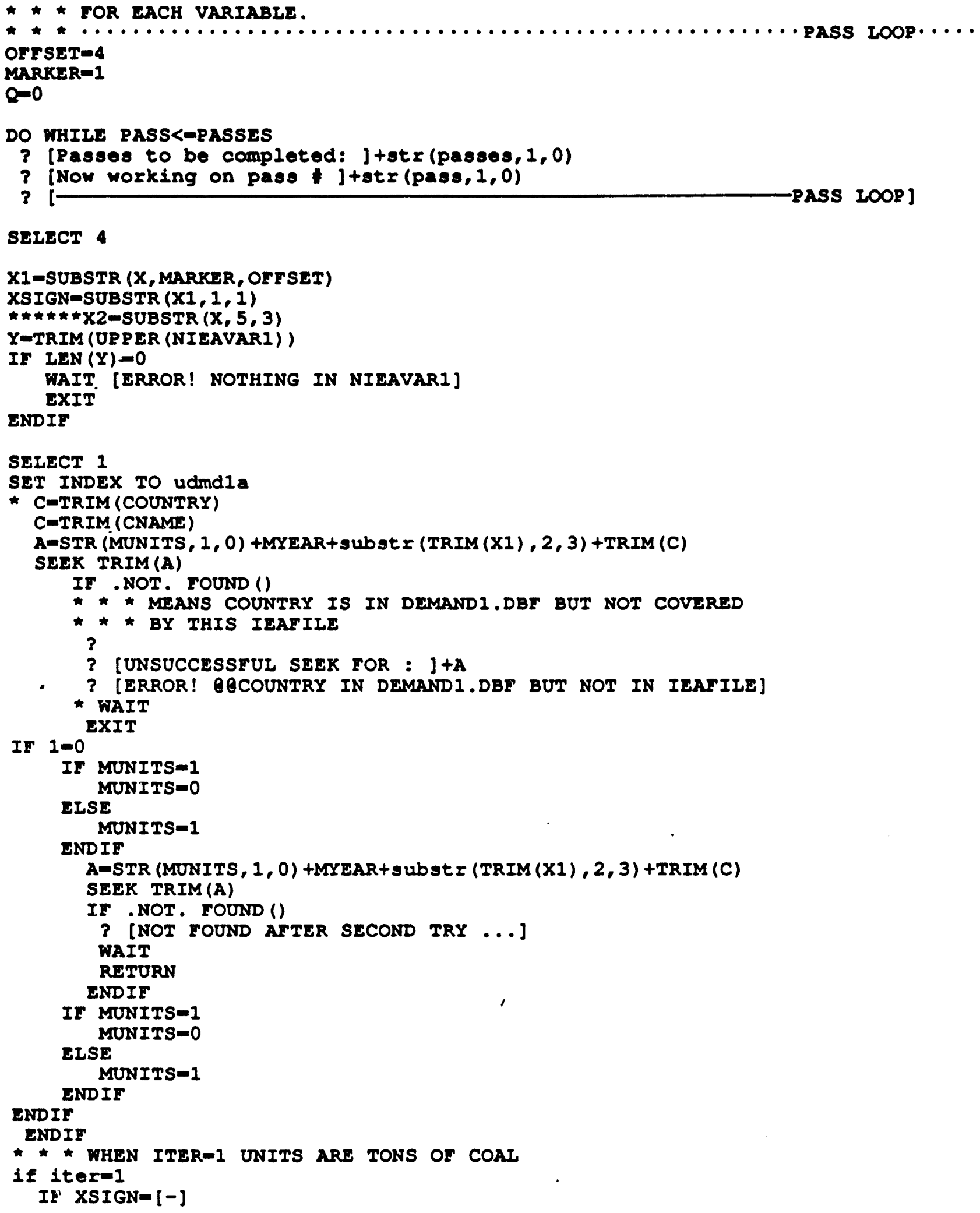

\section{SELECT 4}

X1-SUBSTR (X, MARKER, OFFSET)

XSIGN-SUBSTR $(X 1,1,1)$

$\star \star \star \star \star \star X 2-\operatorname{SUBSTR}(X, 5,3)$

$Y=T R I M$ (UPPER (NIEAVARI))

IF IEN $(Y)=0$

WAIT [ERROR! NOTHING IN NIEAVARI]

EXIT

ENDIF

SELECT 1

SET INDEX TO udmdla

* C=TRIM (COUNTRY)

C-TRIM (CNAME)

A-STR (MUNITS, 1, 0) +MYEAR+subst I (TRIM (X1), 2, 3) +TRIM (C)

SEEK TRIM(A)

IF .NOT. FOUND ()

* * * means country is IN DHMaNdi.dBF but nOt covered

* * * BY THIS IEAFILE

? [UNSUCCESSFUL SEEK FOR : ] +A

- ? [ERROR! QQCOUNTRY IN DEMAND1.DBF BUT NOT IN IEAFILE]

* WAIT

IF $1=0$

$$
\text { EXIT }
$$

IF MUNITS=1

MUNITS=0

LISE

MONITS-1

ENDIF

A=STR (MONITS, 1, 0) +MYEAR+subst I (TRIM (X1), 2, 3) +TRIM (C)

SEEK TRIM(A)

IF .NOT. FOUND ()

? [NOT FOUND AFTER SECOND TRY ...]

WAIT

RETURN

ENDIF

IF MUNITS-1

MONITS $=0$

ELSE

MUNITS-1

ENDIF

ENDIF

ENDIF

* * * WHEN ITER-1 UNITS ARE TONS OF COAL

if iter=1

IF $\mathrm{XSIGN}=[-]$ 


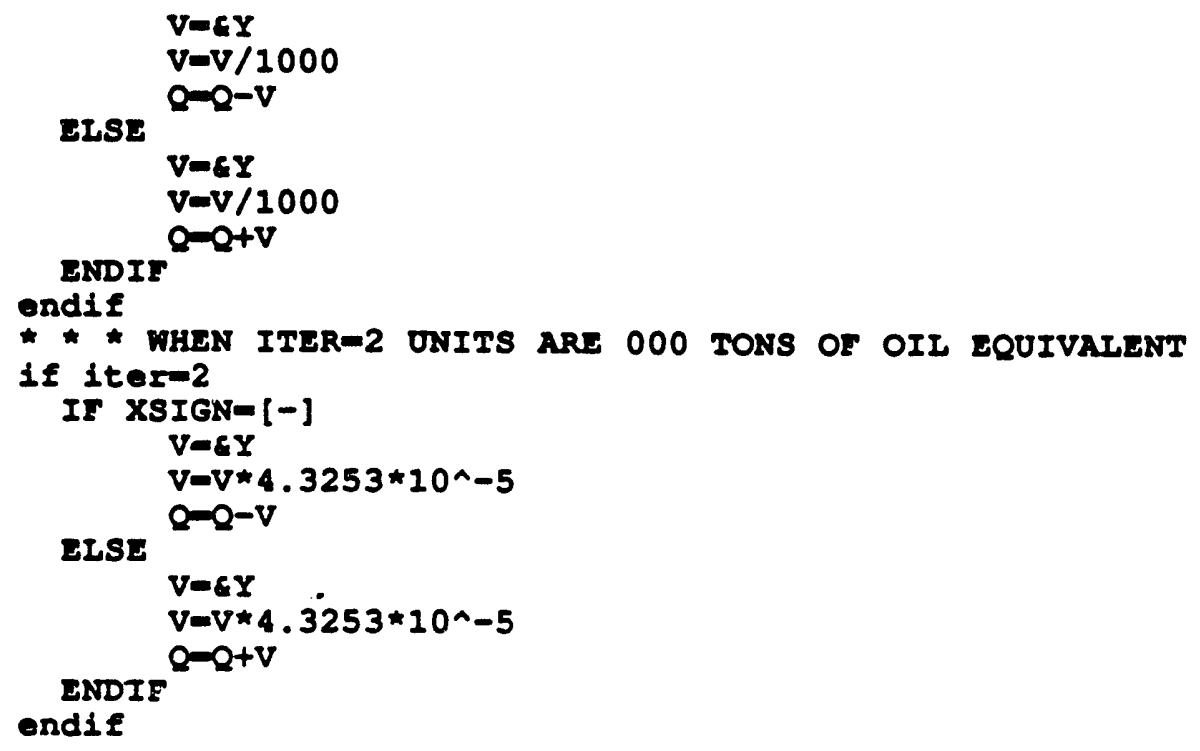


PASS-1

SLIECI 4

SKIP

$\star \star \star$

INDDO

SELE 3

SKIP

$\star * *$

ENDDO

ITER=ITER+1

ENDDO

RETURN

* * Modified by B. de B. on $09 / 17 / 90$

UDMD 6.PRG

* UDMD6.PRG

parameter aUTO

CIEAR

TEXT

INSTRUCTIONS fOI UDMD6.PRG

UPDATE OF THE IEA COUNTRIES AND NON-IEA COUNTRIES: BES FILES

This program is an intermediate stage in the update of the ICSD DFMAND1.DBF data base. It uses OECD/IFA data, previously converted Erom OECD compressed file format to DIF format using the OECD DECOM program.

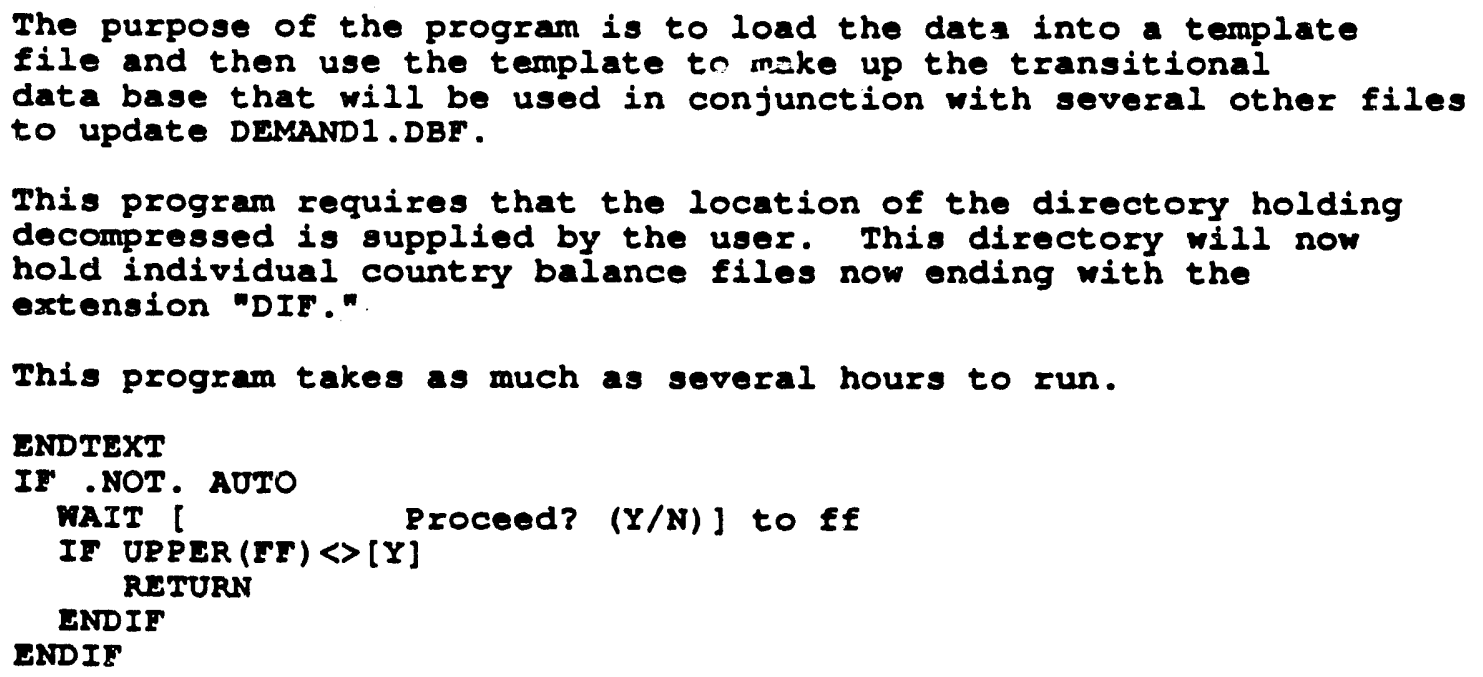




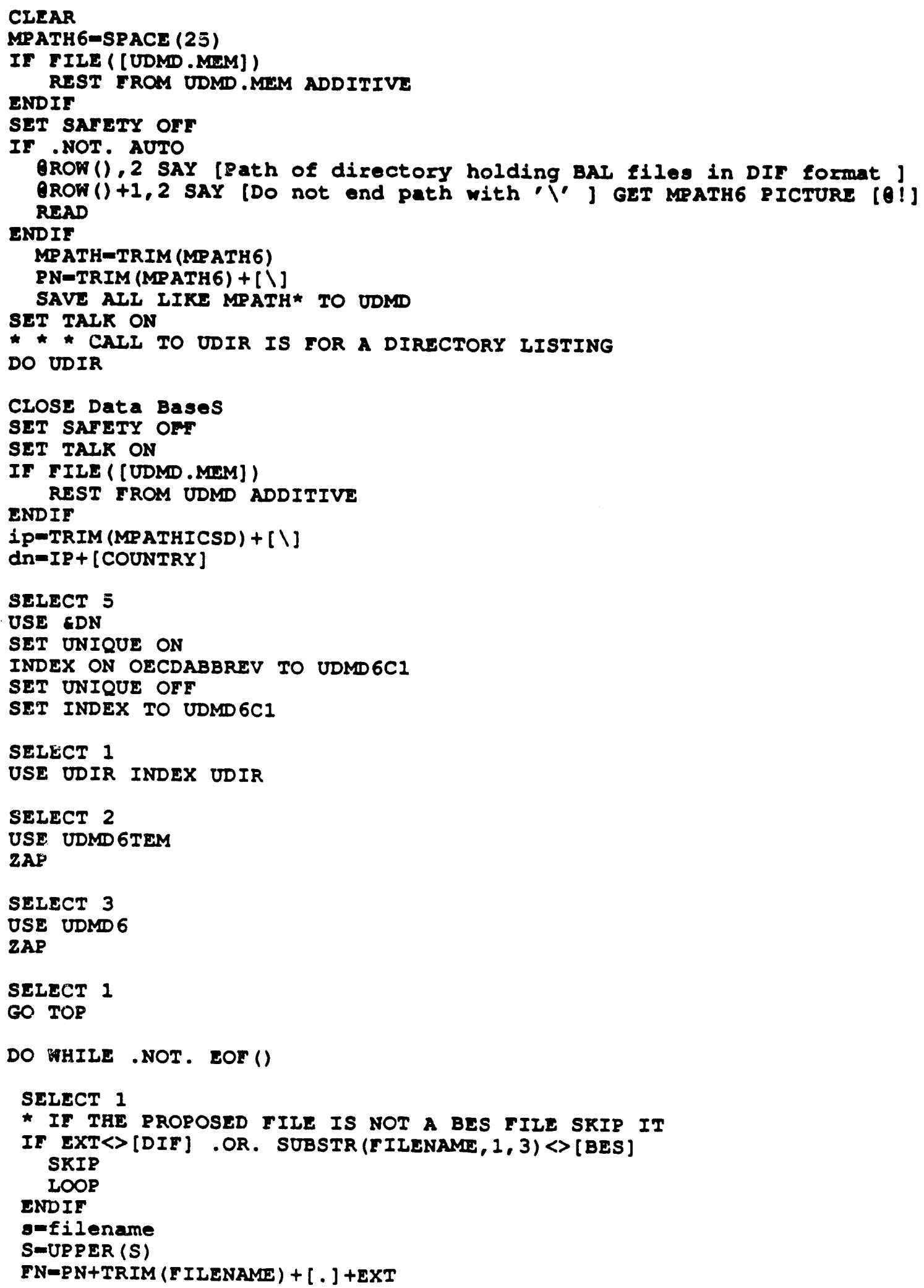




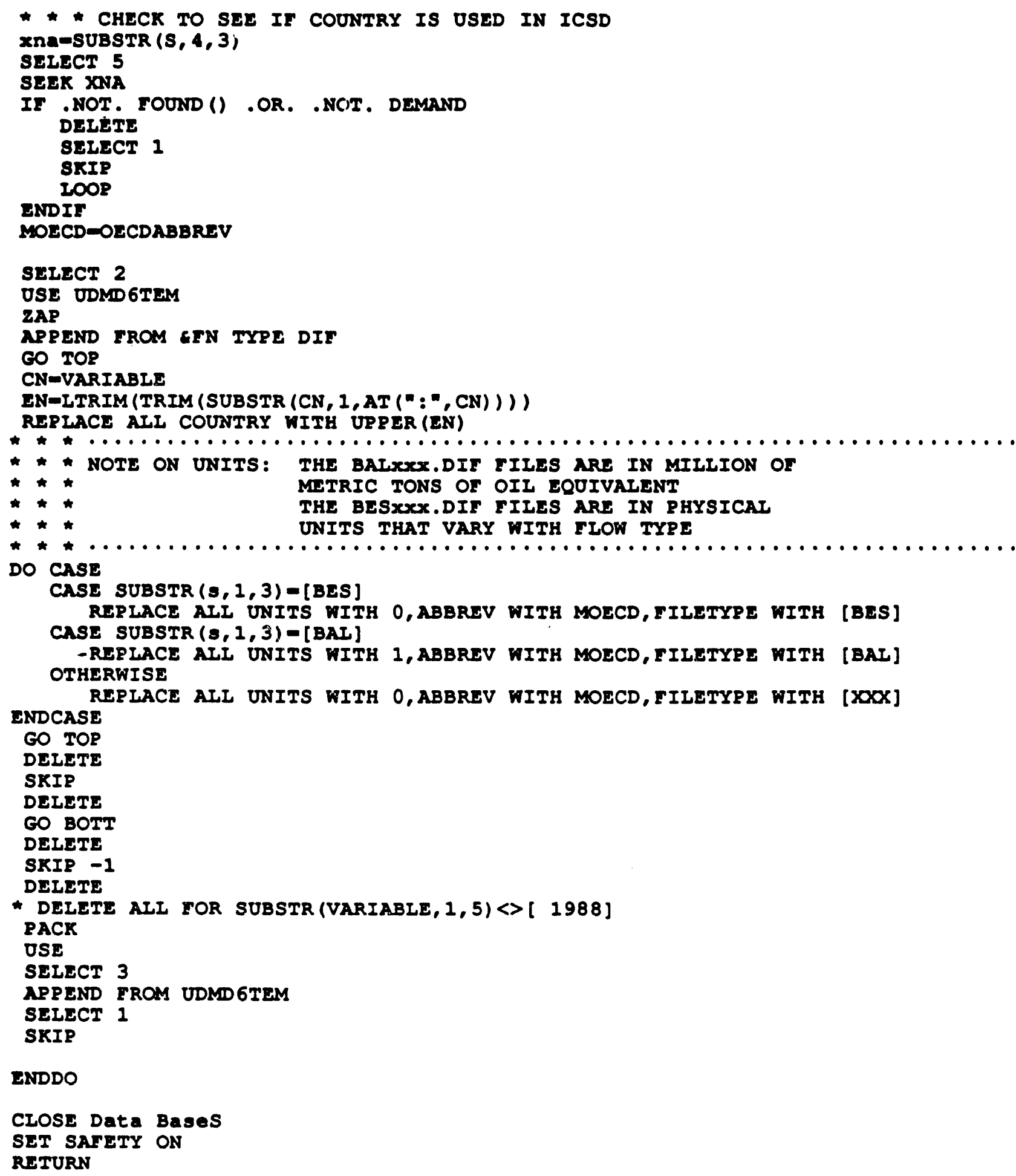




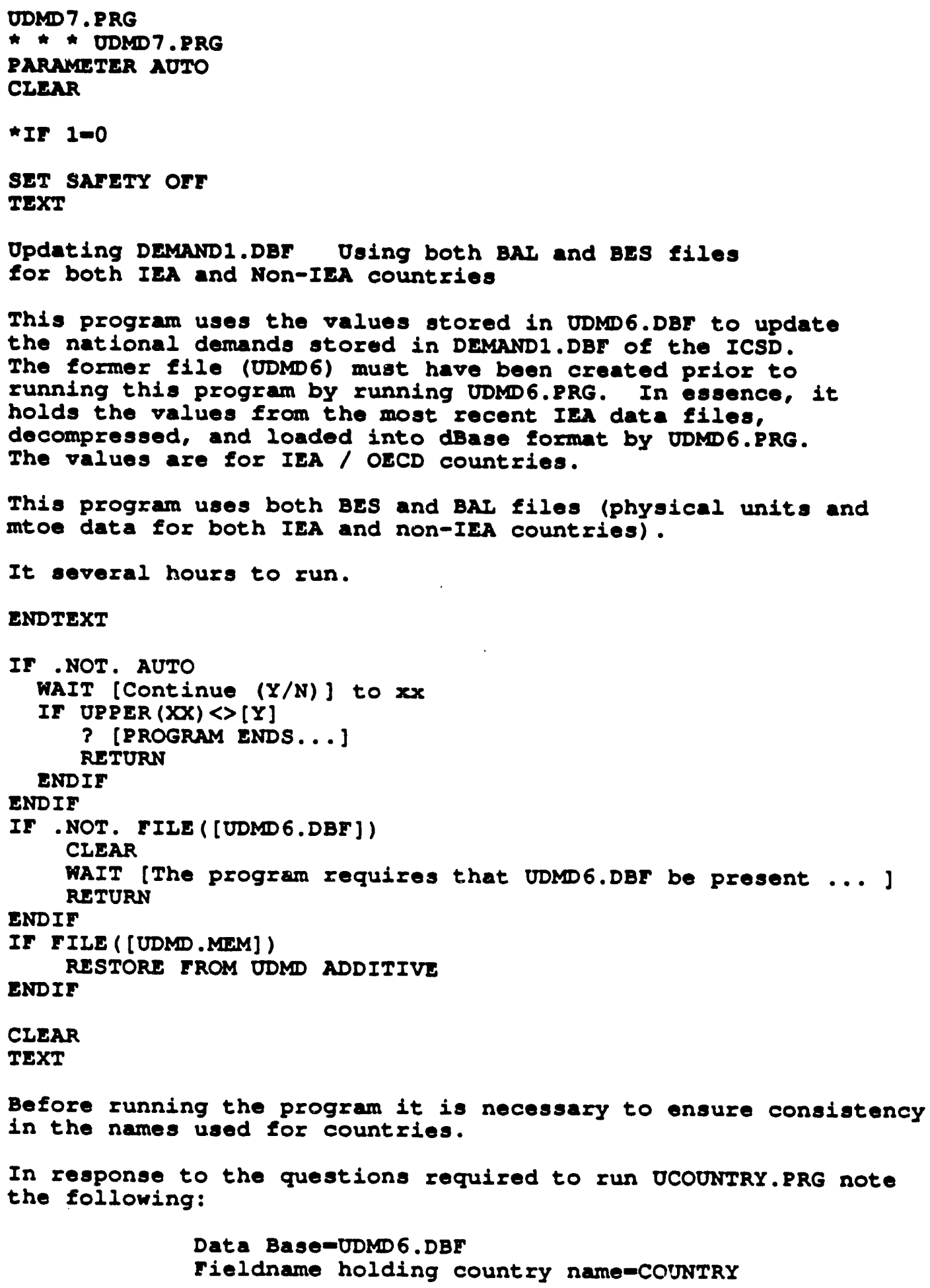




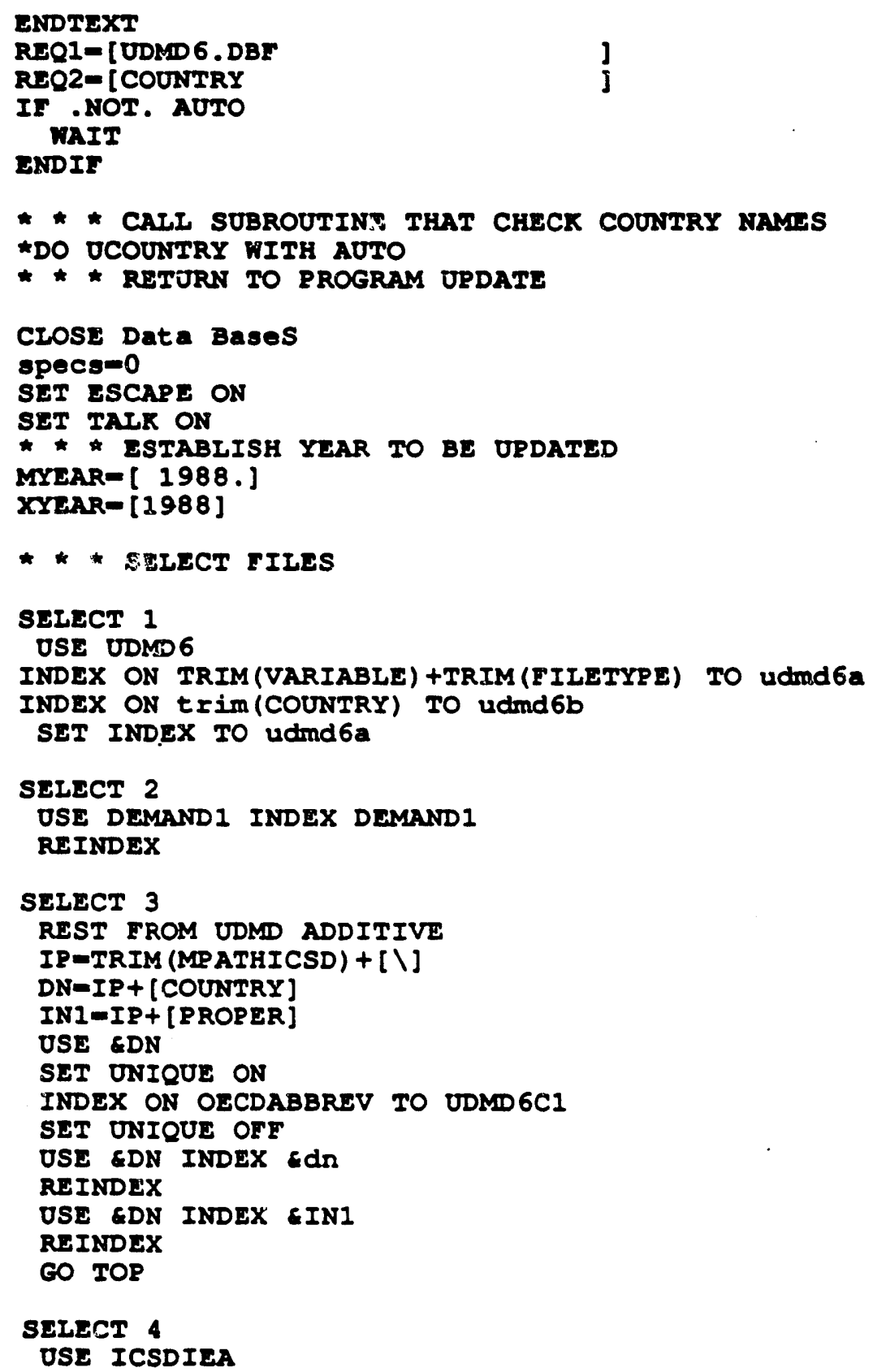


SELE 3

DO WHILE .NOT. EOF()

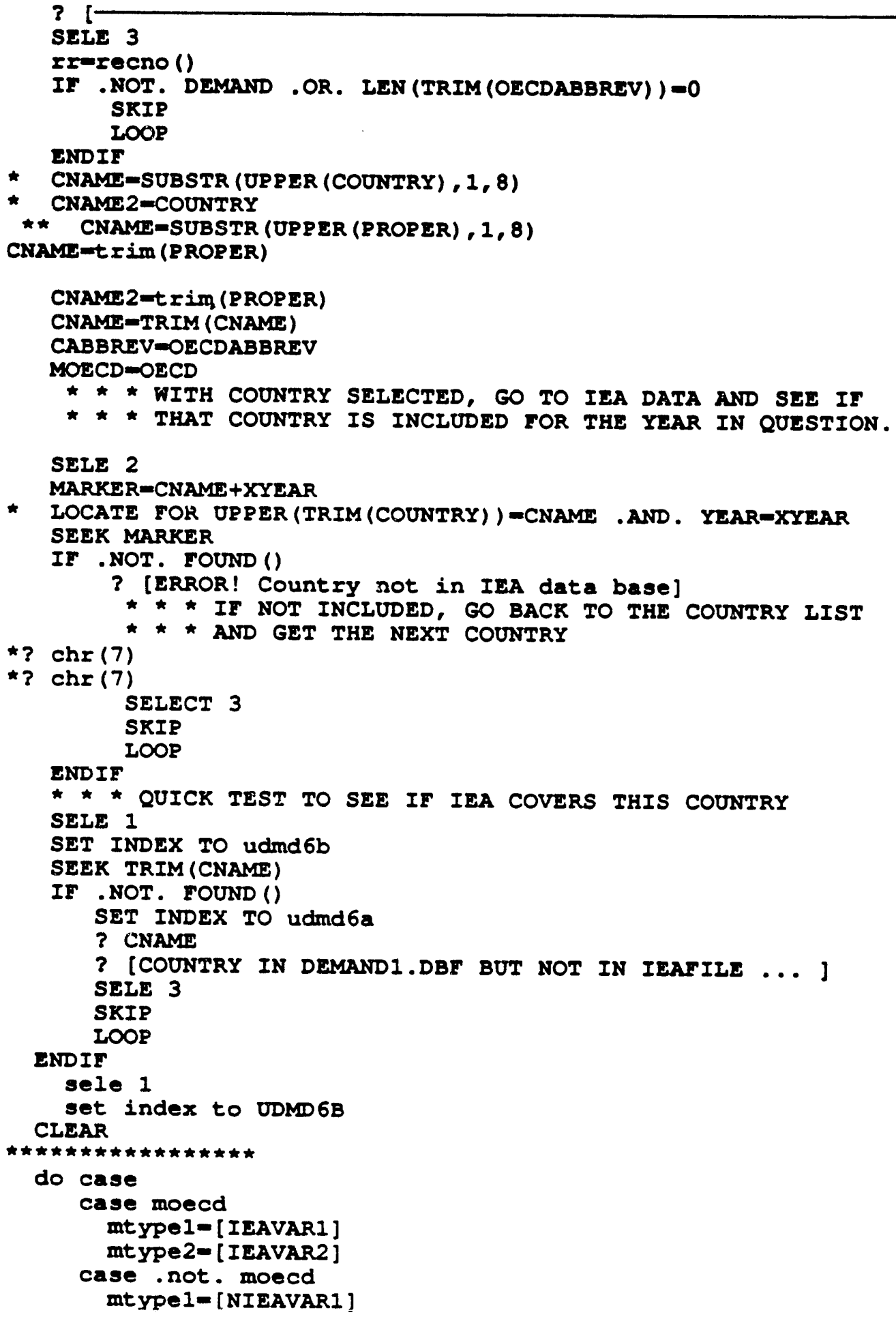




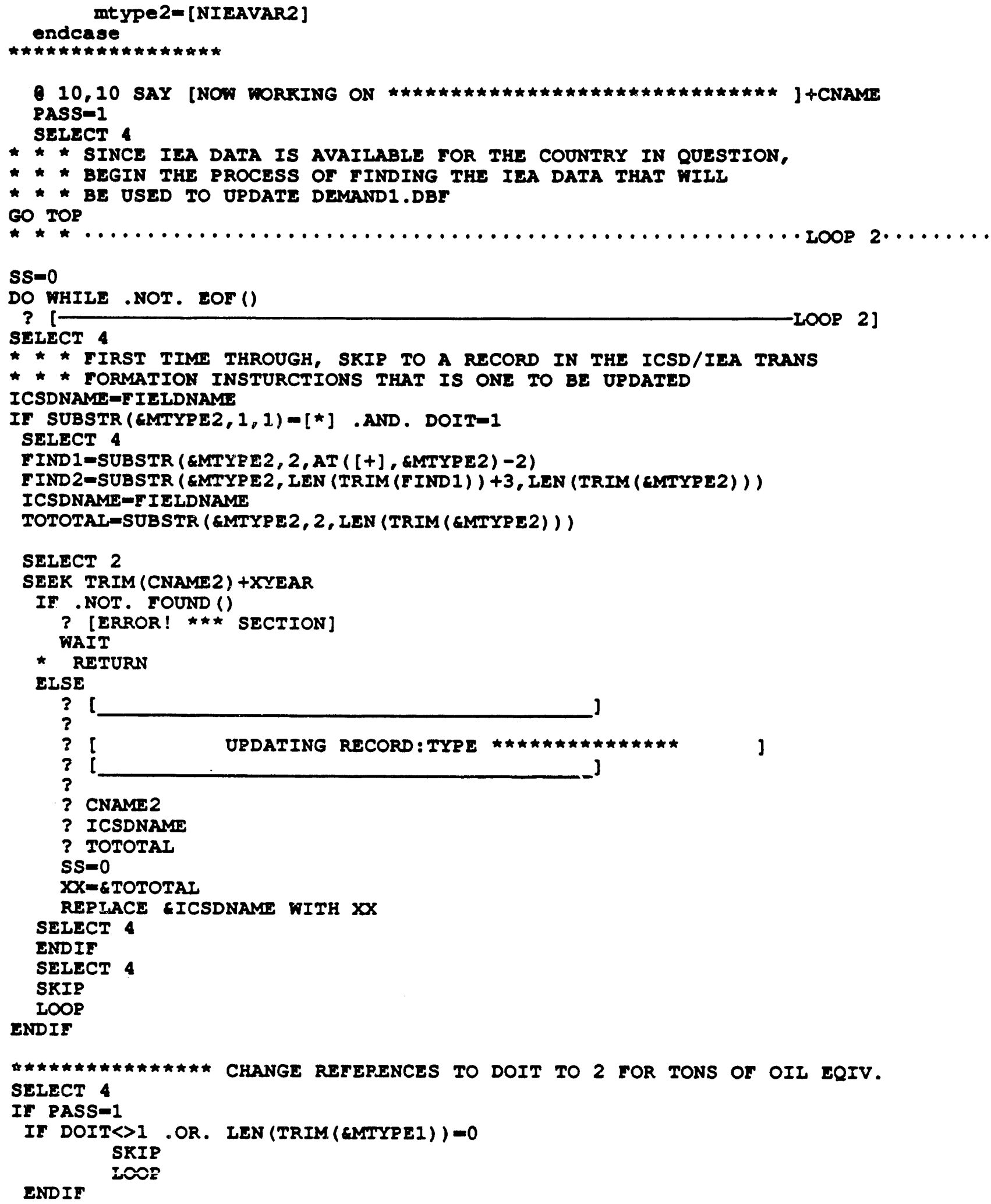




\section{SELECT 1}

SET INDEX TO udmd6a

- C-TRIM (COUNTRY)

C-TRIM (CNAME)

UTYP E = [BES]

$A=[]+C A B B R E V+[]+$. RRODUCT+ [ . ] + LLOW+UTYPE

SEER TRIM (A)

IF . NOT. FOUND()

$?$

? [UNSUCCESSFUL SEER FOR : ] +A

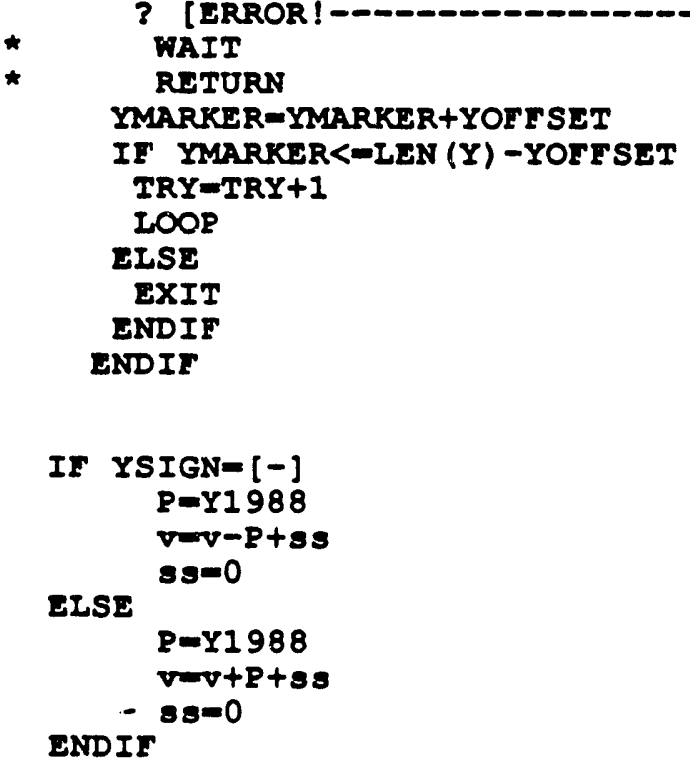

ENDIF

YMARKER = YMARKER+YOFESET
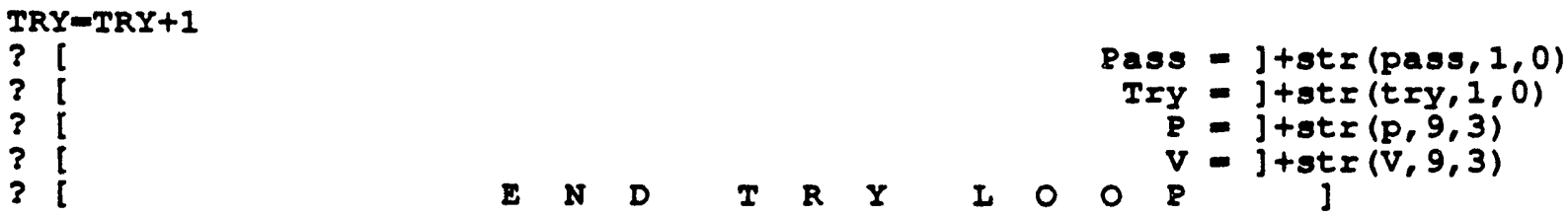

ENDDO

IF XSIGN=[-] $V=V / 1000$

ELSE Q $-\mathbf{Q}-\mathrm{V}$

ENDIE

$v=v / 1000$

$Q=0+V$

$?$ [COUNTRY $=$ ]+Cname

$?$ [VALUE OF $Q=$ ] $+\operatorname{STR}(Q, 8,3)$

$?$ [RASS $=$ ]+STR (RASS $, 5,0$ )

$?$ [VALUE OF $Y=$ ] $+Y$

* * NOW go TO DEMANDI.DBF, FIND THE RIGHT RECORD, AND * * UPdate hith the calculated Value.

if $q<>0$ 
SELECT 2

SEEK TRIM (CNAME2) +XYEAR

IF . NOT. FOUND()

? [ERROR! COUNTRY NOT FOUND IN DEMANDI.DBE, DESPITE TESTS...] VAIT

* RETURN

ELSE

* clear

? 1

$?$

$?$

$?$

$?$

$?$ CNAME 2

$?$ ICSDNAME

IF SUBSTR (i codname, 1,1$)=[X]$ specseq

ELSE ququpecs

REPIACE EICSDNAME WITH abs (q) specs=0

ENDIF

ENDIF

endif

SELECT 4

RASS-RASS +1

MARKER-MARKER+OETSET

TRY $=1$

$\star \star \star$

ENDDO

PASS $=1$

SELECT 4

SKIP

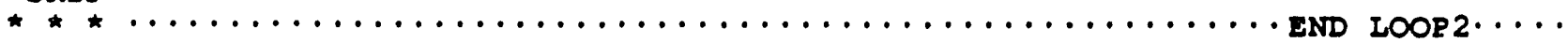

ENDDO

SELE 3

SKIP

$\star \star \star$ 1

ORDATIKG RECORD ]+STR (PASS, 3, 0) + ]

[D]

ENDDO

*ENDIF $E \& \&$ IF $1=0$ IF 


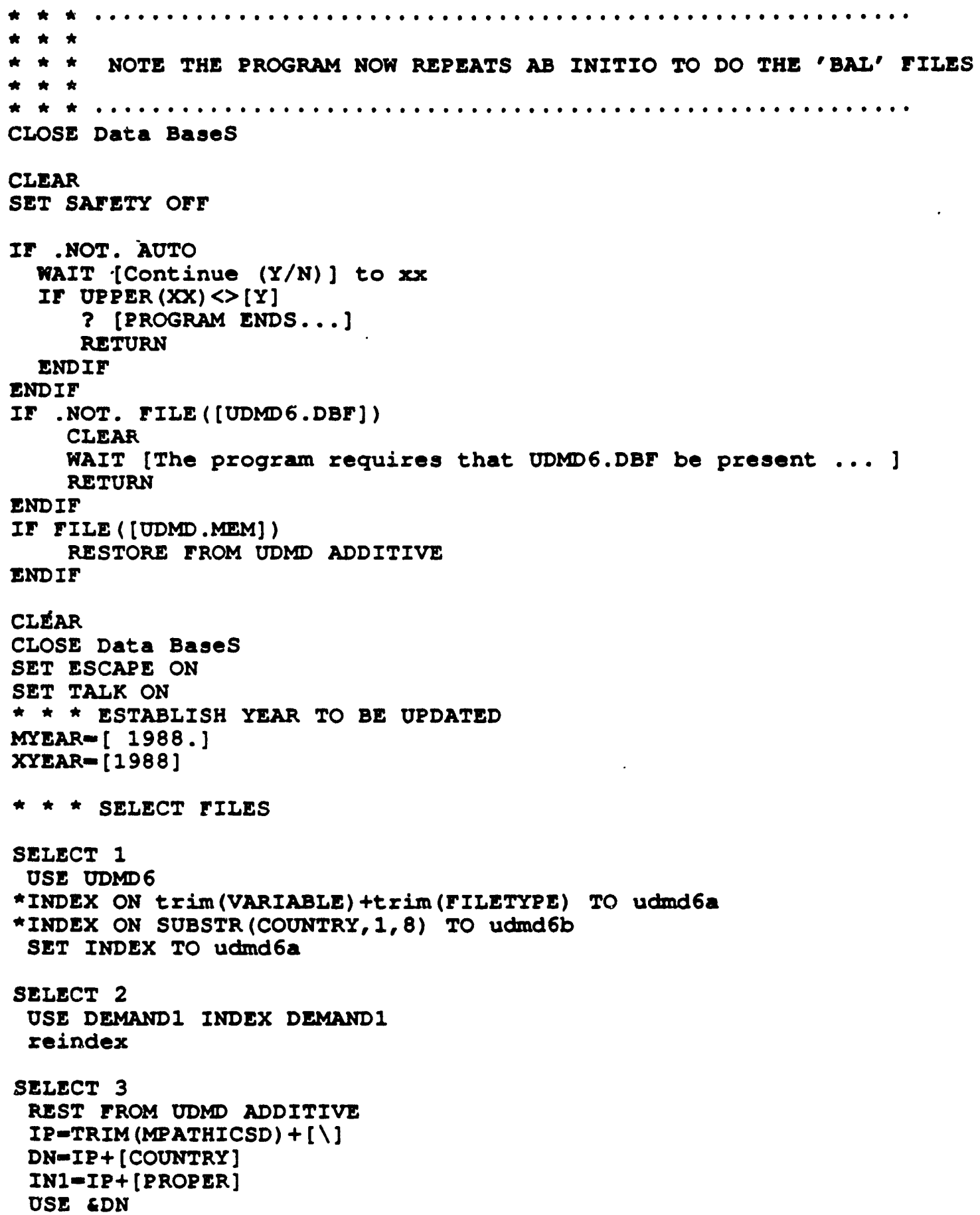




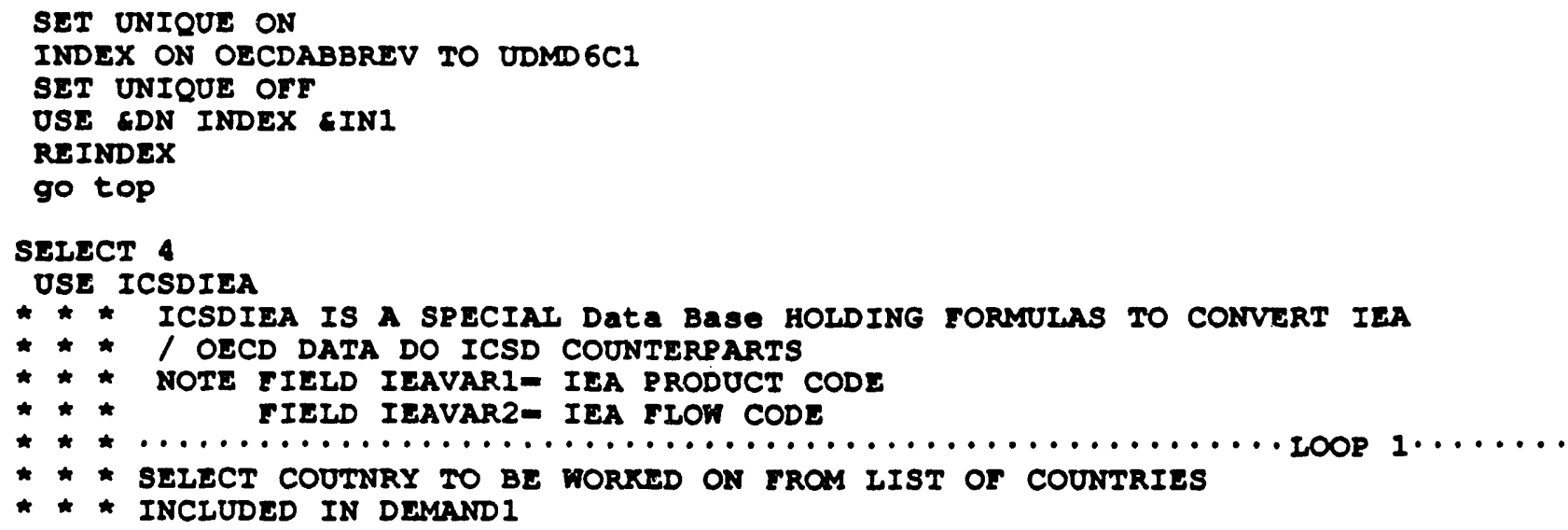

* LOCATE FOR UPPER (TRIM (COUNTRY)) =CNAME. AND. YSAR=XYEAR SEEK MARKER 


\section{ELSE}

MUNITS-1

ENDIF

ENDIF

ENDIF

* * * WHEN ITER-1 UNITS ARE TONS OF COAL

1 iter=1

II XSIGN=[-]

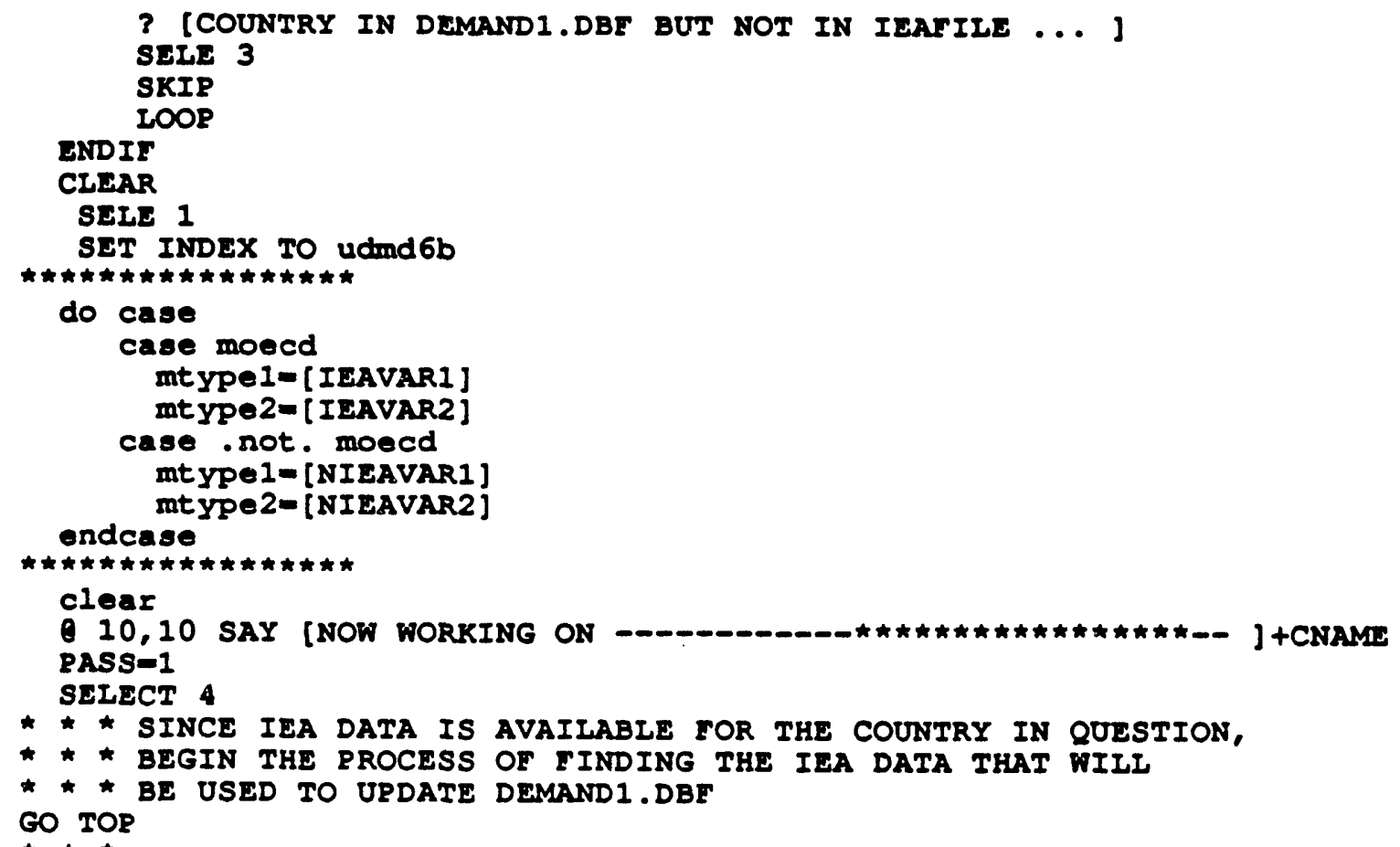




\section{ENDIE}

SEIECT 4

SKIP

IOOP

ENDIF

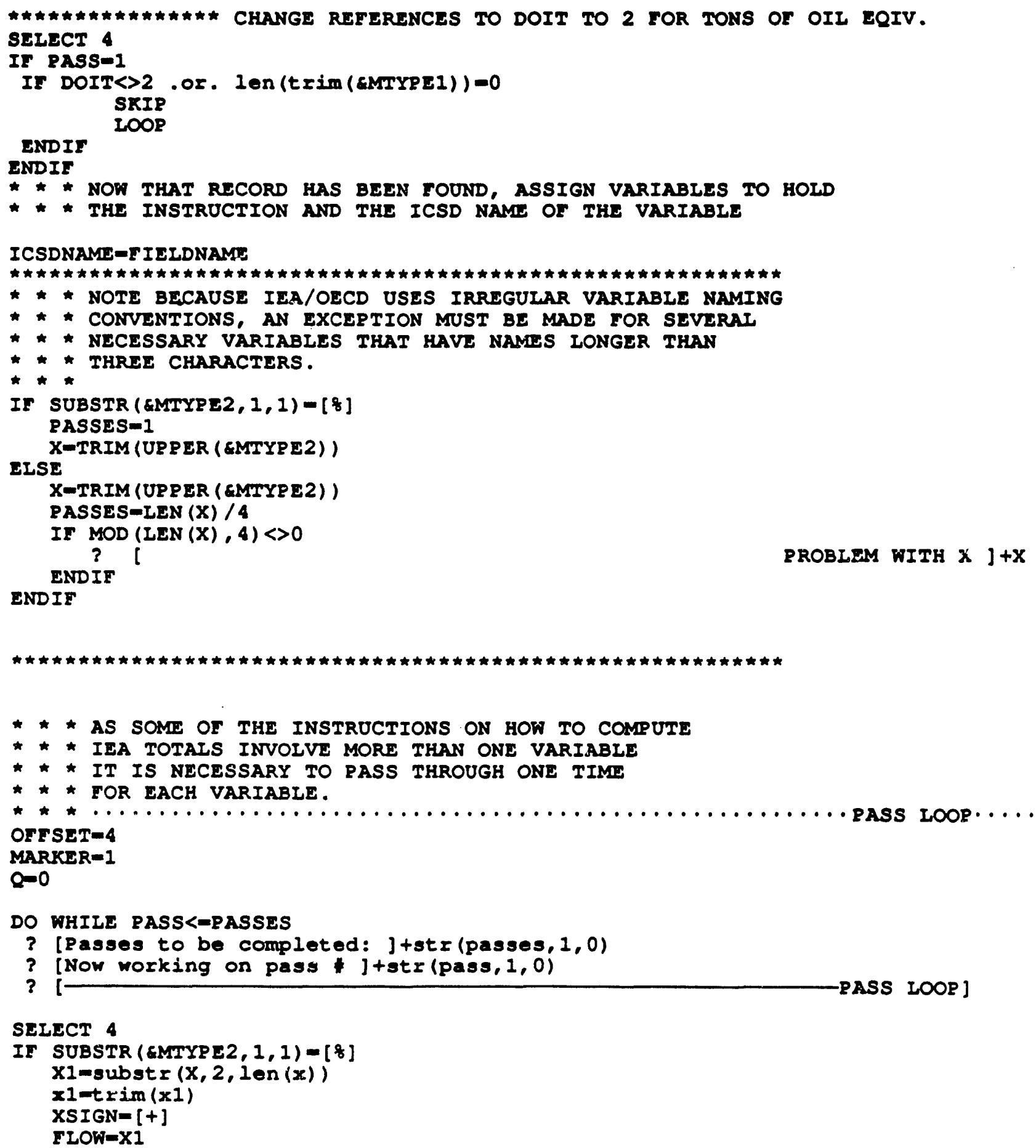


EISE

X1-SUBSTR (X, MARKER, OFTSET)

XSIGN=SUBSTR $(X 1,1,1)$

ENDIF

FLOW=SUBSTR (X1,2, IEN (XI))

IF $\operatorname{SUBSTR}($ MTYYE $1,1,1)-[\%]$

TRYS=1

YOTRIM (UPPER (CMTYPEI))

ELSE

$Y=T R I M(U P P E R$ (EMTYPEI))

TRYS=LEN ( $Y) / 4$

IF $\operatorname{MOD}(\operatorname{LEN}(Y), 4)<>0$

$?$

ENDIF

ENDIF

$V=0$

TRY $=1$

YOFFSET $=4$

MMARKER=1

DO WHILE TRY<-TRYS

SELECT 4

If [TUBSTR (EMTYPE1, 1, 1)-[8]

$Y 1-\operatorname{subst} x(Y, 2, \operatorname{len}(y))$

$y \operatorname{lt} \operatorname{rim}(y)$

YSIGN= [+]

PRODUCT-YI

ELSE

$Y 1=S U B S T R$ ( $Y$, MARKVR, YOFFSEI)

YSIGN=SUBSTR $(Y 1,1,1)$

PRODUCT=SUBSTR $(Y 1,2$, IEN (YI) )

PRODUCT-TRIM (PRODUCT)

ENDIF

PRODUCT-TRIM (PRODUCT)

FLOW=TRIM (FIOW)

SELECT 1

SET INDEX TO udmd6a

* C-TRIM (COUNTRY)

C-TRIM (CNAME)

UTYPE- [BAI]

$A=[$ ] +CABBREV + [ . ] +PRODUCT + [ . ] + FLOW+UTYPE

SEEK TRIM (A)

IF .NOT. FOUND ()

?

? [UNSUCCESSFUL SEEK FOR : ] +A

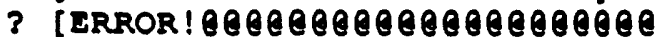

* MAIT

* retura

MMARKER = YMARKER+YOFFSET

IF YMARKER <-LEN $(Y)$-YOFFSET

TRY $=$ TRY + 1

LOOP

ELSE

EXIT
PROBLEM WITH Y J+Y

TRYS LOOP ]

FLOW NOT YOUND FOR THIS COUNTRY ...] 


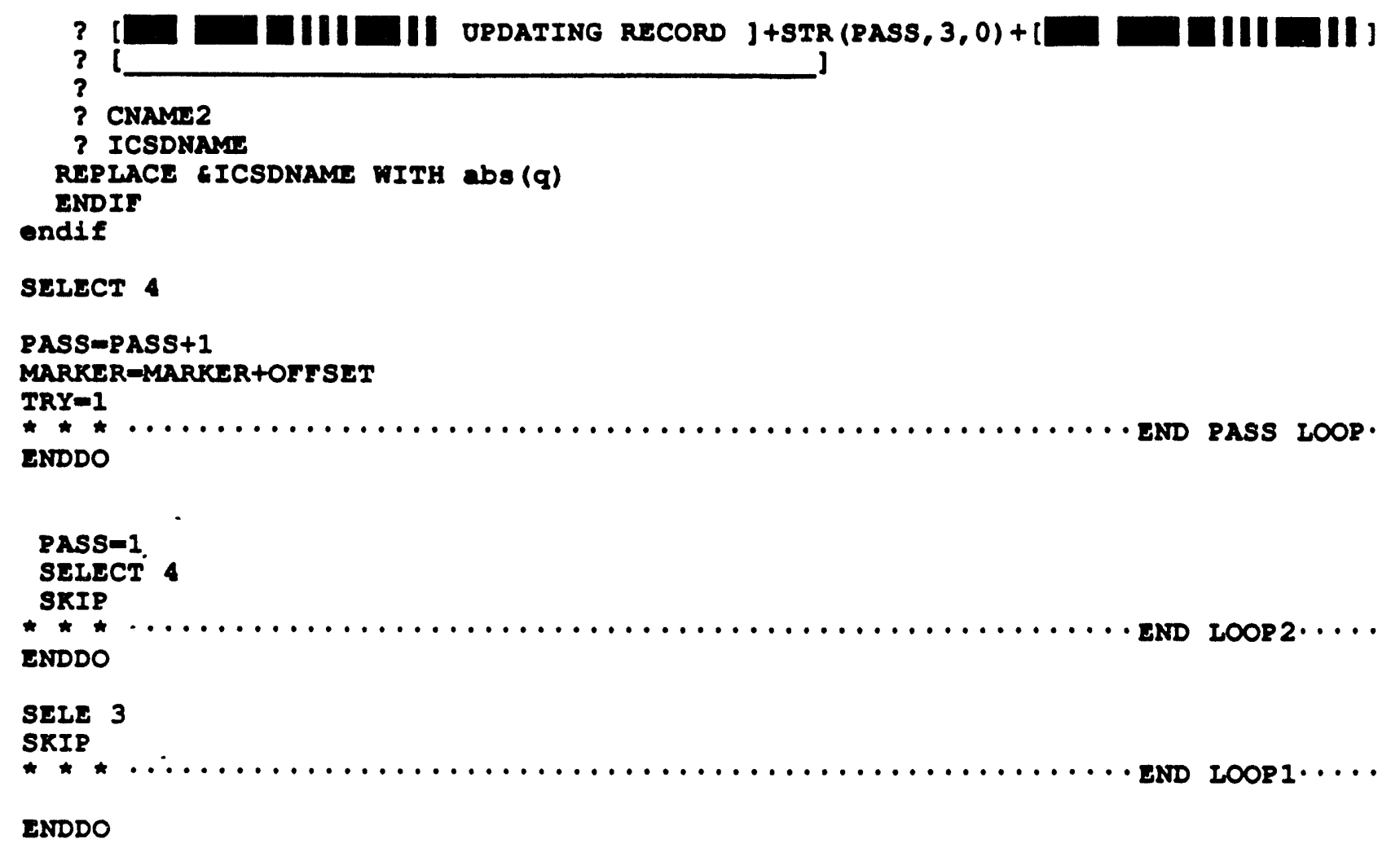

RETURN

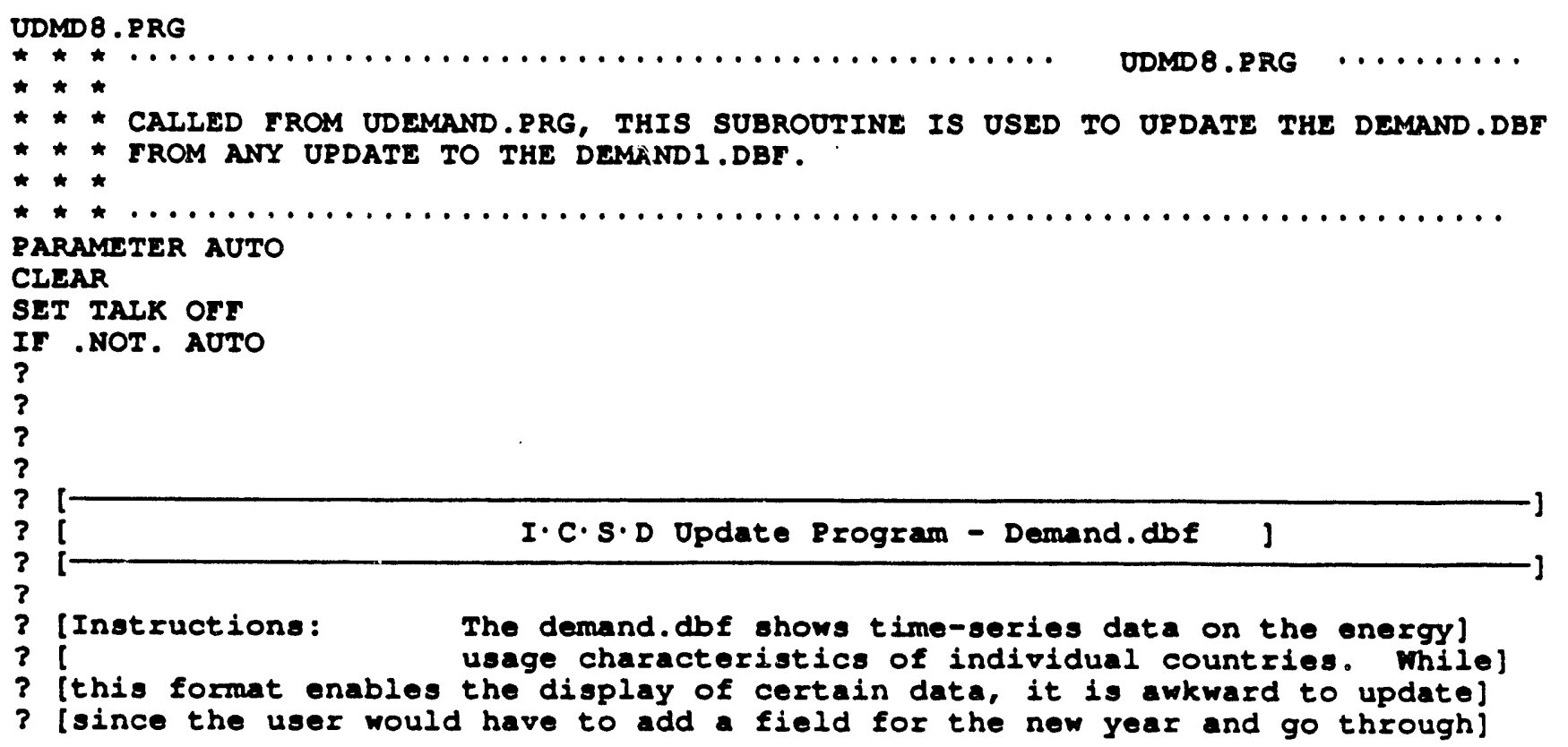


$?$ [more than a thousand records. The purpose of this program is to allow ]

$?$ [update in one form and then transform the now data into ito final form as]

$?$ [the revised demand.dbf.]

8 [New data should be added for each country in the data base for the year in]

? [question. The field names are abbreviations corresponding to the requested]

$?$ [information. If necessary, a list of countries in the data base wil) be]

$?$ [provided.]

$?$

WAIT

ENDIF

REST FROM UDMD ADDITIVE

ONTOS . T.

SELECT I

OSE DEMANDI INDEX DEMANDI

SELECT 2

FNMTRIM (MPATHICSD) + ( ICOUNTRY INDEX ] +TRIM (MPATHICSD) + [ (RRORER]

OSE GFN

REINDEX

SEIECT 1

IF .NOT. AUTO

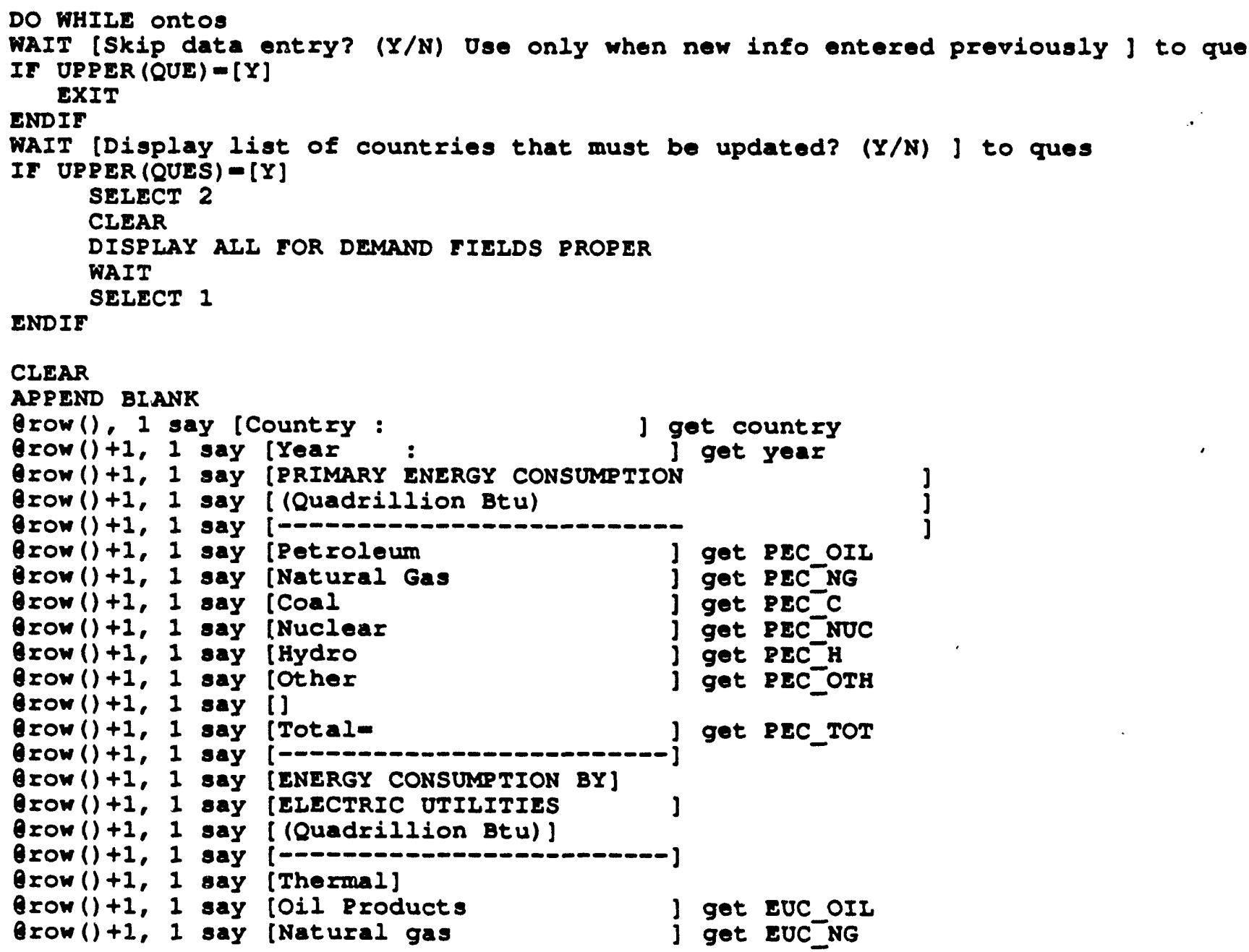




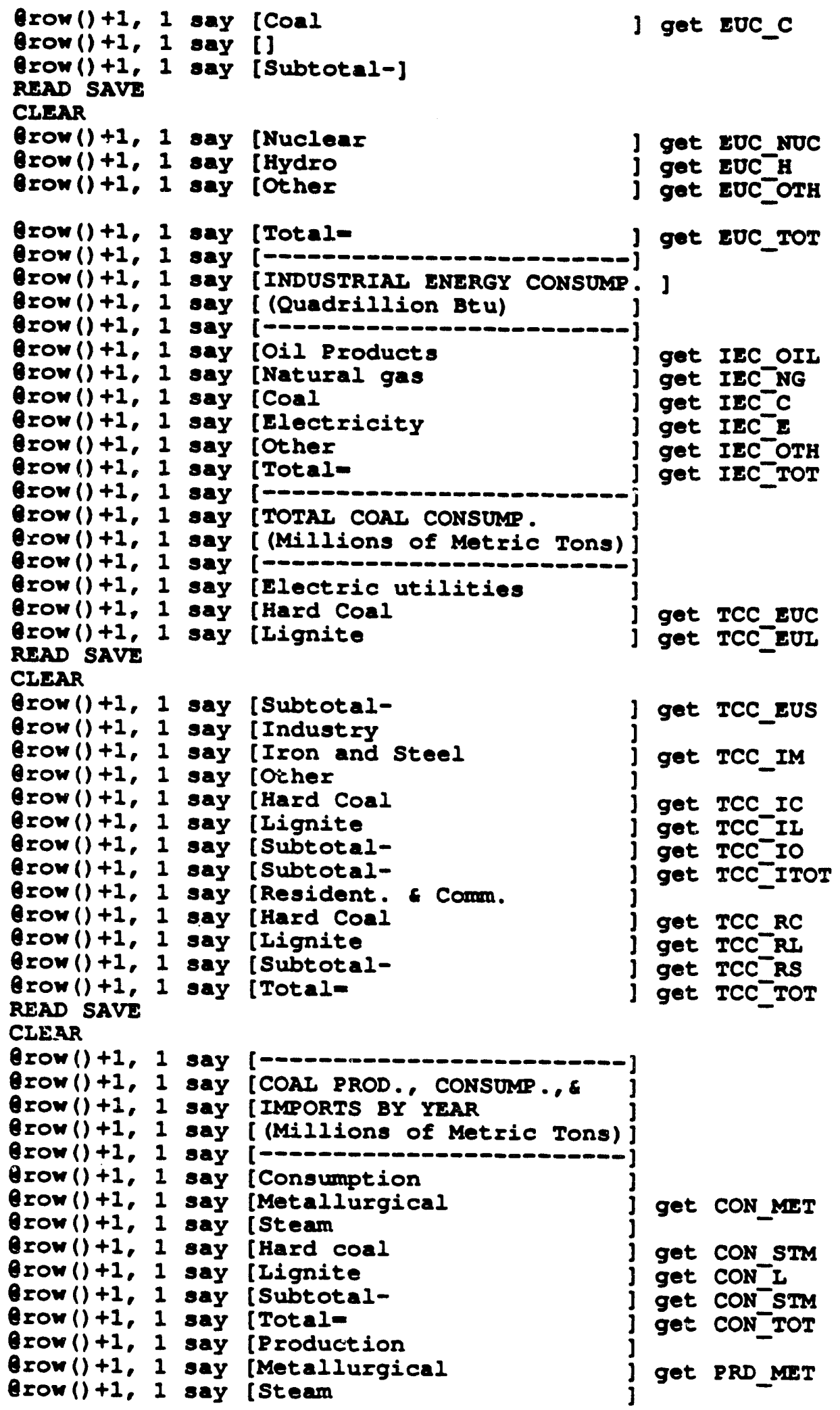




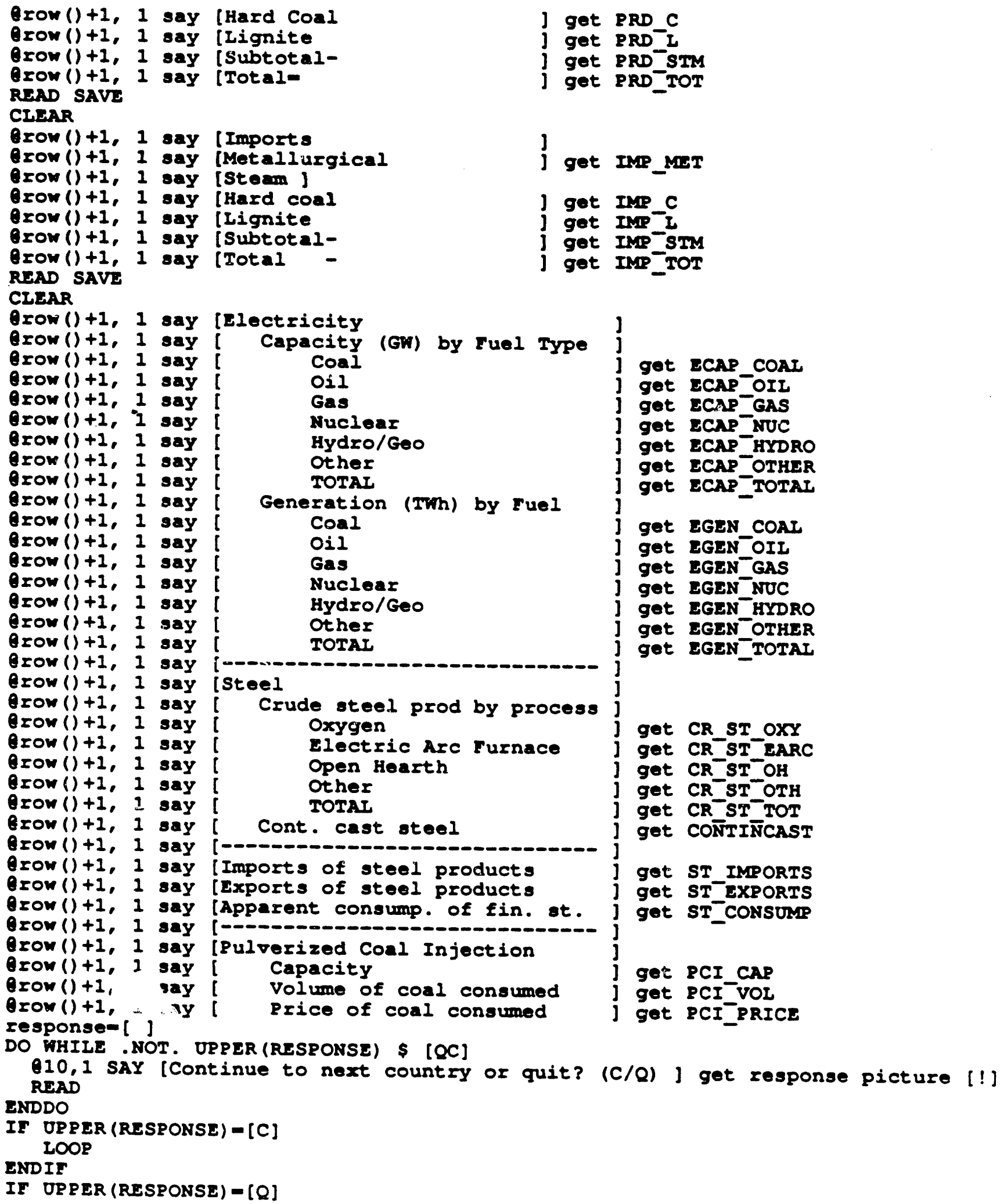

\section{了}

j get IMP MuT

j get IMP $C$

] get IMP I

j get IMP SMM

] get IMP TOT

[-

\section{isteel}

Crude steel prod by process Oxygen

Electric Arc Furnace Open Hearth other TOTAI

Cont. cast steel

[Imports of steel products [Exports of steel products [Apparent consump. of fin. at. [--[Pulverized Coal Injection Capacity Volume of coal consumed Price of coal consumed 


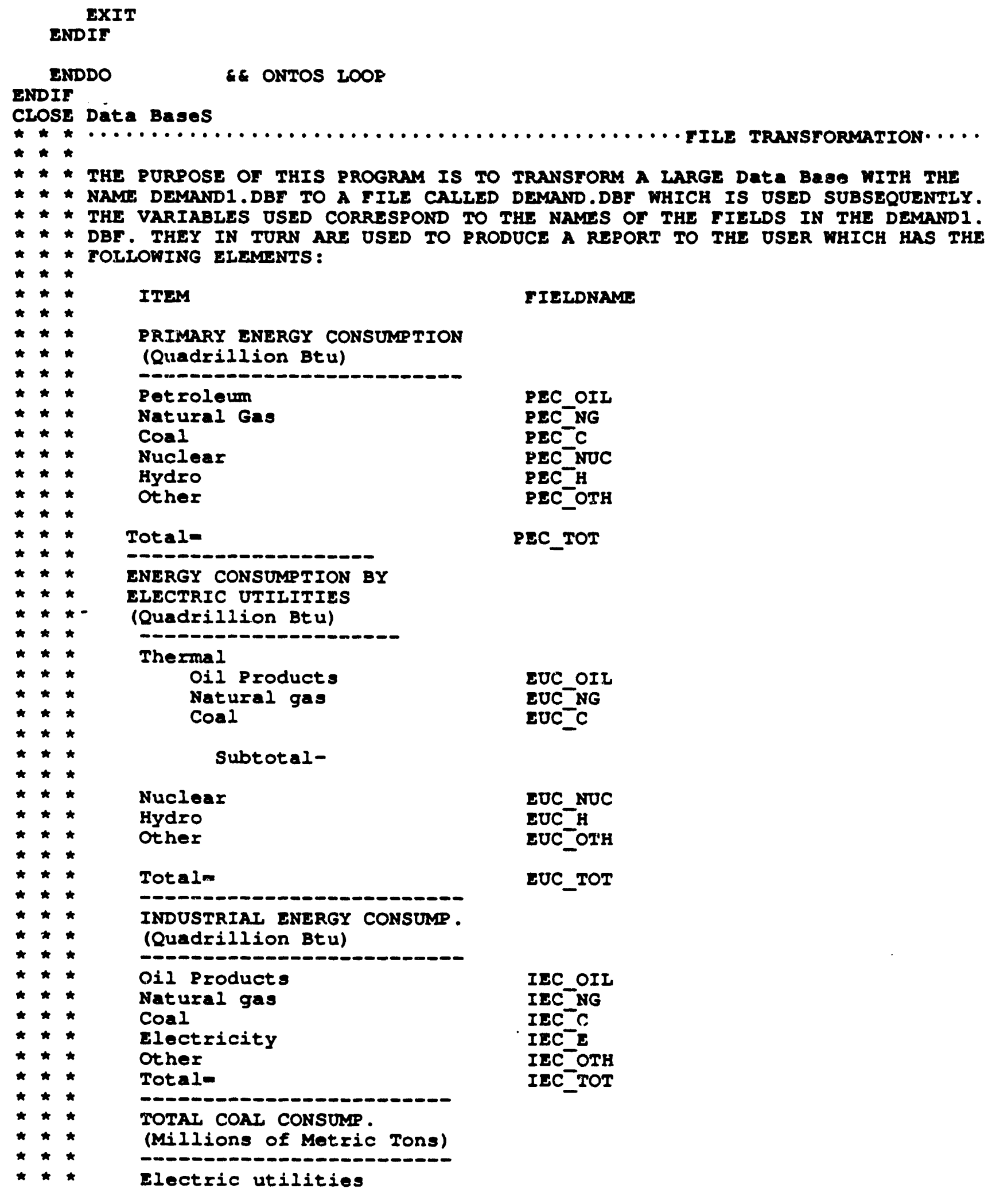




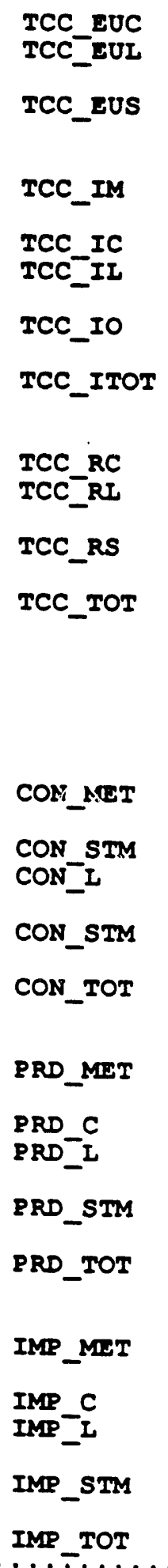




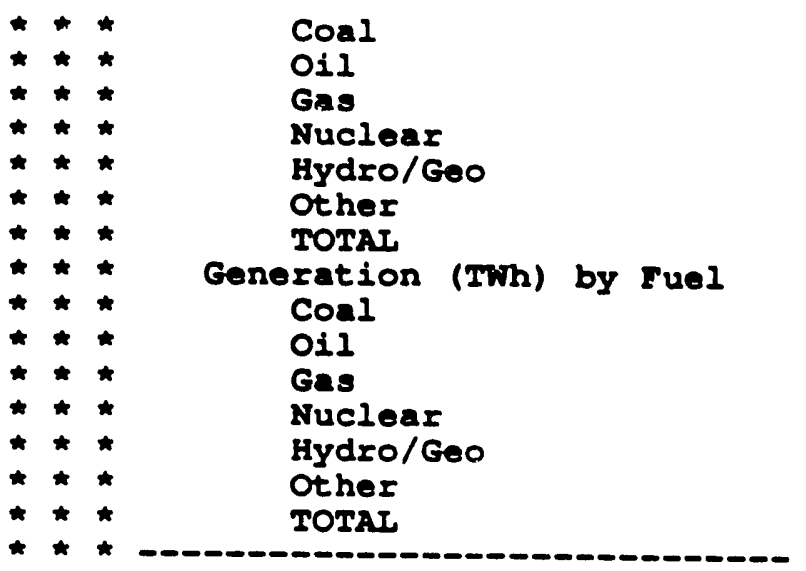

ECAP_COA
ECAP_OII
ECAP_GAS
ECAP_NOC
ECAP_HYRO
ECAP_OTHER
ECAP_TOTAI
EGEN_COAI
EGEN_OII
EGEN_GAS
EGEN_NOC
EGEN_HYDRO
EGEN_OTHER
EGEN_TOTAI

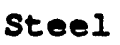

$\star \star \star$

$\star \star \star *$

* * SeleCt Data Bases AND mork ARsas

* * Note: The demand1.dbf is ueed for update purposes only. Onee new data

* * have been added for any year, the entire data base must be converted to

* * the format of the Demand.dbs (1.e. with years as fielda). This procesa

* * takes several hours on a normal IBM PC compatible running at 7.6

* * megahertz. The program also destroys the contents of the original

* * demand.dbf, so a backup may be made before running thia program.

SEIECT 1

OSE DEMANDI INDEX DEMANDI

? [Demand1.dbf being reindexed]

SET TALK ON

REINDEX

SET TALK OFF

SELECT 2

USE DREPORT

SELECT 3

USE DEMAND INDEX DGMAND Clear
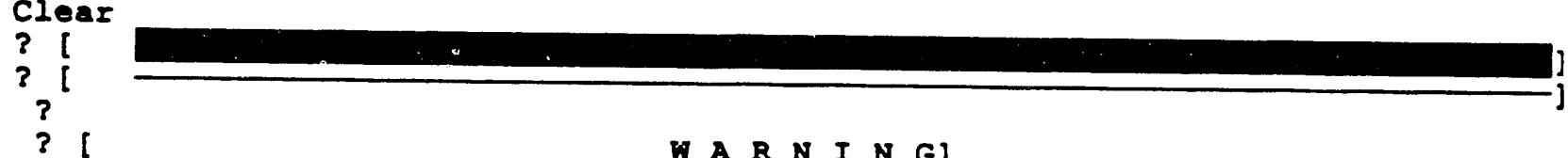

W A R N I N G] 


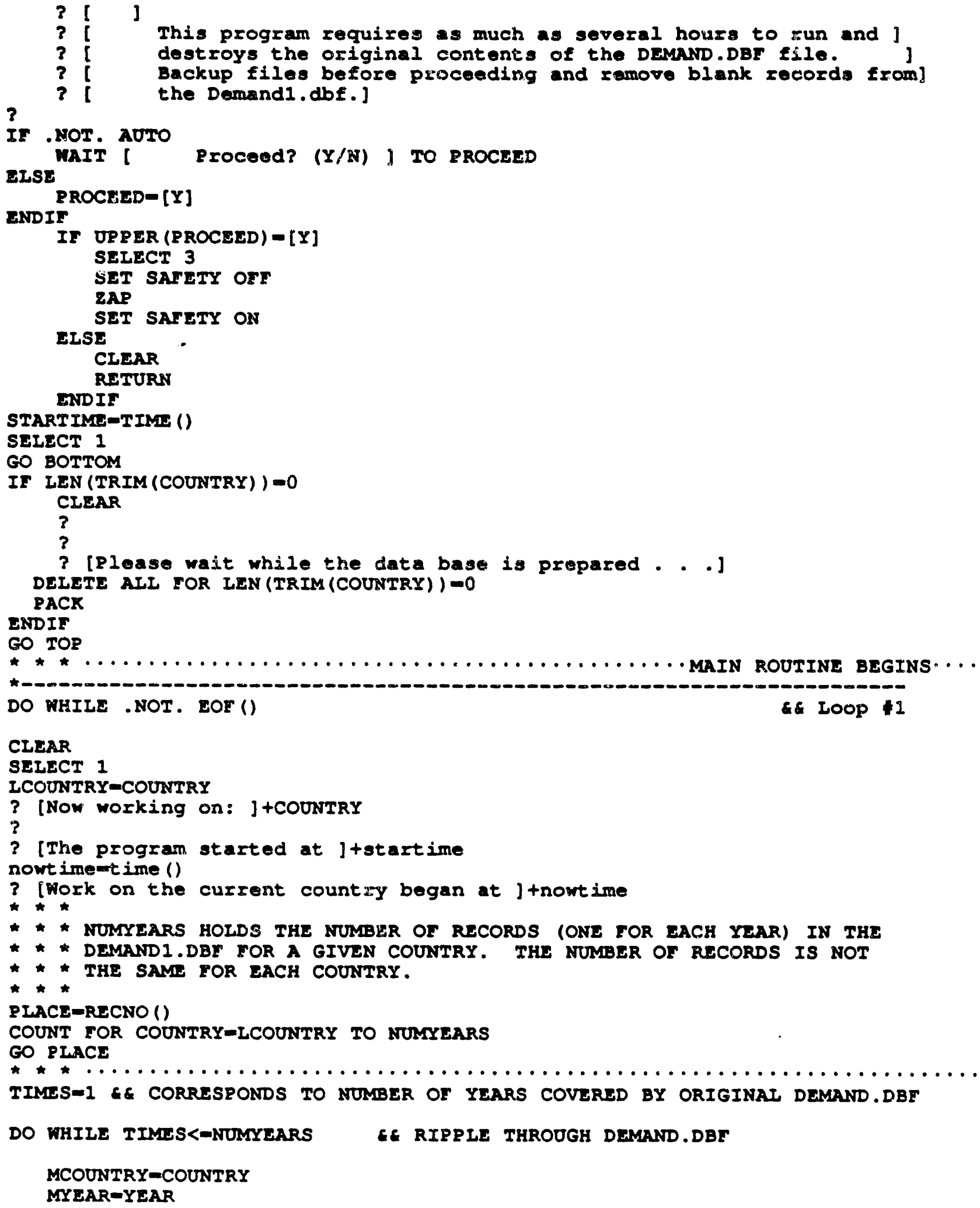


SELECT 2

USE DRERORT $E$ REESTABIISHED BECAOSE CIOSED ON IAST IOOP

RYBAR=[Y]+TRIM (MYEAR) CEFIEID NAMES FOR YEARS BEGIN WITH "Y"THEN YEAR

DO MHILE .HOT. EOT() EERIPPLE THROUGH DREPORT.DBF

REPLACE DREPORT->COUNTRY WITH MCOUNTRY

HOLEER $=$ FIEIDNAMAS

IF IEN (TRIM (HOLDER) ) $=0$

SKIP

ENDIF

holder2-DEMANDI-> GHOIDER

REPIACE GRYEAR MITH holder2

SKIP

ENDDO

GO TOP LE TO PREPARE DREPORT Data Base FOR NEXT RASS THROUGH

OSE C CLOSE DREPORT.DBF UNTII NEXT LOOP TO PERMIT APPEND TO DEMAND SELECT 1 GERTURN TO DEMANDI.DBF

SKIP E GO ON TO NEXT RECORD IN DEMANDI.DBE TO PICK UP NEXT YEAR TIMES $=$ TIMES +1

ENDDO \&\& END RIPRIE THROTGG DEMAND1.DBF FOR YEAR YEAR

SELECT 3

APPEND FROM DREPORT

SEIECT 1

ENDDO

\&\& Loop 2

CLOSE Data Bases

SEIECT 3

USE DEMAND INDEX DEMAND

RIINDEX

CLOSE Data Bases

RETURN

* * Modified by B. de B. on $10 / 24 / 90$

UDMD9.PRG

* UDMDg.PRG

parameter aUto

CLEAR

TEXT

INSTRUCTIONS FOI UDMD9.PRG

OPDATE OF THE IEA COUNTRIES AND NON-IEA COUNTRIES: BAI EILES

This program is an intermediate stage in the update of tho ICSD 


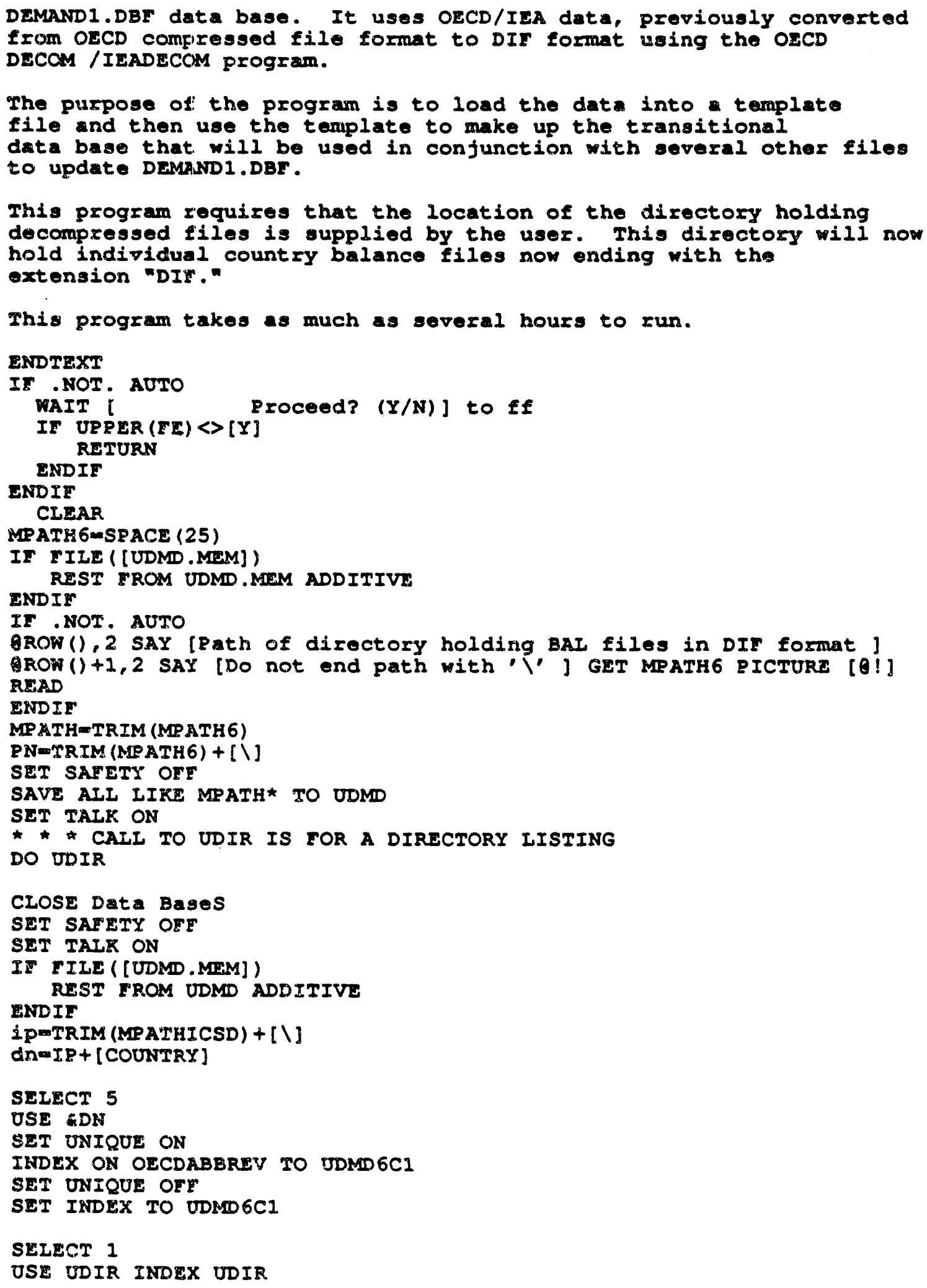


SELECT 2

OSE UDMD 6TEM

ZAP

SELECT 3

TSE UDMD 6

2AP

SELECT 1

GO TOP

DO WHILE .MOT. BOE()

SEIECT 1

* IF THE PROROSED FTLE IS NOT A BAI FILE SKIP IT

IF EXT $<>$ [DIF] .OR. SUBSTR (FIIENAME, 1,3 ) $<>[B A L]$ SRIP

IOOP

ENDIF

awilename

S-ITPPER. (S)

FN-PN+TRIM (IIIENAME) + I . ] EXT

* * CHFCK TO SEE IF COUNTRY IS USED IN ICSD

xnamSUBSTR $(S, 4,3)$

SEIECT 5

SEER XONA

IF .NOT. FOUND () .OR. .NOT. DEMAND

DELETE

SELECT :

SRIP

ENDIF

MOZCDMOECDABBEEV

SEIECT 2

USE UDMD6TEM

ZAP

APPEND FROM EFN TYPE DIF

GO TOP

CNWVARIABLE

EN=LTRIM (TRIM (SUBSTR (CN, 1, AT (" : ", CN))))

REPIACE ALI COUNTKY WITH UPPER(EN)

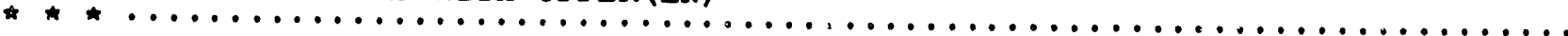

* * NOTE ON UNITS: THE BaLxexx.DIF files are IN MILlion OF

* * * MeTRIC TONS of oIl EQUIVALENT

* * * THE BESXXX.DIF gILES ARE IN PHYSICAL

* * * UNITS THAT VARy MITH FLOH TYPe

DO CASE

CASE SUBS $(5,1,3)=[$ BES $]$

REPLACE ALI UNITS WITH 0,ABBREV WITH MOECD, FILETYPE WITH [BES]

CASE $\operatorname{SUBSTR}(3,1,3)-[B A Z]$

REPLACE ALI UNITS WITH 1, ABBREV WITH MOECD, FILETYPE WITH [BAL]

OTHERHISE

ENDCASE

RERLACE ALI UNITS WITH O,ABBREV WITH MOECD, FILETYPE WITH [XXX]

GO TOP

DELETE 


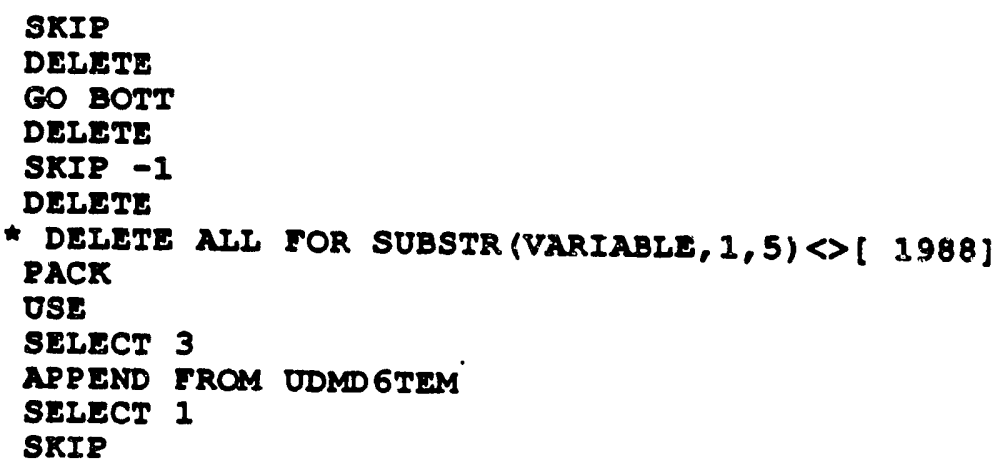

ENDDO

CLOS: Data Bases

SET SAFETY ON

RETURN
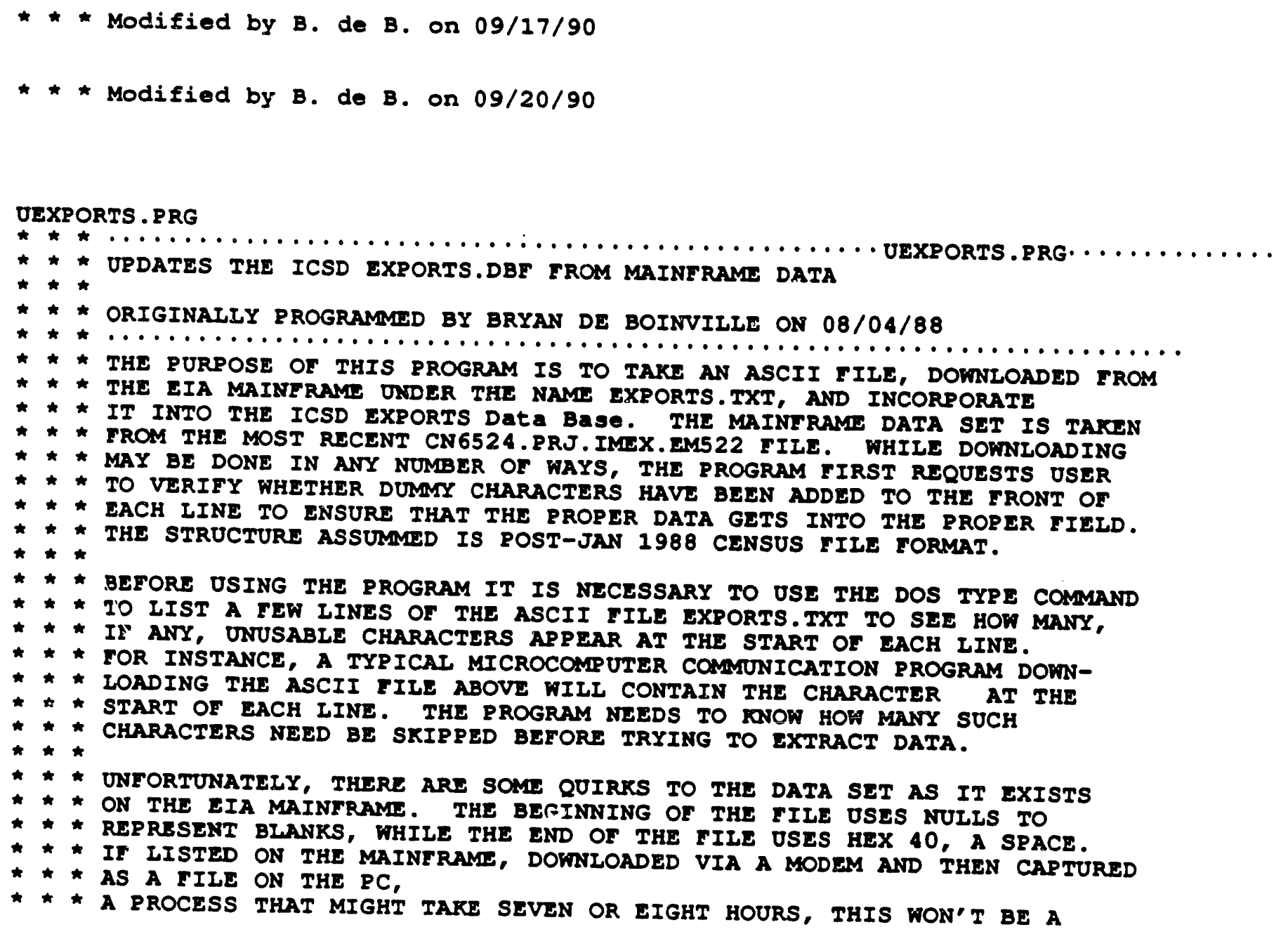
* * PROBLEM. IT VILI BE IF A TRANSFER FACIIITY IIKe EITHER ARBITER OR

* * PC3270 IS USED, AS THEY WIIL FAITHFULLY TRANSIATL THE NULLS AS NUILS.

* * AS DBASE CAN' T DEAL PROPERLY WITH NULLS, IT IS IMPORTANT TO RPPIACE

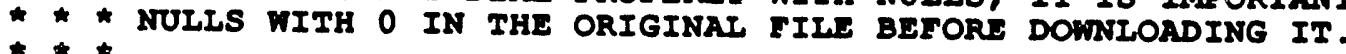

$\star \star \star$

* * UExports

cLmar

DO WHILE .T.

CLEAR

TEXT

ORDATE OF EXPORTS.TXT in two parts

1. Use EXPORTS.TXT (which user must have already created) for loading into oEXPORTS.DBF and, ultimately, EXPORTS. DBE

2. Edit exPORTS.DBF by putting in proper ICSD
codes

3. Return

Complete steps 1 and 2 in sequence. The process takes about four hours. APPROXIMATEIY 10 MEGABYTES OF DISK SPACE IS NECESSARY to hold the large intermediate ilies. Do not start the update unless EXPORTS.TXT has been downloaded to the $P C$, and the required amount of storage space is available.

ENDTEXT

WAIT [

Enter number - ] to RS

RS $=U P R E R$ (RS)

DO CASE

CASE RS= [1]

DO 04

CASE RS = [2]

DO 07

OTHERTISE

ENDCASE

RETURN

ENDDO

RITURN

OIMPORTS.PRG

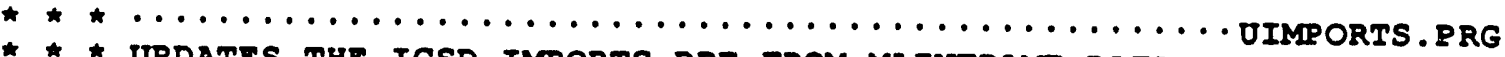

* * UPdates THE ICSD IMPORTS.dBE fROM MaINERAME data

$\star \star \star \star *$

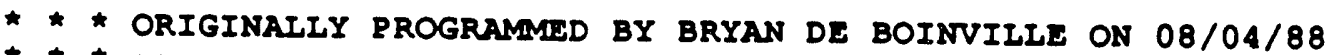

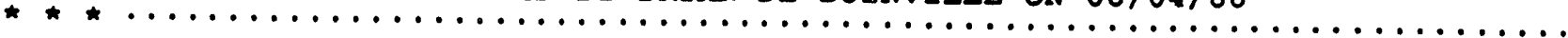

* * tye pURPOSe of this pRogram is to take an ascil file, downLOADED FROM

* * the eIa maintrame UNDER the NAME IMPORTs.TXT, and INCORPORATE 


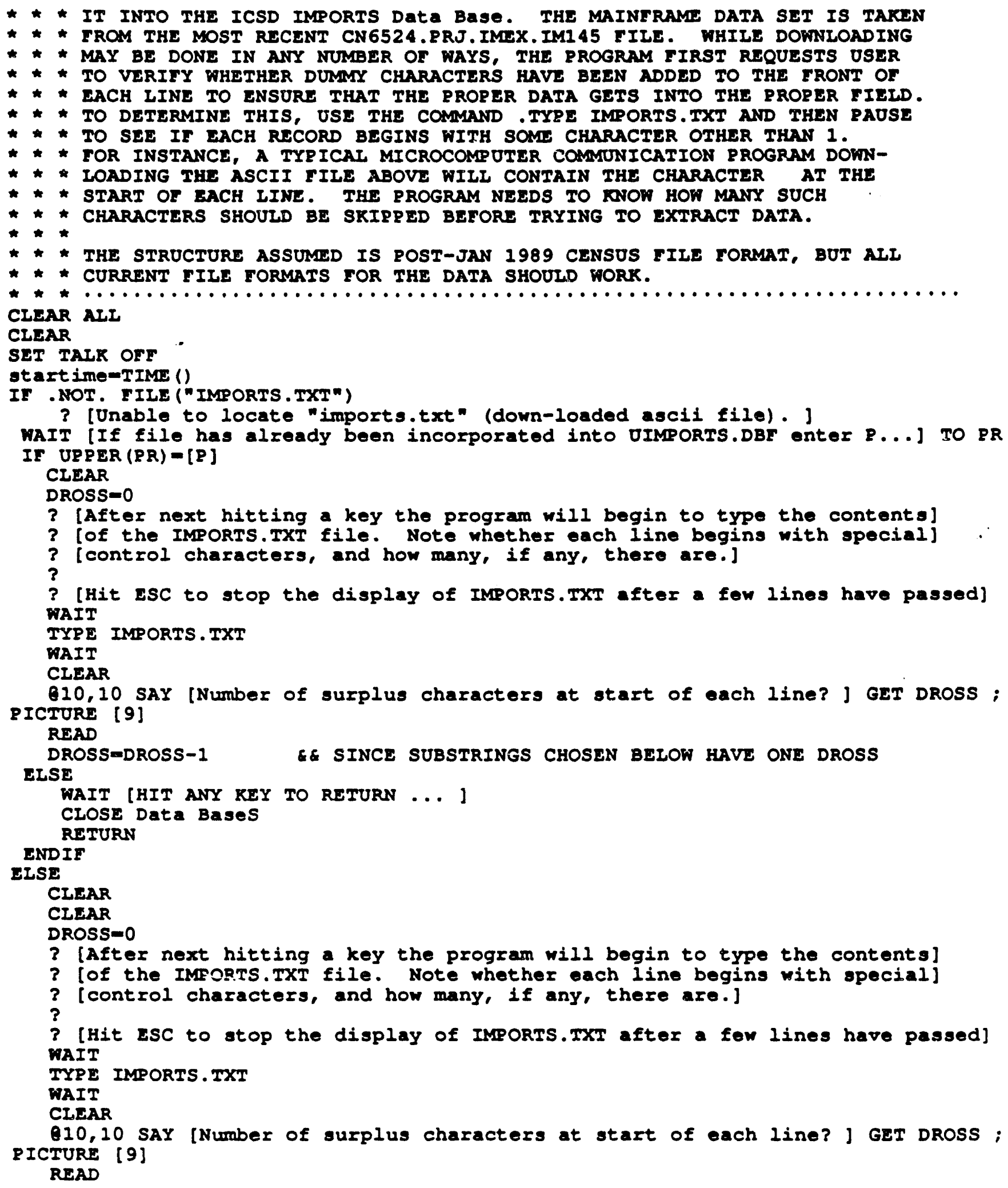




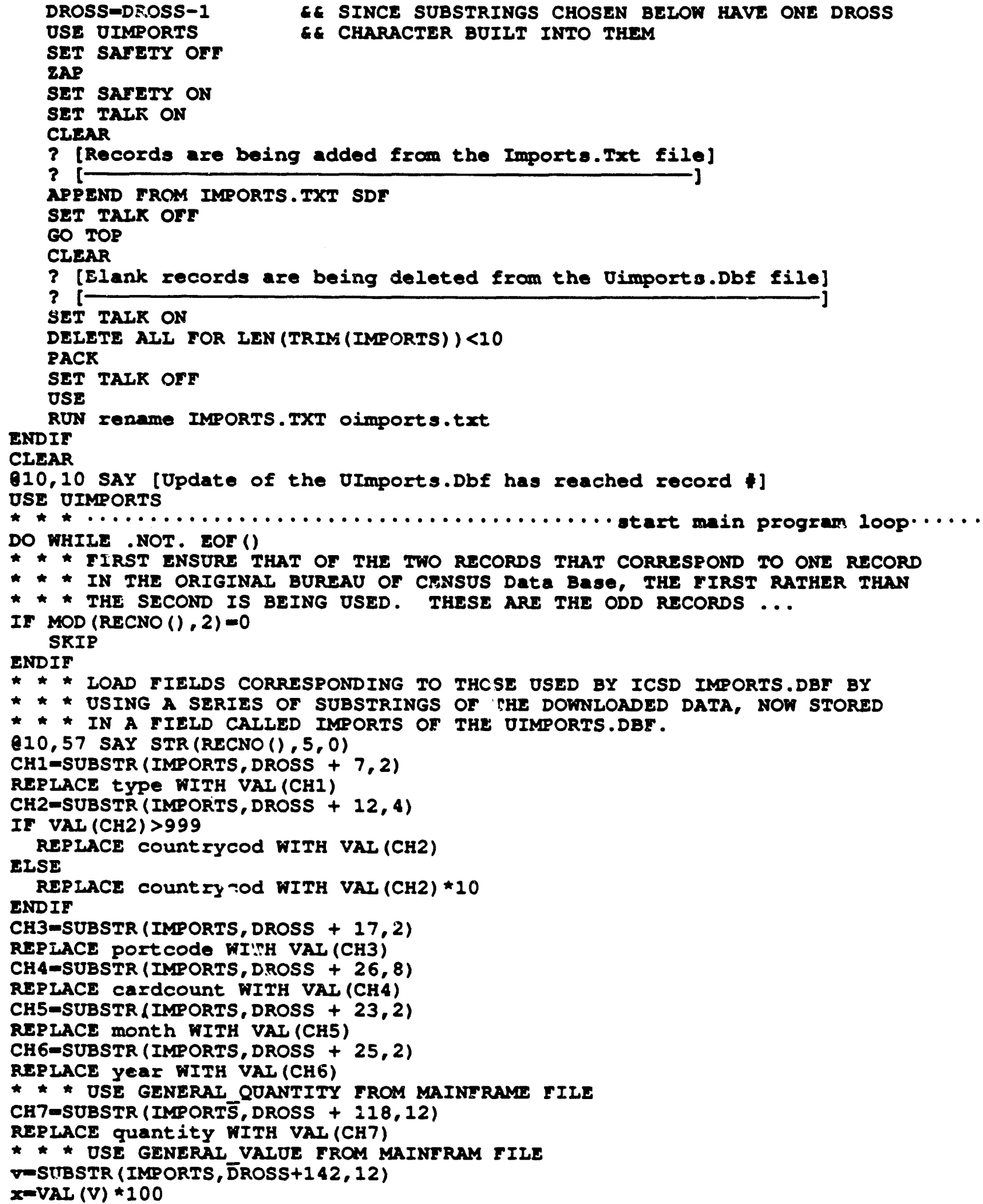


skip 1

$y=$ VAI (SUBSTR (IMPORTS, DROSS+2, 2))

SXIR - 1

CH8 $\mathrm{X}+\mathrm{Y}$

REPIACE value NITH CH8

$\star \star \star \star$

IF QUANTITY >0

REPLACE PRICEPERTN WITH VALOE/QOANTIT:

EISE

REPLACE RRICEPERTN WITH 0

ENDIF

CH10-STR (MONTH, 2, 0) + [/01/] +STR (YEAR, 2, 0)

REPIACE date WITH CTOD (CHIO)

010,56 CLEAR TO 10,79

SRI? 1

CH11=SUBSTR (IMPORTS, DROSS + 123, 20)

SKIP -1

REPLACE harmonizat WITH CHII

SKIP 2

ENDDO

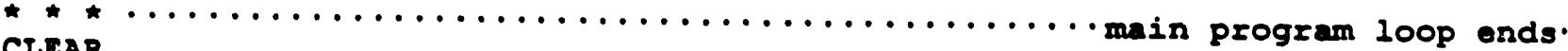

cLear

? [Now removing extraneous records]

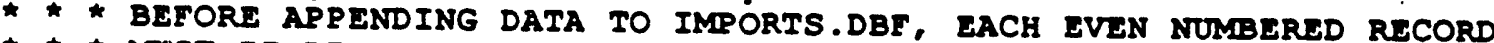

* * * MUST BE DELETED (SINCE IT WAS ORIGINÁLI A CONTINUATION OF THE

* * PRICEDING ODD RECORD).

DELETE AIL FOR MOD (RECNO(), 2)=0

PACK

* * THE UIMPORTS.DBF IS NOW IN SHAPE TO BE ADDED TO THE IMPORTS.DBE

* * t THIS IS DONE MITH THE APPEND COMMAND WHICH WIIL PROBABLY AISO

* * INCLUde a CONDItIONAL - E.g. APPEND FROM UIMPORTS FOR

* * DATE>CTOD ([M/OI/YY]). THIS STEP MUST BE PERFORMED MANUALIY...

$\star \star \star \star *$

* * NOTE THAT WHILE THE UIMPORTS.DBF PICKS UP THE GENERAL C.I.F. VAIUE

* * IT IS NOT NOW USED IN IMPORTS.DBF.

cizar

TEXT

In the next section the user must decide whether the newly created data base holding the IMPORTS.TXT data should:

1. Replace the current IMPORTS.DBF

2. Be added to the end of IMPORTS.DBF

3. Do nothing further, return

The answer will depend on what data is included in IMPORTS.TXT.

Usually, this will be all records, so 1 should be chosen.

ENDTEYT

WA:T [ Enter selection: ] to ans

ar.smupper (ans)

DO CASE

CASE ANS $-[1]$

CLEAR

SET TALR ON

USE IMPORTS 


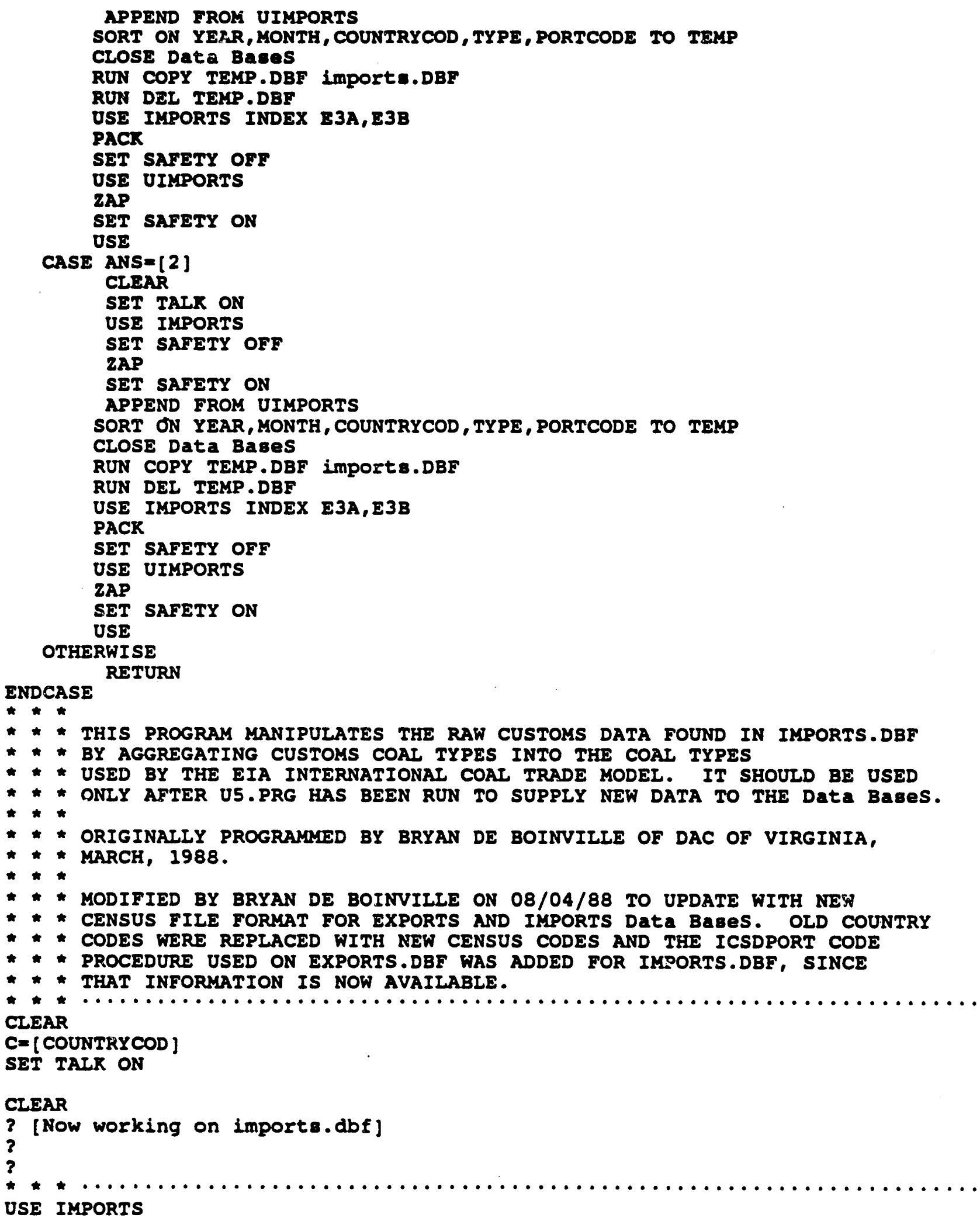


* * SET REgIONAL CODEs, WTERE ICSDREg 1 - CANADA; ICSDREg 2 = SOUTH AMERICA;

* * ICSDREG 3 = NORTH EUROPE; ICSDREg 4 = SOUTH EUROPE C MEDITERRANEAN;

* * ICSDREG 5 = ASIA; AND ICSDREg 6 = EASTERN BLOC

REPLACE ALL ICSDREg WITH 1 FOR EC=1220

REPLACE ALL ICSDREG WITH 2 FOR EC=1000 .OR. CC>=1610 .AND. CC $<=3720$

REPLACE ALI ICSDREG WITH 3 FOR EC=4330 .OR. CCS=4000 .AND. CC $=4280.0 R$. $8 C=4419$

OR. $C C=1010$

REPIACE ALL ICSDREG WITH 4 FOR EC> $=4890$.AND. EC $=5040$.OR. EC>=7140.AND. ;

$C C<=7990$. OR. CC> $=4670$. AND. CC< $=4790$

REPLACE ALI ICSDREG WITH 4 FOR EC=4840 .OR. CC=5080 .OR. EC=5120

REPLACE ALL ICSDREG WITH 5 FOR EC> $=5130$.AND. EC $=5490$.OR. CC> 5540 . AND. EC< $=5680$.OR. \&C> $=5800$. AND. CC< $=6860$

REPLACE AIL ICSDREG NITH 5 FOR EC=5110 .OR. EC=5050 .OR. EC=5070

REPLACE ALL ICSDREG WITH 6 FOR EC> $=4470$.AND. CC $=4610$.OR. \&C> $=5500$. AND. ; $C C<=5530$.OR. CC> $=5700$.AND. CC $<=5790$

REPLACE ALL ICSDREG WITH 6 FOR EC=4810 .OR. EC=4850 .OR. EC=4870 .OR. \&C=4290;

OR. \&C=4350 .OR. \&C=4370 .OR. \&C=2390

* * SET ICSD COAL TYPES, WHERE ICSDTYPE 1 = STEAM; ICSDTYPE 2 = MET AND

* ICSDTYPe 3 = all OTHER

REPLACE ALL ICSDTYPE WITH 1 FOR TYPE=20 . OR. TYPE=70

REPLACE ALL ICSDTYPE WITH 2 FOR TYPE 10

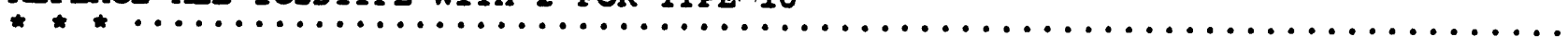

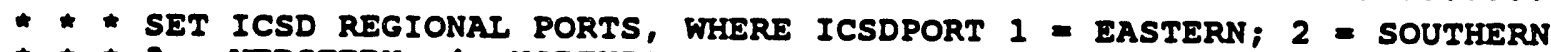

* * 3 = WERSTERN; 4= NORTHERN

$P=[$ PORTCODE]

"REPLACE ALL PORTCODE WITH 14 FOR PORTCODE = 59 G 59 IS AN ICTM CREATION

REPLACE AIL ICSDPORT WITH 2 FOR $Q P>=15$. AND. GP<=60

REPLACE ALL ICSDPORT WITH 3 FOR $Q P>=25$. AND. \&P< $=33$

REPLACE ALI ICSDPORT WITH 4 FOR $Q P>=34$. AND. $\& P<=45$

REPLACE AIL ICSDPORT WITH 1 FOR $\& P<=17$.OR. $\quad Q P=54$.OR. $\& P=59$

REPLACE ALL ICSDTYPE WITH 3 FOR ICSDTYPE $<1$. OR. ICSDTYPE $>2$

USE IMPORTS INDEX E3A, E3B

REINDEX

CLOSE Data Bases

SET TALK OFF

CLEAR

? (The imports/exports update program began at j+otartime

fint ime $=$ TIME ()

? [It finished at ]+fintime

WAIT

RETURN

$\sim \mathbf{z}$

UPDATE . PRG

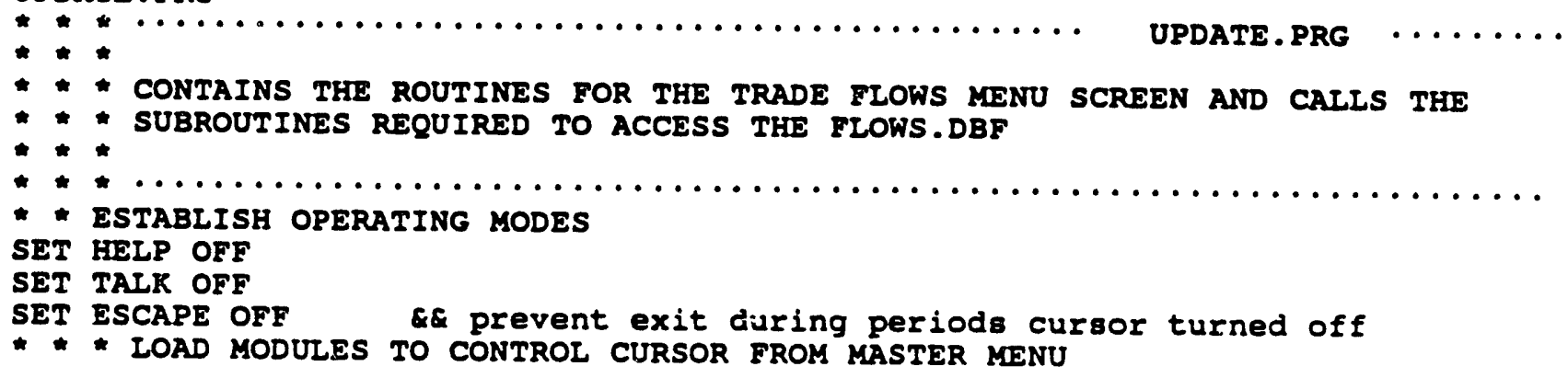


LOAD CURSON.BIN

LOAD CURSOFF.BIN

* * ADVISE PROGRAM OF location OF LOTUS

IF .NOT. FILE("CONEIG . MEM")

ELSE

ENDIF

DO OI SE CALI THE CONFIGURATION SUBROUTINE

* General variables

ontos $=. T$.

cholce $=0$

moniker $=[I \cdot C \cdot S \cdot D]$

* * . be . . . . . . . . . . . . . . . . . . . . . . . . .

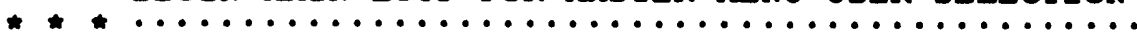

DO WHIL ontos

SET TAIR. OFF

CLEAR

choice $=0$

IF ISCOLOR()

SET COLOR TO $/ W, W / B, R$ CLEAR

ELSE

SET COLOR TO $W / N, N / W, N$

ENDIF

Q 2,7 say "

IF ISCOLOR()

SET COLOR TO /W,.

ELSE

SET COLOR TO $W / N$, ,

ENDIF

e 3,7 say

e 4,7 say

IF ISCOLOR()

SET COLOR TO R/W,,

ELSE

SET COLOR TO $\mathrm{\omega}+/ \mathrm{N}$, ,

\section{ENDIF}

e 4,8 ay

IF ISCOLOR()

I C S D Data Base Update Routines ]

SET COLOR TO N/W, ,

ELSE

SET COLOR TO $W / N$, ,

ENDIF

e 5,7 say

e 6,7 say

a 7,7 say

8,7 say

e 9,7 say

e10,7 say

e11.7 say

e12,7 say

e13,7 say

e14,7 say

e15,7 ay

Q16,7 say

e17,7 say

e18,7 eay

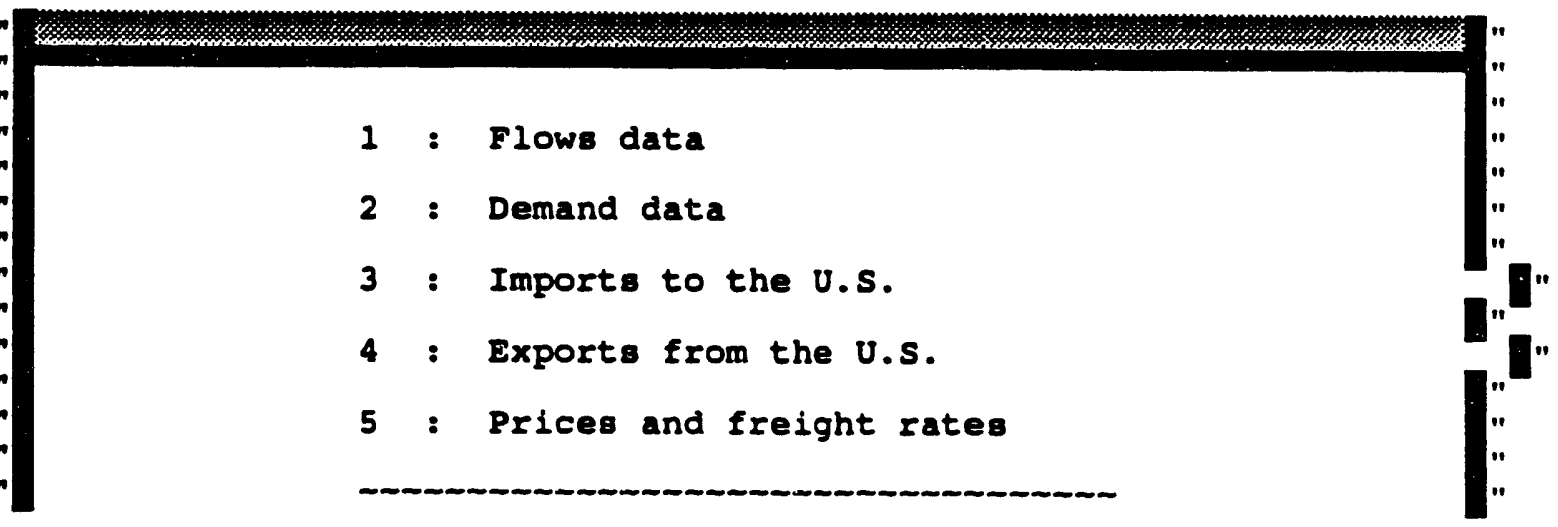




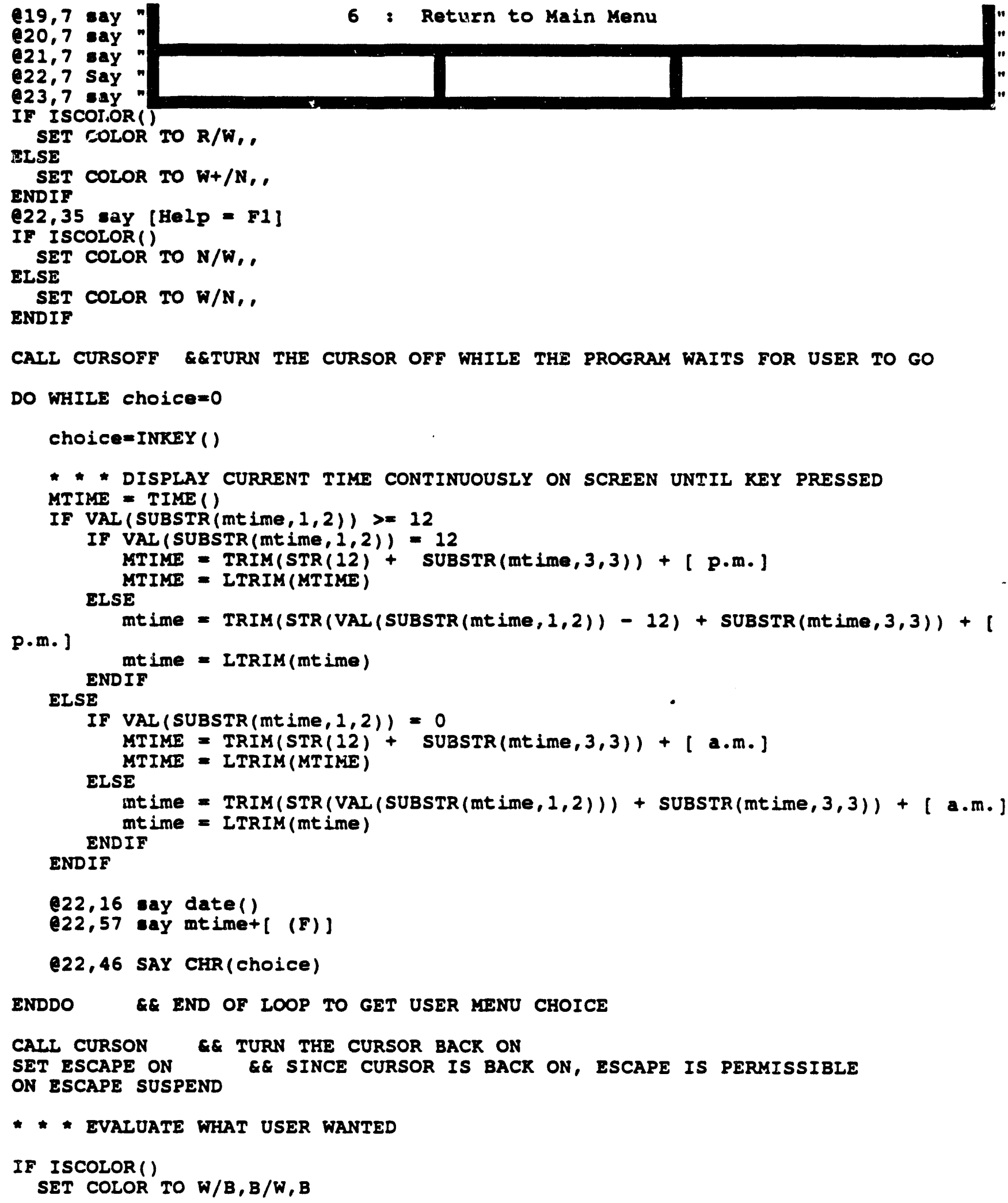




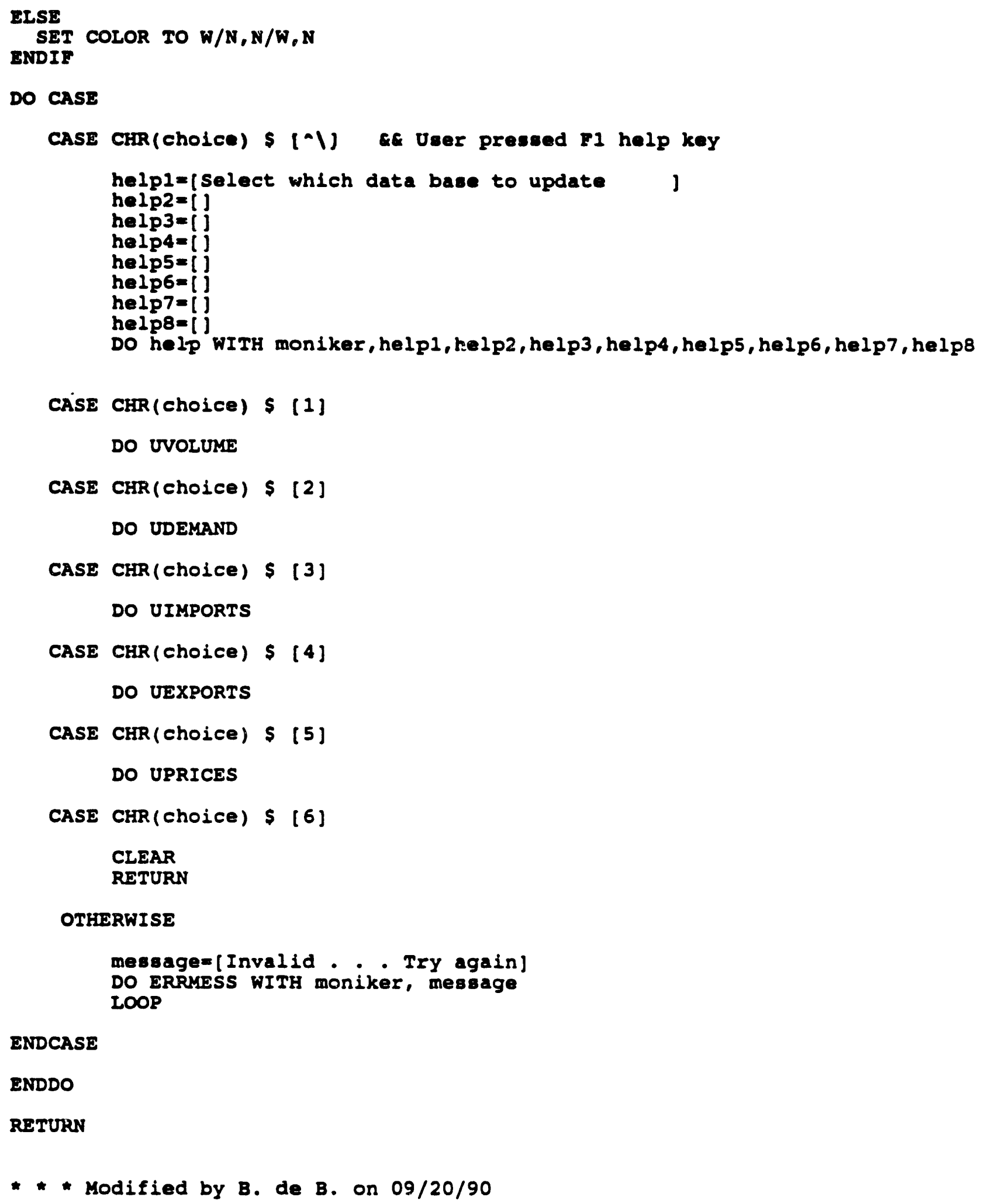




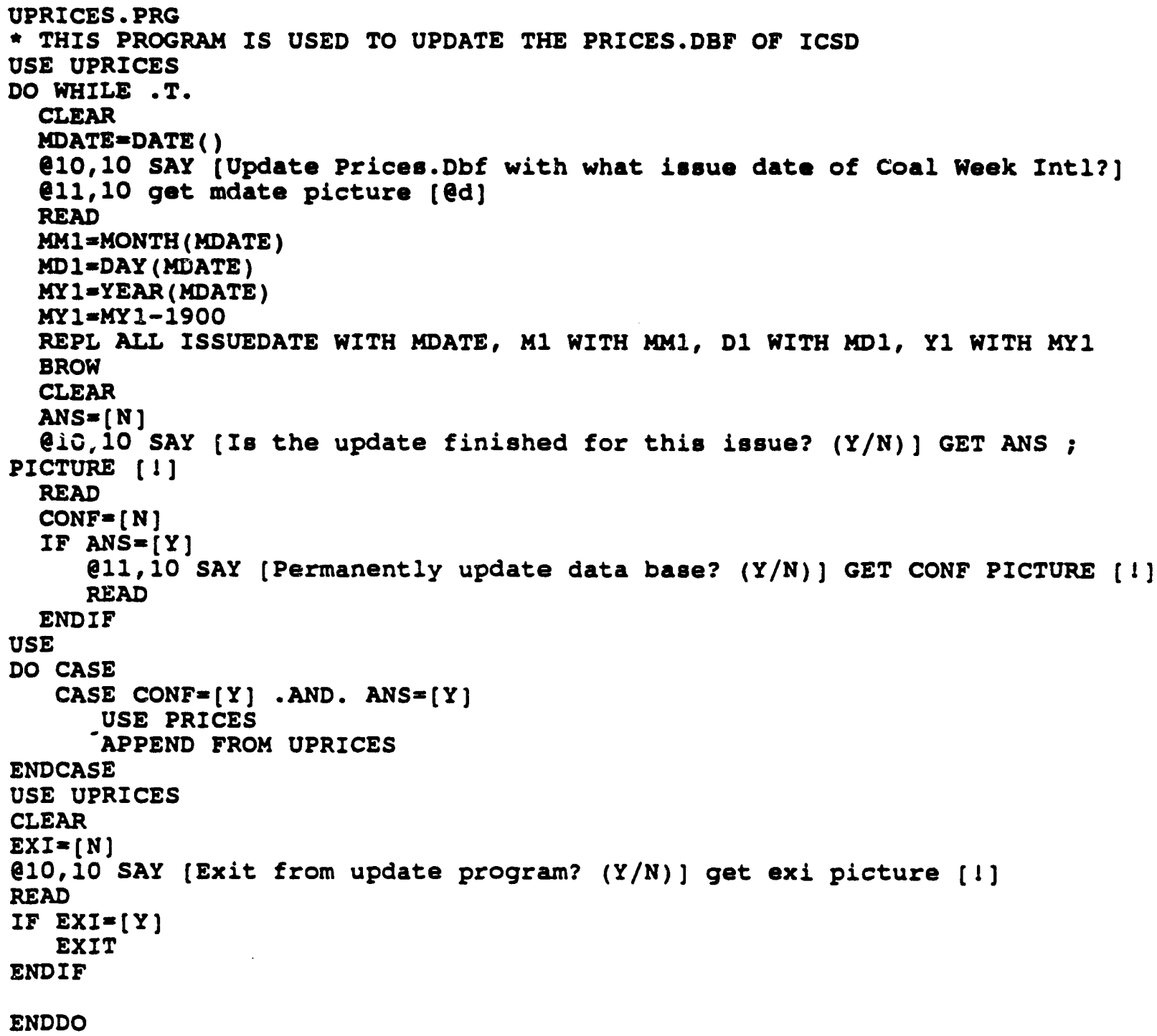




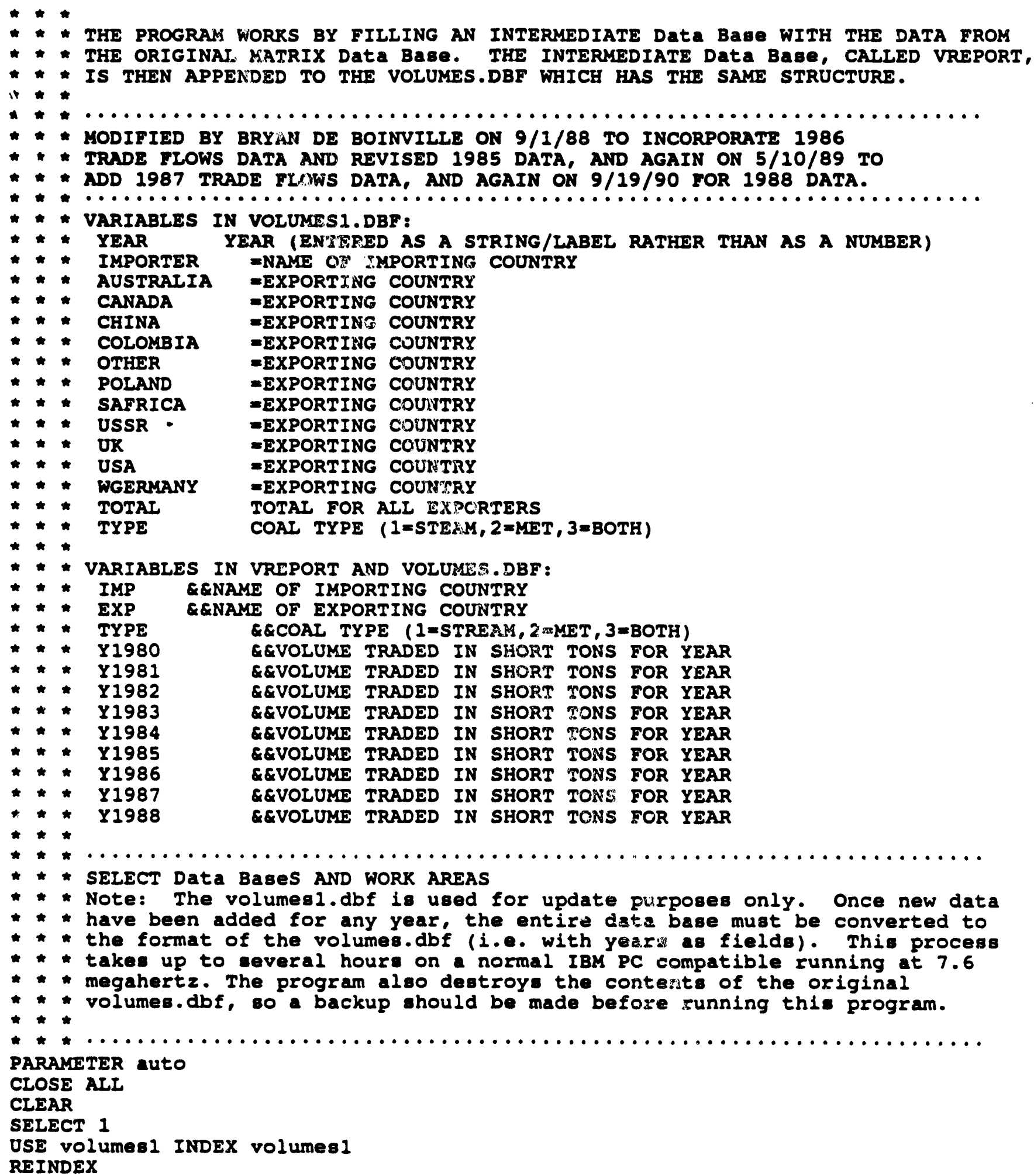

SELECT 2 
USE vreport

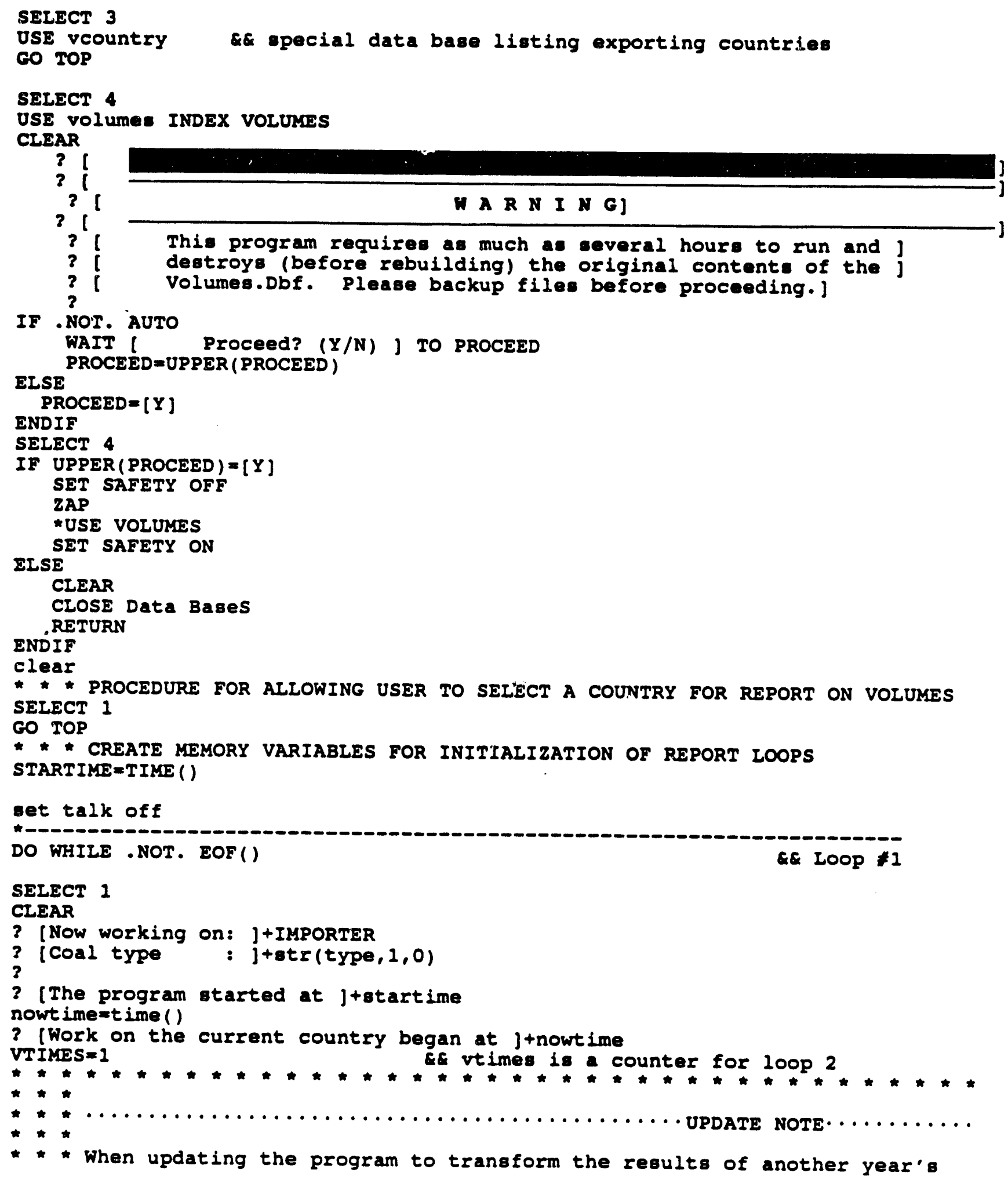




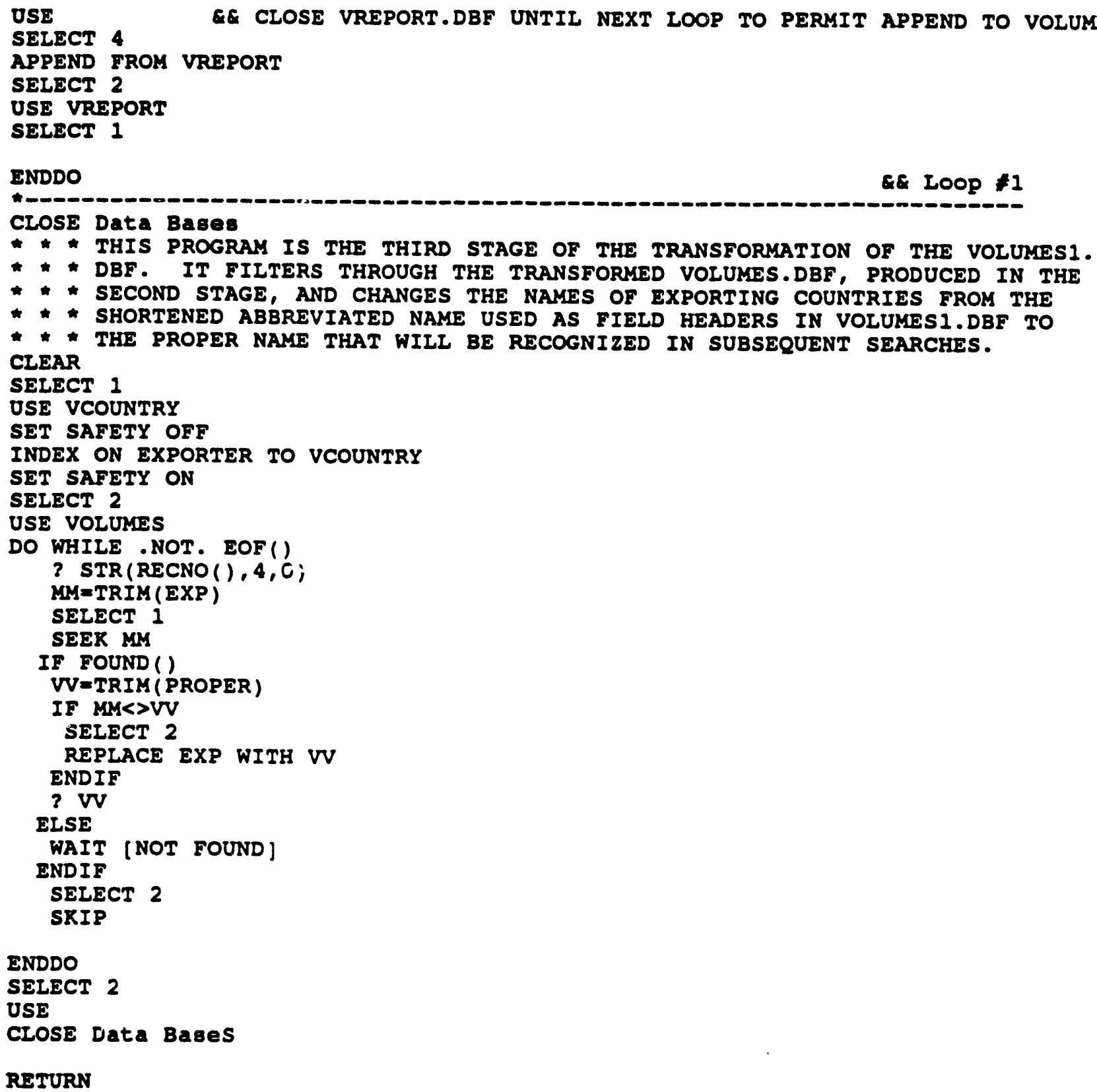

RETURN

- Modified by B. de B. on $09 / 20 / 90$

UVOLUKE . PRG

* THIS PROGRAM CONTROLS UPDATE OF THE TRADE FLOWS DATA IN VOLUMEI.DBF cLear aIl

CLEAR

TEXT 
Opdate of the Trade Flowe Data

nfter preseing a key, the update template for the trade flow data will be loaded. Uee Tables $\mathrm{A}, \mathrm{A}, \mathrm{s}$, and $\mathrm{A} 6$ of Annual Prospecte for World Coal Trade (for steam, met. and total coal flowe in ohort tone) as the source of the data to be entered.

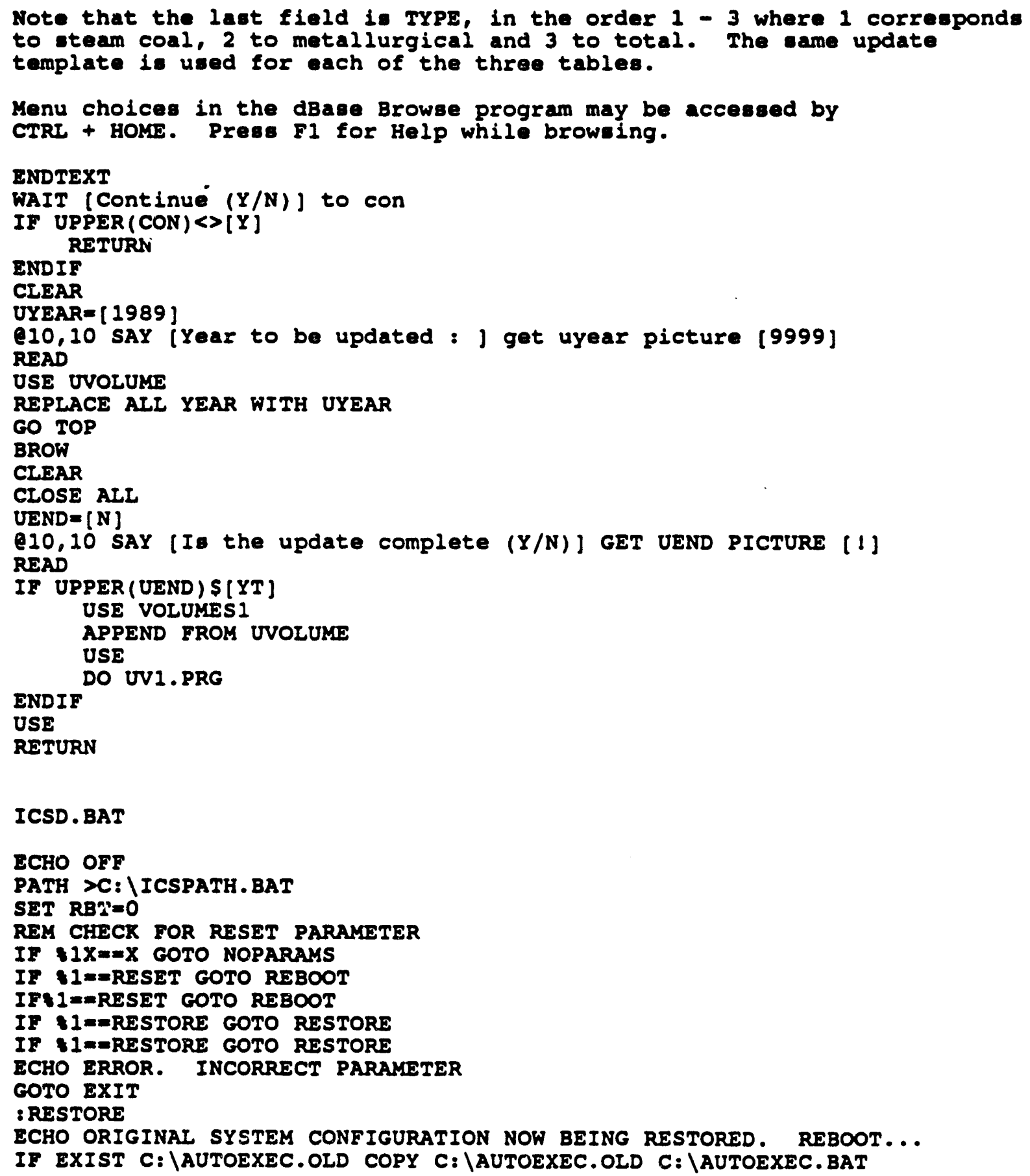




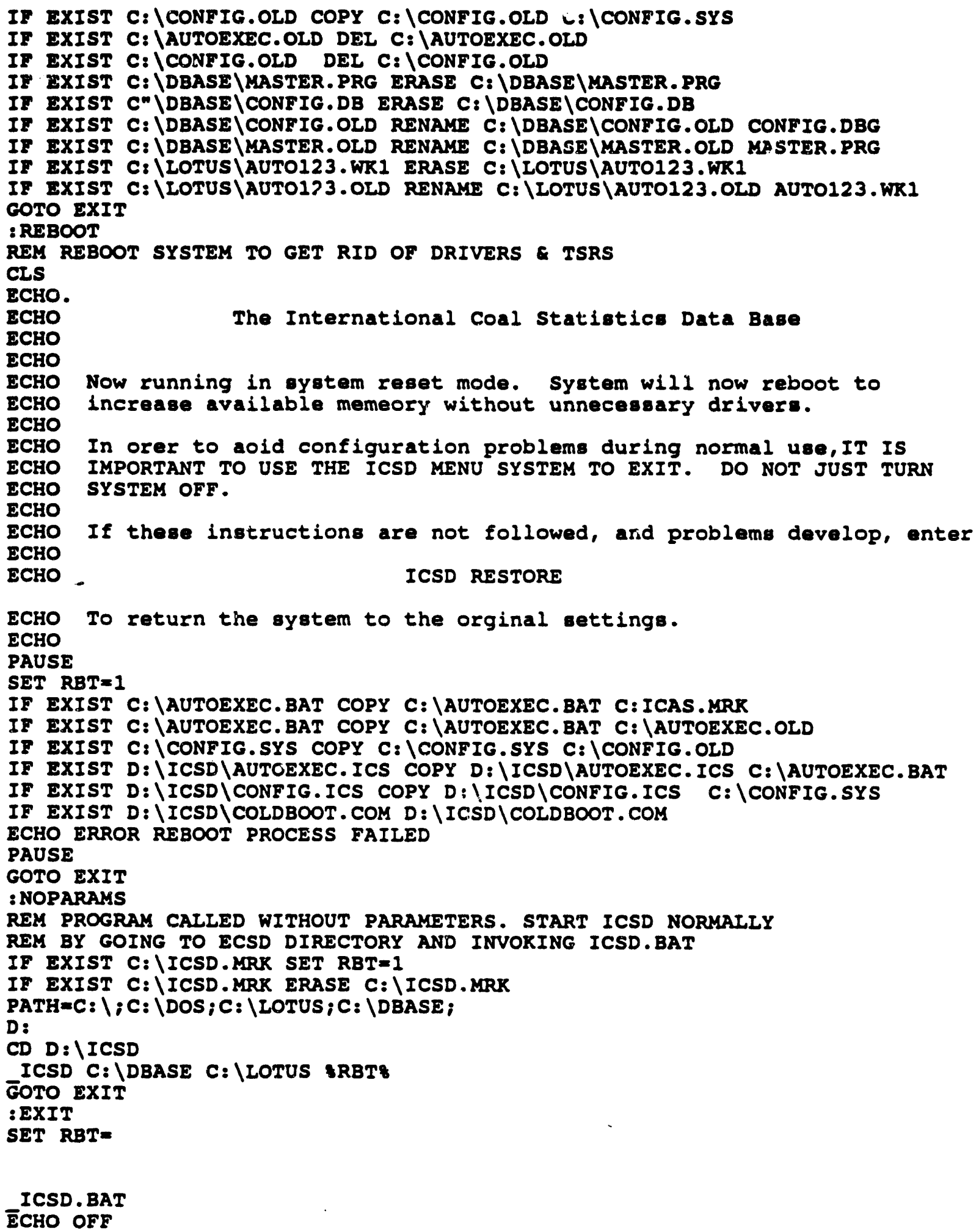

CLS

всно.

ECHO

The International Coal Statistics Data Base

ECHO

ECHO Now running in eystem reset mode. System will now reboot to

ECHO

ECHO

ECHO

ECHO

ECHO

ECHO

ЕСНО ICSD RESTORE

ECHO To return the system to the orginal settings.

ECHO

PAUSE

IF EXIST c:

IF EXIST C: ICONFIG SYS COPY C: $\backslash$ CONFIG SYS C: $\backslash$ CONFIG. OLD

IF EXIST D: \ICSD \AUTOEXEC.ICS COPY D: \ICSD \AUTOEXEC.ICS C: \AUTOEXEC.BAT

IF EXIST D: \ICSD \CONFIG.ICS COPY D:\ICSD\CONFIG.ICS C:\CONEIG.SYS

IF EXIST D: \ICSD \COLDBOOT.COM D: \ICSD \COLDBOOT.COM

PAUSE

GOTO EXIT

: NOPARAMS

REM PROGRAM CALLED WITHOUT PARAMETERS. START ICSD NORMALLY

REM BY GOING TO ECSD DIRECTORY AND INVORING ICSD.BAT

IF EXIST C: \ICSD.MRK SET RBT=1

IF EXIST C: \ICSD.MRK ERASE C: \ICSD.MRK

PATH $=C: \backslash ; C: \mid D O S ; C: \backslash L O T U S ; C: \backslash D B A S E ;$

D:

CD D: \ICSD

ICSD C: \DBASE C: \LOTUS RRTR

GOTO EXIT

EXIT

SET RBT =

$\bar{E}$ CHO 


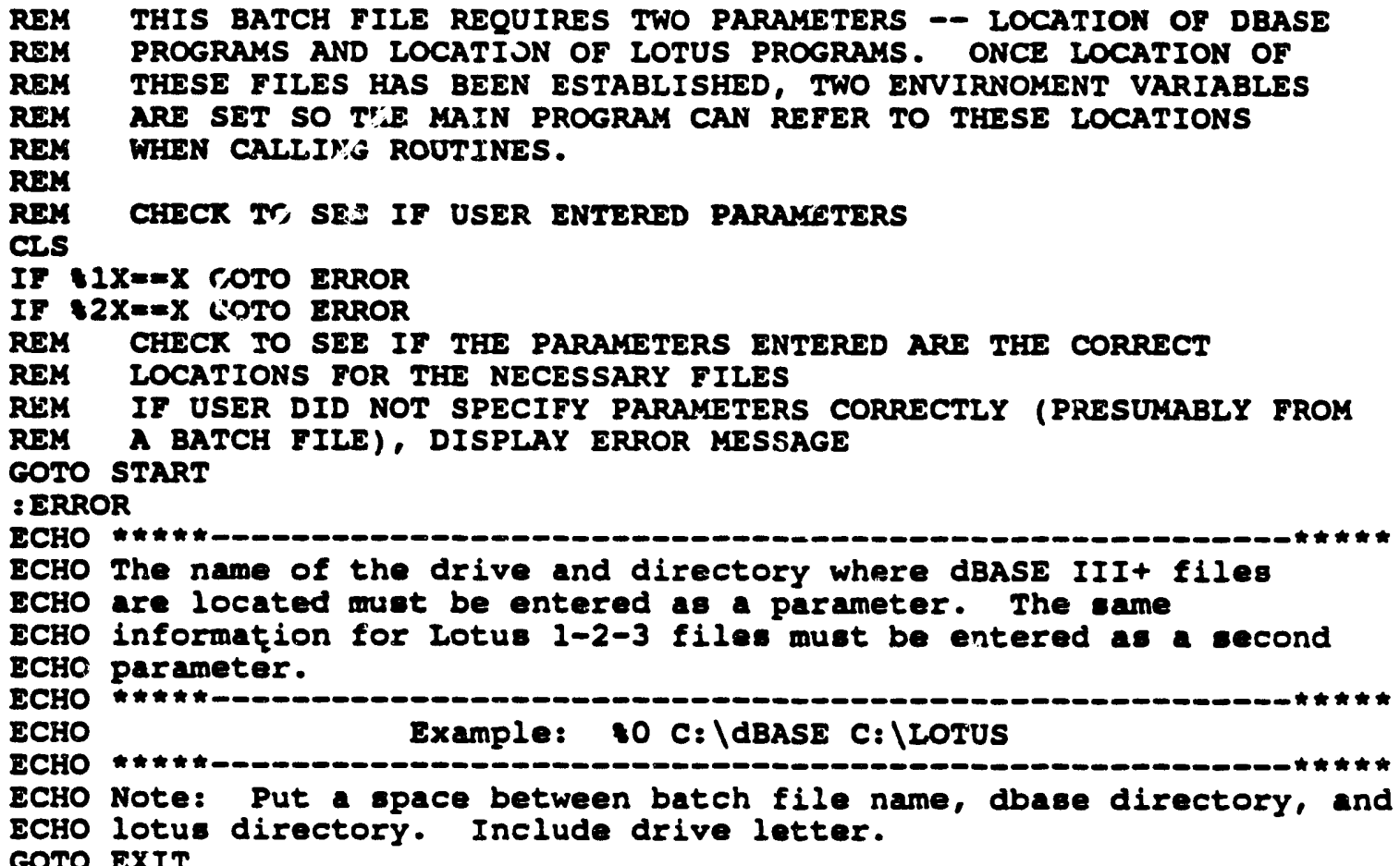

\section{: START}

CLS

IF $R B T==1$ GOTO CLEANFILE

GOTO CHECR

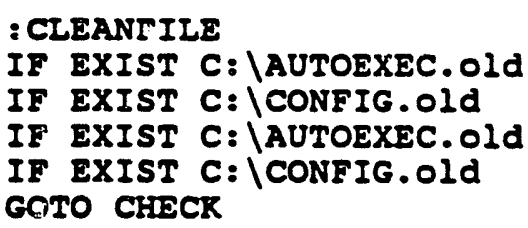
COPY C: IAUTOEXEC.OLd
DEI C: LAUTOEXEC.0Id
C: \AUTOEXEC.BAT
C: \CONFIG.SYS

DEI C: |CONFIG.01d 


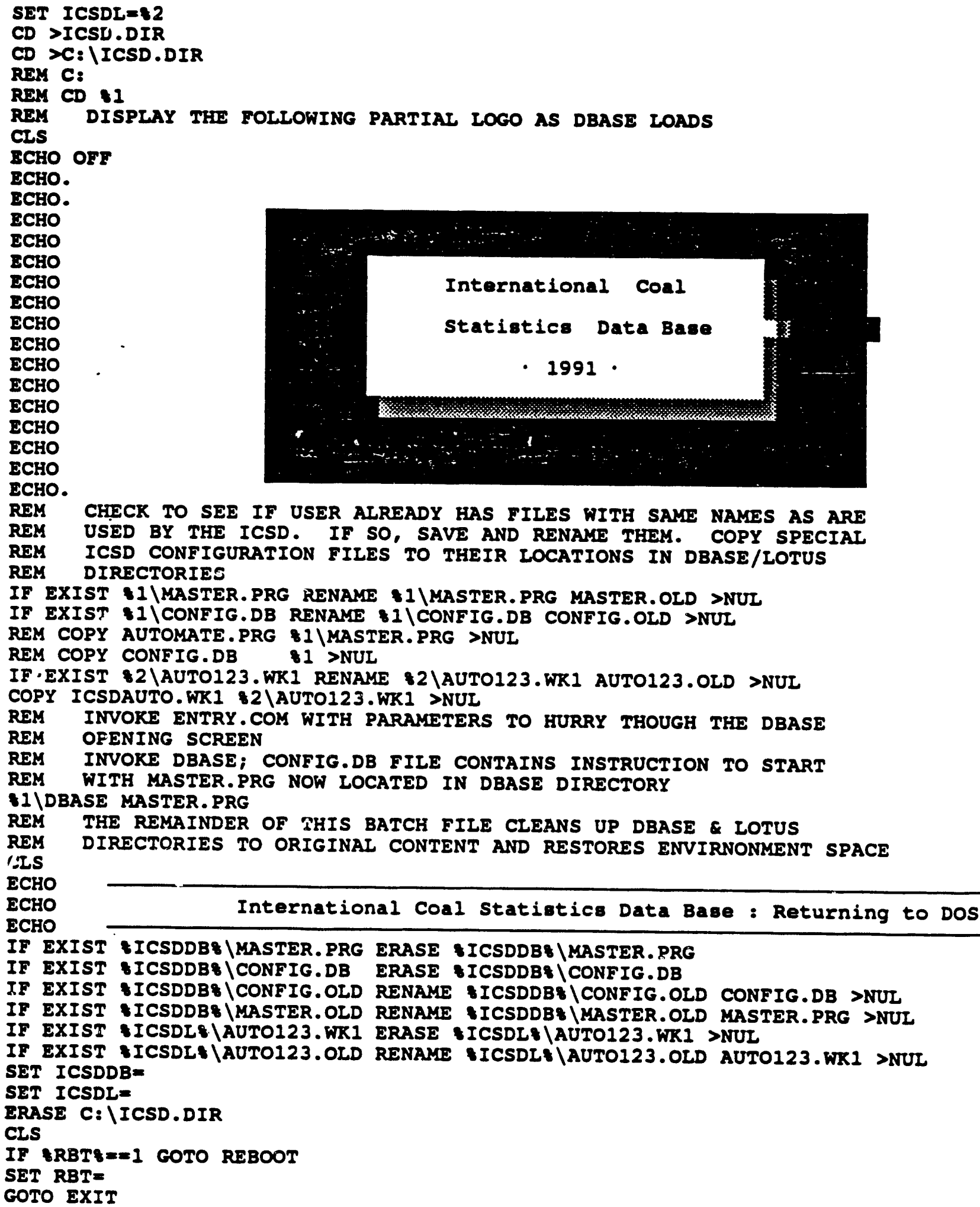


: REBOOT

COLDBOOT

: EXIT

Source Code for ICSD Installation Programe

INSTALL. BAT

ECHO $7 E F$

CLS

SET DYEST=AAAABBBBCCCCDDDDEEEEFFE

IF EXIST COPYFILE.BAT DEL COPYFILE.BAT

STEP1

DBASE INGTALLI

SET DTEST=

CLS

STEP2

IF NOT EXIST COPYFILE.BAT

IF EXIST COPYEILE.BAT

GOTO FAILURE

CALL COPYFILE. BAT

:STEP3

DBASE INSTALL2

COTO EXIT

:FAILURE

CLS

ECHO.

ECHO ERROR! Tranfer of files cannot be completed because a file

ECHO

that should have been created during the installation

ECHO

was not found. Try running INSTALL.BAT again ...

ECHO.

:EXIT

INSTAIL1.PRG

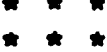

* * Purpobe: INStalls ICSD fILEs. CALIEd By INSTALL.BAT

-

$+\ldots$

SET TAIR OFE

SET COLOR TO B/W,N/BG,N

CLEAR

$M Y=S P A C E(45)$

IF FILE ([ INSTALL . MEM])

RESTORE FROM INSTALI.MEM ADDITIVE

ENDIF

FATAL $=. F$.

NEEDRESET $=. \mathrm{F}$.

MTOTAL $=000000$

MPREE $=000000$ 
REQSPACE $=7800000$

I DIR = [C: IICSD] +SPACE (45)

I LOTUS = [E: [LOTUS]+SPACE (45)

I DBASE= [E: $[\mathrm{DBASE}]+\operatorname{SPACE}(45)$

MREQTOT $=630000$

MREQFREE $=320000$

D_DIR= [A]

TEXT

Inetalling the International coal

Statistice Data Base

Installation of the ICSD requires:

- The seven ICSD program and data dieks

- Lotus 1-2-3 (version 2.01 of 2.2), dBase IIIt, and DOS $3 . x$ or greater.

- Approximately 570,000 bytes of free memory available before dBase III is loaded, or approximately 315,000 bytes of free memory with dBase III loaded (as it is now)

- Approximately 8,000,000 bytes of hard disk etorage space

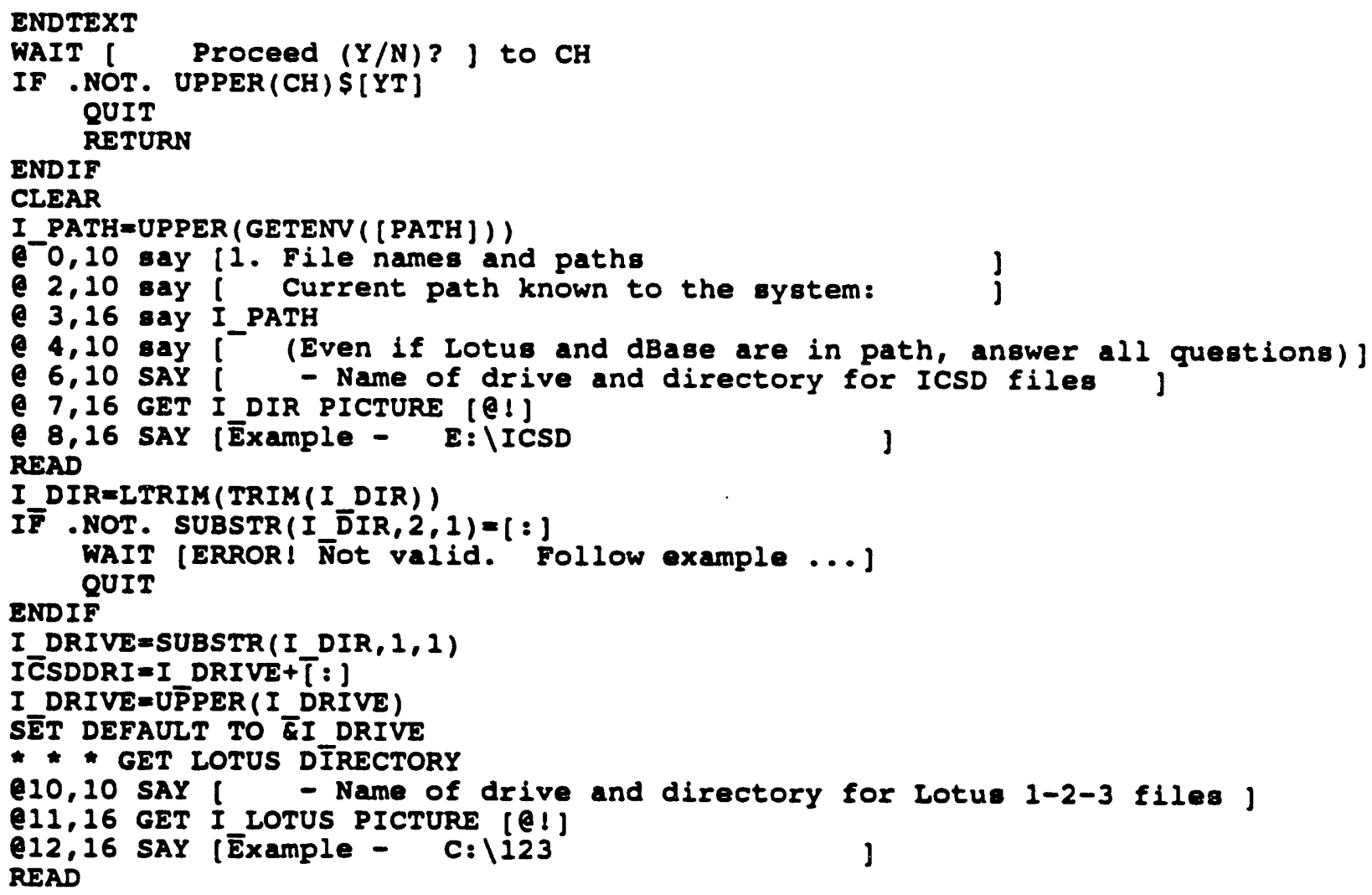




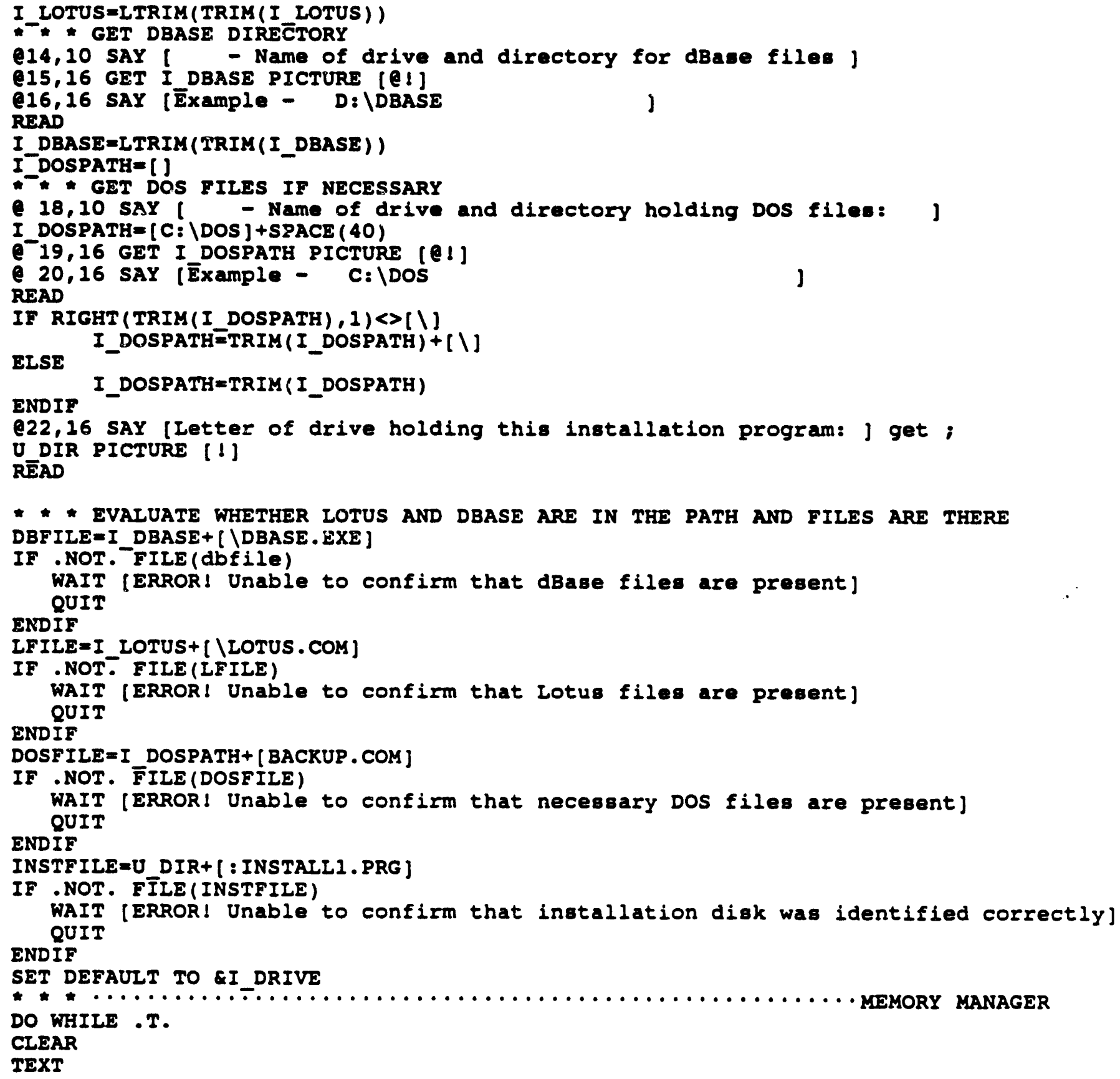


1. Don't know whether a memory manager is used, and/or not sure what it's called (will display contents of CONFIG.SYS)

2. Don't use a memory manager

3. Use a memory manager, name and path to be supplied by user

4. Continue (after selecting either 2 or 3 )

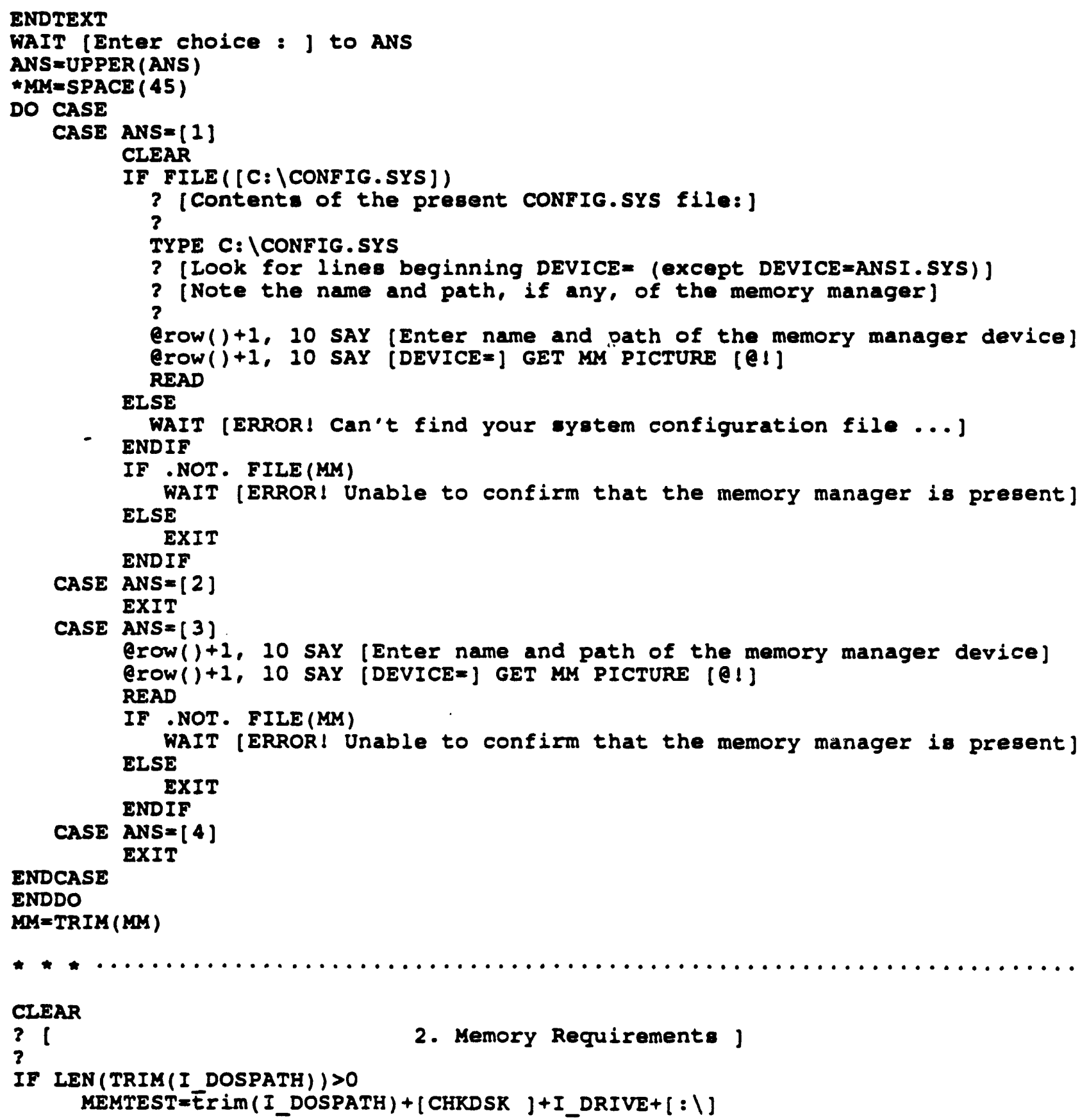


ELSE

ENDIF

WEMTEST=[CHKDSK ]+I_DRIVE+[: \]

SET CONSOLE OFF

RUN CMEMTEST

SET CONSOLE ON

eROW(1), I SAY [Enter total memory = ] GET MTOTAL PICTURE (9999999999]

eROW(), COL()+7 SAY [ and free memory = ] GET MFREE PICTURE [9999999999]

READ

CLEAR

TEXT

3. System Checkout

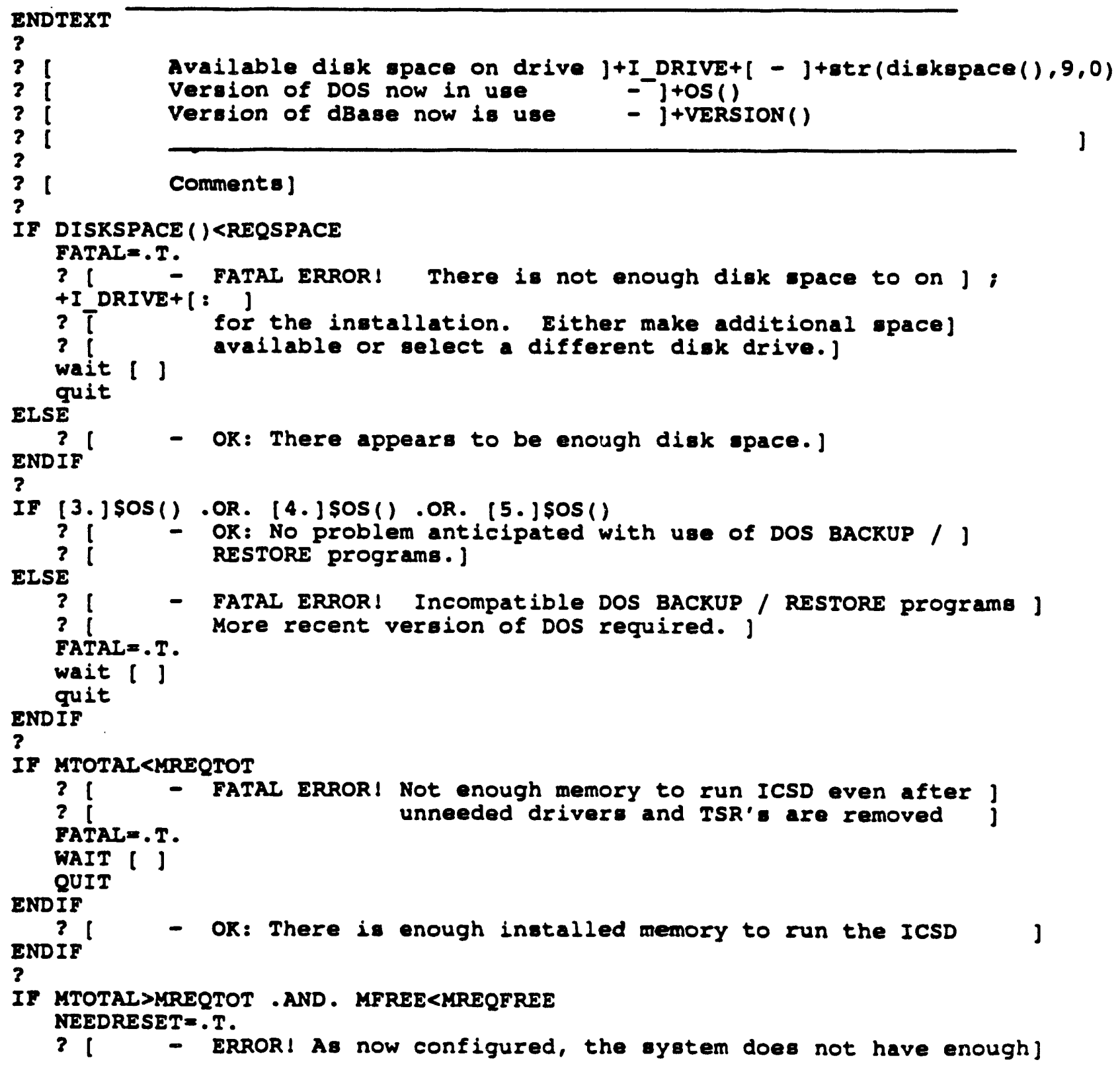




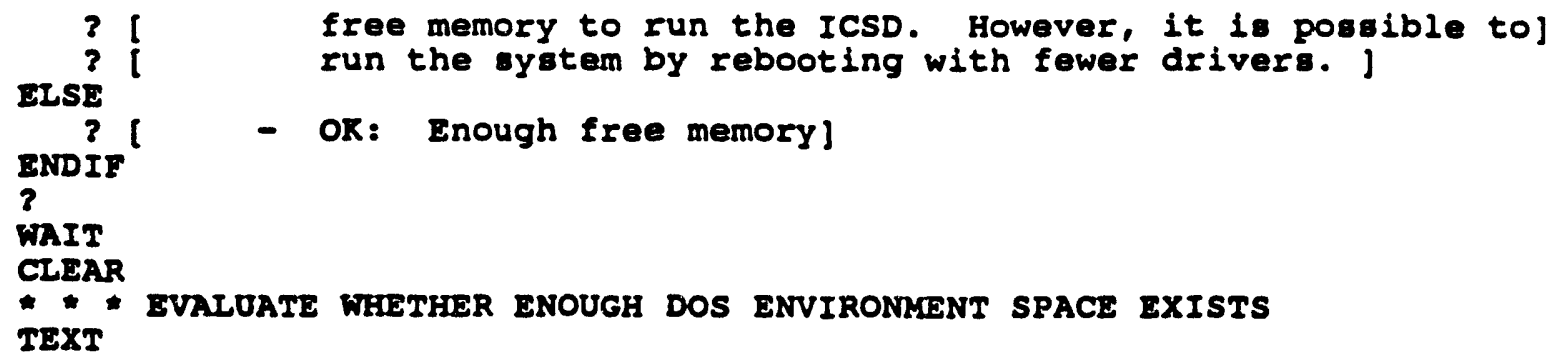

3. System Checkout (Continued)

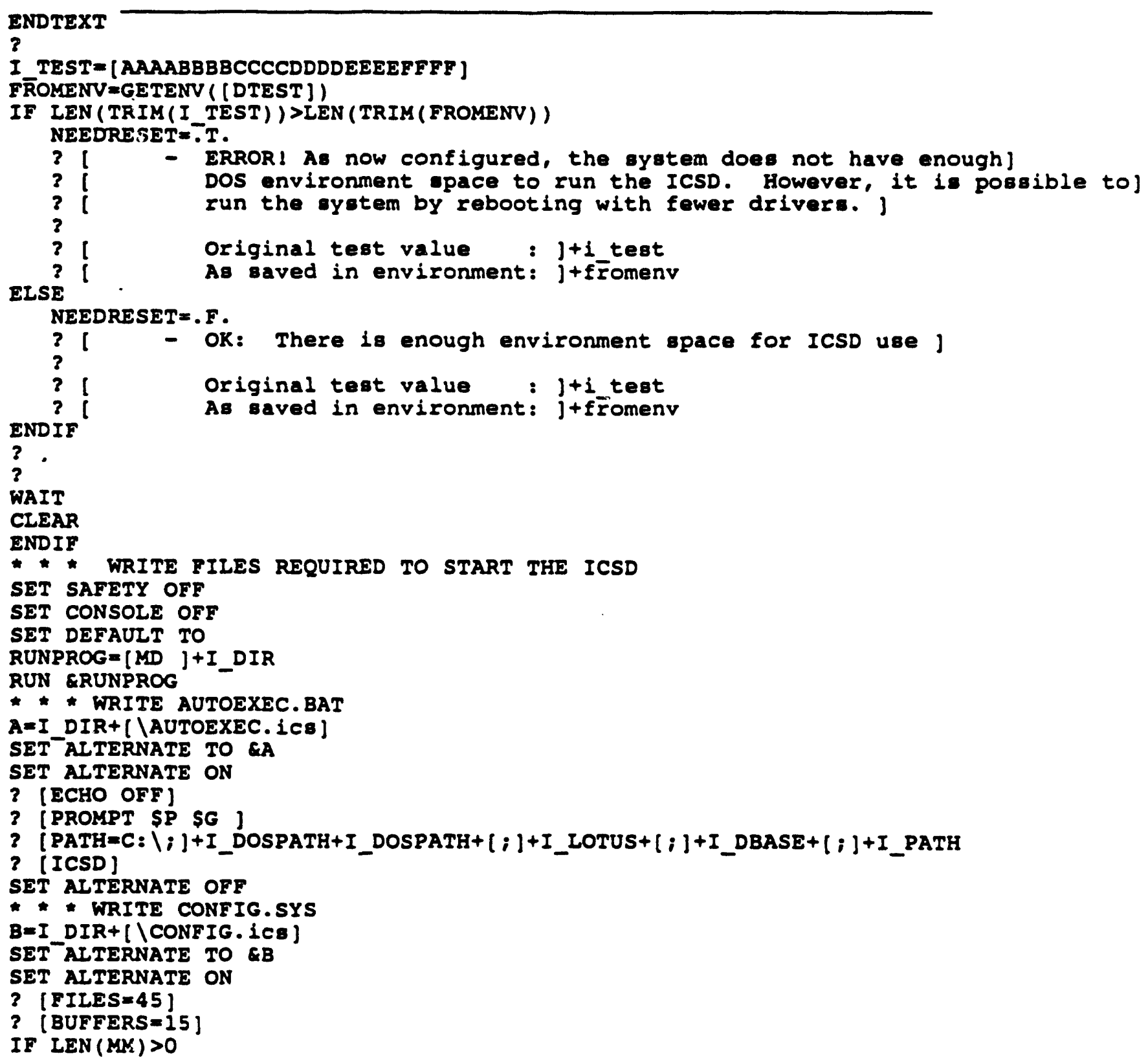




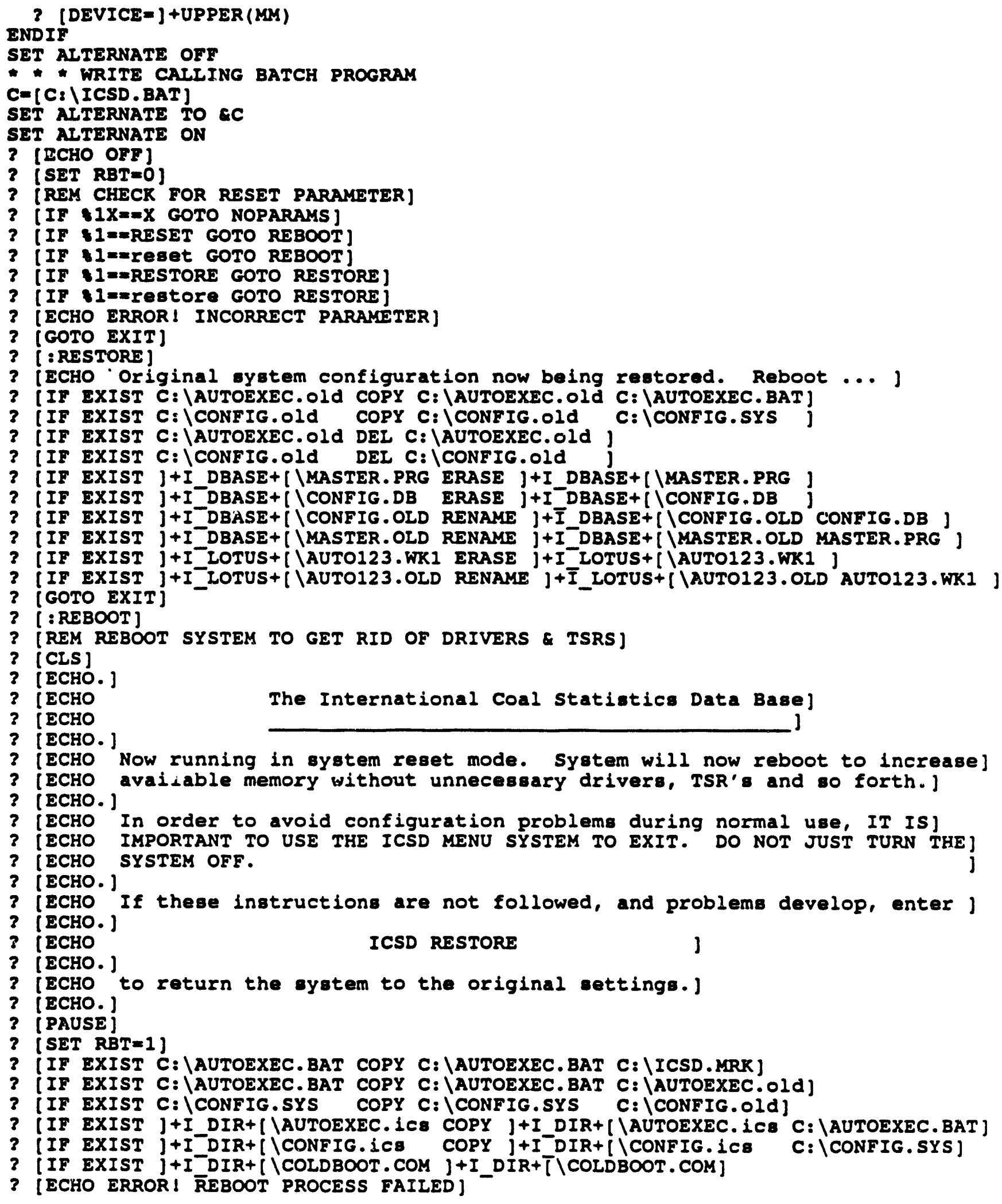




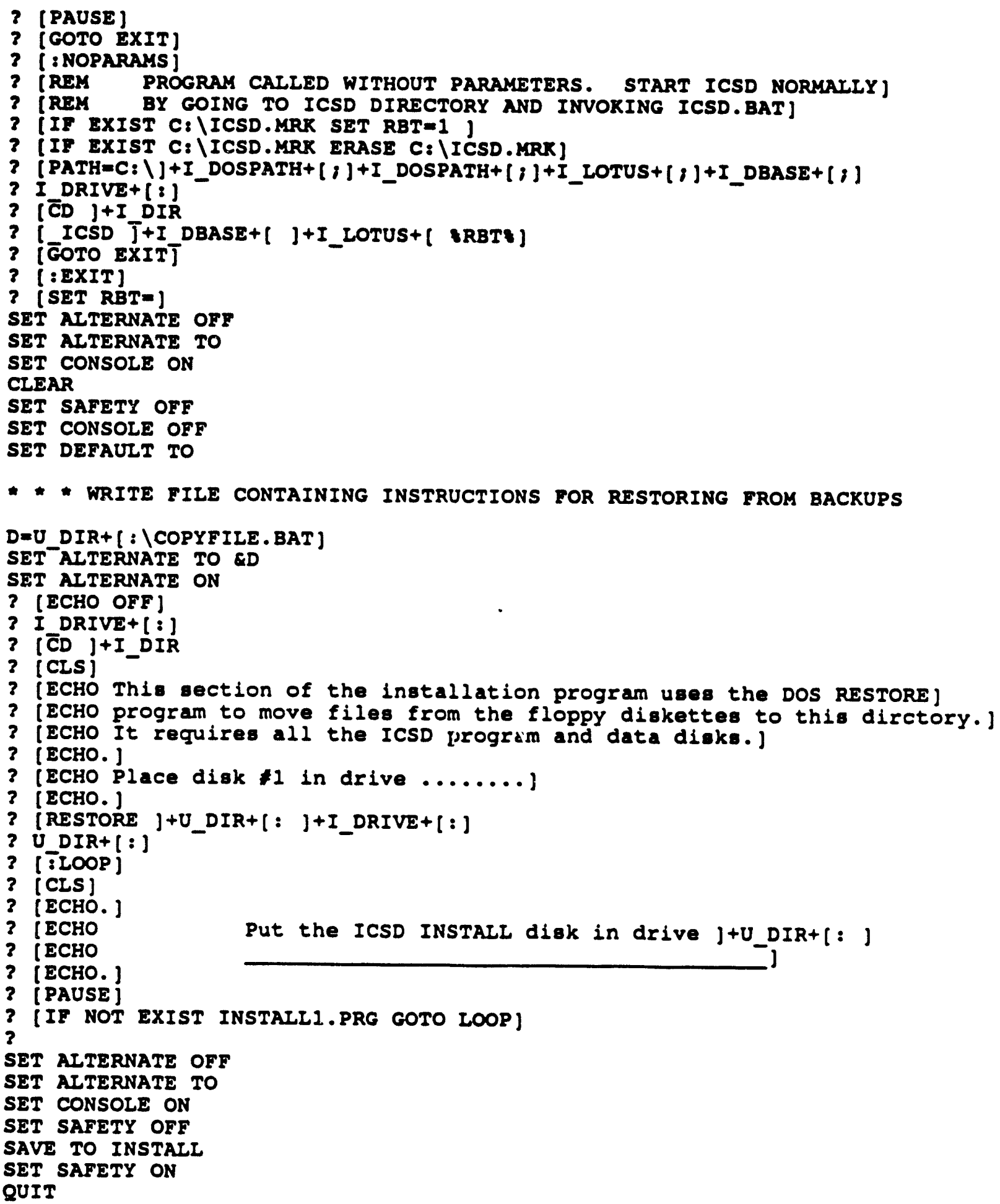


INSTALL2 . PRG

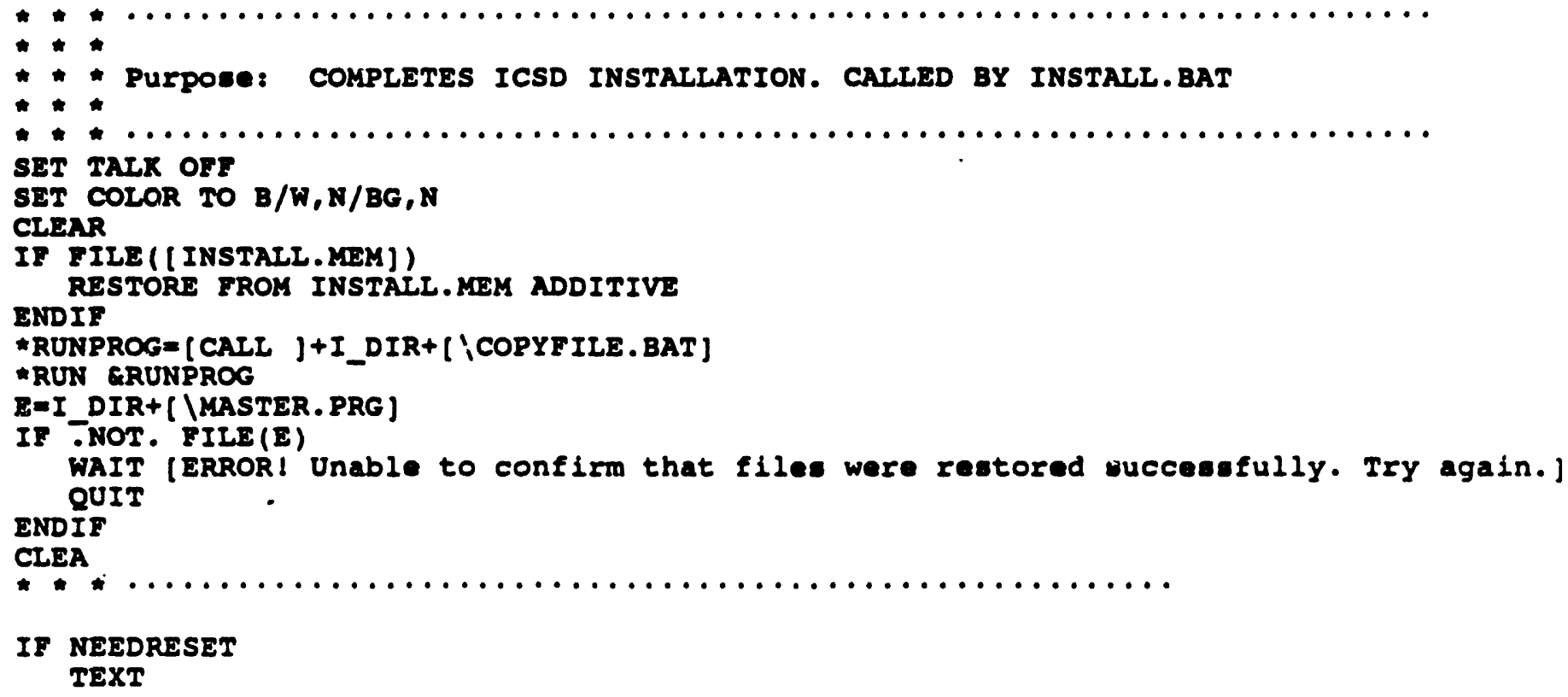

C: IICSD RESET 


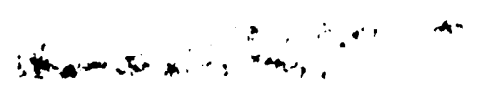

ICSD Program Source Code

L

ENDTEXT

ENDIF

WAIT

CLEAR

QUIT

\subsection{Security}

All data on the ICSD are non-proprietary, therefore no security measures (e.g., passwords) are provided. 

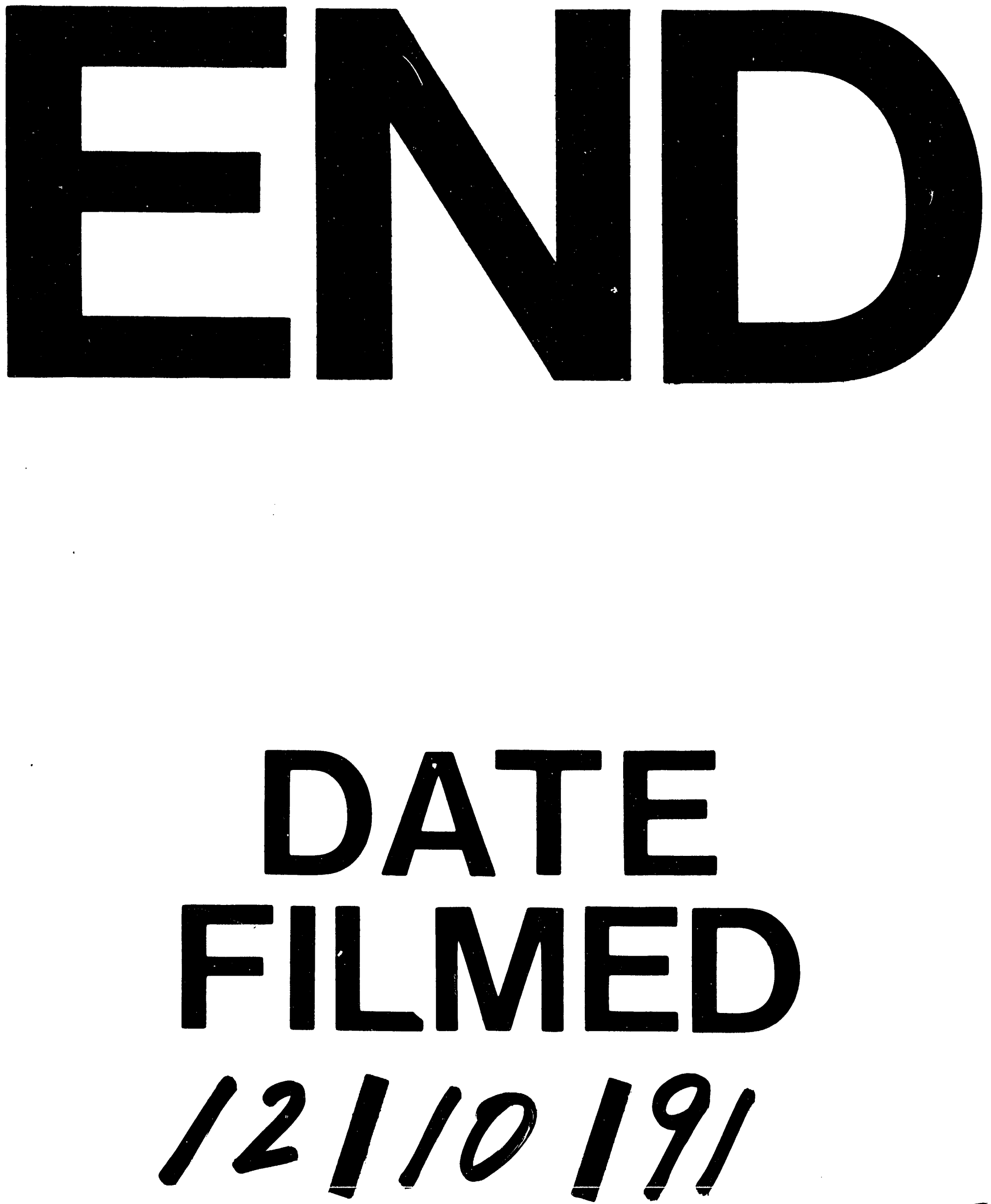
